Revised manuscript for Preslia

\title{
Pladias Database of the Czech Flora and Vegetation
}

Pladias - databáze české flóry a vegetace

\begin{abstract}
Milan Chytrý ${ }^{1}$, Jiří Danihelka ${ }^{1,2}$, Zdeněk Kaplan ${ }^{2,3}$, Jan Wild ${ }^{2}$, Dana Holubová1, Petr Novotný ${ }^{4}$, Marcela Řezníčková1, Martin Rohn ${ }^{5}$, Pavel Dřevojan ${ }^{1}$, Vít Grulich ${ }^{1}$, Jitka Klimešová ${ }^{3,6}$, Jan Lepš ${ }^{7}$, Zdeňka Lososová ${ }^{1}$, Jan Pergl ${ }^{2}$, Jiří Sádlo², Petr Šmarda ${ }^{1}$, Petra Štěpánková1, Lubomír Tichý1, Irena Axmanován, Alena Bartušková6, Petr Blažek $^{7}$, Jindřich Chrtek Jr. ${ }^{2}$, Felícia M. Fischer ${ }^{1}$, Wen-Yong Guo ${ }^{2,8}$, Tomáš Herben ${ }^{2,3}$, Zdeněk Janovský2,3, Marie Konečná7, Ingolf Kühn', Lenka Moravcová2, Petr Petř́ík ${ }^{2}$,

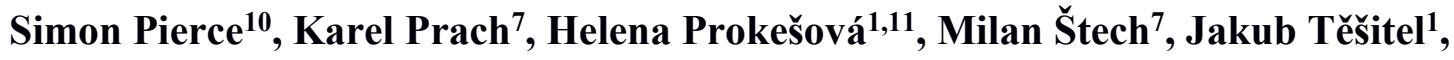
Tamara Těšitelová ${ }^{12}$, Martin Večeřa ${ }^{1}$, David Zelený ${ }^{13}$ \& Petr Pyšek P,14 $^{2}$
\end{abstract}

${ }^{1}$ Department of Botany and Zoology, Faculty of Science, Masaryk University, Kotlářská 2, 61137 Brno, Czech Republic,e-mail: chytry@sci.muni.cz,danihel@sci.muni.cz, danmich@sci.muni.cz,mar.reznickova@seznam.cz,pavel.drevojan@seznam.cz, grulich@sci.muni.cz,lososova@sci.muni.cz,smardap@sci.muni.cz, pstepankova@sci.muni.cz,tichy@sci.muni.cz,axmanova@sci.muni.cz, feliciafischerster@gmail.com,tesitel@sci.muni.cz,martinvec@seznam.cz; ${ }^{2}$ Institute of Botany of the Czech Academy of Sciences, 25243 Pri̊honice, Czech Republic, e-mail:kaplan@ibot.cas.cz,jan.wild@ibot.cas.cz,pergl@ibot.cas.cz,jiri.sadlo@ibot.cas.cz, chrtek@ibot.cas.cz,herben@site.cas.cz,moravcova@ibot.cas.cz,petr.petrik@ibot.cas.cz, pysek@ibot.cas.cz;

${ }^{3}$ Department of Botany, Faculty of Science, Charles University, Benátská 2, 12801 Praha 2, Czech Republic; zdenek.janovsky@natur.cuni.cz;

${ }^{4}$ Department of Teaching and Didactics of Biology, Faculty of Science, Charles University, Viničná 7, 12800 Praha, Czech Republic,e-mail: novotp@natur.cuni.cz; ${ }^{5}$ Babická 2379/1a, 14900 Praha, Czech Republic, e-mail: martin.rohn@gmail.com; ${ }^{6}$ Institute of Botany of the Czech Academy of Sciences, 37982 Třeboň, Czech Republic, email:klimesova@butbn.cas.cz; alena.bartuskova@ibot.cas.cz; 
${ }^{7}$ Department of Botany, Faculty of Science, University of South Bohemia, Na Zlaté stoce 1, 37005 České Budějovice, Czech Republic, e-mail: suspa@prf.jcu.cz, peta.blazek.f@seznam.cz,manuska.brdo@seznam.cz,prach@prf.jcu.cz,stech@prf.jcu.cz; ${ }^{8}$ Section for Ecoinformatics \& Biodiversity, Department of Biosciences, Aarhus University, 8000 Aarhus C,Denmark, e-mail: guowyhgy@gmail.com;

${ }^{9}$ Department Community Ecology Helmholtz Centre for Environmental Research - UFZ, Theodor-Lieser-Str.4, 06120 Halle, Germany,e-mail:ingolf.kuehn@ufz.de; ${ }^{10}$ Agroecosystems Ecology and Conservation Group, Department of Agricultural and Environmental Sciences (DiSAA), University of Milan, via G. Celoria 2, 20133 Milan, Italy, e-mail: simon.pierce@unimi.it;

${ }^{11}$ Administration of the Protected Landscape Area Pálava, Náměstí 32, 69201 Mikulov, Czech Republic, e-mail: helenapro@seznam.cz;

${ }^{12}$ Department of Ecosystem Biology, Faculty of Science, University of South Bohemia, Branišovská 1760, 37005 České Budějovice, Czech Republic, e-mail: tamara.malinova@centrum.cz;

${ }^{13}$ Institute of Ecology and Evolutionary Biology, National Taiwan University, Roosevelt Rd. 1,10617 Taipei,Taiwan; e-mail: zeleny@ntu.edu.tw;

${ }^{14}$ Department of Ecology, Faculty of Science, Charles University, Viničná 7, 12844 Praha, Czech Republic

Chytrý M., Danihelka J., Kaplan Z., Wild J., Holubová D., Novotný P., Řezníčková M., Rohn M., Dřevojan P., Grulich V., Klimešová J., Lepš J., Lososová Z., Pergl J., Sádlo J., Šmarda P., Štěpánková P., Tichý L., Axmanová I., Bartušková A., Blažek P., Chrtek J. Jr., Fischer F. M., Guo W.-Y., Herben T., Janovský Z., Konečná M., Kühn I., Moravcová L., Petřík P., Pierce S., Prach K., Prokešová H., Štech M., Těšitel J., Těšitelová T., Večeřa M., Zelený D. \& Pyšek P. (2021) Pladias Database of the Czech Flora and Vegetation. - Preslia 93: xxx-xxxx.

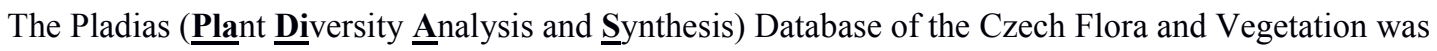
developed by the Pladias project team in 2014-2018 and has been continuously updated since then. The flora section of the database contains critically revised information on the Czech vascular flora, including 13.6 million plant occurrence records, which are dynamically displayed in maps, and data on 120 plant characteristics (traits, environmental associations and other information), divided into the sections (1) Habitus and growth type, (2) Leaf, (3) Flower, (4) Fruit, seed and dispersal, (5) Belowground organs and clonality, (6) Trophic mode, (7) Karyology, (8) Taxon origin, (9) Ecological indicator values, (10) Habitat and sociology, (11) Distribution and frequency, and (12) Threats and protection. The vegetation section 
of the database contains information on Czech vegetation types extracted from the monograph Vegetation of the Czech Republic. The data are supplemented by national botanical bibliographies, electronic versions of the standard national flora and vegetation monographs, a database of more than 17,000 pictures of plant taxa and vegetation types, and digital maps (shapefiles) with botanical information. The data from the database are available online on a public portal www.pladias.cz, which also provides download options for various datasets and online identification keys to the species and vegetation types of the Czech Republic. In this paper, we describe the general scope, structure and content of the database, and details of the data on plant characteristics. To illustrate the data and describe the main geographical patterns in selected plant characteristics, we provide maps of mean values of numerical characteristics or proportions of categories for categorical characteristics on the map of the country in a grid of 5 longitudinal $\times 3$ latitudinal minutes (approximately $6 \mathrm{~km} \times 5.5 \mathrm{~km}$ ). We also summarize the main variation patterns in the functional traits in the Czech flora using the principal component analysis.

Keywords: biodiversity information, Czech Republic, ecoinformatics, flora, online database, plant traits, species distribution data, vascular plants, vegetation types

\section{Introduction}

Collection of botanical data has a long tradition that stretches back for centuries. In many parts of the world, species distribution data have been systematically collected for more than 200 years and vegetation-plot data for about 100 years. A large amount of data on ecological or biogeographical characteristics of plants have been published in various floras and identification keys. With the onset of information technologies, it became feasible to collect data more systematically. These efforts resulted in the creation of several extensive databases collecting information on species distributions (e.g. GBIF, Edwards et al. 2000; BIEN, Enquist et al. 2016; GloNAF, Pyšek et al. 2017, van Kleunen et al. 2019; GIFT, Weigelt et al. 2020), vegetation plots (GIVD, Dengler et al. 2011; EVA, Chytrý et al. 2016; sPlot, Bruelheide et al. 2019) and plant traits (TRY, Kattge et al. 2020; GIFT, Weigelt et al. 2020). Nowadays, the knowledge accumulated in databases covering different aspects of plant diversity can be integrated in order to make full use of its enormous potential. Such database integrations can reveal unknown biodiversity patterns at various scales, answer fundamental questions about the origin of these patterns, or address novel research questions (e.g. van Kleunen et al. 2015, Enquist et al. 2016, Bruelheide et al. 2018).

The Czech Republic is a country with a long history of botanical research, including detailed floristic recording, taxonomic studies, vegetation surveys and various types of 
ecological studies (Danihelka et al. 2017). Detailed information on various aspects of plant diversity is available for the whole national territory and to a large extent, it is stored in electronic databases. However, until very recently, different thematic and regional databases had been maintained separately. The most important sources of information on plant diversity in the Czech Republic are the modern national flora (Hejný et al. 1988 onwards), identification keys (Kubát et al. 2002, Kaplan et al. 2019a), a species list (Danihelka et al. 2012), a vegetation monograph (Chytrý 2007-2013), several databases of plant distribution held by different institutions and individuals, a national database of vegetation-plot records (Czech National Phytosociological Database, CNPD; Chytrý \& Rafajová 2003), and various databases of plant traits (e.g. CLO-PLA, Klimešová \& de Bello 2009), habitat affinities (Chytrý \& Tichý 2003, Sádlo et al. 2007, Prach et al. 2014) and alien species (Pyšek et al. $2002,2012)$. Some steps towards the integration of this information have been done in recent years, primarily motivated by the specific needs of various research projects. For example, the alien species database was linked with the vegetation-plot database (Chytrý et al. 2005) and both of them with a database of geographic information (Chytrý et al. 2009). There were also integrations of plant-trait databases with the alien species databases and a plant distribution database (Pyšek et al. 2009, 2015). Each particular project that involved joint analyses of different databases revealed previously undetected patterns of plant diversity and offered novel explanations contributing to the general understanding of the evolution of plant diversity.

Critical revision and integration of all the available information on various characteristics of vascular plant species and vegetation types occurring in the Czech Republic were among

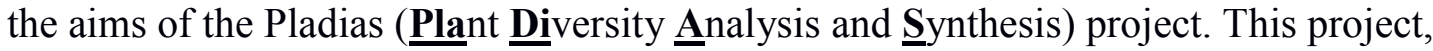
funded by the Czech Science Foundation as a Centre of Excellence in 2014-2018, involved botanists from Masaryk University (Brno), the Institute of Botany of the Czech Academy Sciences (Průhonice, Třeboň and Brno), the University of South Bohemia (České Budějovice) and dozens of external collaborators. The Pladias Database of the Czech Flora and Vegetation was compiled within this project with a proximate aim to support research into trade-offs in life histories of temperate plants, plant community assembly rules and plant invasions. However, the aim of the database compilation was broader, with a longterm vision of developing permanent data infrastructure for botanical survey and research on the national scale. Such an infrastructure should also support biodiversity conservation and environmental assessment by providing critically revised and publicly accessible data on 
plant species occurrences. It should also be useful for education, helping students and the public to identify plants and learn about their characteristics and ecology. In order to support these broader aims, the database was made available to the public on the internet.

The aim of this paper is to (1) present the overall scope, structure and content of the Pladias Database, (2) describe the data on plant characteristics included in the database, and (3) show the main patterns of the spatial distribution of plant characteristics on the national scale by linking the data on species characteristics with species occurrence records.

\section{Database scope}

The Pladias Database includes comprehensive and critically revised information on vascular plant taxa and vegetation types occurring in the Czech Republic. All the native and spontaneously established alien vascular plant taxa ever recorded in the country are included. In addition, the database also contains some commonly cultivated crop plants or alien woody plants that have been traditionally mentioned in the Czech flora handbooks and species lists (Hejný et al. 1988 onwards, Kubát et al. 2002, Danihelka et al. 2012, Pyšek et al. 2012, Kaplan et al. 2019a). In the vegetation part, the database includes information on vegetation types accepted in the current national vegetation classification system (Chytrý 2007-2013), including the syntaxonomic ranks of class, alliance and association.

The expected users of the database include the scientific community (botanists, ecologists, biogeographers and conservation biologists), nature conservation practitioners, teachers, students, amateur botanists and the informed public. The database does not include data related to plant cultivation, medicinal use, edibility or toxicity. The vegetation part of the database contains data on spontaneously established plant communities, excluding planted ecosystems such as forestry plantations or crop fields (except the spontaneously established weed communities in crop cultures).

\section{Database structure}

The Pladias Database comprises three data management modules and the public portal for data presentation (Fig. 1). It contains species occurrence records, data on species 
characteristics, data on vegetation types, pictures, spatial data in the form of digital map layers, bibliographic data and pdf files of key national botanical publications.

The data management modules are used by the database administrators and collaborators for data upload, editing, checking, correcting and export. The first, simplest module, provides tools for editing the taxonomic backbone, i.e. a hierarchical list of plant taxa used in the database. The current state of the taxonomic backbone is used as a source of taxon names and concepts across the whole database. The second module was developed for managing the species occurrence records and the third module for managing the data on plant characteristics. The last two modules contain import functions with various quality assurance tools. For example, these tools check whether the imported taxon names match the taxonomic backbone, whether the values of plant characteristics match the expected data type, and whether the imported values are within a pre-defined range.

Data on species distribution and plant characteristics are changing dynamically in the database. Any change to the database content made by the data managers in the database management modules immediately appears in the public portal. In the case of plant traits, numbered versions of the data are stored in the database whenever data are exported for analyses. The other kinds of data (pictures, information on vegetation types, digital map layers, bibliographies and pdf files) are stored in the database as static packages that are updated occasionally but not subject to ongoing changes. Therefore the database does not contain any management modules for these data.

Data are presented on the public portal "Pladias - Database of the Czech Flora and Vegetation" (www.pladias.cz), which has two parallel language versions, Czech and English. This portal is divided into the sections Species, Vegetation, Identification (both for species and vegetation types) and Download. The section Species summarizes data for vascular plant species but also infraspecific taxa and taxa between the levels of genus and species. The sections Species and Vegetation are organized as sets of factsheets for individual taxa or vegetation types, each containing all the available information for the selected taxon or vegetation type. Any change in taxon occurrence records or taxon characteristics made in the data management modules is immediately displayed in the relevant parts of the sections Species, Identification and Download in the public portal and used by the identification key for species. The section Identification is divided into identification keys for plant species and vegetation types. The section Download provides some of the background datasets used as sources of factsheets in the sections Species and 
Vegetation, which can be downloaded here as spreadsheets suitable for data analysis.

Moreover, this section contains some data that are not available in any other section of the public portal, e.g. digital maps and bibliographies.

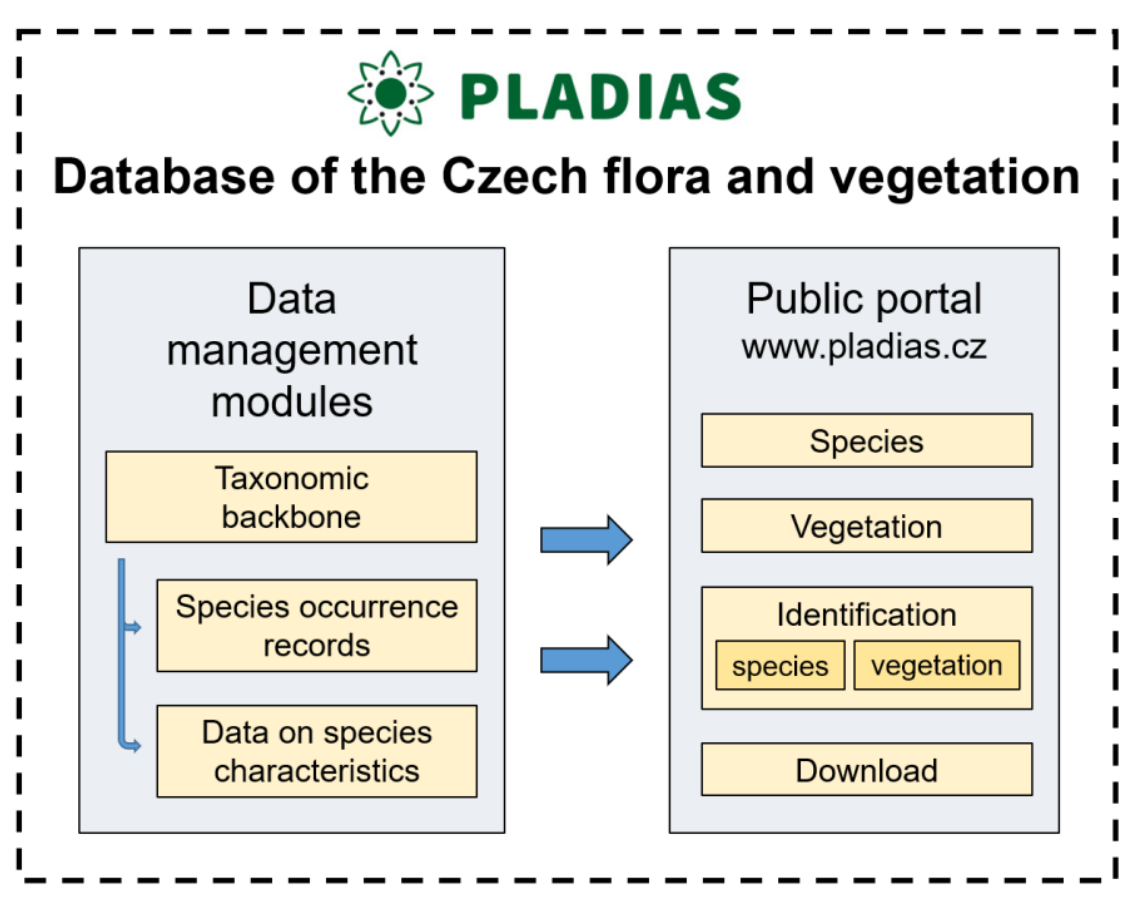

Fig. 1. - Structure of the Pladias Database, with arrows indicating the dynamic data flow.

\section{Database content}

\section{Species distribution data}

In November 2020, the Pladias Database contained approximately 13.6 million taxon occurrence records from the Czech Republic. This subset of the Pladias database was described in detail by Wild et al. (2019). The occurrence records are continuously revised by several experts in the data management module and dynamically displayed in the distribution maps on the Pladias public portal. Once all the occurrence records for a taxon are revised at a level of quadrants of the grid flora mapping, a map of this taxon is published in the series Distributions of vascular plants in the Czech Republic (Kaplan et al. 2015, 2016a, b, 2017a, b, 2018a, b, 2019b, 2020, to be continued). The published map is added to this taxon's factsheet on the Pladias public portal. For some taxa, the published maps 
contain information that is not displayed in the dynamically generated maps on the Pladias website, e.g. different symbols for older $v s$ newer records or occurrences documented by herbarium specimens $v s$ those based on other records.

\section{Data on species characteristics}

The Pladias Database contains information on 120 characteristics of vascular plant species and other taxa below the level of genus. These characteristics are divided into 12 sections: (1) Habitus and growth type, (2) Leaf, (3) Flower, (4) Fruit, seed and dispersal, (5) Belowground organs and clonality, (6) Trophic mode, (7) Karyology, (8) Taxon origin, (9) Ecological indicator values, (10) Habitat and sociology, (11) Distribution and frequency, and (12) Threats and protection.

These 120 characteristics comprise plant traits, environmental associations and other information about plants. Traits are a subset of plant characteristics defined as morphological, physiological or phenological features measurable at the individual plant level, without reference to the environment or population or community level (McGill et al. 2006, Violle et al. 2007, Pérez-Harguindeguy et al. 2013, Garnier et al. 2017). Some traits in the database are functional, i.e. directly affecting plant fitness or its environment. Other traits are morphological characters that may be important for plant identification but have no apparent effect on plant performance. The trait values in the database are means or ranges for a taxon, not multiple measurements for plant individuals. Environmental associations are another subset of plant characteristics defined as non-random associations of individual plants, plant populations or plant species with particular characteristics of the environment (Garnier et al. 2017). They include ecological and biogeographical characteristics. The database also contains other types of information about plant species, such as their legal protection or, for alien species, the year of the first record in the wild in the country. The names of the characteristics were selected considering the proposals in the Thesaurus of Plant Characteristics (Garnier et al. 2017). However, in several cases, we used alternative names in order to follow the original data sources or national and regional tradition.

\section{Other data on species}


In June 2020, the Pladias Database contained a total of 15,677 photographs of whole plants and details important for identification, representing 3480 taxa, which were carefully selected for this purpose. Details and taxa not available from in situ photos were photographed in the Herbarium of Masaryk University (BRNU). Moreover, 502 taxa were illustrated by 725 original drawings of their underground organs by Jitka Klimešová, many of which were also published in the book Temperate Herbs: An Architectural Analysis (Klimešová 2018).

For all the species that were included in the first seven volumes of the Flora of the Czech Republic (Hejný et al. 1988 onwards), the public portal provides a link to a pdf file containing the relevant chapter from this Flora (with permission from the copyright holders).

\section{Data on vegetation types}

The Pladias Database contains the complete information from the monograph Vegetation of the Czech Republic (Chytrý 2007-2013), including textual descriptions of vegetation units, lists of their diagnostic, constant and dominant species, distribution maps, and a link to a pdf file containing the relevant chapter from this vegetation monograph (with permission from the publisher). Each species name in the lists is hyperlinked to information on this species on the Pladias portal. In June 2020, the database also contained 868 photographs representing all 496 phytosociological associations described in Vegetation of the Czech Republic.

The Pladias Database only contains information on vegetation types, not vegetation-plot data from the Czech National Phytosociological Database (Chytrý \& Rafajová 2003). The plot data are kept separately in a database managed using the Turboveg program (Hennekens \& Schaminée 2001), which is specifically tailored for this data type and enables international data sharing (Chytrý et al. 2016, Bruelheide et al. 2019). However, species occurrence records were extracted from the plots stored in the Czech National Phytosociological Database and used as one of the sources of species distribution data.

\section{Supporting data and bibliographies}

Further data included in the Pladias Database are available in the Download section of the public portal. They include spreadsheets containing the species lists of the country's flora 
(Kubát et al. 2002, Danihelka et al. 2012), a list of vegetation units (Chytrý 2007-2013), pdf files of articles describing various datasets integrated into the Pladias Database, and shapefiles with the phytogeographical division of the Czech Republic (Skalický 1988, Kaplan 2012), flora mapping grid (Niklfeld 1971), Map of Potential Natural Vegetation of the Czech Republic (Neuhäuslová et al. 1998) and maps of plant invasions in the Czech Republic (Chytrý et al. 2009).

The public portal also provides bibliographic information from the series Bibliographia botanica čechoslovaca, Bibliographia botanica čechica and Bibliographia syntaxonomica čechoslovaca, all available in a searchable pdf format. A total of 22 volumes of Bibliographia botanica čechoslovaca and Bibliographia botanica čechica were published by the Institute of Botany of the Czechoslovak (later Czech) Academy of Sciences in 19672005. The bibliography contains a list of botanical publications from 1952-1957 and 19592000 related to the Czech Republic and until 1992 also to Slovakia. In addition, there is the Licit database in the Microsoft Access format, which contains a list of botanical publications related to the territory of the Czech Republic mainly from the years 1989-2002 and of Slovakia from 1989-1992. This database, compiled in the Institute of Botany of the Czech Academy of Sciences, was used to prepare two volumes of Bibliographia botanica čechoslovaca for the years 1989-1992 and four volumes of Bibliographia botanica čechica for the years 1993-2000. It also contains a list of publications from 2001 and 2002 compiled for the fifth volume of Bibliographia botanica čechica, which has not been printed. A syntaxonomical bibliography (Bibliographia syntaxonomica čechoslovaca ad annum 1970) was published by the Institute of Botany of the Czechoslovak Academy of Sciences in 1983-1992. The bibliography is organized by the classes of phytosociological classification. Each of its 20 volumes contains a list of literature sources that relate to the individual vegetation classes and a list of subordinate syntaxonomic units of these classes with references to literature sources. The geographic scope of the bibliography is former Czechoslovakia.

\section{Identification keys}

The interactive identification keys that use various information from the Pladias Database are online applications available on the public portal. There are two identification keys, one for plant species and one for vegetation types. 
The species identification key supports the identification of species or, for some genera, also sections or groups or cultivars of cultivated plants. It does not include subspecies, aggregates or any other taxa. In this key, the total species list of the Czech flora can be filtered by selecting attributes of any of these characteristics: genus, family or a higher taxon, height, growth form, life form, life span, leaf presence and metamorphosis, leaf arrangement, leaf shape (with the subcategories of simple leaf division and compound leaf shape), stipules, petiole, leaf life span, leaf deciduousness in woody plants, leaf anatomy, functional leaf type in woody plants, flowering period, flower colour, flower symmetry, perianth, fusion of the perianth, shape of the sympetalous corolla or syntepalous perigon, calyx fusion, inflorescence type, fruit type (with the subcategories of fleshy fruit type and dry fruit type), shoot metamorphosis, fruit colour, parasitism and mycoheterotrophy, carnivory, relationships to light, temperature, moisture, soil reaction, nutrients and salinity (based on Ellenberg-type indicator values with scales merged to three to four categories), habitat type (using 13 broad categories) and elevational belt in the Czech Republic. The application proposes a list of species that are characterized by a combination of the entered values. Species for which the value of at least one of the criteria used in the selection is missing cannot be safely selected or excluded from the selection. Therefore, such species are listed below. The species list can be further filtered by selecting only those species that were previously recorded within $10 \mathrm{~km}$ from the locality of the target plant identified by clicking into an interactive map. It should be noted that this key provides only suggestions for potentially matching species. A safe identification can only be made using taxonomic literature such as a flora manual or an identification key.

The vegetation key enables quick identification of phytosociological associations or alliances according to the Vegetation of the Czech Republic (Chytrý 2007-2013). It uses the probabilistic identification method proposed by Tichý \& Chytrý (2019). The expected input data is information on the structure of the considered vegetation type (forest or scrub vs other vegetation types), a few names of species occurring in the vegetation type, and optionally information on whether some of these species have a high cover. The method uses the data on the occurrence frequency (constancy) of the entered species in individual associations or alliances as published in the synoptic tables in the Vegetation of the Czech Republic. It calculates the probability of the co-occurrence of the entered set of species in each vegetation type and suggests vegetation types with the highest probability as potential matches. The accuracy of the identification increases with the number of entered species. 
However, it usually returns meaningful results already after entering three or four species (see the tests in Tichý \& Chytrý 2019). The vegetation key is also available as an Android application for smartphones

(https://play.google.com/store/apps/details?id=com.test.tichy.vegkey).

\section{Taxonomy}

The taxonomic backbone of the Pladias Database is a hierarchical checklist of the Czech flora based on Danihelka et al. (2012) with further corrections and additions published in the Identification Key to the Czech Flora (Kaplan et al. 2019a). The system at the family level follows version 11 of the Angiosperm Phylogeny Website (http://www.mobot.org/MOBOT/research/APweb/) for angiosperms and Smith et al. (2006) for ferns. The taxonomic ranks used in the database include division, class, order, family, genus, subgenus, section, aggregate, series and other informal infrageneric ranks, species, subspecies, variety, form, group, cultivar, nothospecies and nothosubspecies. Some hybrids are represented by hybrid formulas. Data are systematically collected for the ranks below the genus level.

\section{Software}

The Pladias Database was developed as a complex software stack storing different types of botanical data. It is run on infrastructure hosted by the Institute of Botany of the Czech Academy of Sciences in Průhonice. Its user interface is designed as a web-based grantedaccess application respecting ergonomics of shared data handling. The requirement for longterm sustainability was met by adopting third-party open-source components as much as possible to avoid future software license expenditures. The data store is based on a PostgreSQL object-relational database system with the spatial extension PostGIS. The unified web environment allows for viewing, mapping, searching and downloading separate data on the occurrence and various characteristics of species as well as spatial queries on the combination of both layers (Wild et al. 2019).

The following data types were defined in the Pladias Database to store different types of plant characteristics: 
- Boolean (boolean) - logical values True/False

- Unsorted list (enum_nominal) - a multi-state categorical variable with an a priori list of unsorted categories; each taxon can be assigned to more than one category

- Sorted list (enum_ordinal) - an ordinal variable with an a priori list of sorted categories; each taxon can be assigned to more than one category

- Sorted list without multiplicity (enum_ordinal_single) - an ordinal variable with an a priori list of sorted categories; each taxon can be assigned to a single category

- Integer (integer) - positive or negative whole numbers and zero

- Real number (real) - real (decimal) numbers; each taxon can be assigned to a single value

- Real number with multiplicity (real_multi) - real (decimal) numbers; each taxon can be assigned to more than one value

- Interval with the mean (interval_avg) - a set of values (real numbers) including the ultra-minimum, minimum, mean, standard error of the mean, maximum and ultra-maximum; ultra-minimum and ultra-maximum can be used for rarely occurring outlier values to distinguish them from typical minimum or maximum values

- Percentage (percentage) - percentage values

- Month (month) - intervals of months within a year (values of 1-12)

- Year (year) - years of the Gregorian calendar

- Occurrence frequency (occurrence_frequency) - numbers of taxon occurrences in grid cells generated dynamically from the taxon occurrence data

- List of syntaxa (enum_syntaxons) - unsorted lists of vegetation units

- Inter-taxon association (taxon_taxon_real) - pairs of taxa with a real number quantifying the degree of association between them

\section{Data access, download and export options}

Most data in the Pladias Database are available via the public portal www.pladias.cz. The publicly non-available datasets include older versions of some datasets that are available in an updated version, fragmentary datasets, datasets waiting for revision, and a few datasets 
that cannot be made public because of third-party copyright restrictions. Individuals interested in obtaining additional data not available on the public portal should contact the Governing Board of the Pladias Database, following the Pladias Data Management and Access Rules available at www.pladias.cz/en/homepage/rules.

Various datasets, including digital map layers (shapefiles), can be downloaded in the section Download of the public portal. Data on a large part of plant characteristics are available there in a spreadsheet format, which enables their use in analyses. Most of these spreadsheets are generated from the current version of the database at each download. Consequently, they always contain up-to-date information. If a particular species characteristic is not available in the spreadsheet format on the public portal, the user can contact the data provider. In this section, the user can also generate and export a list of all plant taxa recorded in the selected grid cell or quadrant of the flora mapping. Alternatively, they can also generate a complementary list of all taxa present in the country flora but not recorded in the grid cell or the quadrant. The latter list can be used in the field for a targeted recording of missing taxa.

Both the data management modules of the Pladias Database contain various options of complex data exports, including the automatic transfer of occurrence information or the values of plant characteristics between different taxonomic levels. The transfer can be done either in the top-down direction (from higher to lower taxonomic levels) or the bottom-up direction (Fig. 2). The top-down transfer is only applied if there is a single taxon at the lower taxonomic level in the Czech flora (e.g. a species has only one subspecies). The bottom-up transfer can also be applied if there are two or more taxa at the lower taxonomic level. In such cases, values of the taxa at the lower level are merged according to specific rules for the given data type. For example, True and False in the Boolean data type are merged into True, more categories are added in the Unsorted list data type, or the mean or the maximum value is taken in the Integer or Real number data types. These transfers are also used for generating the dynamic species distribution maps that are displayed on the Pladias public portal. Automatically transferred values are always kept separately from the original values, and their use depends on the specific research needs. 


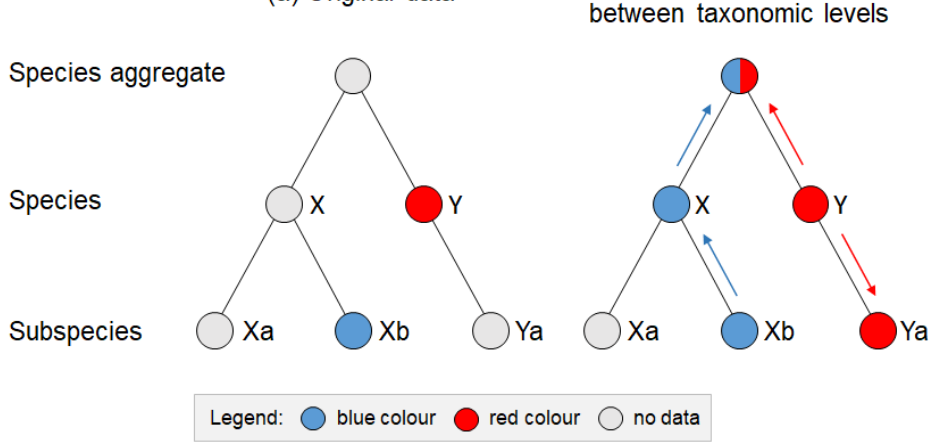

Fig. 2. - A scheme of the attribute value transfer across levels of the taxonomic hierarchy. Flower colour is used as an example characteristic. In the original data (a), the attribute is available only for subspecies Xb of species X (blue) and for species Y (red). After the attribute transfer, species $\mathrm{X}$ is assigned the blue colour from the subspecies $\mathrm{Xb}$. The aggregate, including both species $\mathrm{X}$ and $\mathrm{Y}$, is assigned to both colours. The red colour is also assigned to subspecies Ya of species Y because this is the only subspecies of this species in the national flora. However, no value can be assigned to subspecies Xa.

\section{Plant characteristics in the Pladias Database: data description}

In the following, we provide a detailed description of the publicly available data on plant characteristics contained in the Pladias Database, divided into 12 sections (Table 1). While the data on taxon occurrence and distribution were described by Wild et al. (2009), vegetation data by Chytrý (2007-2013) and other datasets in their corresponding references, this is the first summary of metadata for characteristics of species and other taxa contained in the Pladias Database. In addition to data description, we take advantage of the integration of species occurrence records and species characteristics in a single database and provide maps of the spatial distribution of the values of selected species characteristics across the country.

\section{Origin of the data on plant characteristics}

Data on plant characteristics in the Pladias Database were compiled from multiple sources. Morphological traits, as well as data on plant height, life form and flowering period, were 
collected mainly from the national flora handbooks (Hejný et al. 1988 onwards, Kubát et al. 2002). Data on some traits were revised simultaneously with the preparation of the new edition of the Key to the Flora of the Czech Republic (Kaplan et al. 2019a), in cooperation with its editors and authors. Some pieces of missing information were also extracted from foreign floras. Some parts of the Pladias Database incorporated data from previously established specialized databases. In particular, most of the data on belowground organs and clonality were taken from an updated and aggregated version of the CLO-PLA3 database (Klimešová et al. 2017). This database provides a freely available comprehensive data set of clonal and bud bank traits for almost 3000 species of the central-European flora. Data on the origin, status and introduction time and pathways of alien flora were taken from an updated version of the 2nd edition of the Catalogue of Alien Plants of the Czech Republic (Pyšek et al. 2012). Data on habitat affinity were taken from the database of regional species pools for Czech habitats (Sádlo et al. 2007) and the database developed for the national vegetation classification (Chytrý 2007-2013). Data on eleven characteristics for which there was no original dataset based on information from the Czech Republic were provided by the BiolFlor database (Klotz et al. 2002), which contains plant characteristics of the German flora. Nevertheless, wherever available, we used data representing observations or measurements in the territory of the Czech Republic. The taxon lists used in all of these databases were converted to a single taxon list used in the Pladias Database. If the taxon concepts in the original source and the Pladias Database did not match perfectly, we were careful to correct the taxonomic interpretation in order to assign the values of plant characteristics to the correct taxon.

Several new datasets of plant characteristics were created for the Pladias Database. Some of these not only collated data for commonly used characteristics but also developed novel concepts, e.g. plant dispersal strategies (Sádlo et al. 2018) and disturbance indicator values (Herben et al. 2016). Others were compiled based on the study of plant material across large sets of species, e.g. the checklist of root sprouters of the Czech flora (Bartušková et al. 2017), genome sizes (Šmarda et al. 2019) and myrmecochory (Konečná et al. 2018). Several ecological variables were prepared based on various analyses of the national dataset of vegetation plots (Chytrý \& Rafajová 2003), e.g. ecological specialization indices (Zelený \& Chytrý 2019).

\section{Mapping plant characteristics}


We linked the species distribution data and species characteristics in the Pladias Database and mapped the spatial pattern of plant characteristics across the Czech Republic in a grid of 5 minutes of longitude $\times 3$ minutes of latitude, i.e. approximately $6.0 \times 5.5 \mathrm{~km}$. The mapped values were either means for numerical data types or percentage representation of individual categories for categorical data types. The proportions are related to all the species with available data values (not to the whole flora). If a species had more than one value of a multistate categorical variable (e.g. the life form was both hemicryptophyte and therophyte), each value was counted with no weighting. Data values were transferred to the species according to the scheme described in Fig. 2. The maps are based exclusively on species, while other taxa were not considered.

The classes of the colour scale were defined separately for each characteristic using the kmeans clustering (MacQueen 1967). The algorithm partitioned data into a given number of classes in an iterative way, maximizing the similarity of objects within the same class and minimizing their similarity between different classes. We deliberately did not use the same colour scale for different categories of the same trait, because in such a case, patterns for some categories, especially the rare ones, would not be visible. Nevertheless, it is essential to realize that the same colours of different categories relate to different absolute values. White colour is used for categorical characteristics if the mapped category is missing in the grid cell (i.e. its percentage value is $0 \%$ ).

The maps are presented for those characteristics that show a remarkable non-random geographic pattern that may have ecological meaning. We emphasize that the maps should be understood merely as a part of the data description. The patterns shown are not phylogenetically corrected, and in some cases, they may result from a correlation of the displayed characteristic with other characteristics rather than from the direct effect of the environment on this characteristic. Still, we believe these maps can stimulate further research by suggesting hypotheses about the possible causes of the displayed patterns. For better insights, these maps can be compared with the country-scale maps of environmental variables relevant for plant distributions published by Chytrý (2017).

\section{Description of individual plant characteristics}


(See Electronic appendix 1 for a Czech version of these descriptions.)

\section{Habitus and growth type}

\section{Height}

Plant heights are relevant for the Czech Republic. They are measured in metres and relate to fully developed mature generative plants growing in the wild. Each taxon is characterized by two values: minimum (lower limit of the common range) and maximum (upper limit of the common range). The data are taken from the Key to the Flora of the Czech Republic (Kaplan et al. 2019a).

Data source and citation: Kaplan et al. (2019a).

\section{Growth form (Fig. 3)}

Growth form describes the potential life span of the plant and its parts (ramets), its reproductive strategy and durability of its aboveground parts (Klimešová et al. 2016, Ottaviani et al. 2017). Here the growth form is classified into nine categories, which also consider herbaceous vs woody nature of the stem. Annual herbs live for one season only and reproduce by seed usually in the same season in which they germinated. They may but need not be clonal; their clonality typically does not result in fragmentation. Perennial herbs are divided into three categories: (1) monocarpic perennial non-clonal herbs, which reproduce sexually only once in their life and do not possess woody aboveground parts or organs of clonal growth, (2) polycarpic perennial non-clonal herbs, which reproduce sexually several times during their life span and do not possess organs of clonal growth, and (3) clonal herbs, which possess organs of clonal growth enabling them to make fragments during their life span and to form independent units (ramets) by vegetative reproduction; the whole plant reproduces sexually several times during its life span, while individual ramets may reproduce once or several times during their life span. The other categories include woody plants, which may but need not possess organs of clonal growth and may be able or not of fragmentation and vegetative reproduction. The woody plants are divided into dwarf shrubs (woody plants lower than $30 \mathrm{~cm}$, also including suffruticose plants with erect, herbaceous 
shoots growing from woody stems at the base, which die out in autumn except for the lowest part with regenerative buds), shrubs (woody plants higher than $30 \mathrm{~cm}$, branched at the base), trees (woody plants with trunk and crown), woody lianas and parasitic epiphytes, which include only two species of the Czech flora, Loranthus europaeus and Viscum album. Data were partly taken from the aggregated CLO-PLA 3.4 database (Klimešová et al. 2017). The CLO-PLA categories were further divided into separate categories for herbaceous vs woody plants, and taxa not included in CLO-PLA were added.

\section{Categories}

- annual herb

- monocarpic perennial non-clonal herb

- polycarpic perennial non-clonal herb

- clonal herb
- dwarf shrub

- shrub

- tree

- woody liana

- parasitic epiphyte

Citation: Dřevojan P. (2020) Growth form. - www.pladias.cz.

(a) Annual herbs

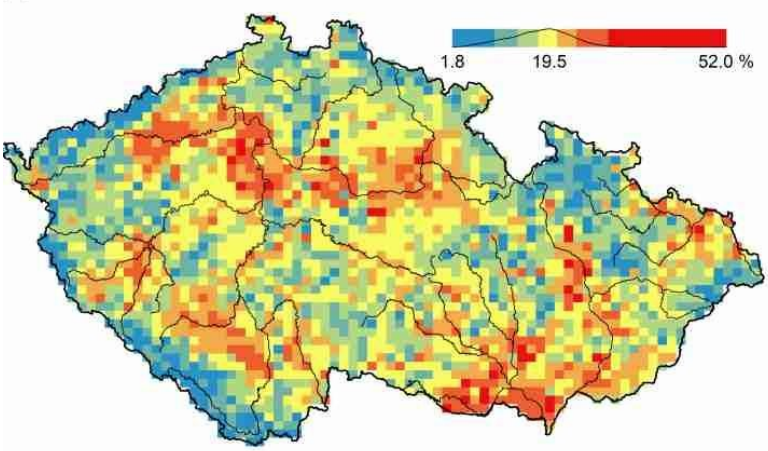

(c) Polycarpic perennial non-clonal herbs

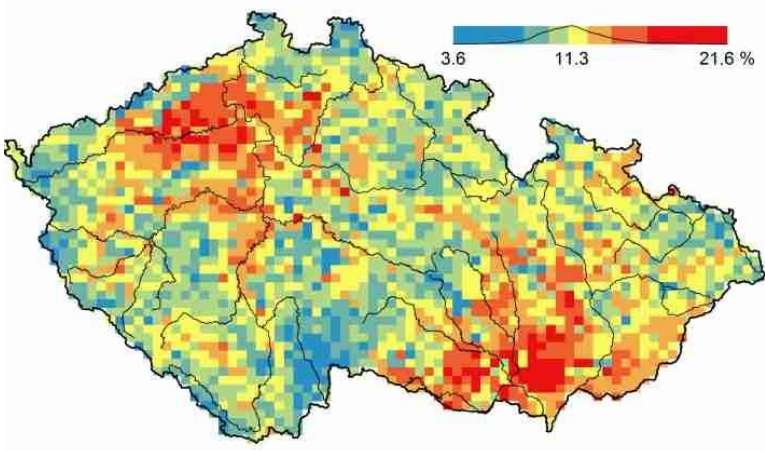

(b) Monocarpic perennial non-clonal herbs

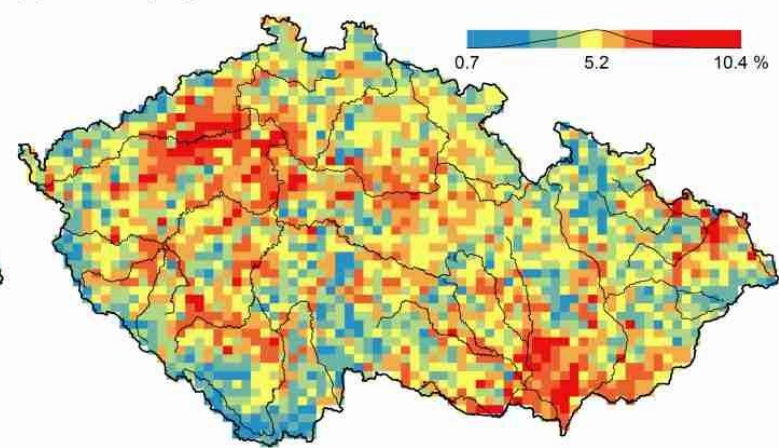

(d) Clonal herbs

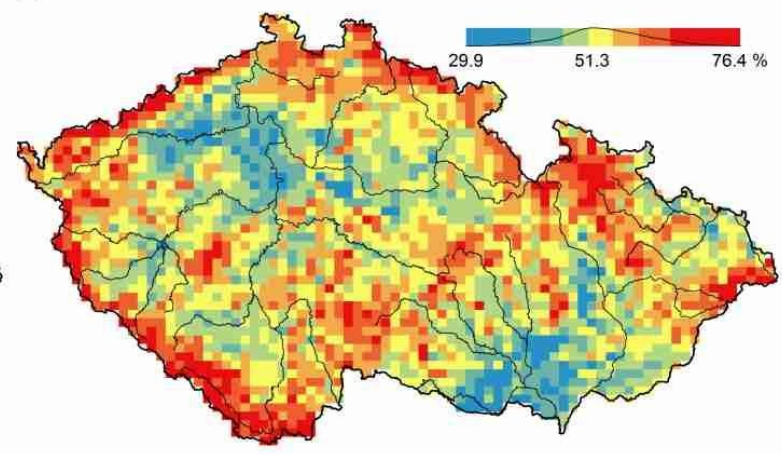


Fig. 3. - Proportion of individual growth forms in the Czech flora. Annual and perennial non-clonal herbs are frequent in the lowlands, whereas clonal herbs are more common in the mountains. Woody growth forms did not reveal any distinct pattern and are not shown. All the maps in this paper are based on taxon lists recorded in quadrants of $5 \times 3$ minutes (approx. $6.0 \times 5.5 \mathrm{~km}$, i.e. $33 \mathrm{~km}^{2}$ ). Only records of species (not other taxa) are mapped. Revised occurrence records marked as erroneous or uncertain were excluded.

\section{Life form (Fig. 4)}

Life form classification follows Raunkiaer (1934) based on the position of the buds that survive the unfavourable season. Macrophanerophytes are woody plants that bear the surviving buds at least $2 \mathrm{~m}$ above the ground, usually trees; nanophanerophytes are woody plants with surviving buds $0.3-2 \mathrm{~m}$ above the ground, usually shrubs; chamaephytes are herbs or low woody plants with surviving buds above the ground, but not more than $30 \mathrm{~cm}$ above it; hemicryptophytes are perennial or biennial herbs with surviving buds on aboveground shoots at the level of the ground; geophytes are perennial plants with surviving buds belowground, usually with bulbs, tubers or rhizomes; hydrophytes are plants with surviving buds in water, usually on the bottom of water bodies; therophytes are summer- or winter-annual herbs that survive the unfavourable season only as seeds germinating in autumn, winter or spring. Data on life forms were taken from the Key to the Flora of the Czech Republic (Kaplan et al. 2019a). Some taxa can belong to more than one life form. In such cases, the dominant life form is listed first.

\section{Categories}

- macrophanerophyte

- nanophanerophyte

- chamaephyte

- hemicryptophyte

Data source and citation: Kaplan et al. (2019a).
- geophyte

- hydrophyte

- therophyte 
(a) Phanerophytes

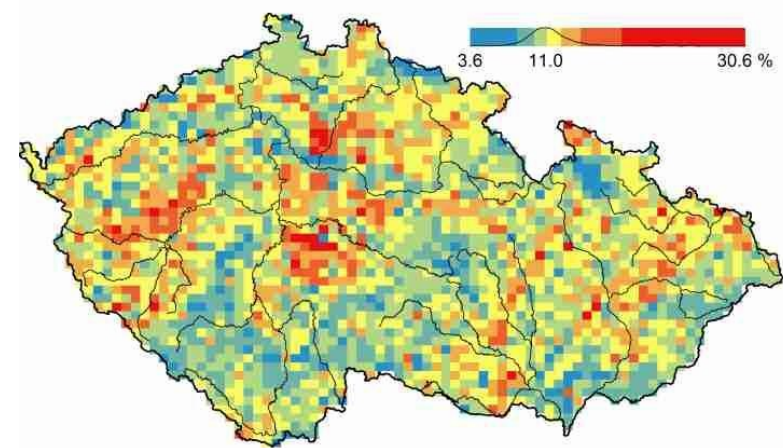

(c) Hemicryptophytes

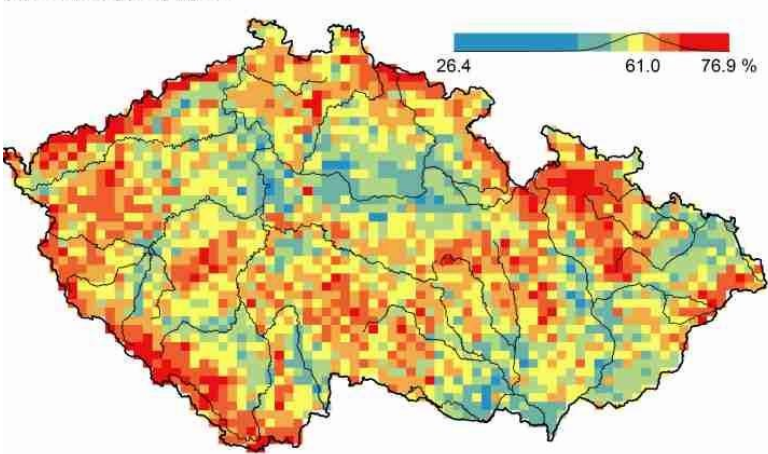

(e) Hydrophytes

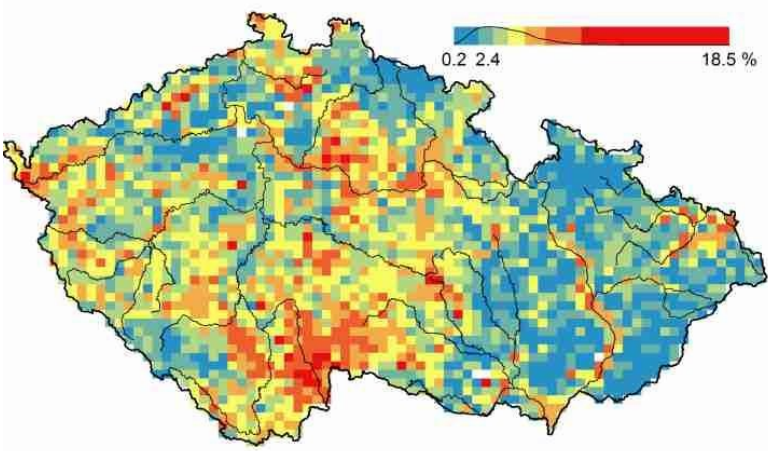

(b) Chamaephytes

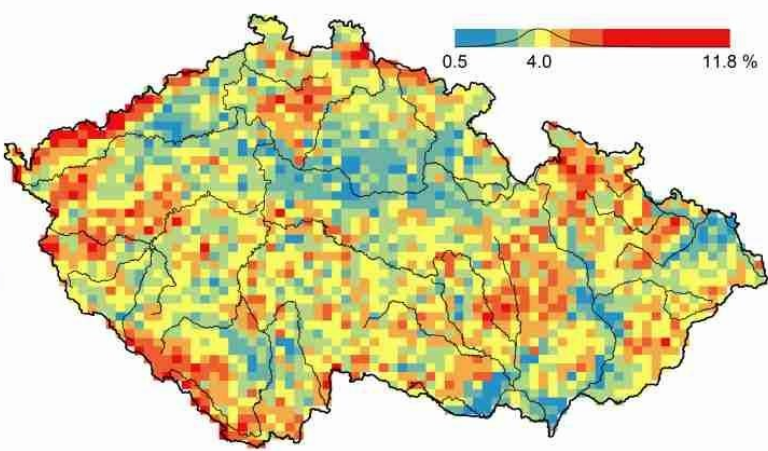

(d) Geophytes

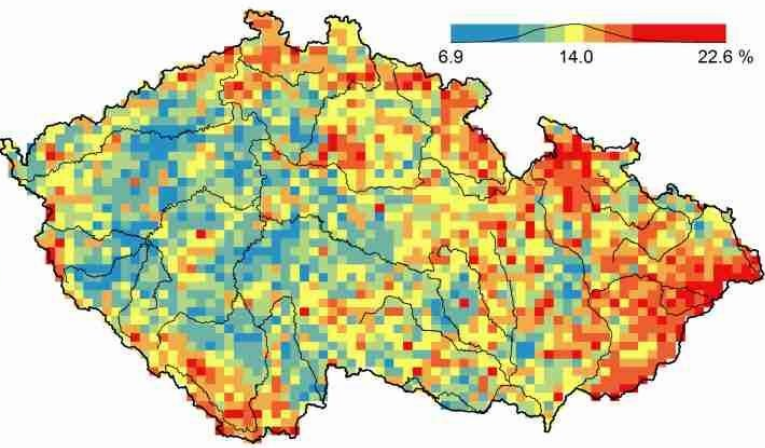

(f) Therophytes

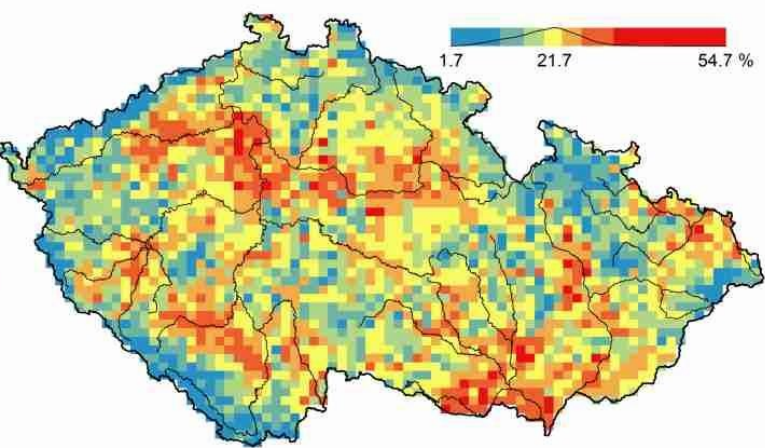

Fig. 4. - Proportion of individual life forms in the Czech flora. Chamaephytes are more common at middle elevations and in the mountains, hemicryptophytes in the mountains, geophytes in submontane areas of the Bohemian Massif and especially in the flysch Carpathians in the eastern part of the country, hydrophytes along rivers and in pond basins, and therophytes in the lowlands. Macrophanerophytes and nanophanerophytes did not reveal any distinct pattern; all phanerophytes are shown together.

\section{Life strategy (Fig. 5)}

Grime (1974, 1979) distinguished three basic ecological strategies of plants: (1) competitive strategy $(C)$, advantageous in stable habitats where resources are abundant, conditions not 
extreme and the disturbance level low; (2) stress-tolerant strategy $(S)$, advantageous where resources are scarce, conditions severe and highly variable, but disturbance is uncommon; and (3) ruderal strategy $(R)$, advantageous where resources are abundant and conditions not extreme, but the disturbance frequency is high.

Taxa of the Czech flora were assigned to life strategies based on the method proposed by Pierce et al. (2017). The life strategies calculated using this method represent the trade-off in resource investment between three key leaf traits: leaf area (LA; high in competitive taxa), leaf dry matter content (LDMC; high in stress-tolerant taxa) and specific leaf area (SLA; high in ruderal taxa). Scores that express the degree of C-, S- and R-selection are calculated from these traits. These scores are expressed on a percentage scale, and the sum of the three scores for individual taxa is $100 \%$. Based on these scores, the taxa are assigned to the basic primary strategies $\mathrm{C}, \mathrm{S}$ and R, intermediate strategies CS, CR, SR and CSR, and transitions between them, e.g. C/CS or SR/CSR (sensu Grime 1979). Data on leaf traits for these calculations or calculated values were taken from the LEDA database (Kleyer et al. 2008) and some other sources (Bjorkman et al. 2018, Dayrell et al. 2018, Findurová 2018, Tavşanoğlu \& Pausas 2018). The Pladias database contains both the score values for the three categories $\mathrm{C}, \mathrm{S}, \mathrm{R}$ and the categorized life strategies.

\section{Categories}

- $\mathrm{C}$

- $\mathrm{C} / \mathrm{CR}$

- $\mathrm{C} / \mathrm{CS}$

- $\mathrm{C} / \mathrm{CSR}$

- $\mathrm{CR}$

- $\mathrm{CR} / \mathrm{CSR}$

- $\mathrm{CS}$
- $\mathrm{CS} / \mathrm{CSR}$

- CSR

- $\mathrm{R}$

- $\mathrm{R} / \mathrm{CR}$

- $\mathrm{R} / \mathrm{CSR}$

- $\mathrm{R} / \mathrm{SR}$

- $\mathrm{S}$
- $\mathrm{S} / \mathrm{CS}$

- $\mathrm{S} / \mathrm{CSR}$

- $\mathrm{S} / \mathrm{SR}$

- $\mathrm{SR}$

- $\mathrm{SR} / \mathrm{CSR}$

Citation: Guo W.-Y. \& Pierce S. (2019) Life strategy. - www.pladias.cz. 
(a) C-score

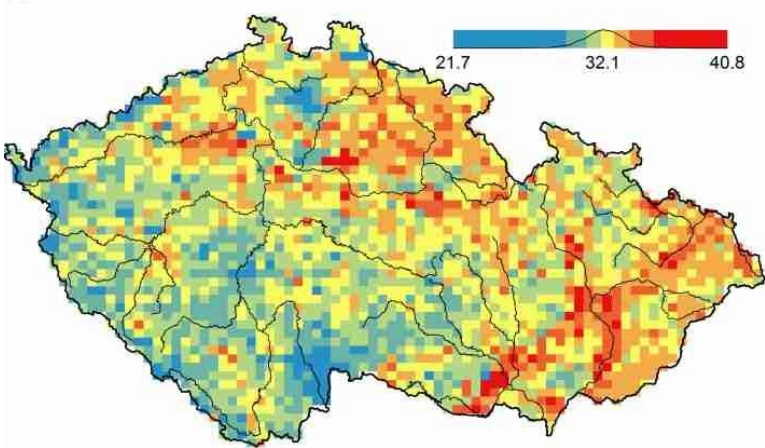

(c) R-score

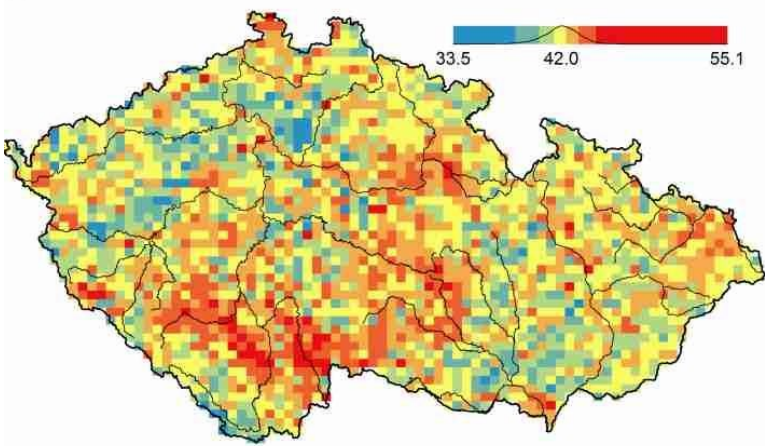

(b) S-score

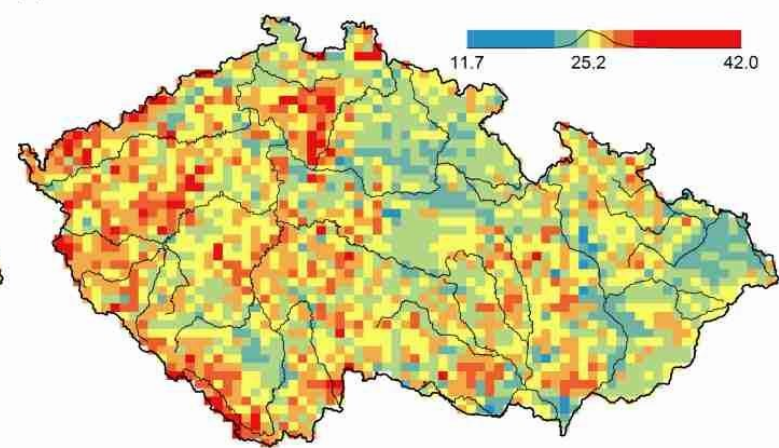

Fig. 5. - Life strategy scores for competitive (C), stress-tolerant (S) and ruderal strategy (R). C-strategists are most common in lowland agricultural areas with fertile soil, S-strategists on siliceous rocks in the Bohemian Massif, including both mountain areas and lowland sandstone areas, and R-strategists in wet basins and fishpond areas.

\section{Leaf}

\section{Leaf presence and metamorphosis}

Data on the presence of leaves on the plant, their metamorphoses and reductions are based on the Flora of the Czech Republic (vols. 1-8; Hejný et al. 1988 onwards) and the Key to the Flora of the Czech Republic (Kaplan et al. 2019a).

\section{Categories}

- leaves present, not modified

- leaves modified to spines

- leaves modified to tendrils

- leaves modified to phyllodes
- leaves modified to pitchers

- leaves reduced to collars

- leaves reduced to sheaths

- leaves reduced to scales 
- leaves absent

Data source and citation: Hejný et al. (1988 onwards), Kaplan et al. (2019a).

\section{Leaf arrangement (phyllotaxis)}

Four basic types of leaf arrangement are distinguished: alternate, opposite, verticillate (whorled) and rosulate (in the basal rosette). The character is assessed in well-developed plants, i.e. not in individuals re-sprouting after damage by mowing or grazing or those with teratological modifications. In some taxa more than one character state may occur (e.g. Hylotelephium jullianum and Salix purpurea): all character states are recorded in such cases.

In some plants, the arrangement of frondose bracts in the inflorescence is assessed separately (e.g., true leaves in Veronica persica and $V$. polita are opposite, while bracts are alternate). Leaves with interpetiolar stipules found in the Rubiaceae family are considered as whorled. In Rhamnus cathartica the leaves are considered as opposite, although in most cases they are sub-opposite.

The information was extracted mainly from the descriptions in the Flora of the Czech Republic (vols. 1-8; Hejný et al. 1988 onwards). In cases of uncertainties, mainly for alien taxa, additional sources were consulted, including the Flora of North America (Flora of North America Editorial Committee 1993 onwards), the Flora of China (Wu et al. 1994 onwards) and the Flora of Pakistan (www.tropicos.org/Project/Pakistan).

\section{Categories}

- alternate

- verticillate

- opposite

- rosulate

Citation: Grulich V., Holubová D., Štěpánková P. \& Řezníčková M. (2017) Leaf arrangement. - www.pladias.cz.

\section{Leaf shape (Fig. 6)}

The primary distinction is made between simple and compound leaves. The simple leaves are categorized based on the leaf blade division associated with venation into palmately 
divided (e.g. Alchemilla), pinnately divided (e.g. Achillea millefolium), forked (e.g. Batrachium, Ceratophyllum and Utricularia) and pedate (e.g. Helleborus). The categorization is based on well-developed leaves. In many taxa, transitions occur between simple leaves with a dentate or serrate margin, and simple divided (pinnately or palmately lobed) leaves. Only the leaves with the lamina divided to at least one-quarter of their width are considered as divided. Many taxa with varying leaf division are assigned to more than one character state.

The compound leaves are divided into palmate and pinnate. The taxa that have both ternate and pinnate leaves, the latter with two pairs of leaflets (e.g. Aegopodium podagraria and some other species of the Apiaceae family), are assigned to both character states. The degree of division in pinnately compound leaves indicated here relates to well-developed leaves, especially to the basal part of the lamina. Taxa with multiple pinnately compound leaves are assigned to two or more character states based on the level of division, but very small leaves, which may correspond to simple leaves, are not considered.

In many cases, there are transitions between simple and compound leaves, especially between pinnatisect and pinnate leaves. Leaves with linear or filiform segments, including the bi-, tri- or even more-pinnatisect or palmatisect leaves (e.g. stem leaves in Batrachium fluitans, Cardamine pratensis and the genus Seseli) are classified as simple (dissected) leaves. In contrast, leaves with broader segments attached to the rachis by a distinct constriction or a petiolule (e.g. stem leaves in Cardamine dentata or ground leaves in Pimpinella saxifraga) are classified as compound.

In heterophyllous taxa, all types of leaves are assessed, and the taxon is assigned to two or more character states. However, less divided leaves found in juvenile plants of some taxa are not considered heterophyllous. The parasitic plants with rudimentary (vestigial) leaves (e.g. Cuscuta) or the plants with phylloclades replacing the vestigial leaves (e.g. Asparagus) are assigned the character state "reduced".

The information was extracted mainly from the descriptions in the Flora of the Czech Republic (vols. 1-8; Hejný et al. 1988 onwards). In uncertain cases, mainly for alien taxa, additional sources were consulted, including the Flora of North America (Flora of North America Editorial Committee 1993 onwards), the Flora of China (Wu et al. 1994 onwards) and the Flora of Pakistan (www.tropicos.org/Project/Pakistan).

\section{Categories}


- simple - entire

- $\quad$ simple - palmately divided

- simple - pinnately divided

- simple - forked

- $\quad$ simple - pedate

- compound - ternate

- compound - palmate (5-foliate)

- compound - palmate (7-foliate)
- $\quad$ compound - palmate (8- and more-foliate)

- compound - imparipinnate

- compound - paripinnate

- compound - interruptedly pinnate

- compound - bipinnate

- compound - tripinnate

- compound - quadripinate

- reduced

Citation: Grulich V., Holubová D., Štěpánková P. \& Řezníčková M. (2017) Leaf shape. www.pladias.cz.

(a) Simple leaves

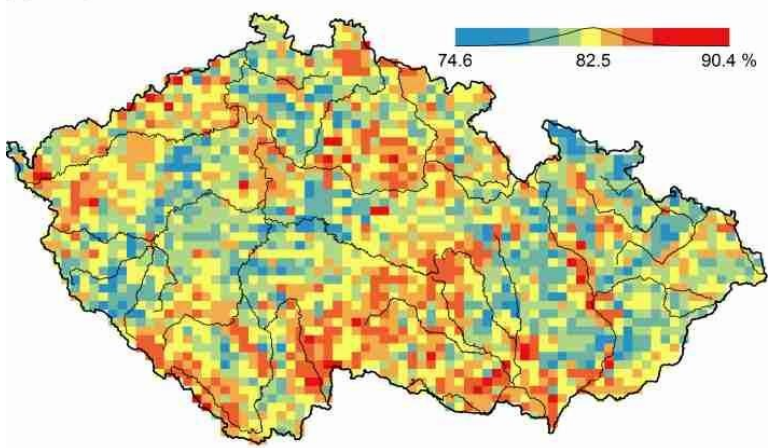

(c) Palmately divided simple leaves

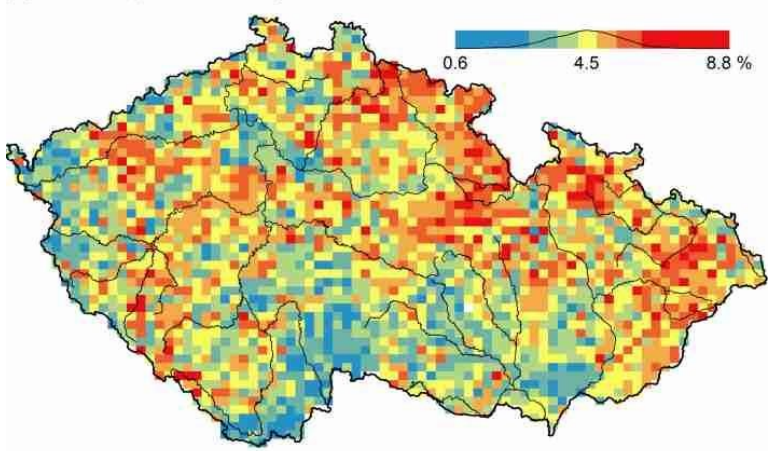

(b) Entire simple leaves

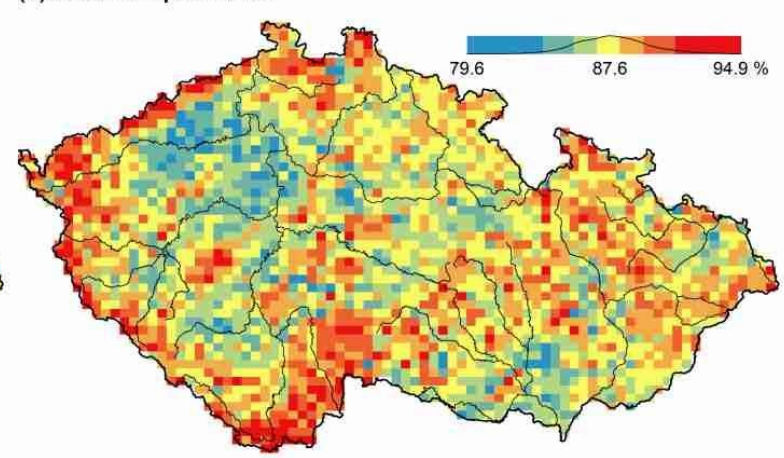

(d) Pinnately divided simple leaves

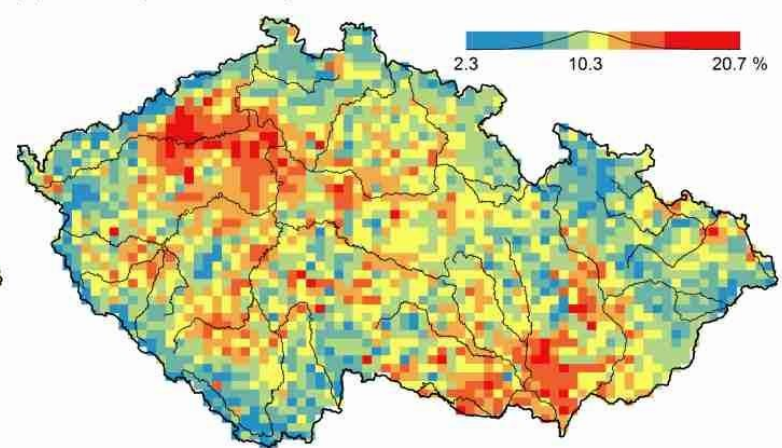

Fig. 6. - Proportion of species with different leaf shapes in the Czech flora. Simple leaves (a) are prevalent in wetland areas, both in pond basins and along large rivers. As the proportion of species with reduced leaves is insignificant in the Czech flora, the map for the proportion of species with compound leaves is essentially inverse to this map. The proportion of the most common types of simple leaves $(b-d)$ is shown relative to all the 
species with simple leaves in the Czech flora. Entire leaves are more frequent in the western mountain areas of the Bohemian Massif and pond basins, palmately divided leaves in the mountain areas in the northeast, and pinnately divided leaves in dry lowlands.

\section{Stipules}

Stipules, i.e. paired leaflike appendages at the base of the petiole or sessile leaf blade, can be present or absent. Caducous stipules, i.e. those disappearing soon after the leaf blade has developed (e.g. Prunus), are considered as present. The interpetiolar stipules, morphologically indistinguishable from true leaves and together forming whorls (e.g. Rubiaceae), are considered as true stipules. In contrast, stipules modified into glands (e.g. Lotus) or hairs (e.g. Portulacaceae) are not considered as stipules here.

Information about the presence of stipules was extracted from the descriptions in the Flora of the Czech Republic (vols. 1-8; Hejný et al. 1988 onwards). In cases of uncertainties, mainly concerning alien taxa, descriptions in the Flora of North America (Flora of North America Editorial Committee 1993 onwards), the Flora of China (Wu et al. 1994 onwards) and the Flora of Pakistan (www.tropicos.org/Project/Pakistan) were consulted.

Categories

- present

- absent

Citation: Grulich V., Holubová D., Štěpánková P. \& Řezníčková M. (2017) Stipules. www.pladias.cz.

\section{Petiole}

Lef petiole can be present or absent. In some plants, it can be present in some leaves but absent in others. The data were extracted from the Flora of the Czech Republic (vols. 1-8; Hejný et al. 1988 onwards), the Key to the Flora of the Czech Republic (Kubát et al. 2002), the New Hungarian Herbal (Király et al. 2011) and the Excursion Flora of Germany (Jäger \& Werner 2000). 
Categories

- present

- mainly present

- both present and absent
- mainly absent

- absent

Citation: Prokešová H. \& Grulich V. (2017) Petiole. - www.pladias.cz.

\section{Leaf life span (Fig. 7)}

Leaf life span is a functional trait important for plant competitiveness. It depends on the climate in the distribution range of the taxon and microclimate, nutrient and light availability in typical habitats of the taxon. Data were taken from the BiolFlor database (Klotz \& Kühn 2002a).

\section{Categories}

- overwintering green - leaves developing in autumn, overwintering green and decaying in spring and summer

- $\quad$ spring green - leaves green from early spring to early summer, then usually decaying

- summer green - leaves green in the warm season

- evergreen - leaves green throughout the year, often living for more than one year (persistent-green)

Data source and citation: Klotz \& Kühn (2002a). 
(a) Overwintering green leaves

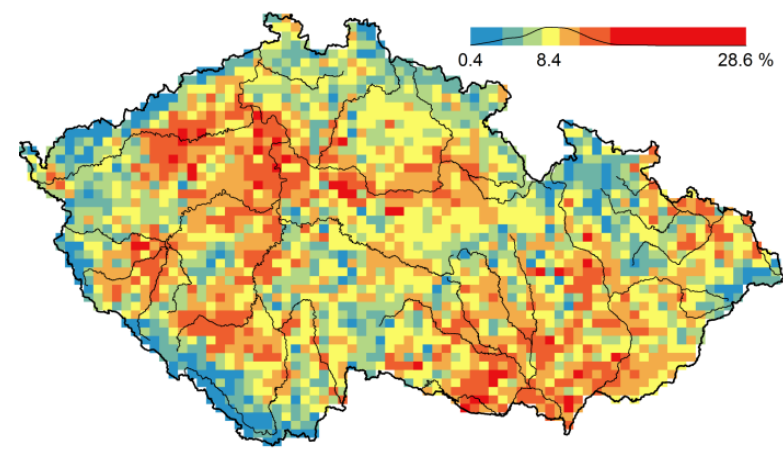

(c) Summer green leaves

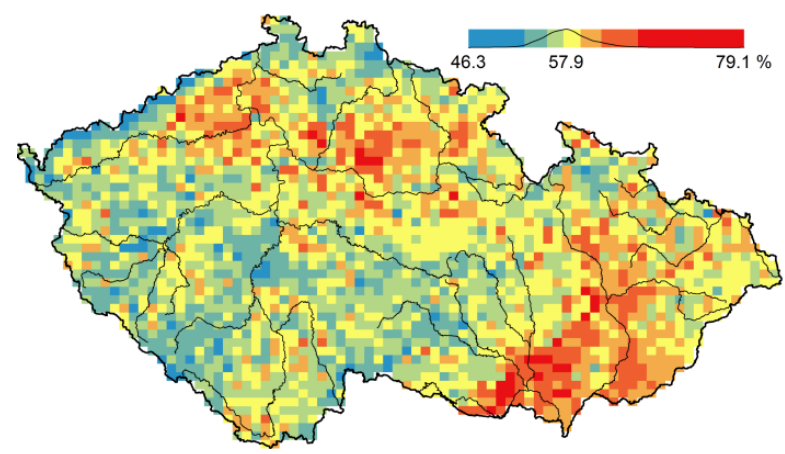

(b) Spring green leaves

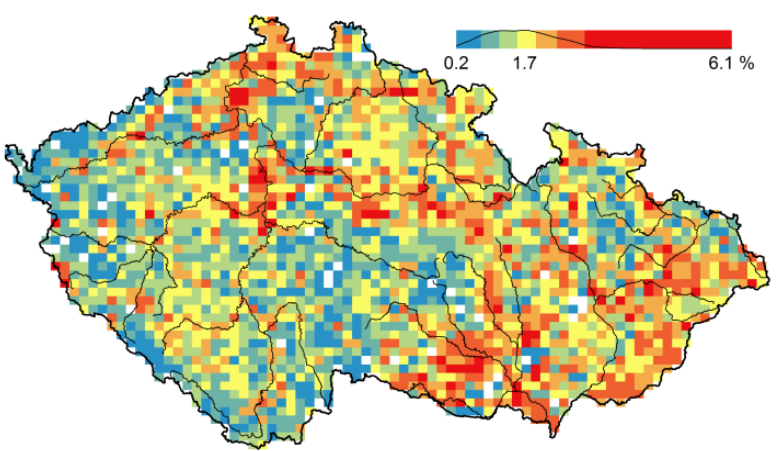

(d) Evergreen leaves

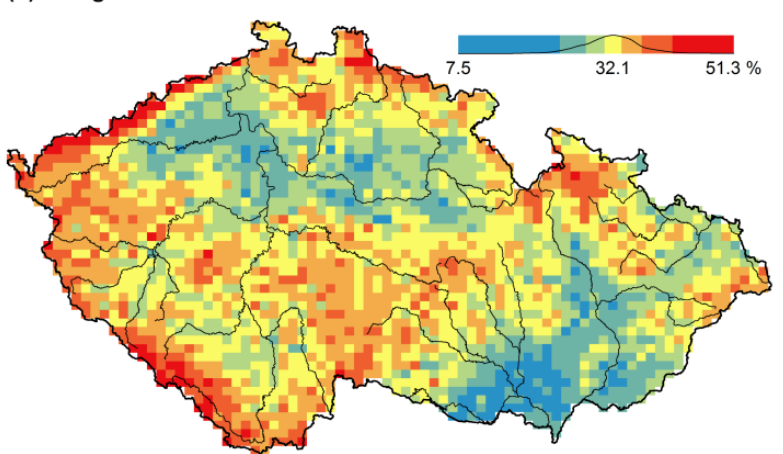

Fig. 7. - Proportion of species with different leaf life span in the Czech flora. Plants with overwintering-green leaves are more common in dry lowlands, those with spring-green leaves also in the lowlands, but especially in areas with rock outcrops, those with summergreen leaves in lowland areas with a large proportion of arable land, and those with evergreen leaves in the mountains.

\section{Leaf deciduousness in woody plants}

Leaves of different woody plant species have distinct phenological patterns. Most species of Central European woody plants have winter-deciduous leaves, while a small proportion has evergreen (persistent-green) leaves. Semi-deciduous leaves are rare, occurring mainly in cultivated species. The category of winter semi-deciduous leaves includes only the leaves that are at least partly green in winter, not marcescent leaves, which die out in autumn and remain attached, in a dry state, to the maternal plant over the winter (e.g. young individuals of Quercus). 
Data on leaf deciduousness were extracted from the Flora of the Czech Republic (vols. 18; Hejný et al. 1988 onwards), Key to the Flora of the Czech Republic (Kaplan et al. 2019a), floras of some other countries, and complemented by original observations.

Categories

- evergreen

- winter deciduous
- winter semi-deciduous

- drought semi-deciduous

Citation: Štěpánková P. \& Grulich V. (2020) Leaf deciduousness in woody plants. www.pladias.cz

\section{Leaf anatomy (Fig. 8)}

Leaf anatomy is an important ecological adaptation which helps plants to optimize photosynthesis under various environmental conditions. It reflects especially the availability of water (Klotz \& Kühn 2002a). Succulent and scleromorphic leaves are adapted to dry conditions. Both of them have thickened epidermis and cuticle, but the former develop a water-storage tissue while the latter have mechanisms to promote water transport in periods of water availability. Mesomorphic leaves are adapted to less dry conditions; hygromorphic leaves to shady conditions that rarely suffer from drought; helomorphic leaves to oxygen deficiency in swampy soils; and hydromorphic leaves to gas exchange in the water. The most common type in the Czech flora is mesomorphic leaves. Data were taken from the BiolFlor database (Klotz \& Kühn 2002a), which contains an extended and corrected version of the dataset published by Ellenberg (1979).

\section{Categories}

- succulent

- scleromorphic

- mesomorphic
- hygromorphic

- helomorphic

- hydromorphic

Data source and citation: Klotz \& Kühn (2002a). 
(a) Succulent leaves

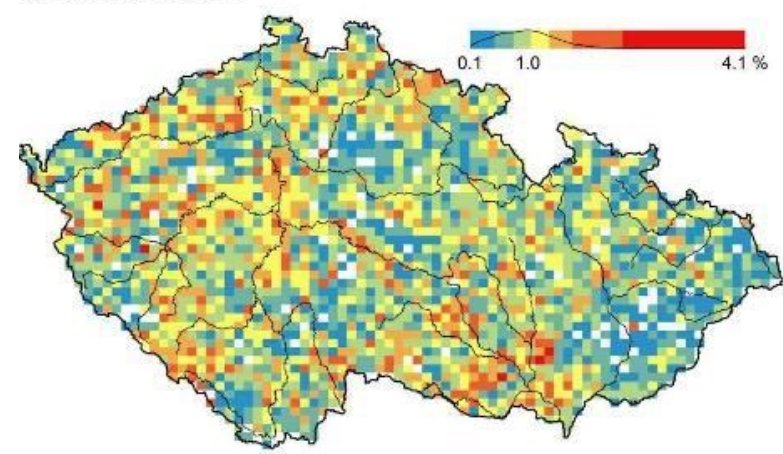

(c) Mesomorphic leaves

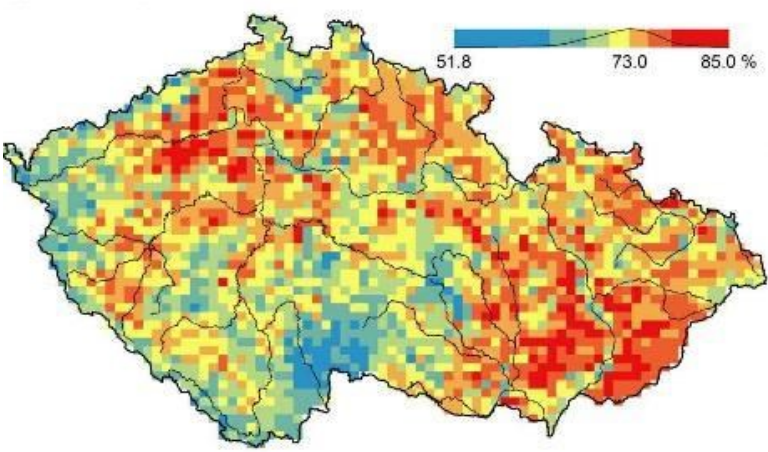

(e) Helomorphic leaves

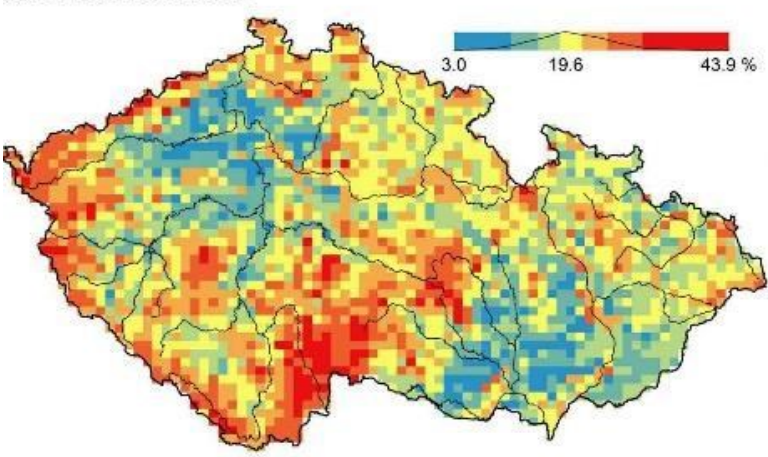

(b) Scleromorphic leaves

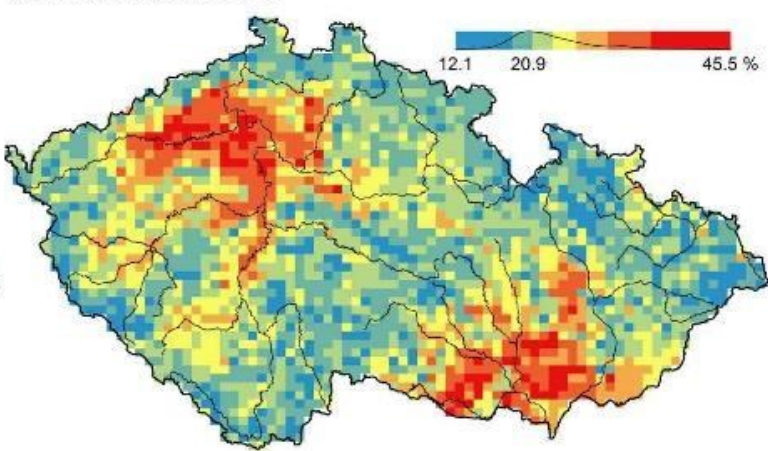

(d) Hygromorphic leaves

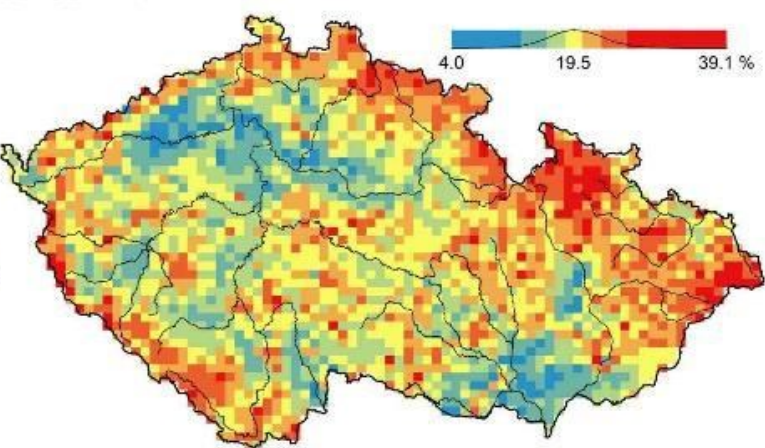

(f) Hydromorphic leaves

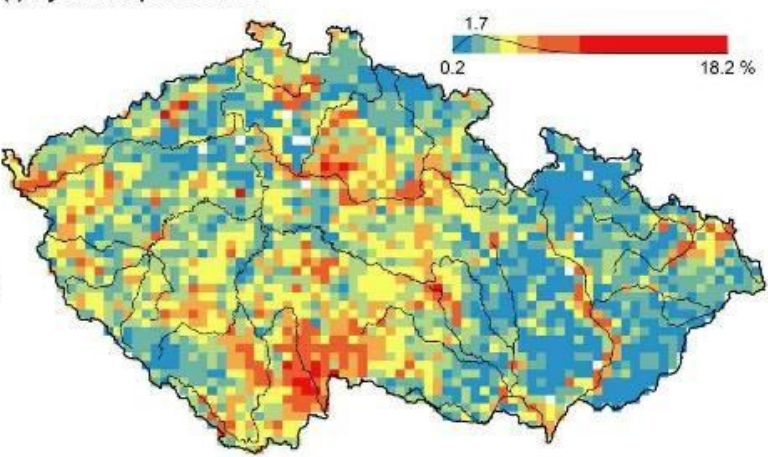

Fig. 8. - Proportion of species with different leaf anatomy in the Czech flora. Species with succulent leaves are common in areas with rock outcrops, those with scleromorphic leaves in dry lowlands, those with mesomorphic leaves in non-wetland lowland to submontane areas, those with hygromorphic leaves in the mountains, especially in the precipitation-rich northeast, those with helomorphic leaves in the western mountains of the Bohemian Massif and in the pond basins, and those with hydromorphic leaves in pond basins and riverine landscapes.

\section{Functional leaf type in woody plants}


Functional leaf types in woody plants, often used for physiognomic classification of forest and scrub vegetation, are distinguished based on their morphology, anatomy and life span. Most angiosperm woody plants of the central-European flora have broad deciduous or semideciduous leaves, which have a large specific leaf area. The other leaf types are, with rare exceptions (Larix), perennial and usually called evergreen. Needle-like and scale-like leaves occur in conifers and some species of Ericaceae. Sclerophyllous leaves are flat but have a strongly developed sclerenchyma, which causes their toughness. They are usually small coriaceous leaves with small specific leaf area, adapted to dry climate. Laurophyllous leaves are larger and thinner than sclerophyllous leaves and have a smaller amount of sclerenchyma. In most cases, they are dark green, smooth and shiny. These leaves are adapted to year-round wet climates with mild winters. A few species that are difficult to classify to these categories are classified as "special type".

Data on functional leaf types were taken from the Flora of the Czech Republic (vols. 1-8; Hejný et al. 1988 onwards), Key to the Flora of the Czech Republic (Kaplan et al. 2019a), floras of some other countries, and complemented by original observations.
Categories
- needle-like
- sclerophyllous
- scale-like
- laurophyllous
- broad deciduous or semi-
- special type deciduous

Citation: Štěpánková P. \& Grulich V. (2020) Functional leaf type in woody plants. www.pladias.cz.

\section{Flower}

\section{Flowering period (Fig. 9)}

The months of the beginning and end of flowering in the Czech Republic are given. Data were taken from the Key to the Flora of the Czech Republic (Kaplan et al. 2019a). 
Data source and citation: Kaplan et al. (2019a).

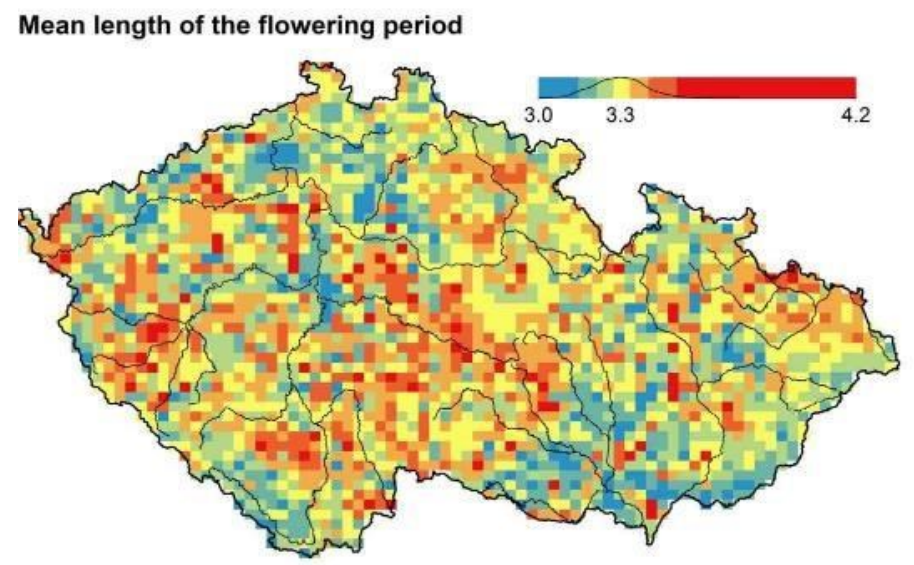

Fig. 9. - Mean length of the flowering period for the species of Czech flora (in months). On average, the most prolonged flowering period is found in mid-elevation areas that are neither too dry nor too cold.

\section{Flowering phase (Fig. 10)}

The flowering period for plants is usually indicated in months. However, as the start and end of the flowering period depend on the weather, the exact time may change from year to year. Therefore, Dierschke (1995) classified plant taxa into symphenological groups, i.e. groups of taxa that usually bloom together. Data are taken from the BiolFlor database (Trefflich et al. 2002).

\section{Categories}

- 1 Corylus avellana-Leucojum vernum (pre-spring)

- 2 Acer platanoides-Anemone nemorosa (start of early spring)

- 3 Prunus avium-Ranunculus auricomus (end of early spring)

- 4 Fagus sylvatica-Galeobdolon (start of mid-spring)

- 5 Sorbus aucuparia-Galium odoratum (end of mid-spring)

- 6 Cornus sanguinea-Melica uniflora (start of early summer)

- 7 Ligustrum vulgare-Stachys sylvatica (end of early summer)

- 8 Clematis vitalba-Galium sylvaticum (mid-summer)

- 9 Hedera helix-Solidago (early autumn) 
(a) Flowering phase 5

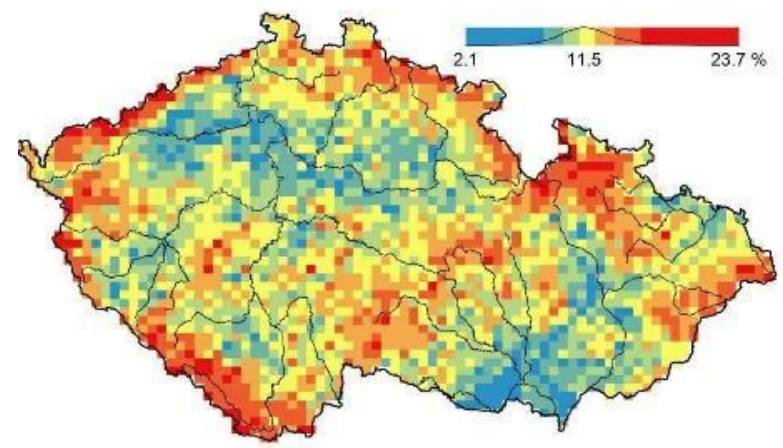

(b) Flowering phase 8

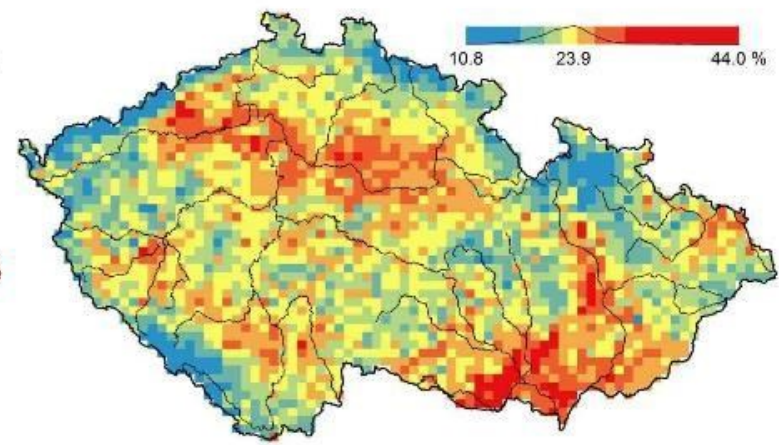

Fig. 10. - Proportion of species assigned to the flowering phases 5 Sorbus aucupariaGalium odoratum (end of mid-spring) and 8 Clematis vitalba-Galium sylvaticum (midsummer) in the Czech flora. The species belonging to phase 5 are remarkably concentrated in the mountains, while those belonging to phase 8 are frequent in the lowland areas with a high proportion of arable land. The other flowering phases do not show such distinct geographic patterns.

Data source and citation: Trefflich et al. (2002).

\section{Flower colour (Fig. 11)}

Flower colour is reported for nearly all angiosperms except duckweeds (Araceae p. p.) and some hybrids for which data on flower colour were not available.

If a species has more than one flower colour, all colours are reported irrespective of their frequency. This approach is used both for species that regularly form populations with different flower colours (e.g. Corydalis cava and Iris pumila) and for species with occasional occurrence of deviating flower colour (e.g. albinism in Salvia pratensis or pink flowers in Ajuga reptans). However, the whole range of variation is not fully reported in cultivated plants, for which some cultivars of different colour may be ignored (e.g. Gladiolus hortulanus and Callistephus chinensis). In plants with flowers of two colours (e.g. Cypripedium calceolus), both colours are reported. In plants with multi-coloured flowers (e.g. the variegated lip in Ophrys apifera) the predominant colour is reported. 
If the flower has a well-developed corolla or perigon, the reported flower colour depends on these parts. If such a flower has bracts of a contrasting colour (e.g. Melampyrum nemorosum), their colour is not considered. If the corolla or the perigon is not developed, the flower colour is based on the calyx (e.g. Daphne mezereum), bracts (e.g. Aristolochia clematitis), the system of bracts and bracteoles in the inflorescence (Euphorbia) or the involucre on secondary peduncles (Bupleurum longifolium). In species of Araceae with spadix and spathe of contrasting colours (e.g. Calla palustris) both colours are reported. The colour of the whole inflorescence is reported for some plants with reduced flowers (e.g. Betula, Salix, some Cyperaceae and Typhaceae). Spikelets in Poaceae are reported as green disregarding a possible violet tint; exceptions include the Melica ciliata agg. and Cortaderia that are reported as white. Also in other, rare cases, the inflorescence colour is reported as flower colour (e.g. green in Ficus carica). In Asteraceae, the colours of the disk flowers and ray flowers are reported separately if the ray flowers are developed and have a contrasting colour (e.g. Bellis perennis). The colour of the involucrum is reported for species with tiny flower heads and indistinct flowers (e.g. Artemisia campestris and Xanthium) and for "immortelles" (e.g. Helichrysum and Xeranthemum).

Information on flower colour is partly based on the field knowledge, partly obtained from various photographs and descriptions in the Flora of the Czech Republic (vols. 1-8; Hejný et al. 1988 onwards). In the taxa that are not reported in the Flora of the Czech Republic, as well as in unclear cases (especially in alien species), other sources were used, especially the Flora of North America (Flora of North America Editorial Committee 1993), Flora of China (Wu et al. 1994) and Flora of Pakistan (http://www.tropicos.org/Project/Pakistan).

\section{Categories}

- white (including grey and silvery, and rare cases of individuals with white colour) e.g. ray flowers of Leucanthemum vulgare, albinotic plants of Glechoma hederacea, catkins of Salix caprea

- yellow-white (including white-yellow and cream) - e.g. Scabiosa ochroleuca

- green-white (including white-green and greenish) - e.g. Orthilia secunda

- green - e.g. Poa pratensis (the colour relates to the glumes and lemmas)

- yellow-green (including green-yellow) - e.g. Acer pseudoplatanus, Rhamnus cathartica

- yellow - e.g. Taraxacum 
- orange - e.g. Pilosella aurantiaca

- pink (including white-pink, pink-white and dark pink) - e.g. Malva alcea, Rosa canina

- pink-violet - e.g. Allium schoenoprasum

- red-e.g. Papaver rhoeas

- red-violet (includes all the hues of purple, pink-red and violet-red) - e.g. Astragalus onobrychis, Cirsium palustre

- violet (including dark violet and black-violet) - e.g. Bartsia alpina, Salvia verticillata

- blue - e.g. Centaurea cyanus

- blue-violet - e.g. Aconitum plicatum

- brown (including yellow-brown, brown-yellow, beige and brown-violet) - e.g. Euonymus verrucosus, Neottia nidus-avis

- red-brown - e.g. Asarum europaeum, Scrophularia nodosa

- black - e.g. Carex acuta (the colour relates to the colour of bracts)

Citation: Štěpánková P. \& Grulich V. (2019) Flower colour. - www.pladias.cz.

(a) Yellow-white and yellow

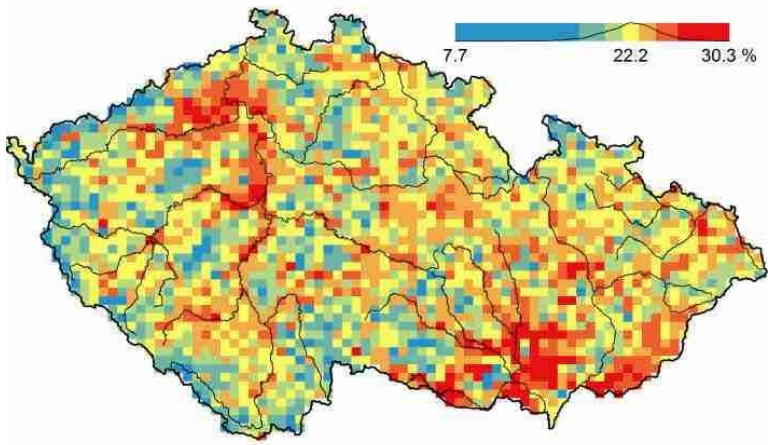

(c) Pink-violet and red-violet

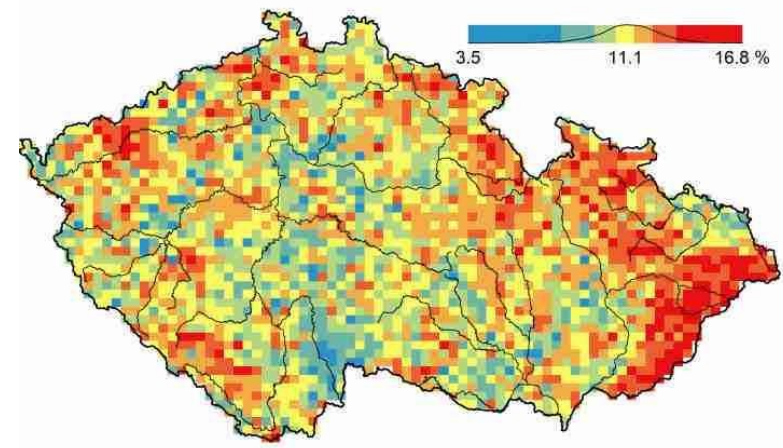

(b) Pink

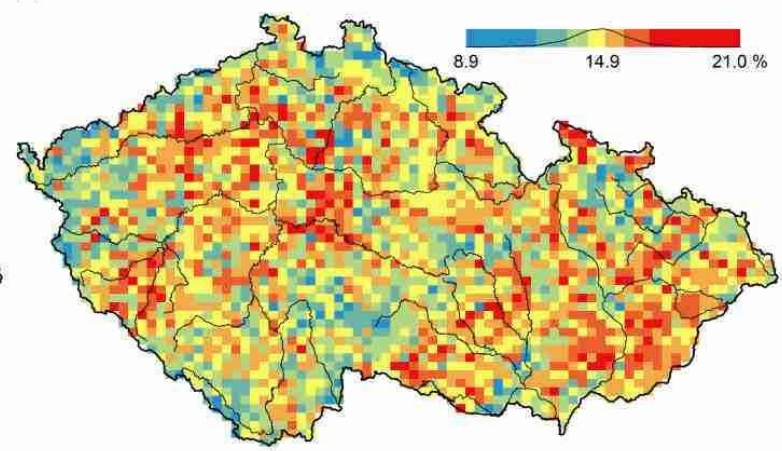

(d) Blue

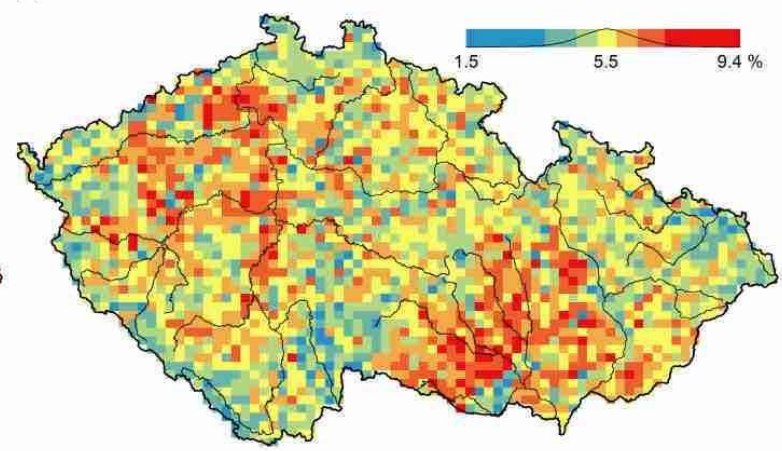


Fig. 11. - Proportion of species with selected colours in the Czech flora. In (a) and (c), two similar colours showing similar spatial patterns were merged. Yellow-white, white and blue colours tend to be frequent in dry and warm lowland areas, pink colours at lower elevations, and pink-violet and red-violet colours at higher elevations, especially in the flysch Carpathians. Most of the other flower colours show less clear geographic patterns.

\section{Flower symmetry (Fig. 12)}

Flowers of angiosperms are divided into zygomorphic (with bilateral symmetry) and actinomorphic (with radial symmetry). This character is not reported for taxa with achlamydeous flowers and taxa with strongly reduced or rudimentary perianth or with a perianth modified into scale-like or setaceous structures. However, it is reported for taxa with the perianth reduced to a corolla-like calyx (e.g. Aizoaceae and Daphne) and in taxa with flowers surrounded by complex structures combining bracts with the proper perianth or petal-like staminodes and stamens (e.g. Canna). Spiral and spirocyclic flowers, though actually asymmetric, are classified as actinomorphic in Nymphaeaceae and most species of Ranunculaceae. In contrast, in some other members of Ranunculaceae (e.g. Aconitum and Delphinium), they are classified as zygomorphic. Bisymmetric flowers (in the Brassicaceae family and the genera Dicentra and Lamprocapnos) are consistently classified as actinomorphic. Both zygomorphic and actinomorphic flowers are reported for taxa with both symmetry types (e.g. Succisa pratensis).

The information about flower symmetry was extracted from the descriptions in the Flora of the Czech Republic (vols. 1-8; Hejný et al. 1988 onwards). If some uncertainty occurred, particularly in some alien taxa, the descriptions in the Flora of North America (Flora of North America Editorial Committee 1993 onwards), the Flora of China (Wu et al. 1994 onwards) and the Flora of Pakistan (www.tropicos.org/Project/Pakistan) were consulted.

\section{Categories}

- zygomorphic

- actinomorphic

Citation: Grulich V., Holubová D., Štěpánková P. \& Řezníčková M. (2017) Flower symmetry. - www.pladias.cz. 


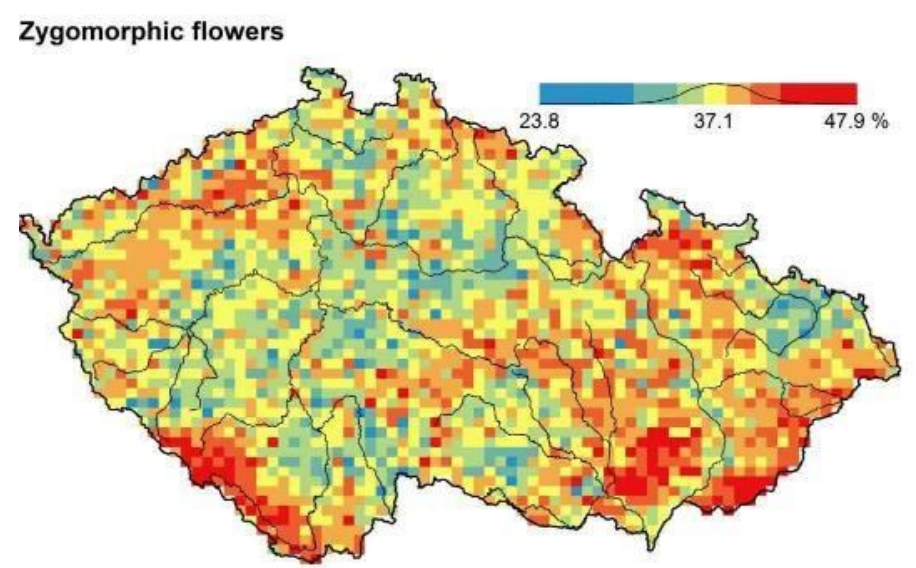

Fig. 12. - Proportion of species with zygomorphic flowers in the Czech flora. These species are frequent in the mountains and lowland non-wetland areas. Note that the proportion of actinomorphic flowers is the complement of the proportion of zygomorphic flowers.

\section{Perianth}

Perianth (perigon), i.e. the non-reproductive part of the angiosperm flower, can be classified into heterochlamydeous and homochlamydeous. Heterochlamydeous flowers are divided into calyx and corolla. In homochlamydeous flowers, calyx and corolla are indistinguishable. Perianth or some of its parts can be reduced or absent; flowers with no perianth are called achlamydeous.

In Apiaceae, the presence of the calyx teeth is assessed as a reduced calyx; if these teeth are not visible, the calyx is considered as absent. In Asteraceae, the presence of a pappus, scales or a collar-like structure is considered as a reduced calyx; if no such structures are present, the calyx is considered as absent. In Cyperaceae, the presence of perigon bristles is assessed as a reduced perigon. All members of the Poaceae family are considered as plants with a reduced perigon. The perianth in the genus Basella is arbitrarily classified as a reduced calyx though it is also often considered as a reduced homochlamydeous perianth. The character states "homochlamydeous, sometimes absent" and "homochlamydeous, reduced or absent" mean that in one plant some flowers may have a well-developed or reduced perianth, while other flowers may be achlamydeous (e.g. Atriplex).

The information was extracted mainly from the descriptions in the Flora of the Czech Republic (vols. 1-8; Hejný et al. 1988 onwards). For the taxa not treated in that flora or if 
some uncertainties occurred, mainly concerning some alien taxa, the descriptions in the Flora of North America (Flora of North America Editorial Committee 1993 onwards), the Flora of China (Wu et al. 1994 onwards) and the Flora of Pakistan (www.tropicos.org/Project/Pakistan) were consulted.

\section{Categories}

- homochlamydeous

- homochlamydeous, sometimes reduced

- homochlamydeous, sometimes reduced or absent

- homochlamydeous, sometimes absent

- homochlamydeous, reduced or absent

- calyx and corolla

- calyx and corolla, corolla reduced or absent

- calyx and corolla, corolla sometimes absent

- calyx present, corolla sometimes reduced

- calyx present, corolla reduced

- calyx present, corolla reduced or absent

- calyx present, corolla sometimes absent

- calyx present, corolla absent

- calyx reduced, corolla present

- calyx sometimes absent, corolla present

- calyx absent, corolla present

- calyx absent, corolla sometimes present

- reduced

- reduced or absent

- flower achlamydeous

Citation: Grulich V., Prokešová H. \& Štěpánková P. (2017) Perianth. - www.pladias.cz.

\section{Fusion of the perianth}

This characteristic of angiosperm flowers is assessed either as a fusion of the corolla or, in homochlamydeous taxa (e.g. Amaryllidaceae, Liliaceae and Orchidaceae) as a fusion of the 
perigon. It is not assessed in achlamydeous groups (e.g. Salix) and plants with a strongly reduced or rudimentary perianth or with the perianth modified in scale-like or setaceous structures with a varying number of bristles, which may be free (e.g. in Cyperaceae) or partially fused (e.g. in most of Poaceae). The perianth of such plants is considered as reduced. The perianth in the genus Aristolochia is also classified as reduced (neither fused nor free): it is modified to scales situated at the bottom of a tube-like structure formed by fused bracts. Both primary character states are assigned to the taxa with unisexual male and female flowers that differ in the fusion of the perianth (e.g. Cannabis). A similar approach is used in the taxa in which some flowers are homochlamydeous while others are achlamydeous (e.g. Atriplex).

The basic information was extracted from the Flora of the Czech Republic (vols. 1-8; Hejný et al. 1988 onwards). If some uncertainty occurred, especially for alien taxa, other sources were consulted, including the Flora of North America (Flora of North America Editorial Committee 1993 onwards), the Flora of China (Wu et al. 1994 onwards) and the Flora of Pakistan (www.tropicos.org/Project/Pakistan).

\section{Categories \\ - free \\ - fused \\ - reduced}

Citation: Grulich V., Holubová D., Štěpánková P. \& Řezníčková M. (2017) Fusion of the perianth. - www.pladias.cz.

\section{Shape of the sympetalous corolla or syntepalous perigon}

This characteristic of angiosperm flowers is not assessed for achlamydeous groups (e.g. Salix) and plants with a strongly reduced or rudimentary perianth or with the perianth modified in scale-like or setaceous structures (e.g. Cyperaceae and Poaceae). In Amaranthaceae and the genus Cannabis, the perianth is recognizable, and the degree of its fusion could be assessed, but not its shape. If the corolla or the perigon have an intermediate shape between two character states, the taxon is assigned to both of them. Many sympetalous corollas and syntepalous perigons have unique shapes that are difficult to 
match to general classification categories. The taxa with such shapes are classified to an auxiliary category “special type” (e.g. Canna, Cyclamen, Dicentra, Gladiolus, Impatiens and Iris).

The basic information was extracted from the Flora of the Czech Republic (vols. 1-8; Hejný et al. 1988 onwards). In uncertain cases, especially in some alien taxa, other sources were consulted, including the Flora of North America (Flora of North America Editorial Committee 1993 onwards), the Flora of China (Wu et al. 1994 onwards) and the Flora of Pakistan (www.tropicos.org/Project/Pakistan).

Categories

- urceolate

- bilabiate

- ligulate

- rotate
- funnel-shaped

- hypocrateriform

- personate

- labiate
- tubular

- campanulate

- filiform

- $\quad$ special type

Citation: Grulich V., Holubová D., Štěpánková P. \& Řezníčková M. (2017) Shape of the sympetalous corolla or syntepalous perigon. - www.pladias.cz.

\section{Calyx fusion}

The calyx of angiosperm flowers can be fused into a calyx tube (synsepalous calyx) or composed of distinct sepals (aposepalous). In some plants (especially in Asteraceae) the calyx is modified into a ring of fine feathery hairs called the pappus. Taxa with both synsepalous and aposepalous calyx (e.g. Platanus) are classified as "synsepalous and aposepalous". A cup-shaped tube formed of fused sepals, petals and stamens is called hypanthium. However, hypanthium may also be interpreted as a product of an intercalary growth of the floral axis (receptacle) up and around the carpels, forming a cup-shaped structure, sometimes even fusing with the outer walls of the carpels and making the ovary inferior. In most genera of the Onagraceae family, the hypanthium forms a floral tube fairly overtopping the apex of the ovary.

The data were taken from the Flora of the Czech Republic (vols. 1-8; Hejný et al. 1988 onwards), the Key to the Flora of the Czech Republic (Kubát et al. 2002), the New 
Hungarian Herbal (Király et al. 2011) and the Excursion Flora of Germany (Jäger \& Werner 2000).

Categories

- aposepalous

- fused at the base

- $\quad$ synsepalous and aposepalous
- $\quad$ synsepalous

- pappus

- hypanthium

Citation: Prokešová H. \& Grulich V. (2017) Calyx fusion. - www.pladias.cz.

\section{Inflorescence type}

Inflorescence types follow the morphological system used in the Flora of the Czech Republic (vols. 1-8; Hejný et al. 1988 onwards). As the Czech terminology used for inflorescences does not match the English terminology, we use Latin terms in the English version of the Pladias Database. The exact identification of the inflorescence type is often equivocal because of varying interpretations of the same object. In species with unisexual flowers, male and female flowers can occur in different inflorescence types. In other cases, it is not possible to identify the inflorescence without detailed knowledge of evolutionary morphology, e.g. umbella vs pseudumbella in the genus Butomus. There are also compound inflorescences, in some cases with very different structure of their parts, especially in Asteraceae, which can have even triple inflorescences (e.g. Echinops sphaerocephalus often has an anthella ex capitulis anthodiorum composita).

The information was extracted mainly from the descriptions in the Flora of the Czech Republic (vols. 1-8; Hejný et al. 1988 onwards). For the taxa not treated in that flora or if some uncertainties occurred, mainly concerning some alien taxa, the descriptions in the Flora of North America (Flora of North America Editorial Committee 1993 onwards), Flora of China (Wu et al. 1994 onwards) and Flora of Pakistan (www.tropicos.org/Project/Pakistan) were consulted. In critical groups (e.g. Rubus), especially in recently described species, inflorescence type was taken from the original descriptions.

\section{Categories}


- amentum

- amentum e floribus femineis

- amentum e floribus masculis

- anthella

- anthella e floribus masculis composita

- anthella e spiculis composita

- anthella ex capitulis anthodiorum composita

- anthella ex anthodiis composita

- anthodium

- anthodium solitarium

- bostryx

- capitulum

- capitulum e floribus femineis compositum

- capitulum e floribus masculis compositum

- capitulum e spiculis compositum

- capitulum e verticillastris compositum

- capitulum ex anthodiis compositum

- cincinnus

- corymbothyrsus

- corymbothyrsus e fasciculis compositus

- corymbothyrsus ex anthodiis compositus

- corymbothyrsus ex fasciculis anthodiorum compositus

- corymbus

- corymbus ex anthodiis compositus
- dichasium

- dichasium e floribus femineis compositum

- dichasium ex anthodiis compositum

- fasciculus

- fasciculus e floribus femineis compositus

- fasciculus e floribus masculis compositus

- fasciculus ex anthodiis femineis compositus

- flores solitarii

- flores solitarii feminei

- flores solitarii masculi

- panicula

- panicula e bostrychibus composita

- panicula e capitulis composita

- panicula e cincinnis composita

- panicula e corymbis composita

- panicula e dichasiis composita

- panicula e fasciculis composita

- panicula e floribus masculis composita

- panicula e pseudospicis composita

- panicula e spiculis composita

- panicula e spiculis masculis composita

- panicula ex capitulis anthodiorum composita

- panicula ex anthodiis composita

- pseudoracemus

- pseudospica 
- pseudospica e capitulis composita

- pseudospica e floribus masculis composita

- pseudospica e spiculis composita

- pseudospica e verticillastris composita

- pseudospica ex anthodiis composita

- pseudumbella

- pseudumbella e cyathiis composita

- pseudumbella ex anthodiis composita

- racemus

- racemus e capitulis compositus

- racemus e cincinnis compositus

- racemus e fasciculis compositus

- racemus e floribus femineis compositus

- racemus e floribus masculis compositus

- racemus e spiculis compositus

- racemus e verticillastris compositus

- racemus ex anthodiis compositus
- racemus ex corymbis anthodiorum compositus

- racemus ex anthodiis masculis compositus

- racemus ex umbellis compositus

- rhipidium

- $\quad$ spadix

- spadix e floribus femineis compositus

- spica

- $\quad$ spica e floribus femineis composita

- spica e floribus masculis composita

- spica e spiculis composita

- spicula

- strobilus

- syconium

- umbella

- umbella composita

- umbella e spicis spicularum composita

- verticillastrum

Citation: Grulich V. \& Štěpánková P. (2019) Inflorescence type. - www.pladias.cz.

\section{Dicliny (Fig. 13)}

Dicliny characterizes the level of spatial separation of male and female reproductive organs. Monoclinous (synoecious) plants, including most taxa of the central-European flora, have only bisexual (hermaphroditic) flowers. The plants with unisexual flowers are either monoecious (with both male and female flowers growing on the same individual) or 
dioecious (with male and female flowers growing on different individuals).

Gynomonoecious plants have female and bisexual flowers on the same individuals, while andromonoecious plants have male and bisexual flowers on the same individuals.

Gynodioecious plants have female and bisexual flowers on different individuals, or some individuals have only female flowers, and other individuals have both male and female flowers. Androdioecious plants have male and bisexual flowers on different individuals, or some individuals have only male flowers, and other individuals have both male and female flowers. Trioecious plants have individuals with male flowers, individuals with female flowers, and individuals with bisexual (or both male and female unisexual) flowers. Trimonoecious plants have a male, female and bisexual flowers on the same individual. Other plants can be male sterile. Data on dicliny were taken from the BiolFlor database (Durka 2002).

Categories

- synoecious

- monoecious

- dioecious

- gynomonoecious
- andromonoecious

- gynodioecious

- androdioecious

- trioecious
- trimonoecious

- male-sterile

Data source and citation: Durka (2002). 
(a) Synoecious

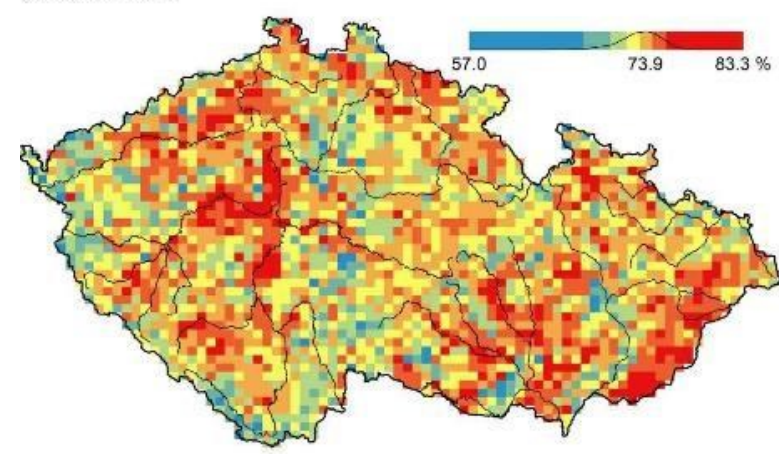

(c) Dioecious

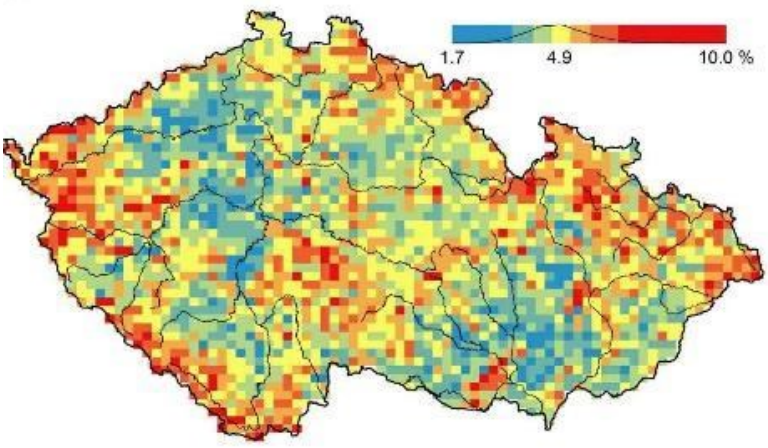

(b) Monoecious

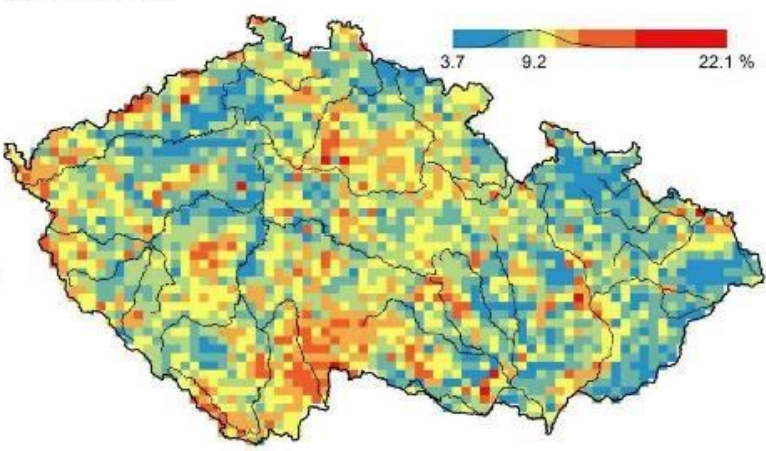

Fig. 13. - Proportion of synoecious, monoecious and dioecious species in the Czech flora. Synoecious species are frequent in the mountains and deep river valleys, monoecious in pond basins and some riverine landscapes, and dioecious in the mountains, mid-elevation areas and lowland river landscapes.

\section{Generative reproduction type (Fig. 14)}

The type of generative reproduction (breeding system) is defined by the origin of gametes that fuse to form offspring. On the one hand, it includes obligate outcrossing, which can be controlled by genetic mechanisms of recognition and rejection of self-pollen before the fertilization of the egg cell (allogamy, self-incompatibility), sequential hermaphroditism (dichogamy) or unisexuality of plant individuals (dioecy). On the other hand, it includes obligate autogamy, which refers to the fusion of two gametes that both originate from one flower or one individual. However, various mixed strategies are common, including reproduction by both self-fertilization and mating with other individuals. The degree of selffertilization can be affected by both genetic and ecological factors, among others by frequency, diversity and foraging strategy of pollinators. Three categories are distinguished: (1) facultative allogamy (outcrossing prevails, but selfing is possible), (2) facultative 
autogamy (mainly selfing, outcrossing is rare) and (3) mixed mating, in which both outcrossing and selfing are common, sometimes with different frequencies among populations. The last main category, apomixis, includes seed production without fertilization. It can be either obligate (offspring is genetically identical with the maternal plant) or facultative (accompanied by residual sexuality, as a rule with a low frequency). Hybrid plants are often sterile, but can sometimes reproduce vegetatively and persist for a long time. In some cases (e.g. Pilosella), such sterile hybrids are considered as species and included in this list. Some morphologically well-defined and widely accepted taxa consist of populations with contrasting modes of reproduction (as a rule connected with ploidy levels). For example, some populations are sexual and allogamous while others are apomictic. Data on generative reproduction types of the taxa of Czech flora were obtained through a search of the available literature.

\section{Categories}

- allogamy

- allogamy self-incompatibility

- facultative allogamy

- autogamy

- facultative autogamy
- $\quad$ mixed mating

- apomixis

- obligate apomixis

- facultative apomixis

- sterility

Citation: Chrtek J. Jr. (2018) Generative reproduction type. - www.pladias.cz.

(a) Autogamy

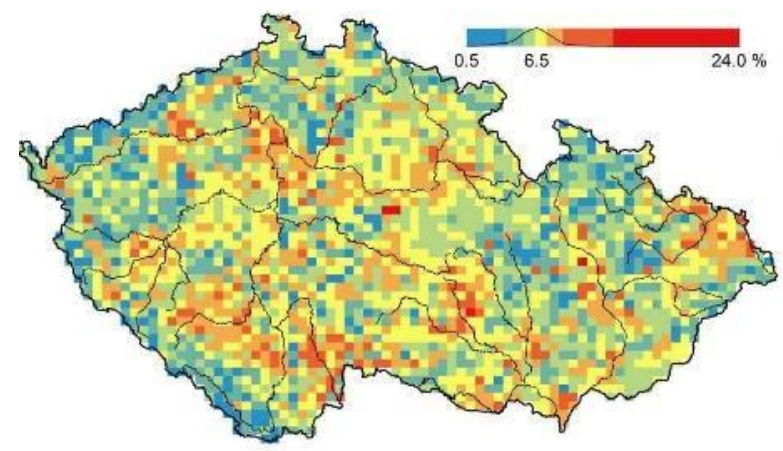

(b) Obligate apomixis

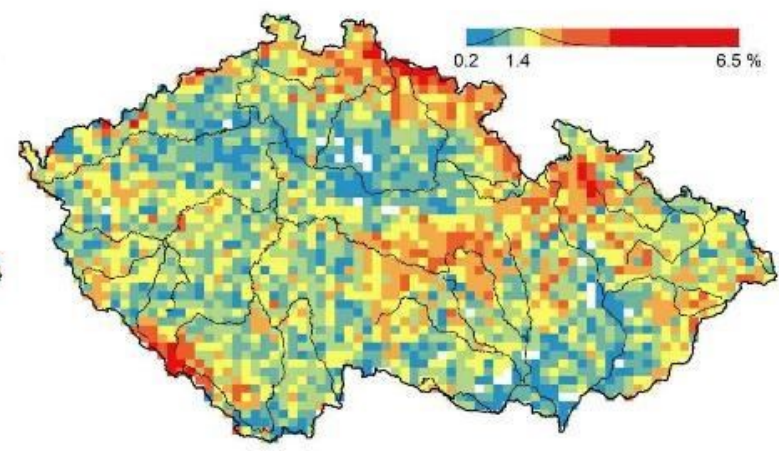


Fig. 14. - Proportion of autogamic and obligate apomictic species in the Czech flora. The former are frequent in pond basins and lowland riverine landscapes, the latter in the highest mountain areas.

\section{Pollination syndrome (Fig. 15)}

Pollen is transferred to stigma by different vectors, including abiotic vectors such as wind (anemophily) or water (hydrophily), or biotic vectors such as insects (entomophily). An alternative mechanism is selfing (autogamy), which can include special mechanisms such as cleistogamy (selfing in rudimentary, obligatorily autogamous flowers), pseudocleistogamy (selfing in flowers that do not open due to adverse environmental conditions) or geitonogamy (selfing by pollen from a neighbouring flower of the same plant except the cases of pollen transfer by a vector). Pollination syndromes are adopted from the BiolFlor database (Durka 2002).

\section{Categories}

- wind-pollination

- water-pollination

- insect-pollination

- selfing

Data source and citation: Durka (2002).
- cleistogamy

- pseudocleistogamy

- geitonogamy 
(a) Wind-pollinated

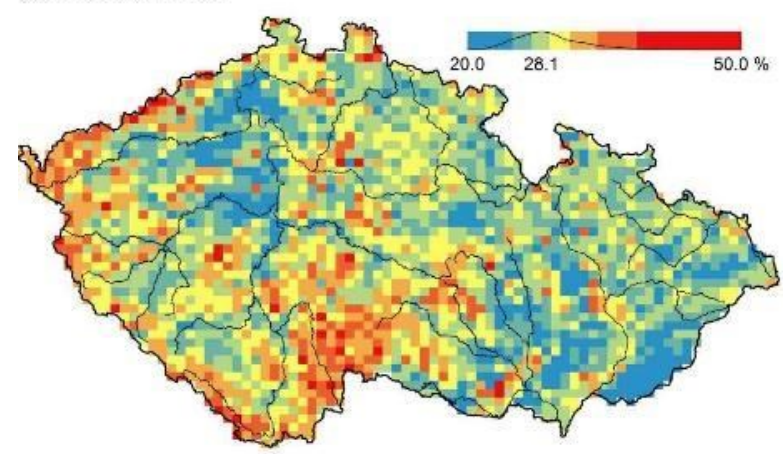

(c) Insect-pollinated

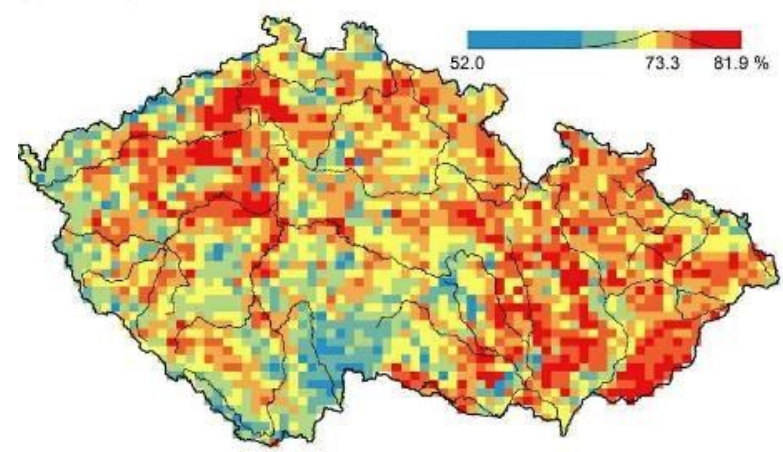

(b) Water-pollinated

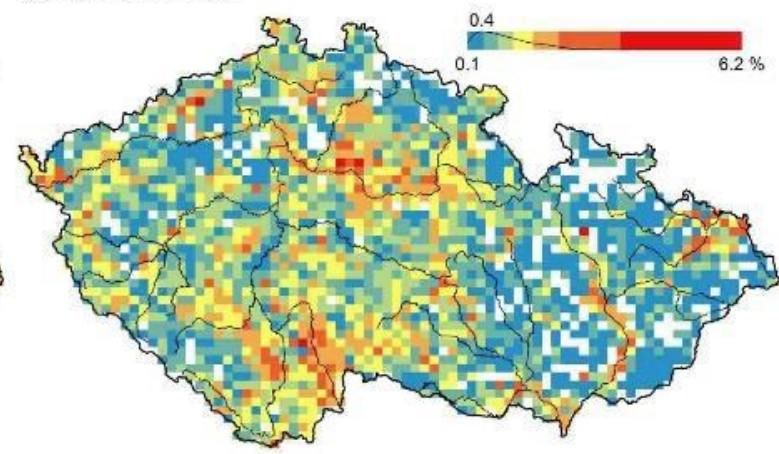

(d) Self-pollinated

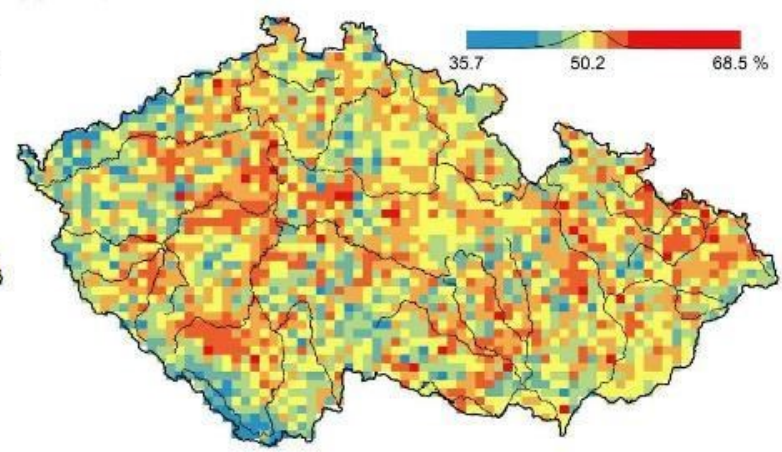

Fig. 15. - Proportion of wind-, water-, insect- and self-pollinated species in the Czech flora. Wind-pollinated plants are frequent in the western mountains of the Bohemian Massif and in pond basins, water-pollinated plants in the pond basins and lowland riverine landscapes, insect-pollinated plants in dry lowlands outside the large river floodplains and in the flysch Carpathians, and self-pollinated plants in lowlands and mid-elevation areas.

\section{Pollinator spectrum}

The data describe the representation of abundances of pollinator functional groups for a given plant taxon. Pollinator taxa are divided into 13 functional groups (plus the category "unknown" for insufficiently identified pollinators). The delimitation of these groups reflects (1) similarity of pollination behaviour of the pollinator taxa included; (2) precision of identification of the particular group by pollination biologists; and (3) frequency of occurrence among visitors of Czech plant taxa (e.g. moths and hawkmoths constitute a welldefined functional group, but they were included among butterflies due to their rare occurrence in the dataset). Only a list of pollinator functional groups of a given plant taxon is shown on the Pladias Database portal. Pollinator functional groups with less than $10 \%$ share on the total pollinator composition are listed in brackets. 
The data are based predominantly ( $\sim 80 \%)$ on European studies that quantitatively recorded all the pollinator functional groups visiting the focal plant species. The literature data were supplemented by original research ( 20\%). Pollinator spectra were established mainly for common non-forest herbs, based on approximately 240,000 recorded pollinator individuals. A plant taxon is included in the database if at least 25 pollinator individuals were recorded from it. Pollinator spectrum is based on the sum of all observed pollinator individuals from a given plant taxon. Pollinator records in percentages needed to be recalculated to abundances before summing up with pollinator abundances recorded from the same plant species. For such recalculation, it was conservatively assumed that the pollinator taxon with the lowest recorded percentage corresponds to one observed individual. The abundances of other pollinators were recalculated accordingly. In some studies, the pollinator percentages were calculated only after averaging data from several subplots, and the above-mentioned approach thus could not be employed (due to obvious overestimation of abundances in such cases). Pollinator abundances were therefore estimated as one half of the back-transformed fitted value of the following regression equation: $\log (\#$ individuals $) \sim 0.461 \times \log (\#$ taxa $)+0.815\left(\mathrm{~F}_{1,3774}=1073 ; \mathrm{p}<0.001 ; \operatorname{adj} . \mathrm{R}^{2}\right.$ $=0,221)$, which were obtained for particular site-by-plant taxon combinations from all studies with pollinator spectra reported as abundances.

\section{Categories}

- honeybee - Apis mellifera

- bumblebees - Bombus spp. incl. Psithyrus

- solitary bees - anthophilous pollen-collecting taxa from Apoidea other than honeybees and bumblebees

- other Hymenoptera - Hymenoptera other than bumblebees, solitary bees and honeybee

- hoverflies - Syrphidae larger than $5 \mathrm{~mm}$

- flies s. 1. - flies, flower flies and similar (families Muscidae, Anthomyiidae, Fanniidae, Scathophagidae, Sphaeroceridae) larger than $5 \mathrm{~mm}$

- meat flies s. 1. - meat flies and blow flies (families Sarcophagidae, Calliphoridae, Rhinophoridae)

- other Diptera - Diptera other than flies, meat flies and hoverflies (or from those groups but smaller than $5 \mathrm{~mm}$ ) 
- butterflies - butterflies (Lepidoptera, including moths and sphingids)

- beetles - beetles (Coleoptera; except nitidulids)

- nitidulids - small floricolous beetles with aggregated distribution (families Nitidulidae, Kateridae, Byturidae, Phalacridae)

- thrips - Thysanoptera

- other pollinators - regular flower visitors presumably contributing to pollination (except for the orders Diptera, Hymenoptera, Lepidoptera, Coleoptera and Thysanoptera)

- unknown - pollinators without further identification by authors (or identification including more than one recognized pollinator functional group)

Citation: Janovský Z. (2020) Pollinator spectrum. - www.pladias.cz.

\section{Fruit, seed and dispersal}

\section{Fruit type}

The primary classification of fruit types is into dry and fleshy. Within each of these two groups, fruit types are further classified based on the scheme outlined in the first volume of the Flora of the Czech Republic (Slavíková 1988), which consistently uses the typological method. This means that fruits are classified based purely on their morphology following the formal definitions of the fruit type, regardless of the fruit type found in closely related species or genera.

One-seeded fruits in Brassicaceae (e.g. Crambe) are classified as achenes, not siliculas. Indehiscent two- and more-seeded fruits in the same family, breaking mainly in constrictions (e.g. in Bunias and Raphanus), are consistently classified as a loment, even if the fruit breaks into two distinct parts, of which one is one-seeded and the other, of strikingly different shape, two- or more-seeded and dehiscent, such as in Rapistrum rugosum. A similar approach is used for the classification of fruits in Fabaceae. Dehiscent fruits of most taxa are classified as legumes, while indehiscent two- and more-seeded fruits breaking into single-seeded parts (e.g. in Hippocrepis and Securigera) are classified as loments. Oneseeded indehiscent fruits (e.g. in Onobrychis and Trifolium) are classified as achenes. Two- 
or more-seeded indehiscent fruits (e.g. in Sophora japonica and Vicia faba) are also classified as legumes. The fruits of all Euphorbia species are classified as capsules, although in some cases the seeds are not released. Fleshy false fruits of the genera Basella, Ficus, Maclura, Morus, Nuphar and Nymphaea are merged into a separate category.

The information about fruit type was extracted mainly from the descriptions in the Flora of the Czech Republic (vols. 1-8; Hejný et al. 1988 onwards). For the taxa not treated in that flora or in case of uncertainties, especially regarding alien taxa, descriptions in the Flora of North America (Flora of North America Editorial Committee 1993 onwards), the Flora of China (Wu et al. 1994 onwards), the Flora of Pakistan (www.tropicos.org/Project/Pakistan), and Flora Iberica (Castroviejo et al. 1986 onwards; mainly for the Fabaceae family) were consulted.

Categories

- dry fruit - disciform breaking into mericarps

- dry fruit - pair of nutlets

- dry fruit - cremocarp

- dry fruit - double samara

- dry fruit - legume

- dry fruit - follicle

- dry fruit - achene/cypsela/samara

- dry fruit - nut enclosed in a utricle

- dry fruit - caryopsis

- dry fruit - nut

- dry fruit - schizocarp

- dry fruit - cluster of follicles

- dry fruit - head of achenes

- dry fruit - loment/transversely dehiscent siliqua
- dry fruit - siliqua

- dry fruit - silicula

- dry fruit - capsule

- dry fruit - cluster of four oneseeded nutlets

- dry fruit - dry schizocarp with an apical beak

- fleshy fruit - berry

- fleshy fruit - pome

- fleshy fruit - drupe

- fleshy fruit - head of one-seeded drupes

- fleshy fruit - hip

- fleshy fruit - special type

Citation: Grulich V., Holubová D., Štěpánková P. \& Řezníčková M. (2017) Fruit type. www.pladias.cz. 


\section{Fruit colour}

Data on fruit colour according to the Flora of the Czech Republic (vols. 1-8; Hejný et al. 1988 onwards) and the Key to the Flora of the Czech Republic (Kubát et al. 2002). Fruit colours are standardized into ten colours. A single dominant colour of ripe fruit is reported for each taxon.

Categories

- white

- green

- yellow

- orange
- violet

- red

- blue

- brown

Data source and citation: Hejný et al. (1988 onwards), Kubát et al. (2002).

\section{Reproduction type (Fig. 16)}

Reproduction is the production of offspring that are physically separated from the parental plant. Plants reproduce either by seed (or spores) or vegetatively, while the combination of these two types of reproduction in the same taxon is common. Asexual seed production (apomixis) is not considered as vegetative reproduction. Data are taken from the BiolFlor database (Durka 2002).

\section{Categories}

- only vegetatively

- mostly vegetatively, rarely by seed/spores

- by seed/spores and vegetatively

- mostly by seed/spores, rarely vegetatively

- only by seed/spores

Data source and citation: Durka (2002). 

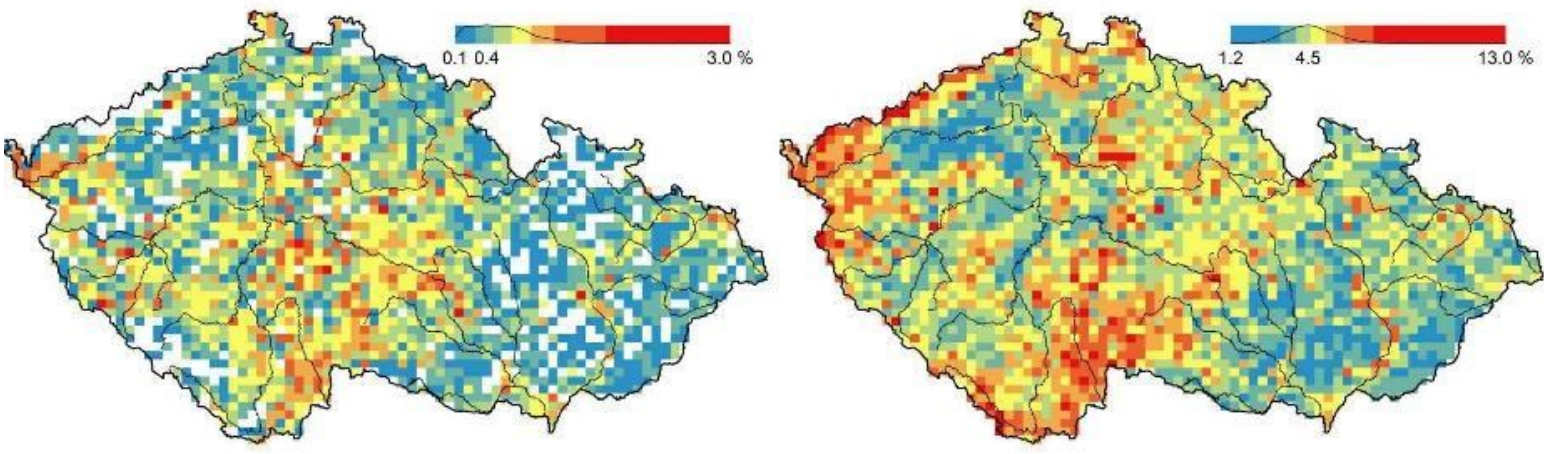

(c) Reproduction by seed-spores and vegetatively

(d) Reproduction mostly by seed-spores
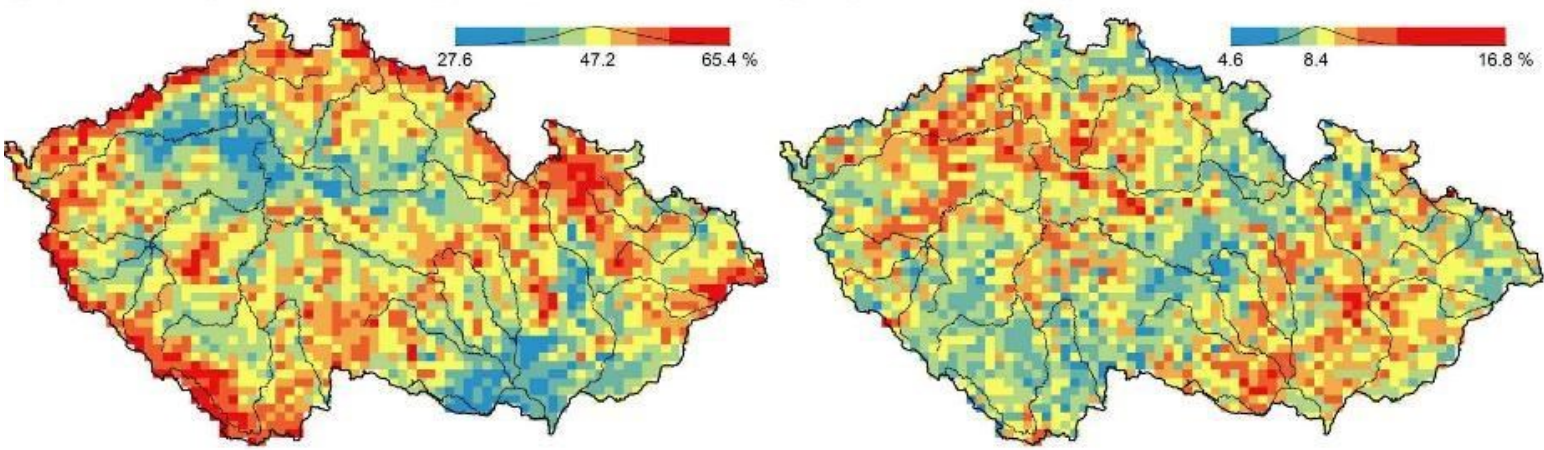

(e) Reproduction only by seed-spores

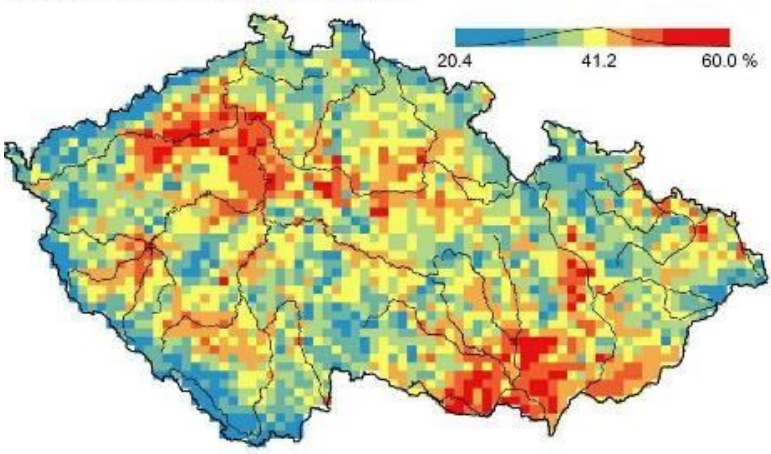

Fig. 16. - Proportion of species with different proportions of vegetative and generative reproduction in the Czech flora. Plants reproducing only vegetatively are more common in the mid-elevation areas of the Bohemian Massif, those reproducing mostly vegetatively in pond basins and lowland riverine landscapes, those reproducing by both seed/spores and vegetatively in the mountain area, those reproducing mostly by seed/spores in lowland areas and those reproducing only by seed/spores in dry lowland areas.

\section{Dispersal unit (diaspore)}


Diaspore, also called dispersule or propagule, is a generative or vegetative part of the plant body that is dispersed from the parental plant and can produce a new individual. Generative diaspores include spores, seeds and fruits or similar dispersal units (e.g. aggregate fruits in Fragaria, multiple fruits in Morus, gymnosperm cones, epimatium-bearing seed in Taxus, spikelets or their various fragments in Poaceae). If the seed is released from dehiscent fruit or decaying ripe fleshy fruit, both seed and fruit can be considered as diaspores. In plants with indehiscent fruits, only the fruit is considered as a diaspore. A specific category of generative diaspore is tumbleweeds, i.e. mature plant parts including stem branches and large inflorescence (e.g. Crambe tataria and Falcaria vulgaris).

Vegetative diaspores are viable and movable parts of plants that originate above ground or in water and disconnect from the parent plant before sprouting. We did not consider as vegetative diaspores clonal organs connected with the maternal plant until the new plant becomes independent (e.g. stolons in Fragaria) and various types of below-ground organs or shoot bases embedded in soil (e.g. tubers of Helianthus tuberosus or grass tillers). Vegetative diaspores include (1) turions (e.g. Myriophyllum and Utricularia) and similar overwintering structures (detachable buds in Elodea and Groenlandia and shortened shoots of some pondweeds produced by rhizome or stolon, e.g. Potamogeton alpinus); (2) bulbils and tubers of stem origin (e.g. Allium oleraceum and Dentaria bulbifera) or root origin (Ficaria only); (3) plantlets born by pseudovivipary (e.g. Poa alpina); (4) plantlets born from buds on leaves (e.g. Cardamine pratensis); (5) plantlets born on free ends of stolons, detachable before establishing (e.g. Hydrocharis and Jovibarba); (6) unspecialized fragments of the shoot (e.g. Sedum album and many aquatic plants), shoot tips (e.g. Ceratophyllum demersum) or detachable offsprings born from axillary buds (e.g. Agrostis canina, Arabidopsis halleri and Rorippa amphibia); (7) budding plants (Lemnaceae only); and (8) gemmae produced by gametophytes (Trichomanes speciosum only).

Data are taken from Sádlo et al. (2018).

Categories

- seed

- spore

- fruit, infructescence or its part

- tumbleweed

- turion
- bulbil or tuber

- pseudovivipary

- leaf-born plantlet

- stolon-born plantlet

- shoot fragment 
Data source and citation: Sádlo et al. (2018).

\section{Dispersal strategy (Fig. 17)}

Plants use different dispersal modes, also called dispersal syndromes, depending on different dispersal vectors. For example, anemochory is the dispersal by wind, hydrochory by water, epizoochory by attachment to an animal body and endozoochory by animals via ingestion. However, single plant species usually use a combination of several dispersal modes rather than a single mode. Distinct combinations of dispersal modes repeatedly occurring in different plant taxa are called dispersal strategies. Sádlo et al. (2018) distinguished nine dispersal strategies named for the genus names of typical representatives. Taxa of the Czech flora are assigned to individual strategies based on this source.

\section{Categories}

- Allium type - mainly autochory, less frequently anemochory, endozoochory and epizoochory. This is the most common dispersal strategy, including about 56\% taxa of the Czech flora. About half of the included taxa are dispersal generalists lacking a clear morphological indication of anemochory or zoochory. Most myrmecochorous or probably myrmecochorous species are also assigned to this category.

- Bidens type - mainly autochory and epizoochory, less frequently endozoochory. This dispersal strategy is characterized by two essential dispersal modes, of which autochory is the more important, despite the presence of morphological structures indicating epizoochory.

- Cornus type - mainly autochory and endozoochory. Herbaceous plants, shrubs and small trees with fleshy fruit, often of the Rosaceae family, typically have this strategy. Furthermore, tall trees bearing large, heavy and nutrient-rich seeds are also included.

- Epilobium type - mainly anemochory and autochory, less frequently endozoochory and epizoochory. This dispersal strategy is typical of taxa growing in mesic and dry habitats. 
- Lycopodium type - mainly anemochory, less frequently autochory, endozoochory, epizoochory, hydrochory. This dispersal strategy relies on light, very small spores and seeds that are dispersed, besides wind, by a wide range of vectors. Compared to other strategies, the role of autochory is small.

- Phragmites type - mainly anemochory and hydrochory, less frequently autochory, endozoochory and epizoochory. Wetland taxa with light diaspores (both seed and fruit) equipped with a hairy flying apparatus. Most of the taxa with this dispersal strategy lack vegetative diaspores. Woody plants, stout clonal graminoids and herbaceous plants are typical growth forms associated with this dispersal strategy.

- Sparganium type - mainly autochory and hydrochory, less frequently endozoochory and epizoochory. This dispersal strategy is a wetland analogue of the Wolffia type, assigned to aquatic plants. It applies mainly to monocotyledonous taxa producing achenes with good buoyancy and with vegetative diaspores having an important role.

- Wolffia type - mainly hydrochory, less frequently endozoochory and epizoochory. This dispersal strategy is typical of aquatic macrophytes spread by fruit, seed or spores. However, vegetative reproduction dominates in most cases, including stem fragmentation, the formation of stolons or, in Lemnaceae, budding colonies.

- Zea type. Taxa with this dispersal strategy rarely or never disperse by generative diaspores and do not form vegetative aboveground diaspores.

Data source and citation: Sádlo et al. (2018). 
(a) Dispersal strategy Allium

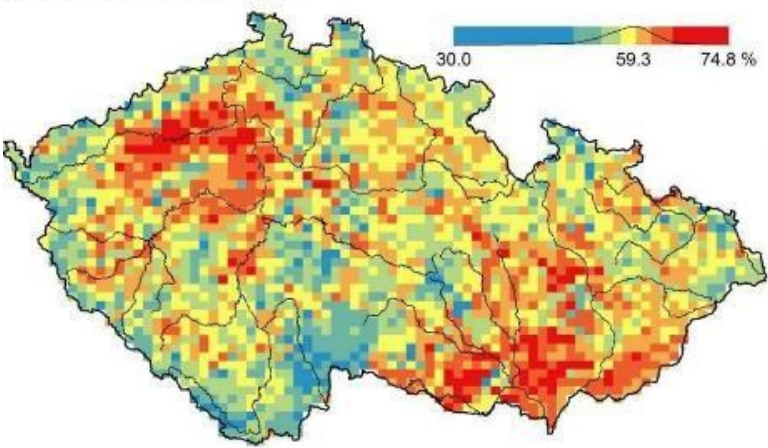

(c) Dispersal strategy Cornus

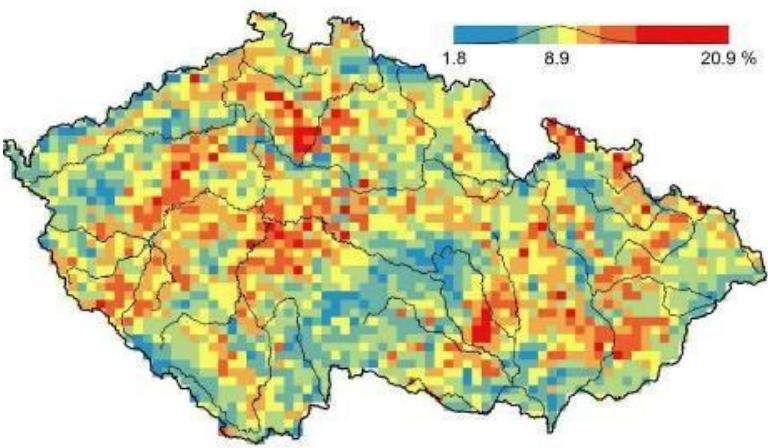

(e) Dispersal strategy Lycopodium

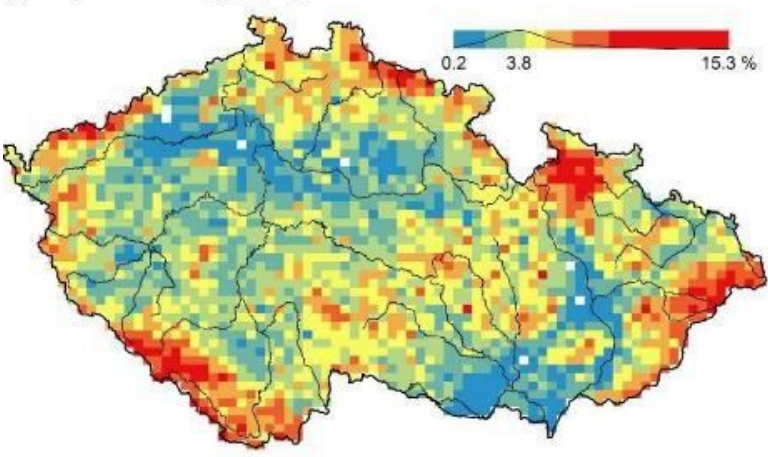

(g) Dispersal strategy Sparganium

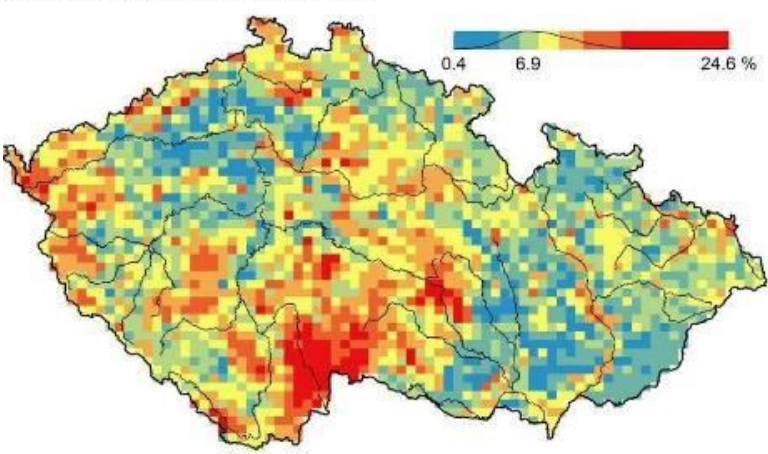

(b) Dispersal strategy Bidens

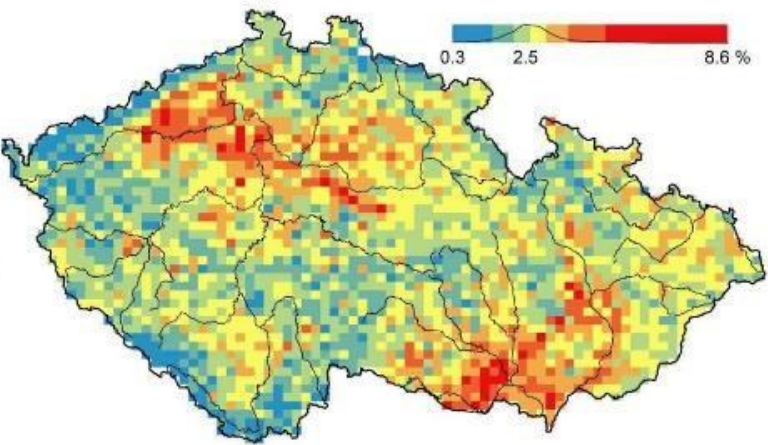

(d) Dispersal strategy Epilobium

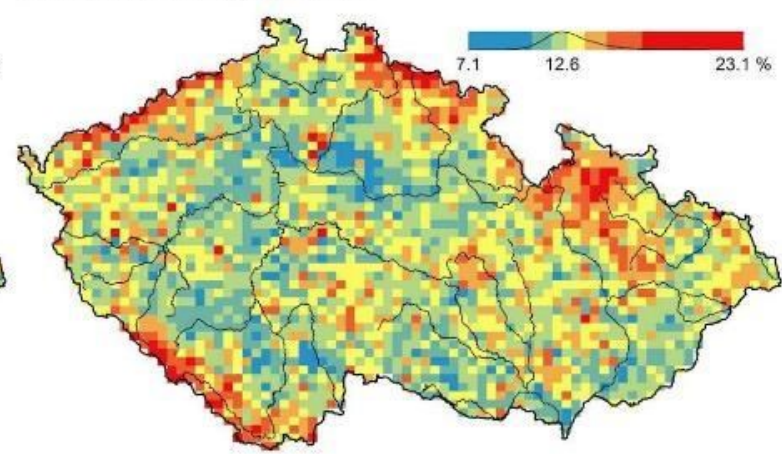

(f) Dispersal strategy Phragmites

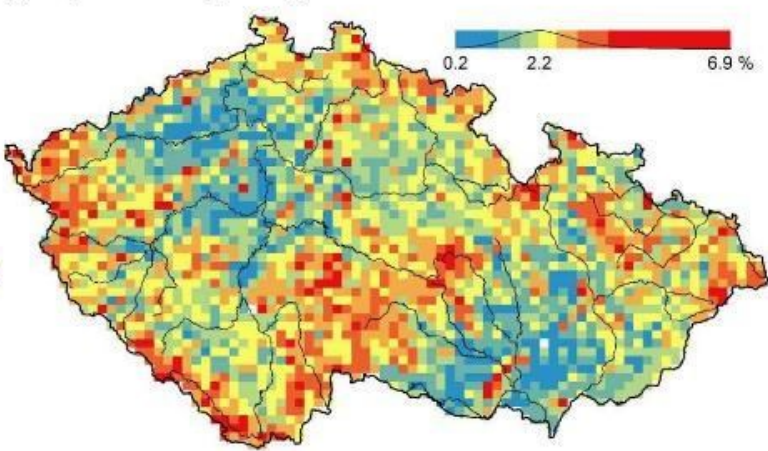

(h) Dispersal strategy Wolffia

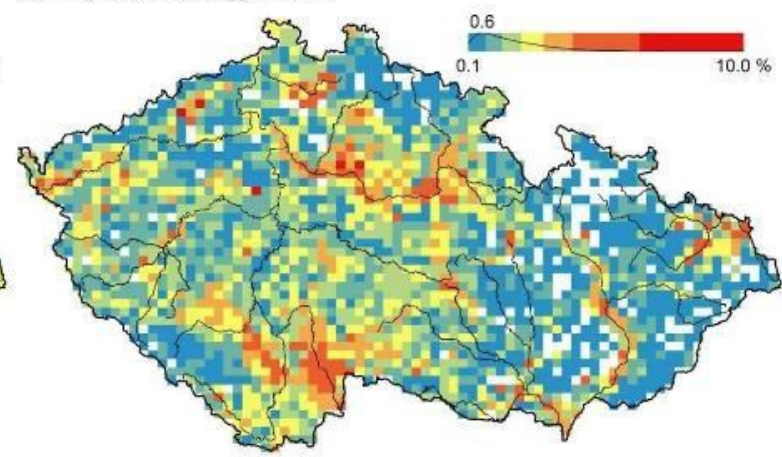

Fig. 17. - Proportion of species with different dispersal strategies in the Czech flora. The Allium dispersal strategy is frequent in dry lowlands, Bidens strategy in various lowland and mid-elevation areas, Cornus strategy also in various lowland and mid-elevation areas, but outside the pond basins and large river floodplains, Epilobium strategy in the high 
mountains of the Bohemian Massif, Lycopodium and Phragmites strategies in the mountain areas of both the Bohemian Massif and the Carpathians, and Sparganium and Wolffia strategies in pond basins and lowland riverine landscapes, the former being more common in pond basins and the latter in riverine landscapes.

\section{Myrmecochory (Fig. 18)}

Myrmecochorous plants, i.e. taxa dispersed by ants, possess an elaiosome, a nutrient-rich fleshy appendage of seed or fruit. However, in many taxa, the morphological indication or direct evidence of myrmecochory is equivocal. Removal experiments (seeds with and without elaiosome offered to ants) or chemical analysis (nutrient content is different between seed and elaiosome of nutrients; Konečná et al. 2018) would be needed to decide whether the appendage is elaiosome or not. Therefore, more categories than a simple binary distinction between myrmecochorous and non-myrmecochorous are recognized here:

- myrmecochorous - an elaiosome (a conspicuous fleshy appendage of seed or fruit) is present

- probably myrmecochorous - a fleshy structure resembling an elaiosome is present, but the appendage:seed size ratio is very small so that the possible advantage of seed transport for the ants would be small

- probably non-myrmecochorous - seed or fruit bears a structure not similar to elaiosome, e.g. a non-fleshy appendage or rim

- non-myrmecochorous (a) - an elaiosome is not present although the taxon is reported as myrmecochorous in the literature or is a close relative of taxa considered as myrmecochorous

- non-myrmecochorous (b) - elaiosome is not present, and the taxon does not belong to a family reported as containing myrmecochorous species in the literature

Plant taxa that are often carried by ants to the nest although having no elaiosome (e.g. cheaters in this plant-ant mutualism or plant parts used as a building material for ant hills) are classified as non-myrmecochorous.

The data are based on the literature search and examination of seed samples of the taxa that are reported as myrmecochorous and their closely related congenerics. The list of these taxa with seed images is available at http://botanika.prf.jcu.cz/myrmekochorie/. These taxa were selected from the families represented in the Czech flora that contain at least one taxon 
reported as myrmecochorous in the literature (Sernander 1906, Hejný et al. 1988 onwards, Fitter \& Peat 1994, Klotz et al. 2002, Grime et al. 2007, Kleyer et al. 2008, Lengyel et al. 2010, Servigne 2008, Študent 2012). Such taxa were found in 37 families including Amaryllidaceae, Apiaceae, Apocynaceae, Aristolochiaceae, Asparagaceae, Asteraceae, Boraginaceae, Campanulaceae, Caryophyllaceae, Celastraceae, Colchicaceae, Crassulaceae, Cyperaceae, Dipsacaceae, Euphorbiaceae, Fabaceae, Iridaceae, Juncaceae, Lamiaceae, Liliaceae, Linaceae, Montiaceae, Orobanchaceae, Oxalidaceae, Papaveraceae, Plantaginaceae, Poaceae, Polygalaceae, Polygonaceae, Portulacaceae, Primulaceae, Ranunculaceae, Rosaceae, Resedaceae, Santalaceae, Urticaceae and Violaceae. All the taxa not belonging to these families were classified as non-myrmecochorous (b).

For each of the five categories, a subcategory nv (= non vidimus, i.e. not seen) is used in the taxa for which we found neither information in the literature nor a photograph of a seed, and failed to collect seeds from living plants, but the assignment to the category is likely based on the traits of closely related taxa. For example, we have no data for Centaurea bruguiereana but we classify it as myrmecochorous nv, because all the taxa of Centaurea for which we have data possess an elaiosome.

\section{Categories}

- myrmecochorous

- myrmecochorous nv

- probably myrmecochorous

- probably myrmecochorous nv

- probably non-myrmecochorous
- probably non-myrmecochorous nv

- non-myrmecochorous (a)

- non-myrmecochorous (a) nv

- non-myrmecochorous (b)

- non-myrmecochorous (b) nv

Citation: Konečná M., Štech M. \& Lepš J. (2018) Myrmecochory. - www.pladias.cz. 


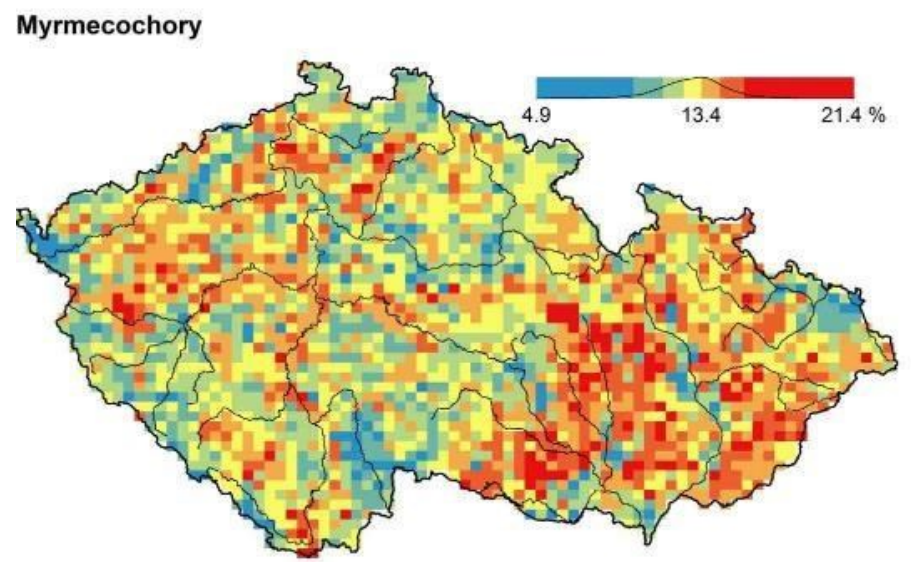

Fig. 18. - Proportion of species dispersed by ants in the Czech flora (merged categories 1 and $1 \mathrm{nv})$. Myrmecochorous plants tend to avoid mountain ranges, river floodplains and pond basins, reflecting the fact that ants, in general, tend to avoid cold and flooded habitats.

\section{Belowground organs and clonality}

\section{Shoot metamorphosis}

Shoot metamorphoses are modifications of the shoot that involve the development of different structures for special tasks such as vegetative spread or storage. Data about shoot metamorphoses are adopted from the BiolFlor database (Krumbiegel 2002).

\section{Categories}

- stolon - lateral shoot (exceptionally the main shoot) with long thin internodes and adventitious roots; separation from the mother plant causes the formation of individual ramets

- stolon with tuberous tip - subterranean stolon with tuberous swelling of several internodes at the distal end, which mostly develops at the end of the growing season for storing nutrients; aboveground shoots develop from the tuber in the following season

- stolon with bulbous tip - subterranean stolon with a bulbous tip at the distal end; aboveground shoots develop from the bulb in the following season 
- rhizome - subterranean or surface-close, mostly thickened shoot living for more than one year, bearing adventitious roots, buds and usually also cataphylls (tiny reduced leaves); it has both spreading and storing function

- stolon-like rhizome - rhizome with longer internodes that has mainly the spreading function

- pleiocorm - a system of compact, perennial shoots at the proximal end of the persistent primary root; the innovation shoots arise from the buds in the axils of basal leaves, and the connections between the shoots and the primary root are persistent

- rhizome-like pleiocorm - a pleoicorm in which the first innovation shoots arise from the basal leaf axils, but later shoots arise from rhizome-like, adventitiously rooted shoots, which later lose their connection with the primary root

- shoot tuber - thickened, mostly subterranean part of a shoot, living for less than one year and used for storage

- bulb - compressed part of a shoot with cataphyll leaves or leaf bases, used for storage or vegetative propagation

- bulbil - compressed aboveground lateral shoot with poorly developed or still absent organs, which develops into a new plant after separation from the mother plant

- brood shoot - spikelet of Poaceae transformed into a tiny shoot, which develops into a new plant after separation from the mother plant

- turion - compressed, mostly bud-like vegetative shoot, which hibernates with leaves or parts of leaves and sprouts only after separation from the mother plant

- shoot thorn - prickly structure rich in strengthening tissue, mostly at the position of a lateral shoot

- shoot tendril - thread-like, ramified or non-ramified shoot used for plant attachment to supporting structures

- shoot succulence - the presence of a large amount of water-storing tissue causing fleshy thickening of shoots

- assimilating shoot - shoot used for assimilation instead of or in addition to leaves

Data source and citation: Krumbiegel (2002).

\section{Root metamorphosis}


Root metamorphoses are modifications of the root that involve the development of different structures for special tasks such as vegetative spread or storage. Types of root metamorphoses are adopted from the BiolFlor database (Krumbiegel 2002).

\section{Categories}

- primary storage root - thickened primary root including the thickened hypocotyl and epicotyl, acting as a storage organ

- secondary storage root - partly thickened adventitious or lateral root acting as a storage organ; in contrast to root tuber, it has not lost the primary functions of roots such as anchoring and absorption of water and minerals

- root tuber - thickened, not ramified adventitious root formed from an innovation bud; it primarily acts as a storage organ, being rarely involved in absorption

- root shoot - adventitiously-rooted shoot growing from the primary or a lateral root; it is either leafless or has cataphyllary leaves during growth within the soil

- buttress root - the upper lateral root of trees; its thickened upper part forms buttresses that strengthen the trunk bases and increase trunk stability

- adhesive root - short aerial root attached to the substrate, trunk or wall without penetrating it

- rootless

Data source and citation: Krumbiegel (2002).

\section{Storage organ}

The occurrence of organs for storage of nutrients or water is usually associated with the ability of vegetative propagation and dispersal. Data on storage organs were taken from the BiolFlor database (Krumbiegel 2002).

Categories (see the definitions under Shoot metamorphosis and Root metamorphosis for the categories where no definition is provided)

- stolon

- stolon with tuberous tip

- stolon with bulbous tip 
- rhizome

- stolon-like rhizome

- pleiocorm

- rhizome-like pleiocorm

- shoot tuber

- bulb

- bulbil

- turion

- succulence - the presence of special water-storing tissue

- primary storage root

- secondary storage root

- root tuber

- tuft - a cluster of more or less orthotropically growing shoots, which are tightlypacked because of numerous, spatially more or less regular ramification of the adventitiously rooting basal parts of the shoots

- hypocotyl bulb- thickened hypocotyl with storage function

Data source and citation: Krumbiegel (2002).

\section{Type of clonal growth organ}

The type of clonal growth is only reported for clonal herbs. Clonal growth is defined here as the growth of the plant body leading to the formation of physically independent asexual offspring. A morphological prerequisite for clonal growth is the formation of adventitious roots on stems or adventitious shoots from root buds that yield (potentially) physically independent individuals (Groff \& Kaplan 1988).

The types of clonal growth organs are morphological categories that are defined based on three main parameters:

1. Bud-bearing organ that gives rise to the clonal growth organ (shoot or root)

2. Position of the organ relative to the soil surface (aboveground, belowground, initially aboveground and later belowground, water)

3. Storage organ (shoot, root, leaf) 
For each taxon, only one type of the clonal growth organ is reported, although some taxa possess several independent types of such organs (Klimešová \& Klimeš 2006). The reported type is considered as the most important for the life cycle of the taxon, producing the highest number of offspring or permitting the individual to spread its offspring over large distances. Some of these types are vegetative diaspores, while others are used for local spread but not long-distance dispersal. The clonal growth organs are divided into aboveground and belowground and sorted within each category by their decreasing frequency in the Czech flora.

\section{Categories}

Aboveground organs

- stolon - a horizontal aboveground shoot rooting in the soil and providing connection between offspring plants and the mother plant or formed by a creeping main shoot

- turion - a detachable over-wintering bud of aquatic plants composed of tightly arranged leaves filled by storage compounds

- stem fragment - a detached part of the shoot with rooting ability

- budding plant - an extremely reduced body of aquatic plants formed by a small frond (e.g. Lemna)

\section{Belowground organs}

- epigeogenous rhizome - a perennial clonal organ of stem origin growing horizontally at the soil surface; its distal part is covered by soil and litter or pulled into the soil by the contraction of roots; nodes bear green leaves, the internodes are usually short

- hypogeogenous rhizome - a perennial clonal organ of stem origin usually growing horizontally at a species-specific depth belowground; after some time its tip turns up, becoming orthotropic and forming aboveground shoots; the horizontal part of the rhizome has long internodes and bears bracts and roots (usually only on the nodes)

- belowground stem tuber - a belowground, usually short-lived storage and regenerative organ of shoot origin

- bulb - a storage organ consisting of storage leaves and a shortened stem base

- root with adventitious buds - primary root including the hypocotyl or adventitious root forming adventitious buds spontaneously or after an injury

- root tuber - a belowground storage organ of root origin growing from a bud-bearing stem 
- stolon with tuber - a stolon with a belowground, usually short-lived storage and regenerative organ developing at its distal end

Data source and citation: Klimešová \& Klimeš (2006).

\section{Freely dispersible organs of clonal growth (Fig. 19)}

This trait is defined only for clonal herbs. Clonality of herbs can be realized by the formation of freely dispersible clonal offspring, i.e. new individuals that are separated from the mother shoots very shortly after their formation and before they develop roots attaching them to the soil. They are dispersed by water or other agents. Typical examples are plantlets, bulbils, turions or stem fragments of aquatic plants. The data reported here are based on individual observations in the CLO-PLA 3.4 database (Klimešová \& Klimeš 2006, Klimešová et al. 2017).

\section{Categories}

- present

- absent

Data source and citation: Klimešová \& Klimeš (2006), Klimešová et al. (2017).

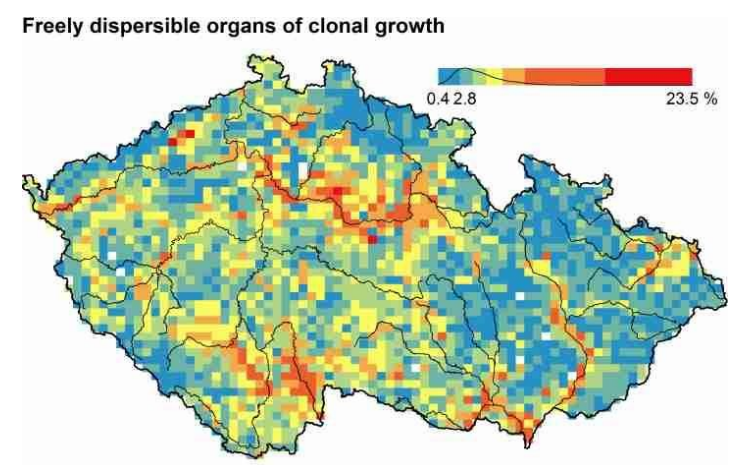

Fig. 19. - Proportion of species with freely dispersible organs of clonal growth among the clonal species in the Czech flora. Such species are frequent along large lowland rivers.

Shoot life span (cyclicity) (Fig. 20a) 
This trait, defined for herbs, is measured as the number of years from the emergence of the aboveground part of the shoot till its flowering and fruiting (Serebryakov 1952). Based on the analysis of morphological traits, we distinguish shoots with cyclicity of one year (monocyclic) from those that live longer (di- and polycyclic). In plants with sympodial branching, cyclicity refers to all shoots, while in plants with monopodial branching, it refers only to flowering shoots, although flowering and sterile shoots can be present simultaneously. Monocyclic plants usually do not possess a leaf rosette, and all shoots in a population can flower. In contrast, di- and polycyclic shoots possess a basal leaf rosette and shoot populations contain flowering and sterile shoots at the same time.

The data are based on individual observations in the CLO-PLA 3.4 database (Klimešová \& Klimeš 2006). If more types are reported for one taxon, the most frequently observed type is given (Klimešová et al. 2017).

\section{Categories}

- monocyclic shoots prevailing

- dicyclic or polycyclic shoots prevailing

Data source and citation: Klimešová \& Klimeš (2006), Klimešová et al. (2017). 
(a) Monocyclic shoots prevailing

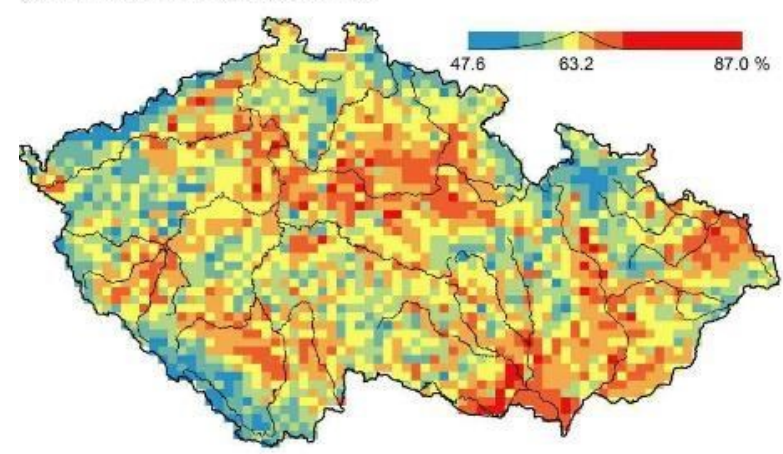

(c) Sympodial branching

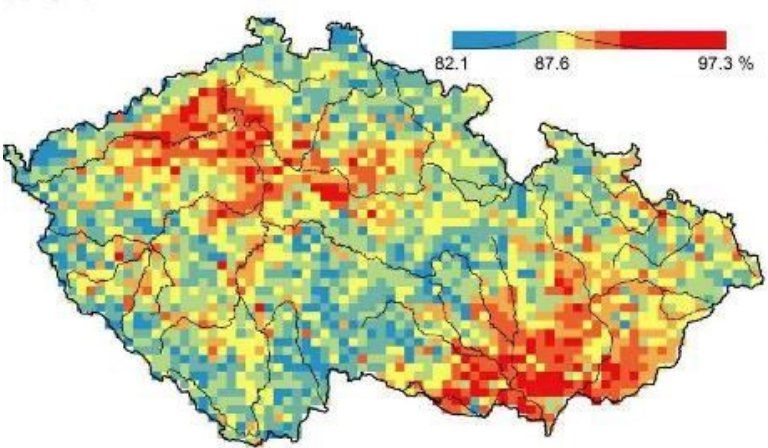

(b) Monopodial branching

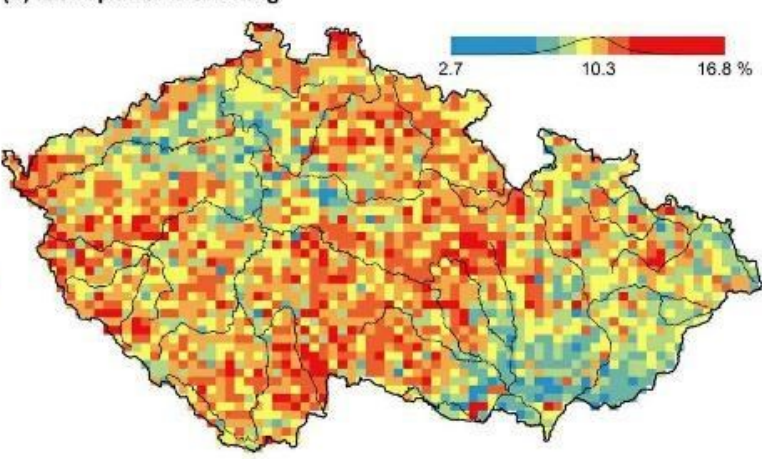

(d) Dichotomous branching

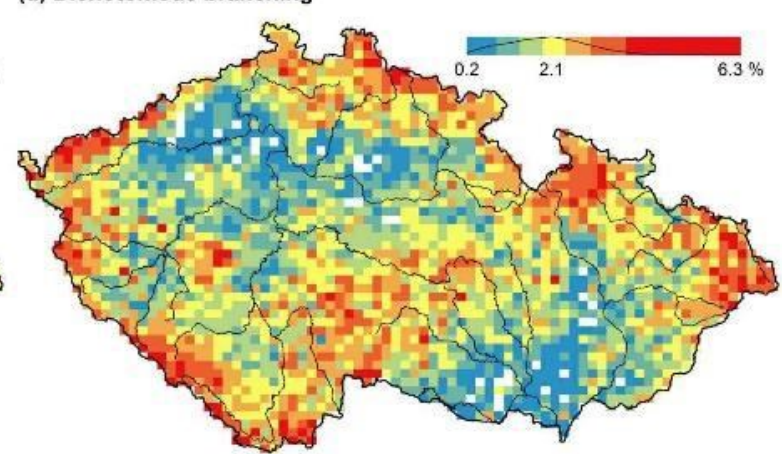

Fig. 20. - Proportion of species with prevailing monocyclic (annual) shoots (a) and proportion of species with monopodial, sympodial and dichotomous branching (b-d) in the Czech flora. The species with monocyclic shoots are frequent in lowland areas with a large proportion of arable land. The species with monopodial branching are frequent at middle elevations and basins of the Bohemian Massif, those with sympodial branching in dry lowland areas and those with dichotomous branching in higher mountain areas.

\section{Branching type of stem-derived organs of clonal growth (Fig. 20b-d)}

Branching type is defined for clonal herbs. It determines whether individuals possess two different shoot types (flowering and sterile) or only one shoot type (which can potentially flower). In plants with sympodial branching, all shoots are identical in their construction, replacing each other during ontogeny of the individual; all of them can potentially flower. In contrast, plants with monopodial branching possess two shoot types, one of which never flowers, whereas the flowering shoots arise from axillary buds of the non-flowering shoot. Finally, ferns and lycophytes can possess dichotomous branching that is functionally similar to monopodial branching. 
The data reported here are based on individual observations in the CLO-PLA 3.4 database (Klimešová \& Klimeš 2006). If more types are reported for one taxon, the most frequently observed type is given here (Klimešová et al. 2017).

\section{Categories}

- monopodial

- $\quad$ sympodial

- dichotomous

Data source and citation: Klimešová \& Klimeš (2006), Klimešová et al. (2017).

\section{Primary root (Fig. 21a)}

The presence of the primary root is only defined for herbs. The primary root can be either present for the whole life of a plant or replaced during the ontogeny by adventitious roots. If the primary root is the only root for the whole life of a plant, the plant is not capable of forming adventitious roots on stems; therefore it is not clonal (unless it is able to form adventitious buds on roots; Groff \& Kaplan 1988). In contrast, if the primary root is existing only in an early ontogenetic stage and later replaced by adventitious roots formed on belowground parts of the stem, the plant can grow clonally. In older individuals of some taxa that preserve the primary root, this root can split into parts, giving rise to several independent plant individuals. Some taxa only form adventitious roots under specific conditions (soil moisture, root injury or old age).

The data reported here are based on individual observations stored in the CLO-PLA 3.4 database (Klimešová \& Klimeš 2006). If more types are reported for one taxon, the most frequently observed type is given (Klimešová et al. 2017).

\section{Categories}

- present

- absent

Data source and citation: Klimešová \& Klimeš (2006), Klimešová et al. (2017). 


\section{Persistence of the clonal growth organ}

Persistence of the clonal growth organ, defined for clonal herbs, determines the life span of the physical connection between the parent and offspring shoots. Because morphological analysis does not permit the identification of such life span beyond a period of few years, the persistence of the connection is assessed in categories $(<1,1-2,>2$ years; Klimešová \& Klimeš 2006). From those categories, mean values of their ranges $(0.5,1.5$ and 4 years $)$ are used, and the final value is the mean of all records for the given taxon and the given type of the clonal growth organ in the CLO-PLA 3.4 database (Klimešová et al. 2017).

Data source and citation: Klimešová \& Klimeš (2006), Klimešová et al. (2017).

\section{Number of clonal offspring}

This trait is only defined for clonal herbs. The number of offspring shoots produced per parent shoot of a clonal herb per year is estimated in categories $(<1,1,2-10,>10$;

Klimešová \& Klimeš 2006), which are represented by the mean values of their ranges $(0.5$, 1,6 , and 15). The reported value is the mean of these values across all the available measurements for individuals of the given taxon and type of clonal growth organ in the CLO-PLA 3.4 database (Klimešová et al. 2017).

Data source and citation: Klimešová \& Klimeš (2006), Klimešová et al. (2017).

\section{Lateral spreading distance by clonal growth}

The lateral spreading distance by clonal growth is defined for clonal herbs as the distance between parental and offspring shoots. Freely dispersible vegetative diaspores are not considered. Lateral spreading distances were estimated in categories $(<0.01 \mathrm{~m}, 0.01-0.25$ m, > $0.25 \mathrm{~m}$; Klimešová \& Klimeš 2006), which are represented by the mean values of their ranges $(0.005 \mathrm{~m}, 0.13 \mathrm{~m}, 0.5 \mathrm{~m})$. The reported value is the mean of these values across all records for the given taxon and the given type of clonal growth organ in the CLO-PLA 3.4 database (Klimešová et al. 2017). 
Data source and citation: Klimešová \& Klimeš (2006), Klimešová et al. (2017).

Clonal index (Fig. 21b)

The Clonal index (Johansson et al. 2011) is a measure of taxon's clonal ability. It is defined for clonal herbs as the sum of the ranks of the four categories of "Number of clonal offspring" (coded as 1, 2, 3, 4) and the three categories of "Lateral spreading distance by clonal growth" (coded as 1, 2,3) with the presence of freely dispersible vegetative diaspores added as the fourth category (4). The index values range from 2 to 8 , with higher values indicating better clonal ability. The index is defined for clonal herbs.

The data reported here are based on the categories of "Number of clonal offspring" and "Lateral spreading distance by clonal growth" aggregated from individual records in the CLO-PLA 3.4 database (Klimešová \& Klimeš 2006, Klimešová et al. 2017).

Data source and citation: Klimešová \& Klimeš (2006), Klimešová et al. (2017).

(a) Primary root presence

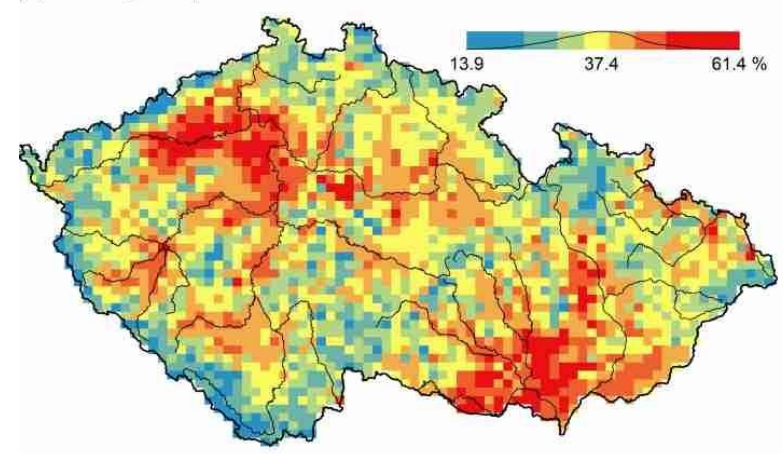

(b) Clonal index

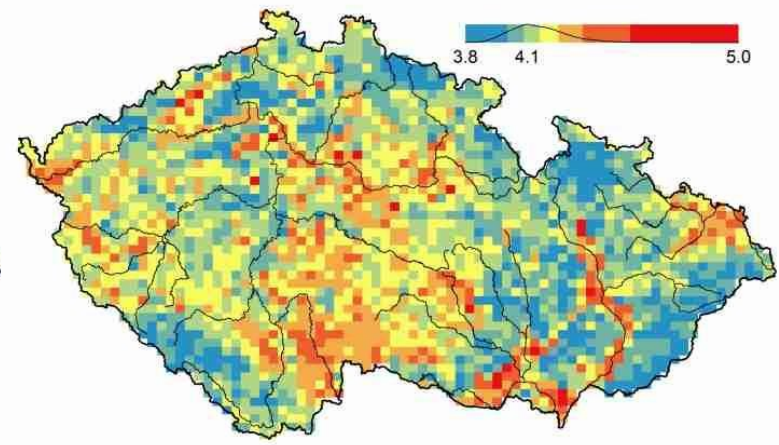

Fig. 21. - Proportion of species with a primary root (a) and mean clonal index for the clonal herbs (b). The species with the primary root are frequent in dry lowland areas, which is partly due to the prevalence of primary root in therophytes. The clonal index tends to be higher in wetland areas, both in pond basins and along large lowland rivers. The two variables that are combined in this index, Number of clonal offspring and Lateral spreading distance by clonal growth, both display a similar geographic pattern (not shown).

\section{Position of root buds}


In contrast to stem buds, which are always located in a leaf axil, adventitious buds on roots (or hypocotyl) are not located at specific positions of the roots. They occur only in some root types or may only appear after the individual is injured. Root buds are found in approximately $10 \%$ of species in the Czech flora. Adventitious buds may be located on the hypocotyl, on the primary root, or on lateral roots. We list the hypocotyl only if the roots are found exclusively on it. We report the primary root if the buds are never formed on lateral roots, and we report the lateral roots if root buds are potentially found on all three types of bud-bearing organs. Data are taken from Bartušková et al. (2017).

\section{Categories \\ - hypocotyl \\ - primary root \\ - lateral roots}

Data source and citation: Bartušková et al. (2017).

\section{Role of root buds in the life-history of a plant}

Adventitious buds on roots or hypocotyl occur in only about $10 \%$ species of the Czech flora and have different roles in individual taxa. In some taxa, they occur only after the plant is injured and play a role in regeneration after such injury (regenerative role). In other taxa, these buds are formed without such an external stimulus. Consequently, they increase the number of shoots and thereby the number of offspring, both clonally and by seed. In most taxa, such buds occur only in some individuals and are not necessary for completing the life cycle; we denote them as additive (or accessory) root buds. In a few taxa, the formation of root buds is necessary for completing the life cycle and flowering. They develop in all individuals, and survival/flowering or overwintering of an individual is dependent on them (Rauh 1937, Klimešová 2007). Data are taken from Bartušková et al. (2017).

\section{Categories}

- regenerative

- additive

- necessary 
Data source and citation: Bartušková et al. (2017).

\section{Bud bank (Fig. 22)}

Bud bank denotes all inactive (dormant) buds on the plant body that can give rise to new shoots, including both shoot buds and root buds (Klimešová \& Klimeš 2007). The most important part of the bud bank is located at the soil surface or belowground, out of the reach of disturbance or seasonal frost or drought (Raunkiaer 1934). Consequently, only data on buds located at the soil surface or in the soil are reported here.

The number of buds on plant organs located at different soil depths was assessed according to morphological characters (Klimešová \& Klimeš 2007). The assessment was based on the assumption that each leaf (or leaf scale) axil contains a bud. Assessment of bud numbers in individual plants was done in three categories $(0,0-10,>10$ buds per shoot; Klimešová \& Klimeš 2006). These categories were respectively represented by values of 0 , 5,15 buds per shoot. The value for the taxon was calculated as the mean of these values across the individuals of this taxon and particular soil depth as reported in the CLO-PLA 3.4 database (Klimešová et al. 2017). The size of the belowground bud bank was determined as the sum of bud numbers per shoot summed over the soil profile. The depth of the belowground bud bank was determined as the average depth of the buds in the soil. In addition to stem-derived buds, around $10 \%$ of taxa in the Czech flora possess the ability to form adventitious buds on the root or hypocotyl (here collectively called root buds). As root buds cannot be counted (they are formed freely along the root), 15 buds were arbitrarily added per each $10 \mathrm{~cm}$ of depth for categories that include root buds. All the bud-bank characteristics are given for stem-derived buds only (root buds excluded) and all the buds (root buds included):

- Number of buds per shoot at the soil surface (root buds excluded)

- Number of buds per shoot at a depth of 0-10 $\mathrm{cm}$ (root buds excluded)

- Number of buds per shoot at a depth greater than $10 \mathrm{~cm}$ (root buds excluded)

- Size of the belowground bud bank (root buds excluded)

- Depth of the belowground bud bank (root buds excluded)

- Number of buds per shoot at the soil surface (root buds included)

- Number of buds per shoot at a depth of 0-10 cm (root buds included) 
- Number of buds per shoot at a depth greater than $10 \mathrm{~cm}$ (root buds included)

- Size of the belowground bud bank (root buds included)

- Depth of the belowground bud bank (root buds included)

Data source and citation: Klimešová \& Klimeš (2006), Klimešová et al. (2017).

(a) Number of buds at the soil surface

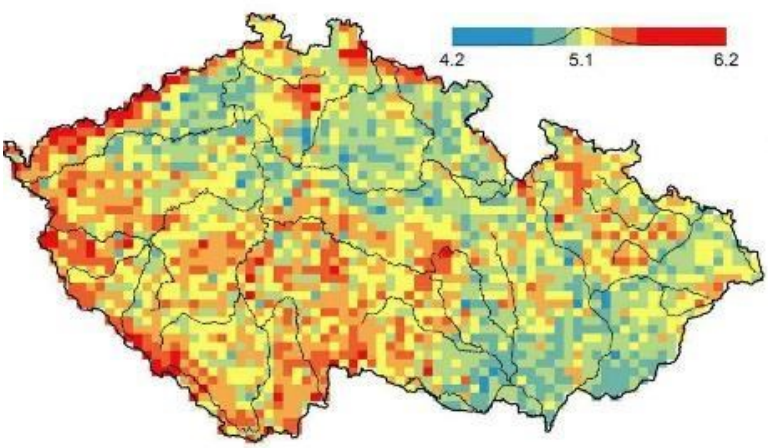

(c) Number of buds at a depth greater than $10 \mathrm{~cm}$

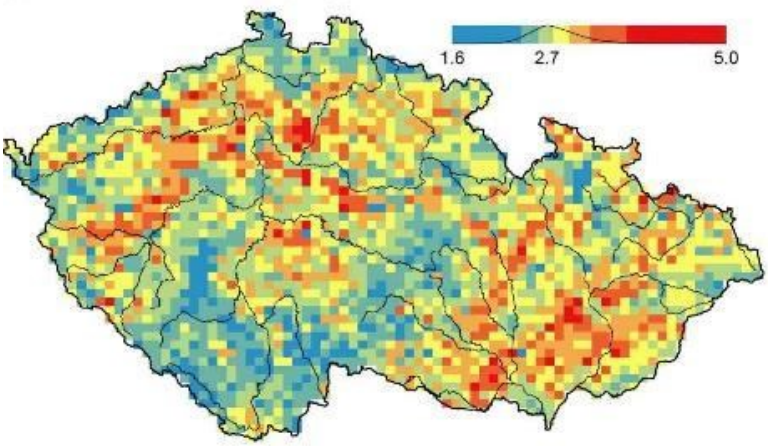

(b) Number of buds at a depth of $0-10 \mathrm{~cm}$

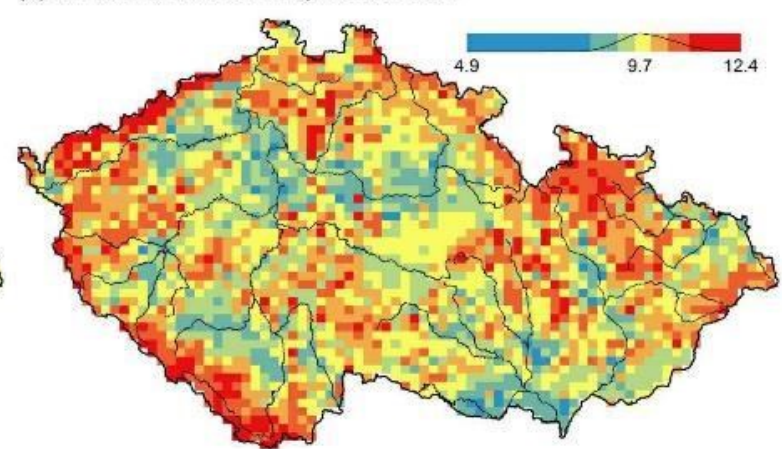

(d) Size of the belowground bud bank

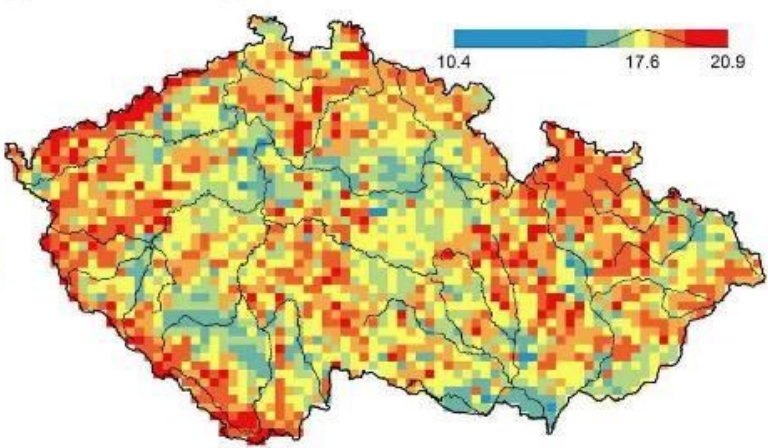

Fig. 22. - Mean number of buds per shoot (including root buds) at different depths and the size of the belowground bud bank for species of the Czech flora that form a bud bank.

Higher numbers of buds at the soil surface are typical of middle and higher elevations of the Bohemian Massif. Higher numbers at a depth of $0-10 \mathrm{~cm}$ are typical of all mountain areas, and higher numbers at a depth greater than $10 \mathrm{~cm}$ are typical of low-elevation non-wetland areas. The size of the belowground bud bank is largest in mountain areas and mid-elevation non-wetland areas.

\section{Trophic mode}

Parasitism and mycoheterotrophy (Fig. 23a, b) 
Plant parasitism is based on either of two mechanisms. The first group of parasitic plants involves those parasitizing directly on another plant. These plants are called haustorial parasites. They take resources from the host's vascular bundles using a specialized organ, the haustorium. The second group comprises mycoheterotrophic plants, which parasitize fungi via mycorrhizal interaction and gain organic carbon from them.

Plants in both groups display variable dependence on their host organism. The haustorial parasites include two distinct functional groups: green hemiparasites and holoparasites. Green hemiparasites are partial parasites that retain photosynthetic ability but obtain part of the organic carbon from the host. Holoparasites are non-green full parasites unable to photosynthesize. Location of the haustorial attachment to the host (root or stem) is another essential functional trait. The distinction between partial and full parasitism in haustorial parasites may not be straightforward. In the Czech flora, it is nevertheless possible to distinguish between stem hemi- and holoparasites, which are difficult to separate on the global scale (Těšitel 2016). Consequently, we use a traditional classification here and classify as holoparasites those plants that are in adulthood mostly without chlorophyll, even though some of them might have some chlorophyll and may perform residual photosynthesis (e.g. Cuscuta).

In mycoheterotrophic plants, there is a continuum from initial mycoheterotrophs through partial mycoheterotrophs to full mycoheterotrophs. In the initial mycoheterotrophs only initial stages, i.e. gametophytes or seedlings, are dependent on the fungus, whereas adult plants are autotrophic, while still depending on mycorrhizal symbiosis as a source of water and mineral nutrients. In the partial mycoheterotrophs photosynthesizing adults obtain from their mycorrhizal fungi not only water and mineral nutrients but also different amounts of organic carbon. The full mycoheterotrophs lost their chlorophyll and are thus fully parasitic. In some partial mycoheterotrophs (e.g. the genus Cephalanthera), chlorotic individuals can be found, which lack chlorophyll and fully depend on their hosts.

Classification of haustorial parasites follows Těšitel (2016) with a further distinction of stem hemi- and holoparasites, and identification of mycoheterotrophs follows Merckx (2012).

Categories

- autotrophic

- root hemiparasite
- stem hemiparasite

- root holoparasite 
- stem holoparasite

- full mycoheterotroph

- partial or initial mycoheterotroph

Citation: Těšitel J., Těšitelová T., Blažek P. \& Lepš J. (2016) Parasitism and mycoheterotrophy. - www.pladias.cz.

Carnivory (Fig. 23c)

Carnivorous plants attract, trap and kill their prey, animals (mainly insects and small crustaceans) and protozoans, and subsequently absorb the nutrients from their dead bodies.

Categories

- carnivorous

- non-carnivorous

Data source and citation: Hejný et al. (1988 onwards).

(a) Root hemiparasitism

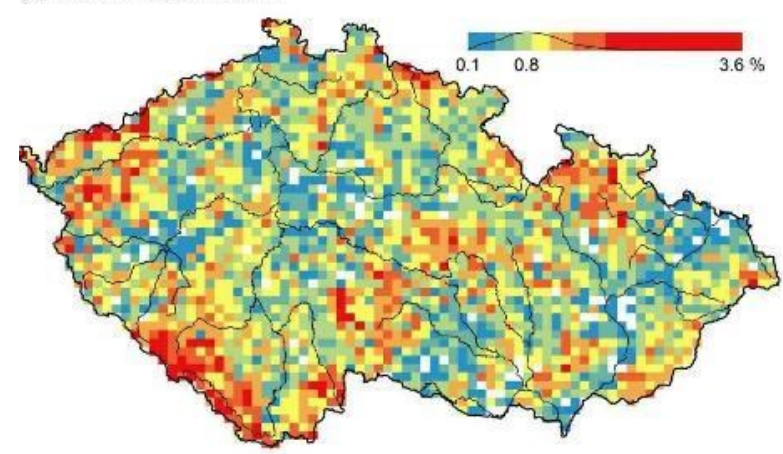

(c) Carnivory

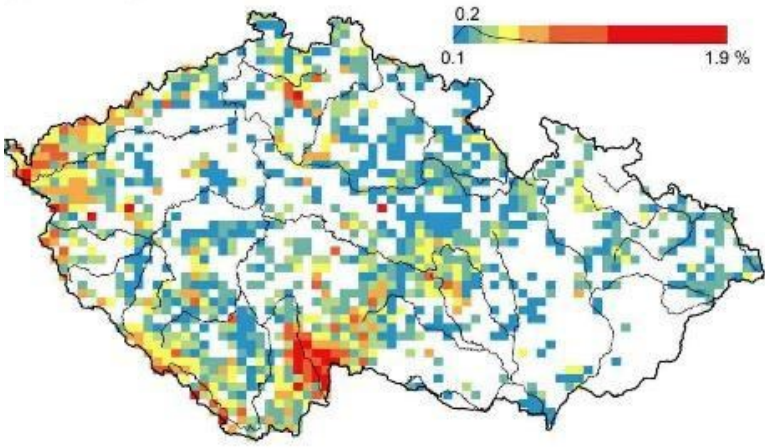

(b) Partial or initial mycoheterotrophy

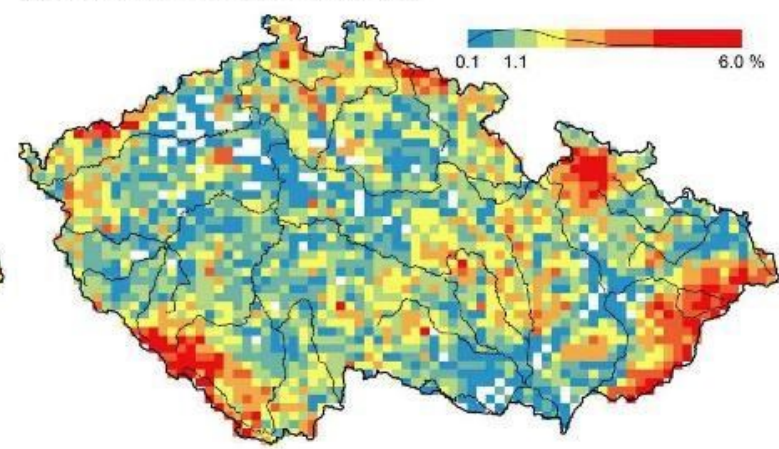

(d) Symbiosis with rhizobia

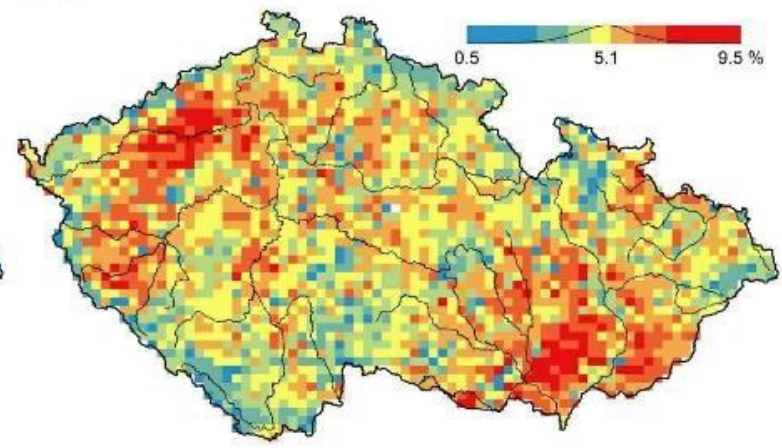


Fig. 23. - Proportion of species with alternative trophy strategies in the Czech flora. Roothemiparasitic species are more common at middle and higher elevations (a), partially or initially mycoheterotrophic species in the highest mountains of the Bohemian Massif and in the flysch Carpathians (b), while the other categories of parasitism and mycoheterotrophy are represented by very few species. Carnivorous species are most common in areas with mires, both on flat mountain plateaus in the western Bohemian Massif and in pond basins (c). Species forming a symbiosis with rhizobia are concentrated in dry lowland areas outside river floodplains (d); this pattern is identical with the pattern of proportional representation of Fabaceae species.

Symbiotic nitrogen fixation (Fig. 23d)

Plants are classified into those without symbiotic nitrogen fixers and those that form a symbiosis with nitrogen-fixing bacteria. The latter are further divided into those forming symbiosis with rhizobia (e.g., Allorhizobium, Bradyrhizobium, Mesorhizobium, Rhizobium and Sinorhizobium) and those forming the symbiosis with the genus Frankia, the latter called actinorhizal plants (Bond 1983, Pawlowski \& Sprent 2007, Sprent 2008, Benson 2016).

Categories

- symbiosis with rhizobia

- $\quad$ symbiosis with Frankia

- no nitrogen-fixing symbionts

Citation: Blažek P. \& Lepš J. (2016) Symbiotic nitrogen fixation. - www.pladias.cz.

\section{Karyology}

\section{Chromosome number (2n)}

Chromosome number is the somatic number of chromosomes in the zygotic stage, i.e. without possible endopolyploidy of somatic tissues. If different chromosome numbers are 
known for a taxon, the database contains primarily the number reported from the Czech Republic or the number that is the most common in this country or can be expected to be the most common based on the data from neighbouring countries. Other existing and less common chromosome numbers are reported in brackets. The survey does not take into account odd chromosome numbers of individual, aneuploid, euploid, haploid or autopolyploid plants, which may rarely originate in natural or experimental populations. It also disregards the numbers reported in early studies or from geographically distant areas for which the taxonomic identity with Czech plants is unclear.

The data compilation is based mainly on the Flora of the Czech Republic (vols. 1-8; Hejný et al. 1988 onwards) and the Chromosome Count Database (Rice et al. 2015; http://ccdb.tau.ac.il/). If only information about ploidy level is available from flow cytometry measurements, but no chromosome number is known, the number typical of the given ploidy in closely related taxa is indicated.

Citation: Šmarda P. (2018) Chromosome number (2n). - www.pladias.cz.

Ploidy level (x) (Fig. 24a, b)

Ploidy level is the number of somatic chromosomal sets in the zygotic stage, i.e. without the possible endopolyploidy of somatic tissues. Ploidy level determines the minimum copy number of most genes, influences minimal cell size and other morphological and ecological properties of the taxon (Stebbins 1950, Levin 2002, Tate et al. 2005). The data presented here are based on the traits "Chromosome number" and "2C genome size", and to a lesser extent also on a literature search of flow cytometry studies related to the area of the Czech Republic. The reported values are especially those reported from the Czech Republic or those ploidy levels that are most frequent in this country or at least are assumed to be the most frequent based on the data from neighbouring countries. The other existing (minor) ploidy levels (cytotypes) that are documented from the Czech Republic or that may be expected to occur here based on the records from neighbouring countries are indicated in brackets. The survey does not take into account the observations of individual haploid or autopolyploid plants which may rarely originate in natural or experimental populations. It also disregards the ploidy levels derived from the numbers of chromosomes reported in early 
studies or from geographically distant areas, where taxonomic identity with Czech plants is uncertain.

The size of one chromosomal set $(\mathrm{x})$ or the "base chromosome number" for calculating the ploidy level is derived here from the lowest chromosome number known in the given genus or the group of closely related genera (e.g. Raven 1975). This minimum chromosome number is generally considered to correspond to diploids (i.e., two chromosomal sets). A taxon is considered as polyploid whenever its chromosome number and genome size are jointly \pm doubled (or otherwise multiplied) compared to the diploid taxa of related genera. It may therefore sometimes happen that no diploid taxa are known in some genera. The absence of diploids in a given genus may result from (1) the lack of karyological data, (2) the extinction of the diploid relative(s), or (3) a polyploidy event that predated the origin of the whole genus, with the current genomes still showing little signs of backward "diploidization". The joint usage of the chromosome number and genome size enables estimation of ploidy levels also for the taxa with holocentric chromosomes (Cyperaceae, Drosera, Juncaceae, Cuscuta sect. Cuscuta and C. sect. Gramica). In these taxa, the chromosome number does need to be positively correlated with the ploidy level due to possible chromosomal fissions and fusions (agmatoploidy and symploidy, respectively; Bureš et al. 2013). To handle the chromosomal fusions in Luzula, chromosome size categories as defined by Nordeskiöld (1951) were further considered to estimate the actual ploidy level. Ploidy level estimates in highly polyploid genomes of Viola follow Marcussen et al. (2015).

Citation: Šmarda P. (2018) Ploidy level (x). - www.pladias.cz. 

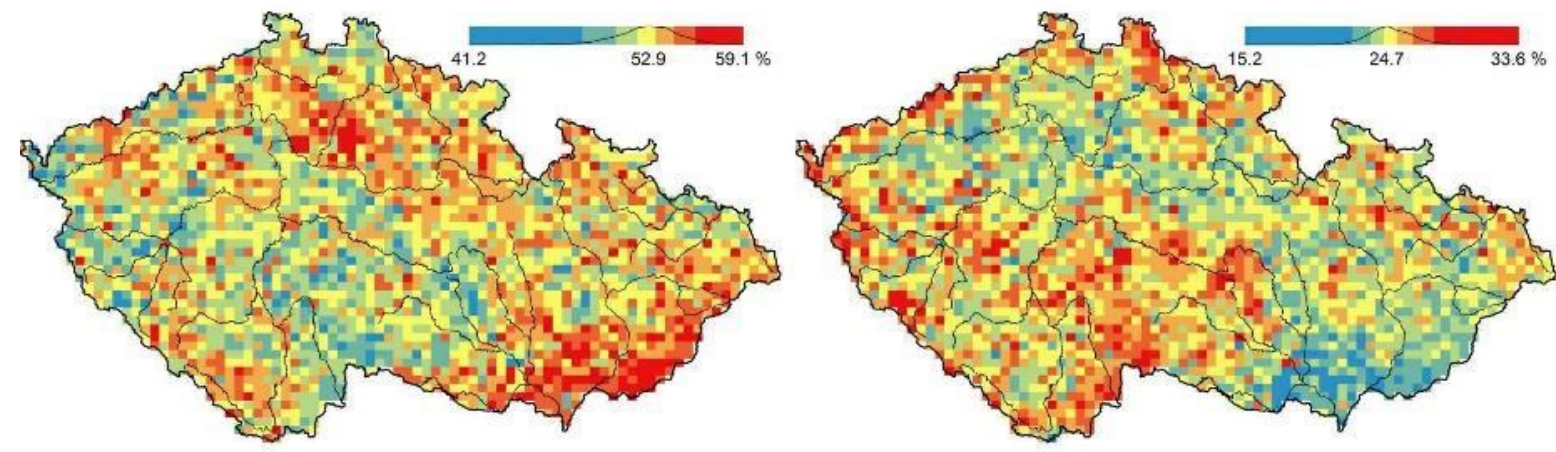

(c) Monoploid genome size

(d) Genomic GC content
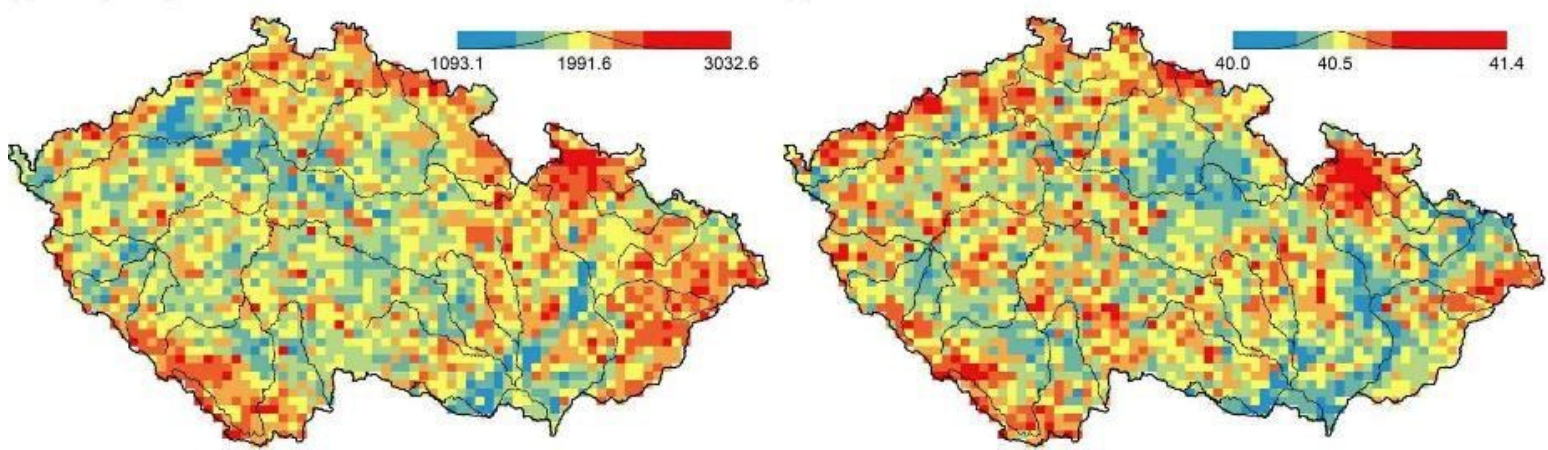

Fig. 24. - Patterns of genomic characteristics in the Czech flora, including the proportion of diploid and tetraploid species $(\mathrm{a}, \mathrm{b})$, mean 1Cx monoploid genome size in DNA base pairs (c) and mean percentage of genomic guanine and cytosine (GC) bases in nuclear DNA (d). Diploids are frequent at low elevations and in the flysch Carpathians, while tetraploids have a complementary distribution pattern. Both the monoploid genome size and genomic CG content attain larger values in the mountains and partly in submontane areas, and small in wetland areas, especially in the floodplains of lowland rivers. This pattern partly reflects the fact that ferns and gymnosperms, i.e. taxa with on average larger genomes than angiosperms, account for a larger proportion of the total flora in the mountains. The geographic pattern of the somatic $(2 \mathrm{C})$ genome size is very similar to that of the $1 \mathrm{Cx}$ genome size (not shown).

\section{$2 C$ genome size}

$2 \mathrm{C}$ genome size is the somatic nuclear DNA content in a zygotic cell measured in megabase pairs (Mbp). This measure can vary among taxa due to both polyploidy and the variability in the content of non-coding DNA (Leitch \& Greilhuber 2013). Genome size influences minimum cell size, duration of the cell cycle and cell division, and nutrient requirements. 
Therefore, it may have a considerable influence on ecological strategies of plants (Bennett 1987, Veselý et al. 2012, Greilhuber \& Leitch 2013). Most values were measured in plants collected in the Czech Republic (Šmarda et al. 2019). The data always refer to the dominant chromosome number and the dominant ploidy level of the given taxon.

Data source and citation: Šmarda et al. (2019).

1Cx monoploid genome size (Fig. 24c)

1Cx monoploid genome size is the amount of DNA contained in one set of chromosomes measured in megabase pairs (Mbp). The data are from Šmarda et al. (2019), where they were obtained for each taxon by dividing its $2 \mathrm{C}$ genome size by the respective ploidy level (Greilhuber et al. 2005). Differences in 1Cx values among taxa are therefore virtually free of the polyploidy effect (i.e. only due to amplification of non-coding DNA). However, the $1 \mathrm{Cx}$ values in polyploids are usually slightly smaller due to the increased tendency to eliminate the duplicated, redundant DNA (Leitch \& Bennett 2004). Because the 1Cx values tend to be similar in related taxa, they can be used to roughly estimate the $2 \mathrm{C}$ genome size in related taxa for which only the ploidy level is known so far. Conversely, they can be used to estimate the ploidy levels based on the known $2 \mathrm{C}$ genome size.

Data source and citation: Šmarda et al. (2019).

\section{Genomic GC content (Fig. 24d)}

Genomic GC content is the percentage of guanine and cytosine bases in nuclear DNA. It influences the thermal stability of DNA, packing of condensed DNA within the nucleus, the energetic cost of DNA synthesis or cell sensitivity to desiccation (Šmarda \& Bureš 2012, $\breve{S}$ marda et al. 2014). For the vast majority of taxa, these data were measured in plants collected in the Czech Republic (Šmarda et al. 2019). The data always refer to the dominant chromosome number and dominant ploidy of the given taxon. Differences up to $1 \%$ in closely related taxa or up to $2 \%$ in unrelated taxa may be considered insignificant because of possible method errors (Šmarda et al. 2012). 
Data source and citation: Šmarda et al. (2019).

\section{Taxon origin}

Origin in the Czech Republic (Fig. 25a-c)

Taxa are classified according to whether they are native or alien to the Czech Republic.

Following the definitions used in invasion ecology, native taxa are those that have evolved in the area of the Czech Republic or immigrated there without human assistance from the area where they had evolved. Alien taxa are those whose presence is a result of intentional or unintentional introduction by human activity and can be divided based on their residence time. The alien taxa are divided based on their residence time into archaeophytes and neophytes. Archaeophytes are taxa occurring in the wild that were introduced between the beginning of Neolithic agriculture and the year 1500, i.e. the beginning of intercontinental overseas trade after the discovery of the Americas. Neophytes are taxa occurring in the wild that were introduced after 1500 (see Richardson et al. 2000 for detailed definitions).

Additionally, some frequently cultivated taxa that are not known to have escaped from cultivation are listed as a separated category.

The data included in the database follow the second edition of the Catalogue of alien plants of the Czech Republic (Pyšek et al. 2012 and references related to individual taxa therein) with the addition of recent records.

\section{Categories}

- native

- archaeophyte
- neophyte

- cultivated only

Data source and citation: Pyšek et al. (2012). 

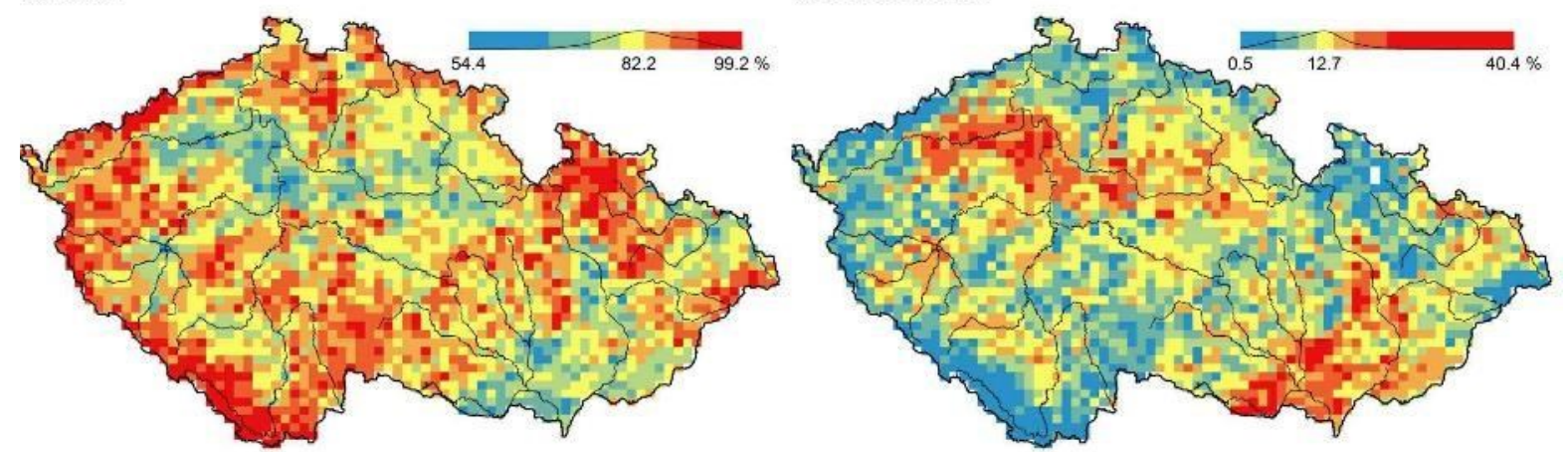

(c) Neophytes

(d) Casual aliens
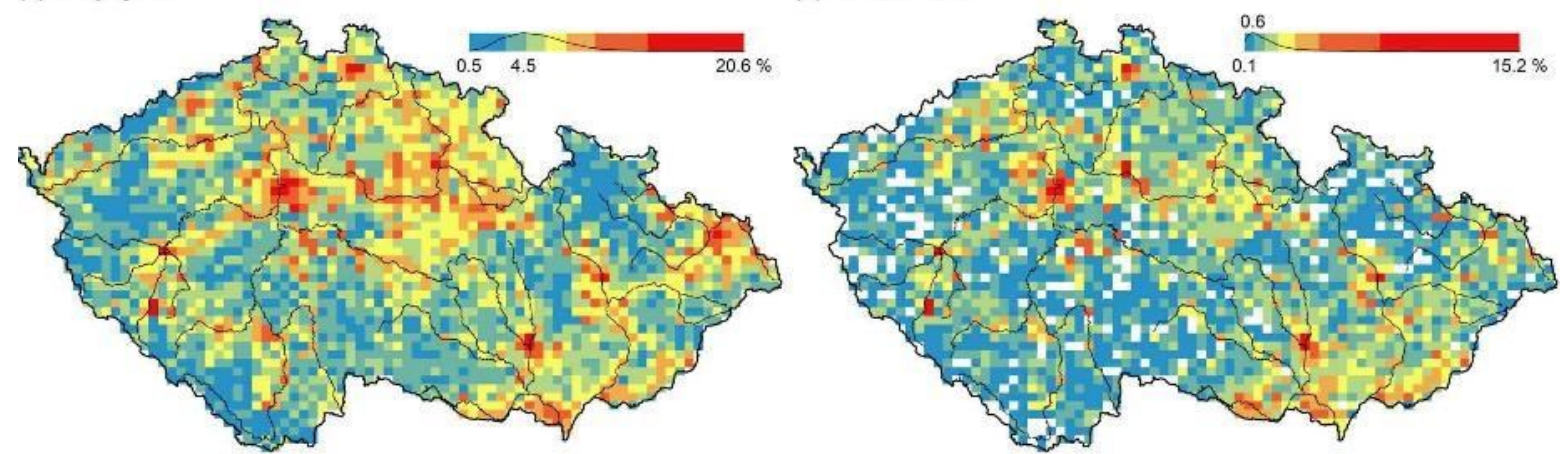

(e) Naturalized aliens

(f) Invasive aliens
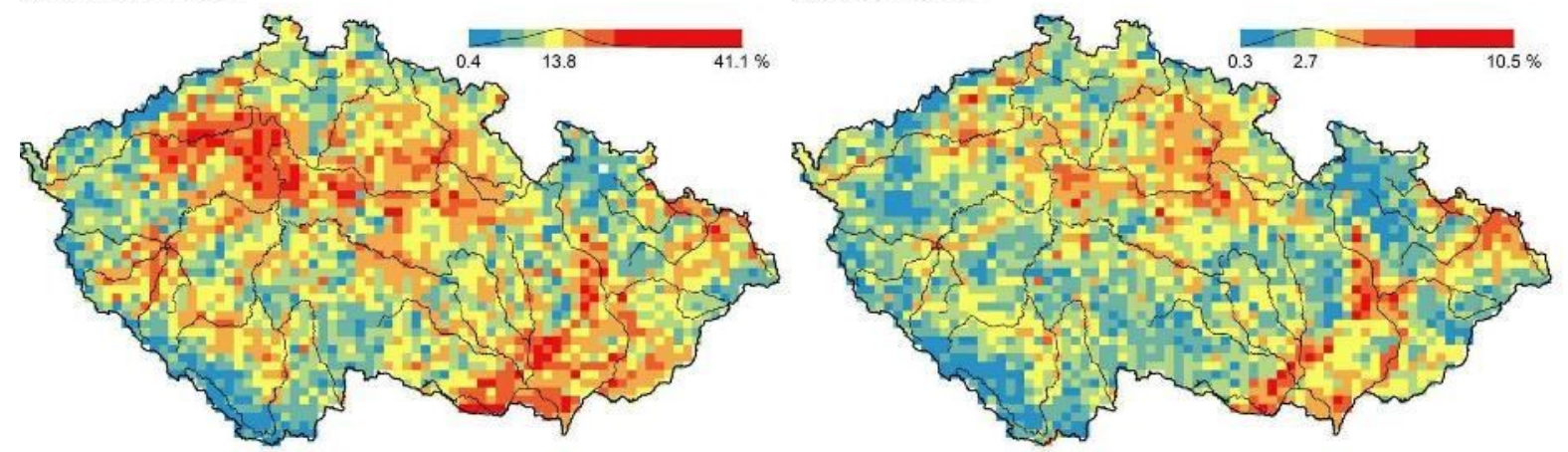

Fig. 25. - Patterns of the origin and invasive status in the Czech flora. Native species are frequent in mountain areas, while both groups of aliens are more common in the lowlands. Archaeophytes are widespread mainly in warm and dry lowland agricultural areas, whereas neophytes are more common in urban areas and along lowland rivers. Casual species are found mostly in urban areas, naturalized species are common across lowland areas, while invasive species show a distinct concentration of occurrence along lowland rivers.

Invasion status (Fig. 25d-e)

Invasion status is a classification of alien taxa into three categories reflecting their position in the invasion process. Alien taxa that only occasionally reproduce in the wild in the Czech 
Republic, do not form self-replacing populations, and rely on repeated introductions for their persistence are termed casual. Naturalized taxa are alien plants that reproduce in the wild and sustain populations over many life cycles without direct intervention by humans (or despite human intervention). Invasive plants are naturalized plants that produce reproductive offspring, often in large numbers, at considerable distances from parent plants and thus have the potential to spread over an extensive area (Richardson et al. 2000, 2011). This classification does not apply to native taxa, which are reported as separate categories. The data are taken from the second edition of the Catalogue of alien plants of the Czech Republic (Pyšek et al. 2012 and references related to individual taxa therein).

\section{Categories}

- casual

- naturalized
- invasive

- native

Data source and citation: Pyšek et al. (2012).

\section{Geographic origin (Fig. 26)}

This information is given for alien taxa only. These taxa are classified according to their geographic origin (native range) at the level of continents; those with a native range encompassing more than one continent are assigned to two or more categories. Origin in Europe refers to the non-Mediterranean parts of this continent other than the Czech Republic. The Mediterranean region comprises parts of southern Europe, northern Africa and western Asia from Turkey and Israel to Afghanistan, which are characterized by the Mediterranean-type climate and corresponding evergreen vegetation. Conversely, records of origin in Africa, Asia and Europe do not relate to the Mediterranean part of these continents. Hybrids and species that originated through recent hybridization are listed as a separate category. Anecophytes are taxa for which native range is unknown or highly uncertain. The data are taken from the second edition of the Catalogue of alien plants of the Czech Republic (Pyšek et al. 2012 and references related to individual taxa therein).

\section{Categories}

- Europe
- Mediterranean

- North America 
- Central America

- South America

- Asia
- Africa

- anecophyte

- Australia

- hybrid origin

Data source and citation: Pyšek et al. (2012).

(a) Aliens of European origin

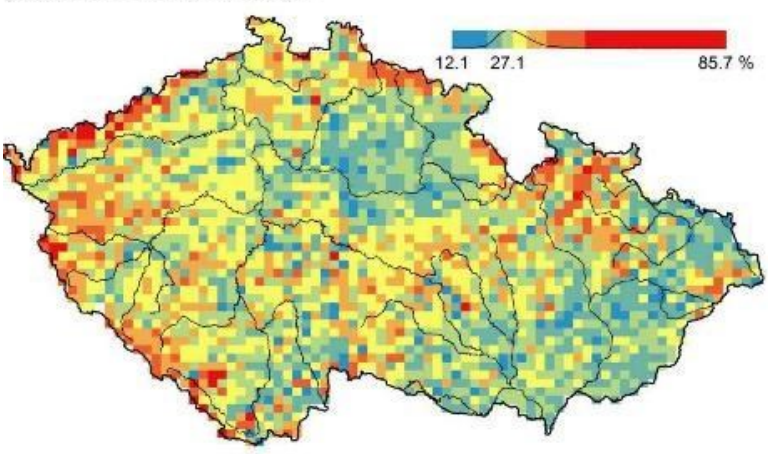

(c) Aliens of North American origin

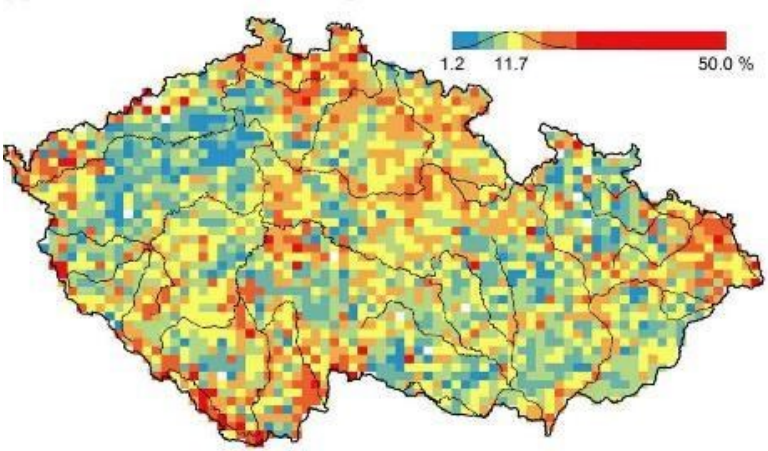

(b) Aliens of Mediterranean origin

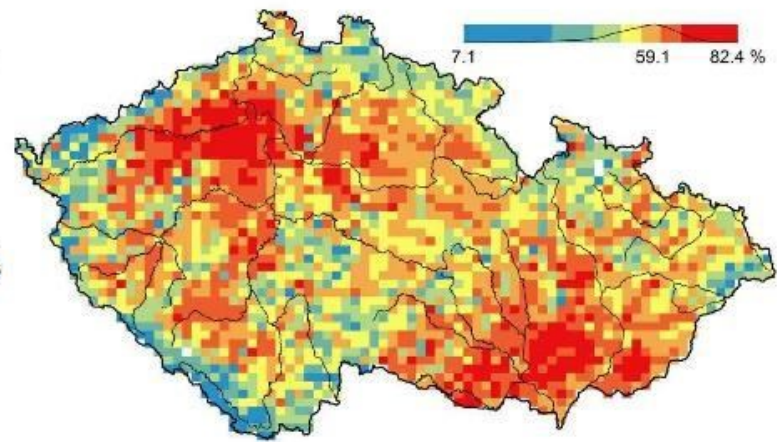

(d) Aliens of Asian origin

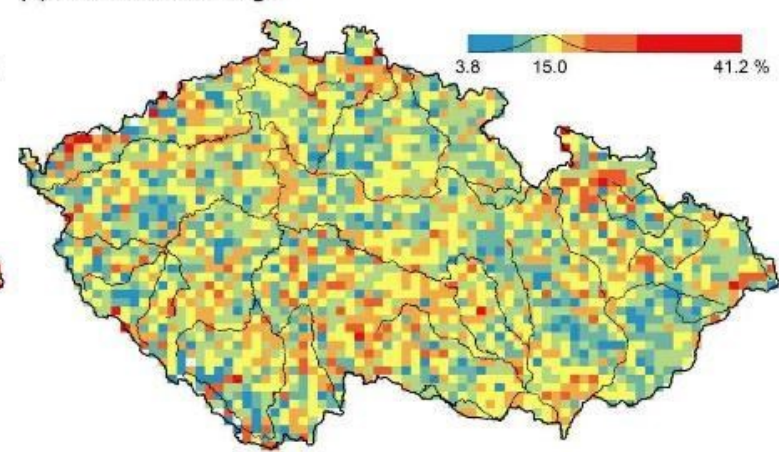

Fig. 26. - Proportion of European, Mediterranean, North American and Asian species in the Czech alien flora (native species are not considered). Species originating on other continents are rare and do not display distinct patterns. The species introduced from other parts of nonMediterranean Europe are frequent in the mountain and submontane areas. Mediterranean species are frequent in the dry and warm lowlands. North American species tend to be more common in wetter areas, both in the precipitation-rich mountains and in the lowland pond basins or riverine landscapes. Asian species do not display any distinct pattern.

\section{Year of the first record in the wild}

The year of the first reported occurrence in the wild in the Czech Republic is given for neophytes. Data were extracted from the second edition of the Catalogue of alien plants of 
the Czech Republic (Pyšek et al. 2012); however, for many species, this information is not available.

Data source and citation: Pyšek et al. (2012).

\section{Introduction pathway (Fig. 27)}

This information is available for alien taxa only. Taxa were classified according to the mode of introduction, with the distinction made between an accidental or deliberate pathway (Hulme et al. 2008). The deliberate introduction refers to the direct release into the wild for landscaping purposes, as well as planting in horticulture, forestry and agriculture and subsequent escape from cultivation. The accidental introductions include import through contamination of a commodity, a stowaway on a transport vector or spread via an infrastructure corridor without which the spread would not be possible (Hulme et al. 2008). A taxon can be assigned to more than one introduction pathway. The data included in the database follow the second edition of the Catalogue of alien plants of the Czech Republic (Pyšek et al. 2012 and references related to individual taxa therein).

\section{Categories}

- accidental introduction

- deliberate introduction

Data source and citation: Pyšek et al. (2012).

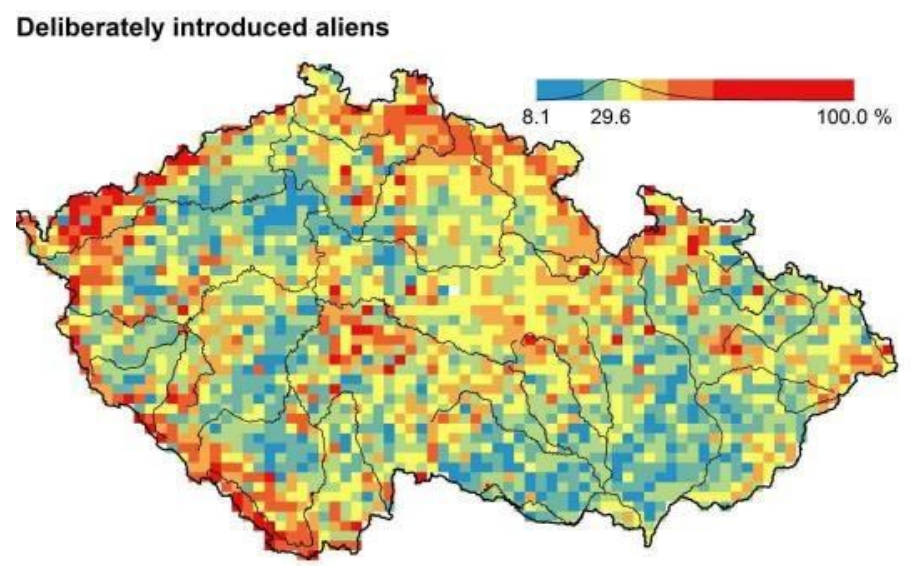


Fig. 27. - Proportion of the deliberately introduced alien species in the Czech alien flora (native species are not considered). Deliberately introduced aliens are particularly frequent in the mountain areas of the Bohemian Massif, whereas accidentally introduced aliens prevail in the lowlands. Note that the absolute number of alien species in the mountain areas is low.

\section{Ecological indicator values}

Ellenberg-type indicator values (Fig. 28)

Indicator values for the main environmental factors affecting plant occurrence are expressed on ordinal scales defined by Ellenberg et al. (1991). The values for individual taxa were modified and extended for the Czech flora by Chytrý et al. (2018). The following indicator values were defined:

- Light indicator value

- Temperature indicator value

- Moisture indicator value

- Reaction indicator value

- Nutrient indicator value

- Salinity indicator value

These scales range from 1 to 9 except for moisture (1-12) and salinity (0-9). The values with " $\mathrm{x}$ " indicate generalists, i.e. taxa with broad ecological range for the given factor. For light, a value of 1 indicates deep-shade plants, while a value of 9 indicates the full-light plants (indicator values for trees relate to juvenile individuals in herb and shrub layers). For temperature, a value of 1 indicates plants of cold areas, occurring only in high mountain areas, while a value of 9 indicates plants of the warmest sites of southern central Europe. For moisture, the taxa with a value of 1 are strong drought indicators, while the taxa with a value of 12 are permanently or almost permanently submerged aquatic plants. The reaction value is a proxy for the $\mathrm{pH}$ of soil or water, especially in acidic environments. In near-neutral or alkaline environments, it is more a proxy for calcium concentration. A reaction value of 1 is assigned to indicators of strong acidity, never occurring in slightly acidic to alkaline soil or water. In contrast, a value of 9 is assigned to base and lime indicators that always occur in 
calcium-rich conditions. The nutrient value is a proxy for the availability of nitrogen or phosphorus and to some extent, also a proxy for site primary productivity. A nutrient value of 1 is assigned to the taxa occurring at nutrient-poorest sites, while a value of 9 belongs to the taxa concentrated at nutrient-richest sites. For salinity, taxa with a value of 0 are glycophytes, i.e. non-salt-tolerant plants. In contrast, taxa with a value of 9 are euhaline to hypersaline, on soils with a very high and in dry periods extremely high salt content. The salinity value is a proxy for concentration in the environment of soluble salts, including sulphates, chlorides and carbonates of sodium, potassium, calcium and magnesium.

Data source and citation: Chytrý et al. (2018).

(a) Light indicator value

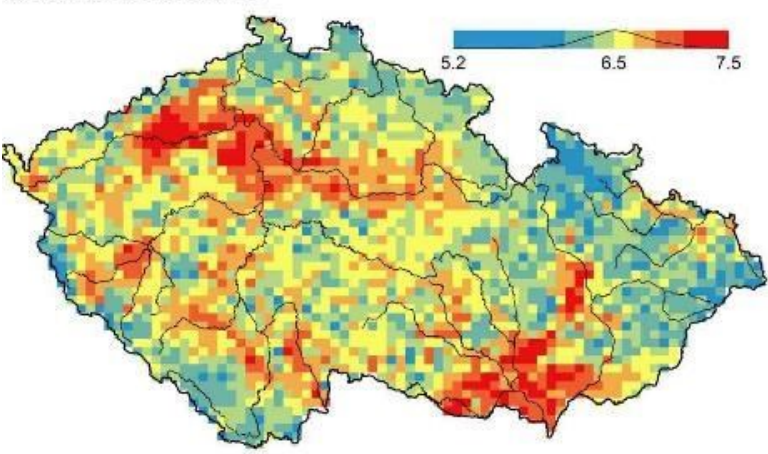

(c) Moisture indicator value

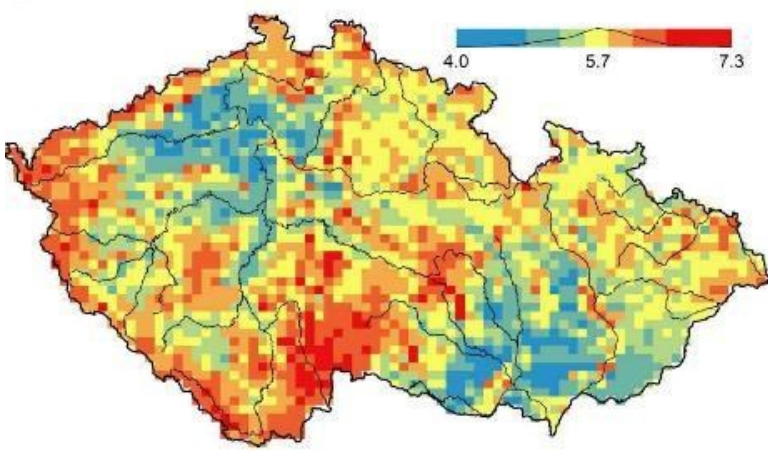

(e) Nutrient indicator value

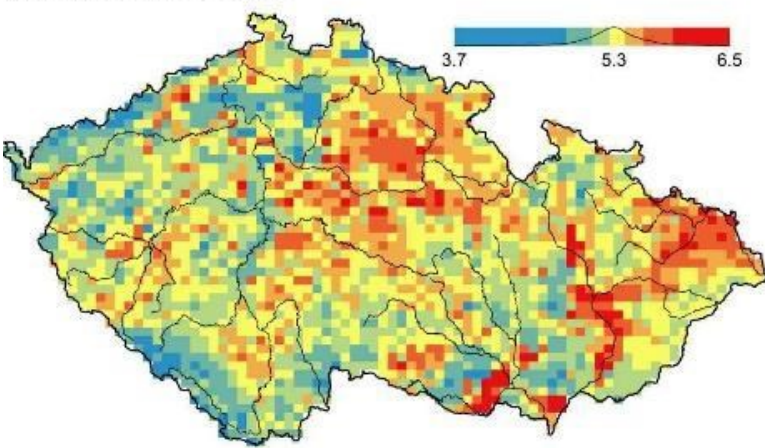

(b) Temperature indicator value

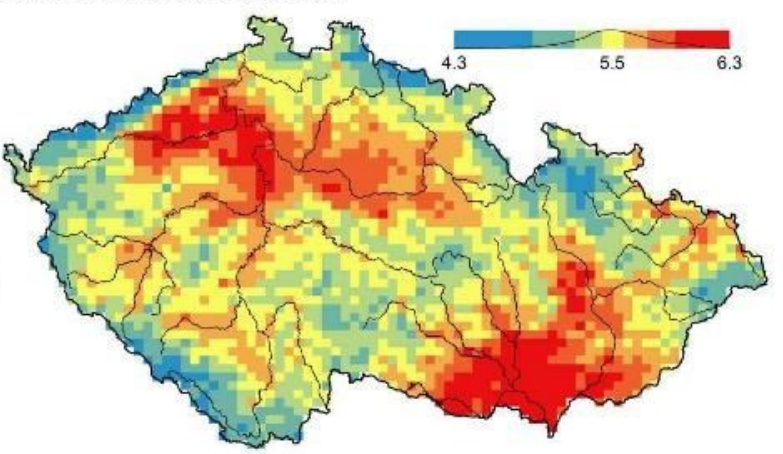

(d) Reaction indicator value

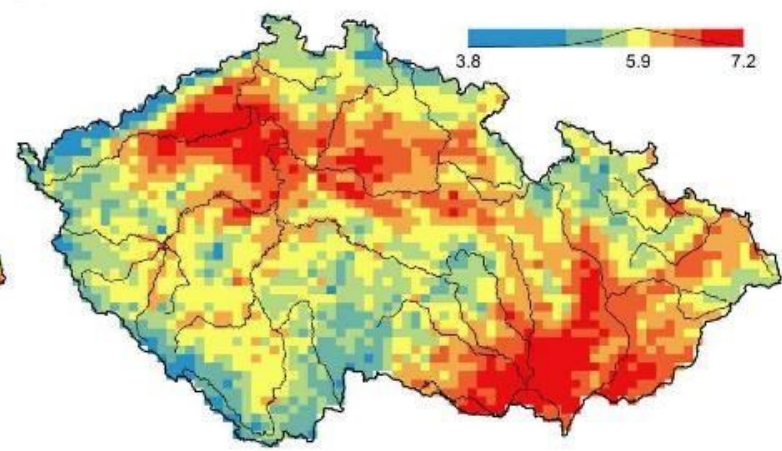

(f) Salinity indicator value

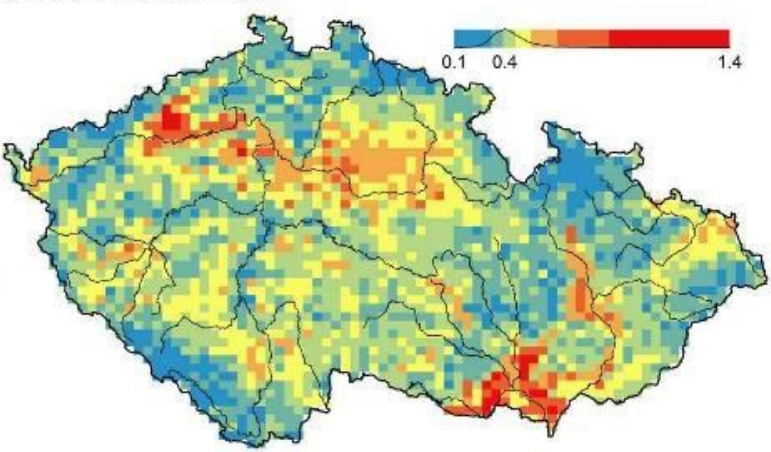


Fig. 28. - Mean Ellenberg-type indicator values for light, temperature, moisture, reaction, nutrients and salinity in the Czech flora. Light-demanding species (a) are frequent in open areas with a low proportion of forest, thermophilous (b) and basiphilous (d) species in the warm and dry lowlands, moisture-demanding species (c) in the western oceanic mountains, basins, fishpond areas and along large rivers, nutrient-demanding species (e) in the lowland areas with deeps soils on soft sediments, and halophytes (f) in the dry areas of northern Bohemia and southern Moravia.

\section{Indicator values for disturbance (Fig. 29)}

Indicator values for disturbance express relationships of common taxa of the Czech flora separately to the frequency and severity of disturbance. Individual disturbance agents are not distinguished, but a wide range of factors is considered including logging, cutting, mowing, herbivory, trampling, damage by herbicides, burning, wind-throws, soil erosion, ploughing, hoeing or burrowing, wave and current action, and flooding. There are three types of indicator values for disturbance:

- Disturbance frequency indicator values are expressed as the inverse of the disturbance return time on a logarithmic scale (in years, common logarithms). For example, a value of -2 refers to the return time of a century, a value of -1 to the return time of ten years, and a value of 0 refers to a disturbance occurring every year. One unit of the index corresponds to a tenfold change in disturbance frequency.

- Disturbance severity indicator values are expressed using an arbitrary scale from 0 (least severe disturbance) to 1 (most severe disturbance). They are based on the assessment of the proportion of above-ground biomass removed and degree of soil disturbance (proportional change in cover of the bare ground) in a single disturbance event. Indicator values for frequency and severity of disturbance are correlated, but still sufficiently independent to express separate components of the taxon's disturbance niche.

- Structure-based disturbance indicator values express disturbance regime based on structural parameters of vegetation plots in which the taxon occurs. These values are normalized to the $0-1$ range, where higher values indicate a higher level of disturbance. 
Each of these three types of indicator values is provided separately for the wholecommunity disturbance events and for smaller disturbance events that affect the herb layer but not the tree layer in forests. Both indicator values are identical for taxa of open habitats.

The following indicator values for disturbance are provided:

- Whole-community disturbance frequency indicator value

- Herb-layer disturbance frequency indicator value

- Whole-community disturbance severity indicator value

- Herb-layer disturbance severity indicator value

- Whole-community structure-based disturbance indicator value

- Herb-layer structure-based disturbance indicator value

Indicator values for disturbance were calculated by Herben et al. (2016) based on an analysis of a stratified subset of 30,115 vegetation plots from the Czech National Phytosociological Database (Chytrý \& Rafajová 2003). Only taxa occurring in at least 20 plots were used. These plots were classified by an expert system into 39 phytosociological vegetation classes as defined in Vegetation of the Czech Republic (Chytrý 2007-2013). For each of these classes, the mean frequency and severity of disturbance were assessed based on field observations. The disturbance indicator value for each taxon was calculated as the average disturbance frequency or severity weighted by the frequency of occurrence of that taxon in the plots assigned to these vegetation classes. The structure-based disturbance indicator values were calculated based on variation in plant height at maturity and variation in summed covers of all taxa recorded in the vegetation plots where the target taxon occurs.

Data source and citation: Herben et al. (2016).

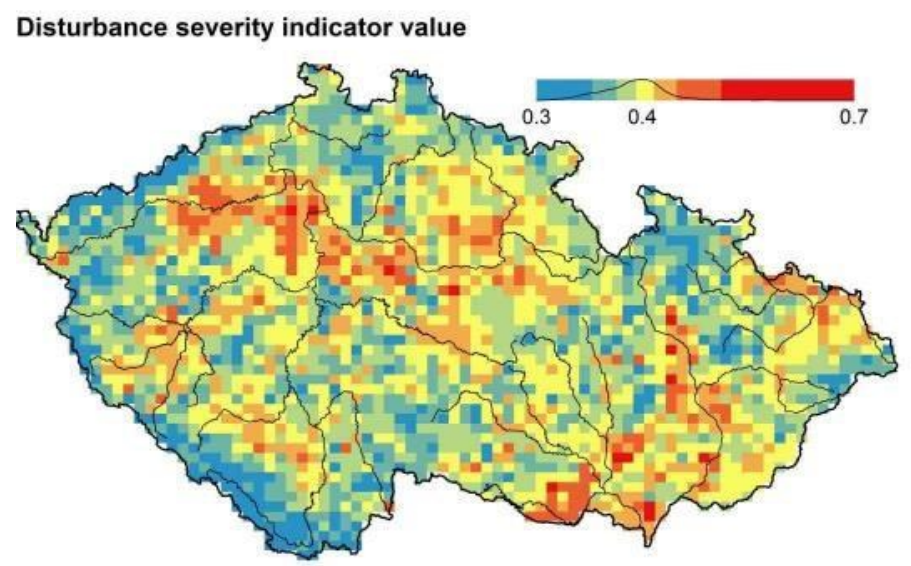


Fig. 29. - Mean whole-community disturbance frequency indicator value. The geographical patterns for the other disturbance indicator values were found to be similar (not shown). The strongest disturbance is indicated in agricultural areas, especially in dry lowlands.

\section{Habitat and sociology}

\section{Occurrence in habitats}

Data on taxon occurrence in habitats of the Czech Republic are based on the analysis of vegetation plots from the Czech National Phytosociological Database (Chytrý \& Rafajová 2003 ) and its expert revision and completion based on the literature and field experience, especially for rare and taxonomically problematic taxa. The classification recognizes 88 basic habitats aggregated to 13 broader habitats that are defined by Sádlo et al. (2007: Appendix 1):

- 1 Vegetation of cliffs, screes and walls

- 1A Calcareous cliffs

- 1B Siliceous cliffs and block fields

- 1C Walls

- 1D Mobile calcareous screes

- 2 Alpine and subalpine grasslands

- 2A Alpine grasslands on siliceous bedrock

- 2B Subalpine tall-forb and tall-grass vegetation

- 3 Aquatic vegetation

- 3A Macrophytic vegetation of eutrophic and mesotrophic still waters

- 3B Macrophytic vegetation of water streams

- 3C Macrophytic vegetation of oligotrophic lakes and pools

- 4 Wetland and riverine herbaceous vegetation

- 4A Reed-beds of eutrophic still waters

- 4B Halophilous reed and sedge beds

- 4C Eutrophic vegetation of muddy substrata

- 4D Riverine reed vegetation

- 4E Reed vegetation of brooks 
- 4F Mesotrophic vegetation of muddy substrata

- 4G Tall-sedge beds

- 4H Vegetation of low annual hygrophilous herbs

- 4I Vegetation of nitrophilous annual hygrophilous herbs

- 4J River gravel banks

- 4K Petasites fringes of montane brooks

- 4L Nitrophilous herbaceous fringes of lowland rivers

- 5 Vegetation of springs and mires

- 5A Hard-water springs with tufa formation

- 5B Lowland to montane soft-water springs

- 5C Alpine and subalpine soft-water springs

- 5D Calcareous fens

- 5E Acidic moss-rich fens and peatland meadows

- 5F Transitional mires

- 5G Raised bogs

- $5 \mathrm{H}$ Wet peat soils and bog hollows

- 6 Meadows and mesic pastures

- 6A Mesic Arrhenatherum meadows

- 6B Montane mesic meadows

- 6C Pastures and park grasslands

- 6D Alluvial meadows of lowland rivers

- 6E Wet Cirsium meadows

- 6F Intermittently wet Molinia meadows

- 6G Vegetation of wet disturbed soils

- 7 Acidophilous grasslands

- 7A Subalpine and montane acidophilous grasslands

- 7B Submontane Nardus grasslands

- 8 Dry grasslands

- 8A Hercynian dry grasslands on rock outcrops

- 8B Submediterranean dry grasslands on rock outcrops

- 8C Narrow-leaved sub-continental steppes

- 8D Broad-leaved dry grasslands

- 8 E Acidophilous dry grasslands 
$\circ \quad 8 \mathrm{~F}$ Thermophilous forest fringe vegetation

- 9 Sand grasslands and rock-outcrop vegetation

- 9B Open vegetation of acidic sands

- 9C Festuca grasslands on acidic sands

- 9D Pannonian sand steppes

- 9E Acidophilous vegetation of spring therophytes and succulents

- 9F Basiphilous vegetation of spring therophytes and succulents

- 10 Saline vegetation

- 10G Continental vegetation of annual halophilous grasses

- $10 \mathrm{H}$ Inland vegetation of succulent halophytes

- 10I Inland saline meadows

- 10J Saline steppes

- 11 Heathlands and scrub

- 11A Dry lowland to subalpine heathlands

- 11D Subalpine acidophilous Pinus mugo scrub

- $11 \mathrm{H}$ Subalpine deciduous scrub

- 11I Willow carrs

- $11 \mathrm{~J}$ Willow galleries of loamy and sandy river banks

- 11L Tall mesic and xeric shrub

- $\quad 11 \mathrm{~N}$ Low xeric scrub

- 11R Scrub and pioneer woodland of forests clearings

- 12 Forests

- 12A Alder carrs

- 12B Alluvial forests

- 12C Oak-hornbeam forests

- 12D Ravine forests

- 12E Herb-rich beech forests

- 12F Limestone beech forests

- $12 \mathrm{G}$ Acidophilous beech forests

- 12H Peri-Alpidic basiphilous thermophilous oak forests

- 12I Sub-continental thermophilous oak forests

- 12J Acidophilous thermophilous oak forests

- $12 \mathrm{~K}$ Acidophilous oak forests 
- 12L Boreo-continental pine forests

- 120 Peri-Alpidic pine forests

- 12P Peatland pine forests

- 12Q Peatland birch forests

- 12R Acidophilous spruce forests

- $\quad 12 \mathrm{~S}$ Basiphilous spruce forests

- 12T Robinia pseudoacacia plantations

- 12U Plantations of broad-leaved non-native trees

- 12V Picea plantations

- 12W Pinus and Larix plantations

- 13 Anthropogenic vegetation

- 13A Annual vegetation of ruderal habitats

- 13B Annual vegetation of arable land

- 13C Annual vegetation of trampled habitats

- 13D Perennial thermophilous ruderal vegetation

- 13E Perennial nitrophilous herbaceous vegetation of mesic sites

- $\quad$ 13F Herbaceous vegetation of forests clearings and Rubus scrub

Taxon occurrence in each habitat is assessed, based on expert judgement, on a four-degree scale:

1 - occurrence - taxon can grow in the habitat, but it is not the ecological optimum for this taxon, which often is rare in this habitat

2 - optimum - the habitat or part of it is the ecological optimum for this taxon

3 - dominant - taxon can be assigned to the previous category, and at the same time it frequently attains a cover above $25 \%$ in areas $\geq 10 \mathrm{~m}^{2}$ or $\geq 100 \mathrm{~m}^{2}$ in herbaceous or woody vegetation, respectively

4 - constant dominant - same as for the previous category but the taxon also determines the general appearance of the habitat (e.g., Calluna vulgaris in heathlands), occurring in $\geq 40 \%$ of the localities of the habitat

Data source and citation: Sádlo et al. (2007).

\section{Affinity to the forest environment}


The affinity of taxa to the forest environment is assessed using the categories of the German national list of forest taxa (Schmidt et al. 2011). Each taxon is assessed separately for the region of Thermophyticum (lowlands with thermophilous and drought-adapted flora) and merged regions of Mesophyticum and Oreophyticum (mid-elevations and mountains with mesophilous and mountain flora; Skalický 1988). The compilation was based on the list of regional species pools of Czech habitats (Sádlo et al. 2007), expert knowledge and various literature sources. It has been integrated into the European forest plant species list (Heinken et al. 2019).

\section{Categories}

- 0 - taxon does not spontaneously occur in Czech forests

- $1.1-$ taxon occurring mainly in the closed forest

- 1.2 - taxon occurring mainly along forest edges and in forest openings, including forest roads and paths, windthrow sites, burnt sites and forest clearings

- 2.1 - taxon occurring both in forest and open vegetation

- 2.2 - taxon occurring partly in forest but mainly in open vegetation

Citation: Dřevojan P., Chytrý M., Sádlo J. \& Pyšek P. (2016) Affinity to the forest environment. - www.pladias.cz.

\section{Diagnostic taxon}

Data on the diagnostic status of taxa for individual phytosociological classes, alliances or associations are taken from the monograph Vegetation of the Czech Republic (Chytrý 20072013). Diagnostic taxa are characterized by a concentration of their occurrence in the stands belonging to the target vegetation unit while being rare or absent in other vegetation units. They were determined based on the calculation of fidelity of each taxon to a group of vegetation plots representing the target vegetation unit in a geographically and ecologically stratified selection of plots of all vegetation types extracted from the Czech National Phytosociological Database (Chytrý \& Rafajová 2003). Fidelity was measured using the phi coefficient of association after the sizes of plot groups were virtually standardized to $1 \%$ of the total size of the data set following Tichý \& Chytrý (2006). The taxa with a value of phi 
higher than 0.25 , whose concentration in the vegetation unit was significant according to Fisher's exact test $(\mathrm{P}<0.001)$, were considered as diagnostic taxa. The numbers of vegetation plots used for the calculations are given in respective volumes of Vegetation of the Czech Republic.

Data source and citation: Chytrý (2007-2013).

\section{Constant taxon}

Data on the constant status of taxa for individual phytosociological classes, alliances or associations were taken from the monograph Vegetation of the Czech Republic (Chytrý 2007-2013). Constant taxa are characterized by frequent occurrence in stands belonging to the target vegetation unit, but unlike diagnostic taxa, they can also commonly occur in other vegetation units. They were determined based on the calculation of percentage frequency (constancy) of each taxon in a group of vegetation plots representing the target vegetation unit in a geographically and ecologically stratified selection of plots of all vegetation types extracted from the Czech National Phytosociological Database (Chytrý \& Rafajová 2003). The taxa with an occurrence frequency in the vegetation unit higher than $40 \%$ were considered as constant taxa. The numbers of vegetation plots used for the calculations are given in respective volumes of Vegetation of the Czech Republic.

Data source and citation: Chytrý (2007-2013).

\section{Dominant taxon}

Data on the dominant status of taxa for individual associations were taken from the monograph Vegetation of the Czech Republic (Chytrý 2007-2013). Dominant taxa are defined here as those occurring with a cover higher than $25 \%$ in more than $5 \%$ of vegetation plots belonging to the target association. They do not need to be the taxa with the highest cover in particular stands. These taxa were determined based on the group of vegetation plots representing the target vegetation unit in a geographically and ecologically stratified selection of plots of all vegetation types extracted from the Czech National Phytosociological Database (Chytrý \& Rafajová 2003). The numbers of vegetation plots 
used for the calculations are given in respective volumes of Vegetation of the Czech Republic.

Data source and citation: Chytrý (2007-2013).

\section{Ecological specialization indices (Fig. 30)}

The degree of ecological specialization for individual taxa is estimated based on their cooccurrence with other taxa. The underlying assumption is that variation in the composition of co-occurring taxa indicates the range of habitat conditions suitable to this taxon (Fridley et al. 2007). A taxon repeatedly co-occurring with a similar set of taxa across different sites is more likely to be a specialist with a preference for a specific habitat. Conversely, a taxon co-occurring with various taxa across different sites is more likely to be a generalist tolerating a wide range of habitats. The ecological specialization index (ESI) of a taxon is inversely related to beta diversity calculated for the set of sites at which this taxon occurs.

The ecological specialization indices were calculated based on the vegetation plots from the Czech National Phytosociological Database (Chytrý \& Rafajová 2003). Three vegetation datasets were selected from a geographically stratified subset of plots from the database: (1) a dataset including all the vegetation types (30,115 plots, 1935 taxa), (2) a dataset including only non-forest vegetation (24,712 plots, 1875 taxa) and (3) a dataset including only forest vegetation (5403 plots, 1264 taxa). Whittaker's multiplicative measure of beta diversity (Whittaker 1960) rarefied to 10 vegetation plots randomly selected from a subset of plots containing the target taxon $\left(\beta_{10}\right)$ was computed for each taxon. Outlier plots with very different species composition were removed from the subset before rarefaction, following a recommendation of Botta-Dukát (2012). Because the calculated value of beta diversity decreases with increasing value of taxon specialization, the value of ESI was calculated as $\mathrm{ESI}=10-\beta_{10}$. This value theoretically ranges from 0 to 9 , with high values indicating specialists and low values indicating generalists.

Each ESI value is accompanied by a taxon weight, which represents the total number of plots in which this taxon occurs within a particular dataset. The weights can be used as a measure of the reliability of the specialization index, which increases with increasing frequency of the taxon in the dataset. Minimum weight is 10 , corresponding to the minimum 
number of occurrences for which ESI was calculated. The theoretical maximum weight is the number of plots in the given dataset.

The following specialization indices and corresponding taxon weights are available (with ranges of values in brackets):

- Ecological specialization index for all vegetation types (2.69-7.95)

- Ecological specialization index for non-forest vegetation (2.63-7.49)

- Ecological specialization index for forest vegetation (2.61-7.95)

- Taxon weights of ESI for all vegetation types (10-5020; theoretical maximum $30,115)$

- Taxon weights of ESI for non-forest vegetation: (10-4542; theoretical maximum 24,712)

- Taxon weights of ESI for forest vegetation: (10-2032; theoretical maximum 5403)

Data source and citation: Zelený \& Chytrý (2019).

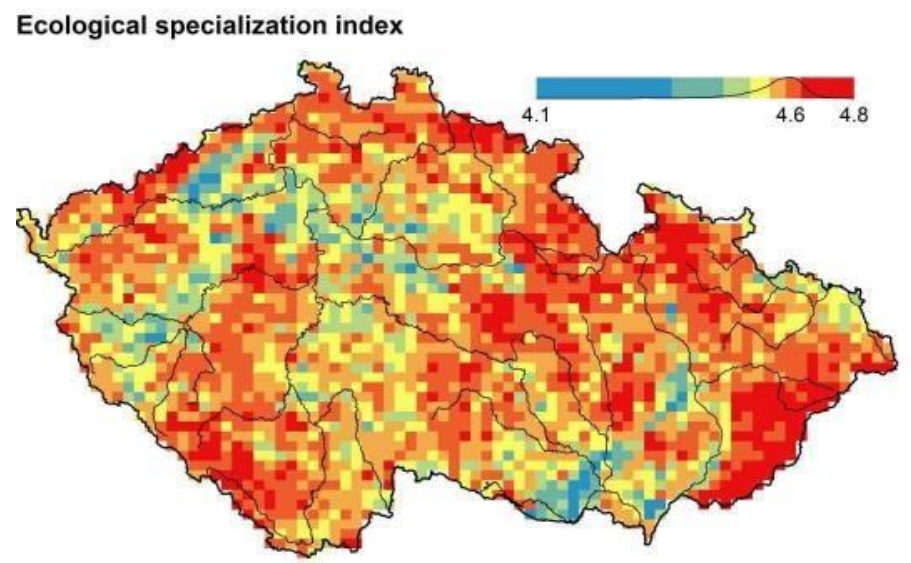

Fig. 30. - Weighted mean ecological specialization index for all vegetation types.

Ecologically specialized species are frequent in the mountains and hilly landscapes, while generalist species are most common in the lowland agricultural areas.

\section{Colonization ability}

The indices characterizing plant colonization ability were published by Prach et al. (2017). The authors derived the index values for individual taxa from a database of 21 succession series (both primary and secondary succession) starting on the bare substrate. This database (Database of Successional Series, DaSS; Prach et al. 2014) contains 1013 taxa of vascular 
plants recorded in 2817 vegetation plots from the Czech Republic sampled in various habitats and successional stages of different age from 1 to 150 years. The following indices are defined:

- Index of colonization success (ICS) expresses taxon frequency in the Database of Successional Series. It was calculated as:

$$
\mathrm{ICS}^{*}=\log ((\mathrm{SF}+\mathrm{EGSSF}) / 2)+1
$$

where SF is the total taxon frequency in the DaSS database, and EGSSF is the taxon frequency in a geographically stratified selection from DaSS. Values of ICS* were subsequently transformed to the range from 1 (absence) to 9 (high frequency of the taxon across successional stages).

- Index of colonization potential (ICP) accounts for the fact that taxon occurrence in successional series is influenced not only by taxon traits but also by the taxon occurrence frequency in the landscape. Therefore, the frequency in successional series was corrected by the frequency of the same taxon within a geographically stratified subset of the Czech National Phytosociological Database (CNPD; 30,115 vegetation plots and 1935 taxa; Chytrý \& Rafajová 2003). The index was calculated as:

$$
\mathrm{ICP}=0.5+\operatorname{arctg}(\mathrm{relEGSSF} / \mathrm{relCNPD}) / 10
$$

where relEGSSF is taxon frequency in a geographically stratified plot selection from DaSS and relCNPD is taxon frequency in a geographically stratified plot selection from CNPD. The index ranges from 1 (low) to 9 (high colonization ability). Values below five indicate underrepresentation of the taxon occurrence in DaSS with respect to CNPD, while values above five indicate overrepresentation in DaSS.

- Optimum successional age is the median of the time in years from the disturbance when the taxon occurs during succession. It ranges from 1 to 50 years. When the calculated median was higher, the value was arbitrarily set to 75 years due to the low number of old successional stages.

Data source and citation: Prach et al. (2017).

\section{Distribution and frequency}

Floristic zone (Fig. 31) 
The floristic zones of the Earth in which the taxon occurs are defined according to Meusel et al. (1965, 1978) and Meusel \& Jäger (1992). Data were taken from the BiolFlor database (Kühn \& Klotz 2002).

\section{Categories}

- $\operatorname{arctic}-$ zone of tundra north of the arctic treeline

- boreal - zone of northern coniferous forests (taiga)

- northern temperate - northern zone of summer-green deciduous forests

- southern temperate - southern zone of summer-green deciduous forests

- submeridional - zone of summer-green dry forests and steppes

- meridional - zone of evergreen broad-leaved and coniferous forests, steppes and deserts

- $\quad$ subtropical - winter-dry zone with savannas and dry forests

- tropical - humid zone with evergreen broad-leaved forests

- austral or antarctic - floristic zones of the southern hemisphere corresponding to the temperate to arctic zones of the northern hemisphere

Data source and citation: Kühn \& Klotz (2002). 
(a) Arctic zone

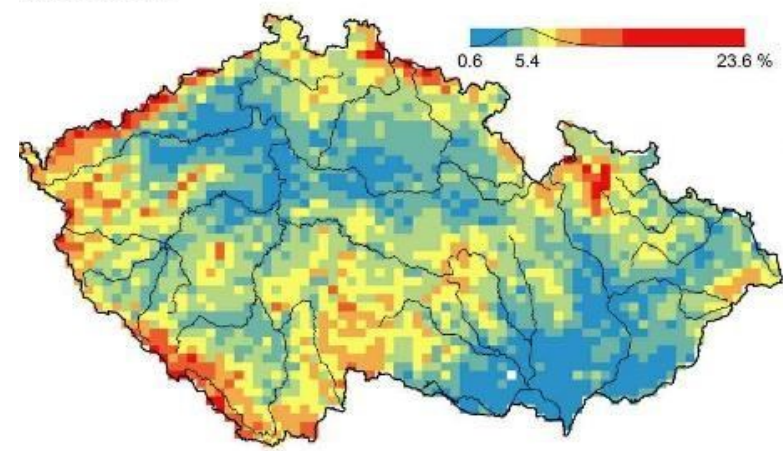

(c) Northern temperate zone

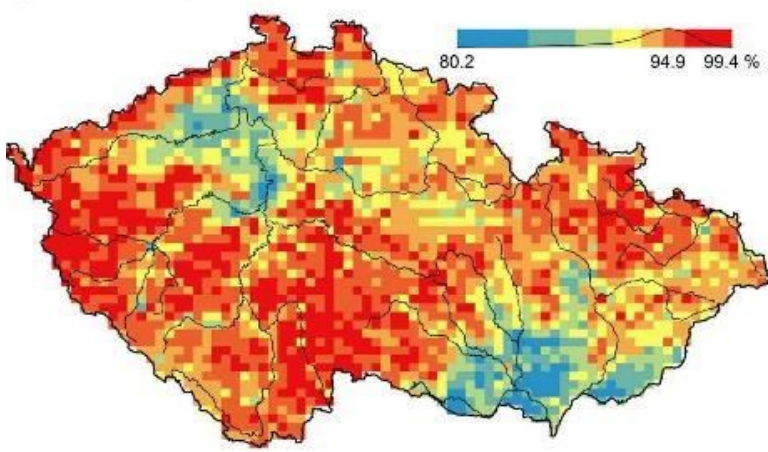

(e) Submeridional zone

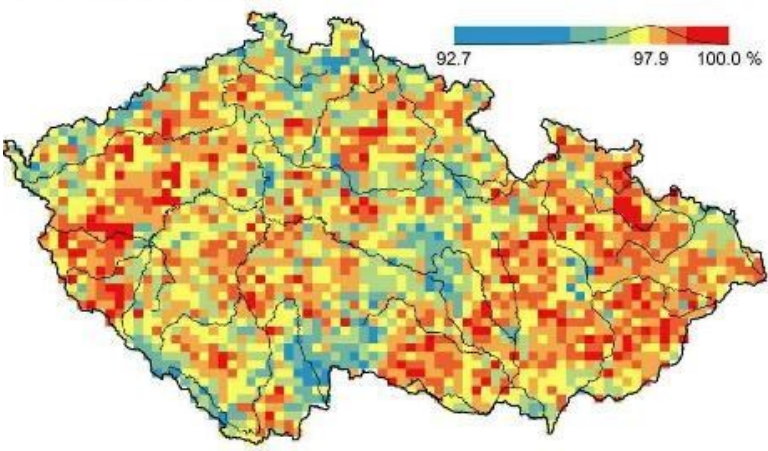

(b) Boreal zone

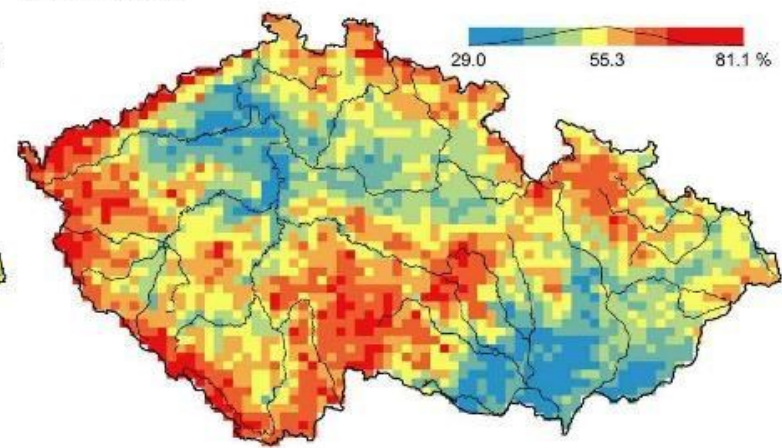

(d) Southern temperate zone

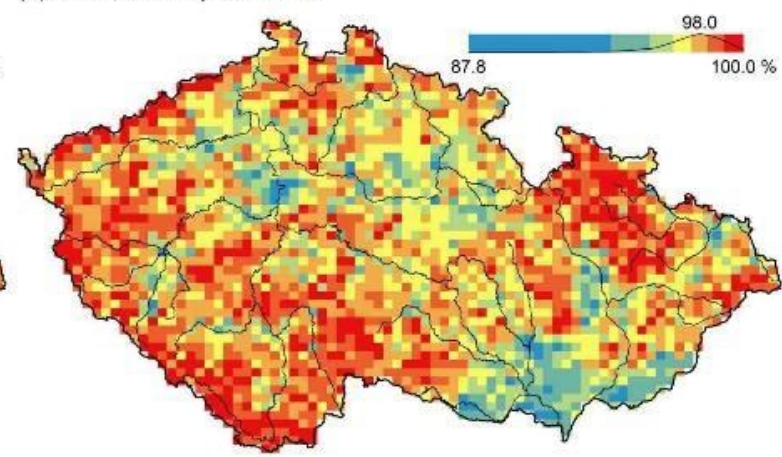

(f) Meridional zone

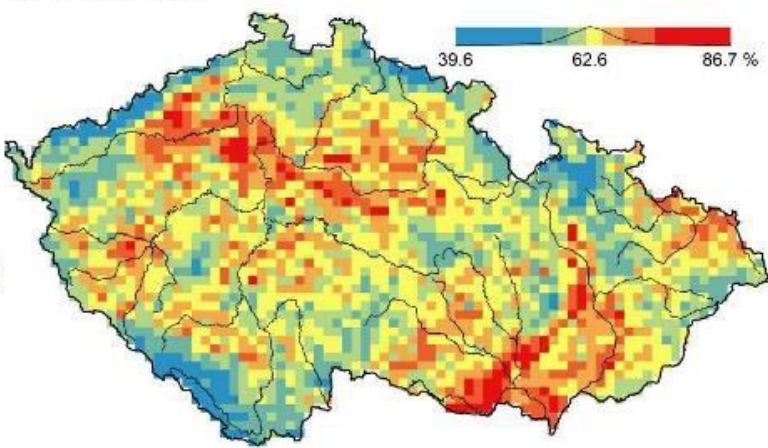

Fig. 31. - Proportion of species from different floristic zones in the Czech flora. Species from more northern zones tend to be concentrated at higher elevations, and vice versa.

\section{Floristic region}

The floristic region is reported as the continent or its part in which the taxon occurs according to the taxon range maps (Meusel et al. 1965, 1978, Meusel \& Jäger 1992). The categories are not discrete, and some of the regions can be included within broader regions (e.g. Western Siberia - Siberia - Asia). From a set of overlapping categories, the one that 
best matches the taxon geographic range or its part is reported. Data were taken from the BiolFlor database (Kühn \& Klotz 2002).

Categories

- Europe

- Europe-Western Asia

- Western Europe

- Eastern Europe

- Alps

- Carpathians

- Caucasus

- Asia
- Western Asia

- Asia Minor

- Near East

- Middle Asia

- Central Asia

- Siberia

- Western Siberia

- Eastern Asia

- Africa
- Eastern Africa

- Americas

- North America

- Eastern America

- Western America

- Greenland

- Australia, New

Zealand

- circumpolar

Data source and citation: Kühn \& Klotz (2002).

Continentality degree (Fig. 32a)

Continentality degree is derived from the position of taxon distribution range on the gradient from oceanic Western Europe to continental Middle Asia. The concept and data are taken from Berg et al. (2017), who revised and corrected a previous system of indicator values for continentality developed by Ellenberg et al. (1991). Higher values on the ordinal scale from 1 to 9 indicate taxa distributed in more continental areas. The taxa that extend over more than four regions assigned to different continentality classes as defined by Jäger (1968) are considered to be indifferent unless their lower continentality border is located in the regions assigned to continentality class 2 or higher.

Data source and citation: Berg et al. (2017).

Distribution range extension along the continentality gradient (Fig. 32b)

Extension of the taxon distribution range along the gradient of continentality from oceanic Western Europe to continental Middle Asia is expressed using the continentality classes 
defined for the Holarctic floristic kingdom by Jäger (1968). The value, ranging from 1 to 10, is the number of adjacent regions assigned to different continentality classes overlapping with the taxon range. Data were taken from Berg et al. (2017).

Data source and citation: Berg et al. (2017).
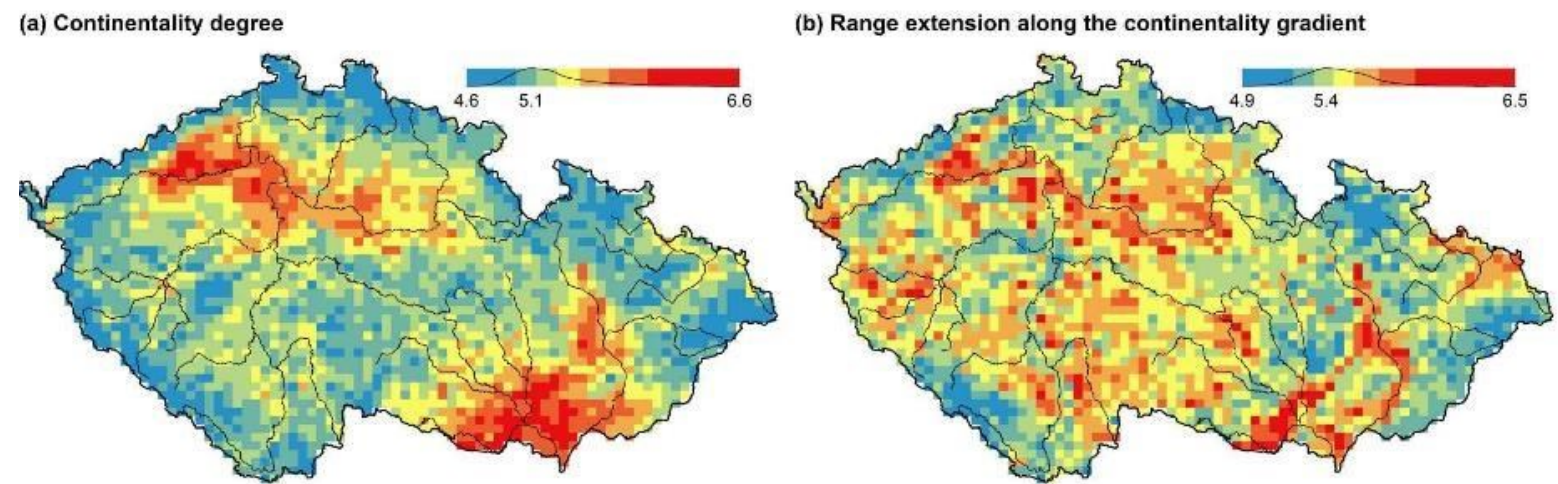

Fig. 32. - Mean continentality degree and mean range extension along the continentality gradient (number of adjacent regions) of species of the Czech flora. The highest mean degree of continentality is found in dry and warm forest-steppe regions of northern and central Bohemia and southern Moravia. The highest range extension along the continentality gradient is encountered in the flora along lowland rivers.

\section{Elevational belt in the Czech Republic}

The lowest and the highest elevational vegetation belt in which the taxon commonly occurs in the Czech Republic. For some taxa, also extremes are shown, i.e. elevational belts in which the taxon rarely occurs outside its main elevational range. The submontane belt comprises merged supracolline and submontane belts, and the montane belt comprises merged montane and supramontane belts according to the classification of elevational vegetation belts used in the Flora of the Czech Republic (Skalický 1988). Data are taken from the Key to the Flora of the Czech Republic (Kaplan et al. 2019a)

\section{Categories}

- lowlands

- colline belt

- submontane belt
- montane belt

- subalpine belt 
Data source and citation: Kaplan et al. (2019a).

Occurrence frequency in the basic grid mapping cells and in quadrants of the basic grid mapping cells

The number of basic grid mapping cells (Central European Basic Area, CEBA) and the number of quadrants of the Central European flora mapping in that the taxon has been recorded within the territory of the Czech Republic are generated dynamically from the current occurrence records in the species distribution module of the Pladias Database. The basic grid cells measure 10 minutes in the west-east direction and 6 minutes in the southnorth direction, which corresponds to approximately $12.0 \times 11.1 \mathrm{~km}\left(133.2 \mathrm{~km}^{2}\right)$ on the 50 th parallel. The Czech Republic comprises 679 basic cells, including incomplete cells on the state borders. The quadrants are the basic grid cells divided into four. They measure 5 minutes in the west-east direction and 3 minutes in the south-north direction, which corresponds to approximately $6.0 \times 5.55 \mathrm{~km}\left(33.3 \mathrm{~km}^{2}\right)$ on the 50 th parallel. Revised occurrence records marked as erroneous or uncertain are not counted.

Citation: Pladias. Database of the Czech flora and vegetation. - www.pladias.cz.

\section{Commonness in vegetation plots from the Czech Republic}

Measures of commonness in vegetation plots indicate taxon frequency in individual vegetation stands and the cover it attains. All these measures were quantified based on a set of vegetation plots representing all vegetation types of the Czech Republic, extracted from the Czech National Phytosociological Database (Chytrý \& Rafajová 2003) in March 2013. These plots were classified to phytosociological associations using the expert system developed in the project Vegetation of the Czech Republic (Chytrý 2007-2013). The plots not assigned to any association were deleted, and a subset of plots of each association was selected based on a geographical stratification that reduced the unbalanced numbers of plots from different regions. The following measures of commonness were computed from the resulting set of 30,115 vegetation plots classified to 496 associations: 
- Occurrence frequency in vegetation plots - percentage occurrence frequency calculated from all plots

- Occurrence frequency in vegetation plots with a cover above 5\% - percentage frequency of occurrence with a cover above $5 \%$ calculated from all taxon occurrences (plots in which the taxon was absent were not considered)

- Occurrence frequency in vegetation plots with a cover above $25 \%$ - percentage frequency of occurrence with a cover above $25 \%$ calculated from all taxon occurrences (plots in which the taxon was absent were not considered)

- Occurrence frequency in vegetation plots with a cover above $50 \%$ - percentage frequency of occurrence with a cover above $50 \%$ calculated from all taxon occurrences (plots in which the taxon was absent were not considered)

- Mean percentage cover in vegetation plots (plots in which the taxon was absent were not considered)

- Maximum percentage cover in vegetation plots

Citation: Chytrý M. (2016) Commonness in vegetation plots. - www.pladias.cz.

\section{Number of habitats with taxon occurrence in the Czech Republic}

The number of habitat types (habitats) in which the taxon occurs was counted based on the data from the Czech National Phytosociological Database (Chytrý \& Rafajová 2003) and their expert revision and completion, especially for rare and taxonomically problematic taxa. This number is a measure of the taxon's ecological range. The classification recognizes 88 basic habitats aggregated into 13 broader habitats that are defined by Sádlo et al. (2007: Appendix 1). The number of habitats is defined in four ways:

- Number of narrow habitats in which the taxon occurs - the number of habitats of the total number of 88 in which the taxon occurs; the taxon may or may not have its ecological optimum in these habitats

- Number of narrow habitats in which the taxon has its optimum - the number of habitats of the total number of 88 in which the taxon occurs and at the same time has its ecological optimum there (it may also be a dominant or constant dominant) 
- Number of broad habitats in which the taxon occurs - the number of habitats of the total number of 13 in which the taxon occurs; the taxon may but does not necessarily have its ecological optimum in these habitats

- Number of broad habitats in which the taxon has its optimum - the number of habitats of the total number of 13 in which the taxon occurs and at the same time has its ecological optimum there (it may also be a dominant or constant dominant)

Data source and citation: Sádlo et al. (2007).

\section{Threats and protection}

Red List 2017 (national categories) (Fig. 33)

National Red List categories are taken from the 2017 edition of the Red List of Vascular Plants of the Czech Republic (Grulich 2017). These categories, introduced in the previous editions of the Czech Red List, are different from the IUCN Red List categories. The main category " $\mathrm{A}$ " includes extinct or missing taxa, while the main category " $\mathrm{C}$ " includes endangered, near threatened and data deficient taxa.

\section{Categories}

- A1 - extinct taxon

- A2 - missing taxon

- A3 - extinct or missing taxon (uncertain case)

- $\mathrm{C} 1 \mathrm{r}$ - critically threatened taxon, rare

- $\mathrm{C} 1 \mathrm{t}$ - critically threatened taxon, declining

- $\mathrm{C} 1 \mathrm{~b}-$ critically threatened taxon, rare and declining

- $\mathrm{C} 2 \mathrm{r}$ - endangered taxon, rare

- $\mathrm{C} 2 \mathrm{t}$ - endangered taxon, declining

- $\mathrm{C} 2 \mathrm{~b}$ - endangered taxon, rare and declining

- $\mathrm{C} 3$ - vulnerable taxon

- $\mathrm{C} 4 \mathrm{a}$ - lower risk, near-threatened

- $\mathrm{C} 4 \mathrm{~b}$ - lower risk, data deficient 
- taxon is not on the Red List

Data source and citation: Grulich (2017).

(a) Critically threatened, rare

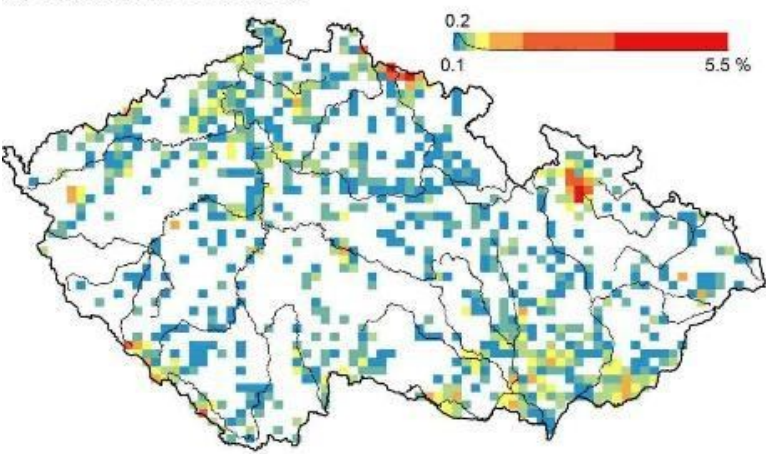

(c) Critically threatened, rare and declining

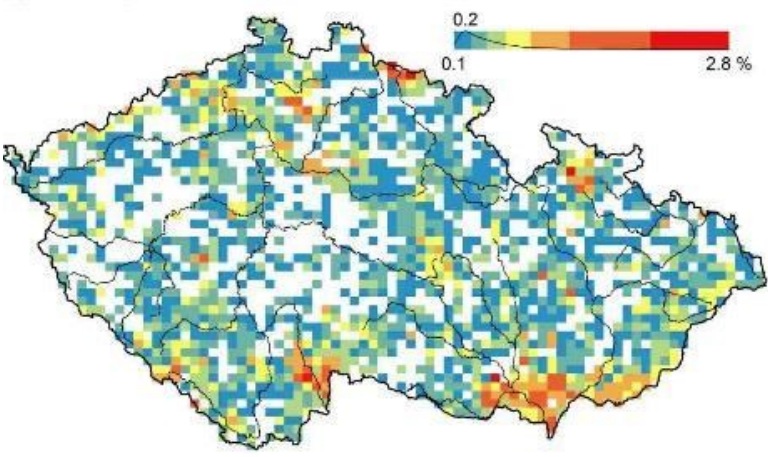

(e) Endangered, declining

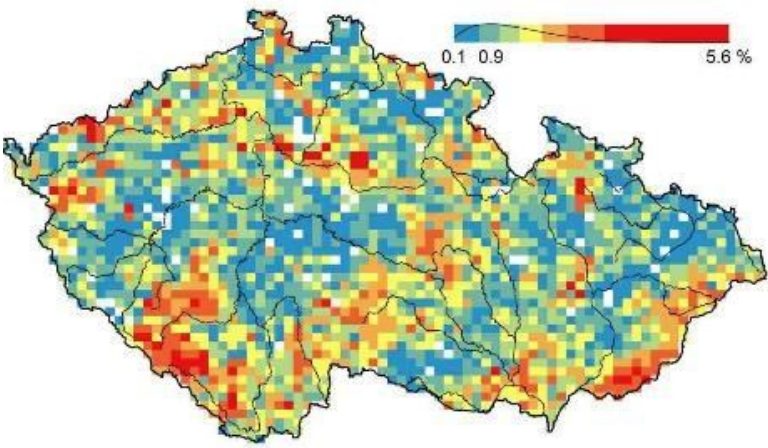

(b) Critically threatened, declining

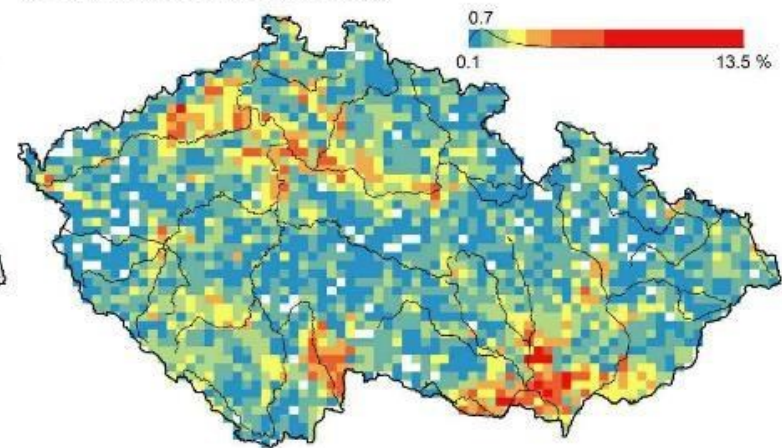

(d) Endangered, rare

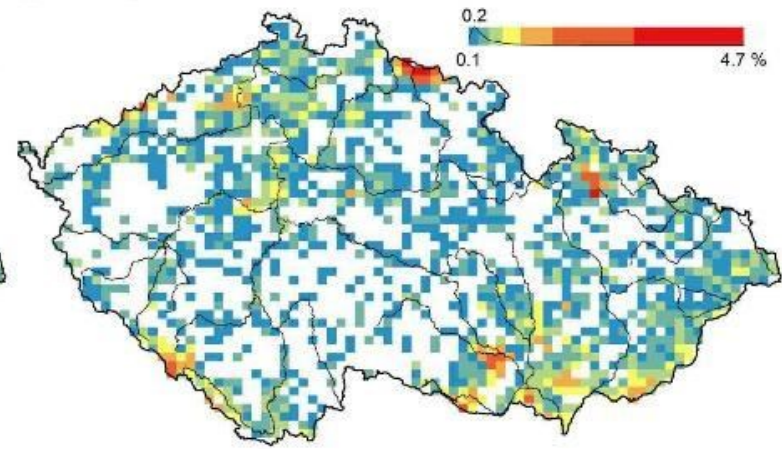

(f) Endangered, rare and declining

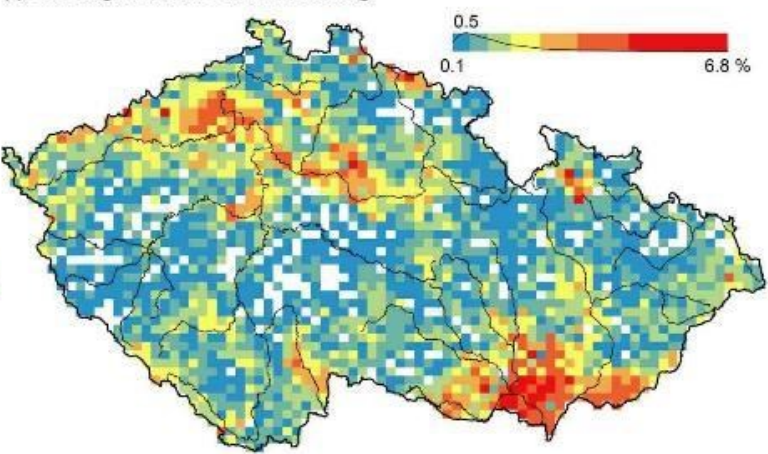

Fig. 33. - Proportion of the species in the national Red List categories Critically threatened (C1) and Endangered (C2) to the whole Czech flora. The species in both categories are divided into those threatened by being rare $(r)$, declining $(t)$ or both rare and declining $(b)$. Species threatened due to rarity are found mainly in the highest mountain groups of the Sudetes (Krkonoše and Hrubý Jeseník Mountains). Declining species are found mostly at middle elevations. In contrast, species threatened by both rarity and decline do not display 
any distinct pattern for critically threatened species but are remarkably concentrated in dry lowland areas for the endangered species.

\section{Red List 2017 (IUCN categories)}

International Red List categories defined by the IUCN are taken from the 2017 edition of the Red List of Vascular Plants of the Czech Republic (Grulich 2017). Taxon assignments to these categories follow the internationally accepted rules (IUCN 2012, 2014). To some extent, the definitions of these categories differ from the national categories used in the previous Czech Red Lists. The national Red List included only threatened or possibly threatened taxa, implying that the non-included taxa are not threatened. Therefore, the nonincluded taxa are classified here as LC(NA) - least concern (taxon is not on the Red List).

\section{Categories}

- $\mathrm{EX}-$ extinct

- $\mathrm{RE}$ - regionally extinct

- $\mathrm{CR}$ - critically endangered

- $\mathrm{EN}$ - endangered

- VU - vulnerable

- $\mathrm{NT}$ - near threatened
- LC - least concern

- $\quad$ LC(NA) - least concern (taxon is not on the Red List)

- DD - data deficient

- $\mathrm{NA}$ - not applicable

- $\mathrm{NE}$ - not evaluated

Data source and citation: Grulich (2017).

\section{Legal protection}

Legal protection in the Czech Republic concerns the specially protected species, i.e. rare taxa, threatened taxa and taxa significant from a cultural or scientific point of view that are listed in Annex II of the Decree of the Ministry of the Environment no. 395/1992. They comprise 487 taxa of vascular plants divided into three categories according to their vulnerability: critically threatened, endangered and vulnerable.

Categories

- critically threatened taxon

- endangered taxon 
- vulnerable taxon

- not protected by law

Data source and citation: Decree no. 395/1992 of the Ministry of the Environment of the Czech Republic.

\section{Summary of the patterns of plant traits in the Czech flora}

The geographic patterns of plant characteristics presented in the maps show a high degree of similarity among different characteristics. This may be caused by the correlation between the values of different characteristics within species. Such correlations suggest the existence of a limited number of viable combinations of plant traits, as indicated in an analysis of global plant trait spectra (Díaz et al. 2016). Here we provide a preliminary analysis of the main axes of trait variation in the Czech flora using ordination of the functional traits from the Pladias Database.

We used the data for species, disregarding the other taxonomic ranks, except for the genera Rubus and Taraxacum, in which we merged groups of numerous closely related species into sections. We selected the traits that are potentially functional, disregarding some morphological traits that have no apparent relationship to plant function, environmental associations and other characteristics. To obtain a more comprehensive picture, we added four traits from the LEDA database (Kleyer et al. 2008) that are not included in the Pladias Database but are often used in functional plant ecology (Westoby 1998): Leaf size, Specific leaf area (SLA), Leaf dry matter content (LDMC) and Seed mass. Data on the first two of these traits were supplemented by new measurements (Findurová 2018). Multi-state categorical variables were transformed into sets of variables with values ranging from 0 to 1 indicating to which extent a taxon exhibits each category (fuzzy coding). For some of those categorical traits, we merged detailed categories into broader descriptors (e.g. for pollination syndrome, we merged the categories Selfing, Cleistogamy, Pseudocleistogamy and Geitonogamy into Autogamy). We excluded the species that are extinct from the Czech flora, casual aliens and the species that are only cultivated in the country. The resulting matrix, used for the analysis, contained 2356 species and 69 numerical traits or individual binary variables representing the categories of multistate traits (Table 1). 
To summarize trait values and their correlations, we computed principal component analysis (PCA). The values of height, leaf size and 2C genome size were log-transformed before analysis to improve normality and homogeneity of variances. Each fuzzy-coded variable was standardized by the margin total (i.e. divided by the row sum of corresponding columns) to ensure the equal weight of individual species in the analysis. The PCA was based on centred and normalized data resulting in an equal weight of each trait (or column in fuzzy-coded variables) in the analysis. As PCA cannot handle missing data, missing values in the trait data matrix were replaced by the overall mean of the given trait. Although this approach involves artificial data imputation, it does not affect the correlation structure among traits. The PCA was computed using the "rda" function in the vegan package (version 2.5-6; Oksanen et al. 2019) in the R software (www.r-project.org). To visualize the main functional pattern in the Czech flora on the map, we used species composition within each geographic grid cell to calculate the average of species scores on the first two axes and plotted them on the map.

The main axis of trait variation (PC 1, Fig. 34) is associated with clonality: clonal herbs including hydrophytes are located on the positive side of the axis while annual non-clonal herbs occupy the negative side. The second axis (PC 2) is associated with plant size. Its negative side is associated with tall species, often trees and shrubs with large leaves and large seeds. In contrast, the positive side is characterized by herbaceous species with large specific leaf area, most of them annual terrestrial herbs or hydrophytes. Both PCA axes also show distinct geographical patterns (Fig. 35). Three contrasting specialized functional groups of the Czech flora can be recognized in the species graph of the first two PCA axes: (1) annual herbs located in the upper left part of the ordination space, (2) trees and shrubs in the lower part and (3) aquatic plants in the upper right part. Perennial herbs typically displaying trait values in between these specialized groups are located in the centre of the ordination space.

This analysis shows that the main pattern in functional trait variation across the Czech flora shares some features with the global flora analysis (Díaz et al. 2016), but there are also significant differences. The main axis of variation in the global dataset was related to the size of the whole plants and their parts, which we identified as the second trait axis. In the herb-dominated flora of the Czech Republic, we identified the importance of clonality and life span, which calls for more emphasis on these relatively understudied traits. Díaz et al. (2016) also identified the leaf economic spectrum as an important axis largely independent 
of plant size. By contrast, our analysis identified a strong correlation between leaf traits and plant size. Nevertheless, these patterns can be influenced by a different set of traits entered in the analysis and phylogenetic relationships, and they require further research.

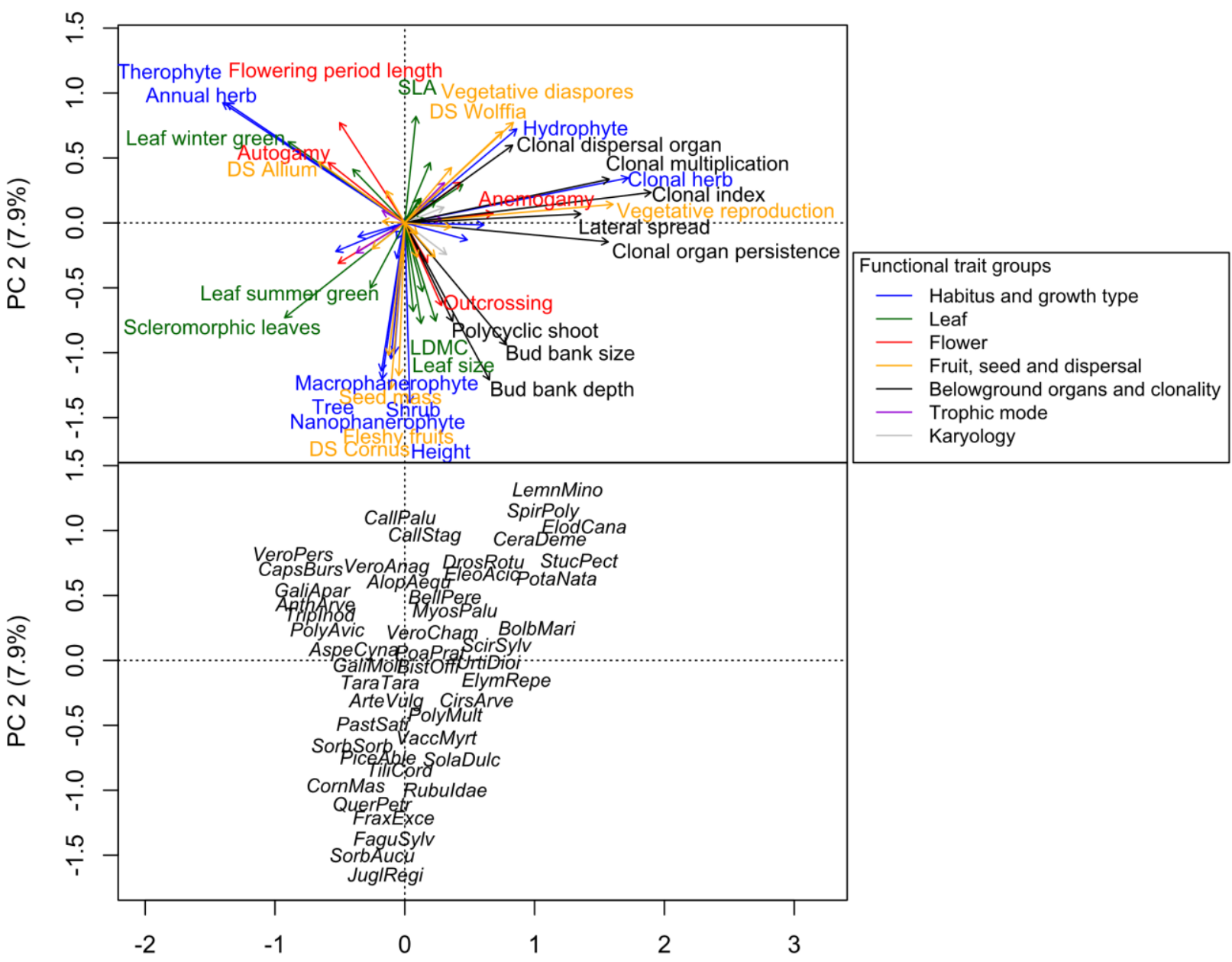

PC $1(9.7 \%)$

Figure 34. Principal component analysis (PCA) of species traits from the Pladias Database. Arrows represent the relation between the traits and the axes (PC 1 and PC 2). Traits reaching $\mathrm{r}^{2} \geq 0.1$ when regressed against the first two axes are labelled with their names. Species are represented based on their scores defined by the "orditorp" function which prevents illegibility by displaying only some of overlapping labels. Label priority was set according to the frequency of the given species in the Czech National Phytosociological Database. Species codes: AlopAequ $=$ Alopecurus aequalis, AnthArve $=$ Anthemis arvensis, ArteVulg = Artemisia vulgaris, AspeCyna $=$ Asperula cynanchica, BellPere $=$ Bellis 
perennis, BistOffi $=$ Bistorta officinalis, BolbMari $=$ Bolboschoenus maritimus, CallPalu $=$ Callitriche palustris, CallStag $=$ Callitriche stagnalis, CapsBurs $=$ Capsella bursa-pastoris, CeraDeme $=$ Ceratophyllum demersum, CirsArve $=$ Cirsium arvense, CornMas $=$ Cornus mas, DrosRotu $=$ Drosera rotundifolia, EleoAcic $=$ Eleocharis acicularis, ElodCana $=$ Elodea canadensis, ElymRepe $=$ Elymus repens, FaguSylv $=$ Fagus sylvatica, FraxExce $=$ Fraxinus excelsior, GaliApar = Galium aparine, GaliMoll = Galium mollugo, JuglRegi $=$ Juglans regia, LemnMino $=$ Lemna minor, MyosPalu $=$ Myosotis palustris, PastSati $=$ Pastinaca sativa, PiceAbie $=$ Picea abies, PoaPrat $=$ Poa pratensis, PolyMult $=$ Polygonatum multiflorum, PolyAvic = Polygonum aviculare, PotaNata $=$ Potamogeton natans, QuerPetr $=$ Quercus petraea, RubuIdae $=$ Rubus idaeus, ScirSylv $=$ Scirpus sylvaticus, SolaDulc $=$ Solanum dulcamara, SorbSorb $=$ Sorbaria sorbifolia, SorbAucu $=$ Sorbus aucuparia, SpirPoly = Spirodela polyrhiza, StucPect $=$ Stuckenia pectinata, TiliCord $=$ Tilia cordata, TripInod $=$ Tripleurospermum inodorum, UrtiDioi $=$ Urtica dioica, VaccMyrt = Vaccinium myrtillus, VeroAnag $=$ Veronica anagallis-aquatica, VeroCham $=$ Veronica chamaedrys, VeroPers $=$ Veronica persica, TaraTara $=$ Taraxacum sect. Taraxacum.

(a) PCA axis 1

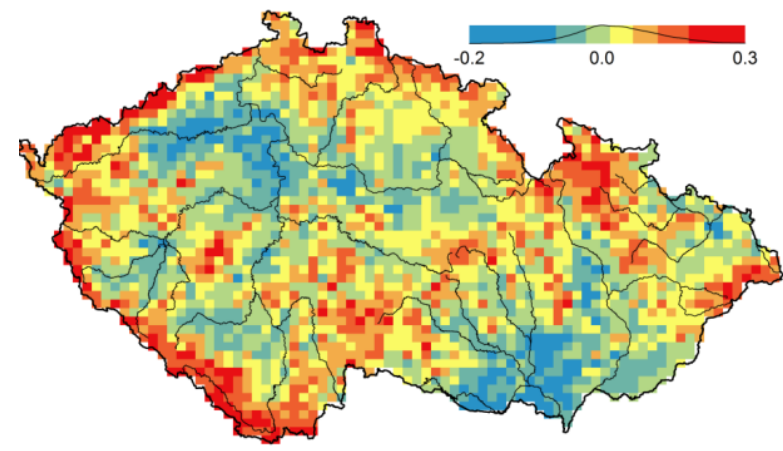

(b) PCA axis 2

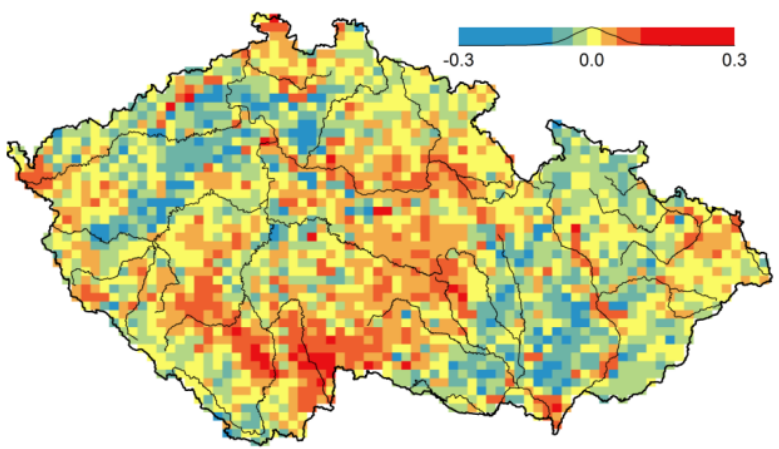

Fig. 35. - Mean scores of species on the first two axes of principal component analysis (PC 1 and PC 2, compare Fig. 34). The first axis shows mainly the contrast between annual herbs vs perennial clonal herbs (compare Fig. 3), the former being frequent in dry and warm lowlands (blue) and the latter prevalent in the mountains (red). The second axis shows the contrast between large species, often woody plants with large leaves and heavy seeds, which are more common in non-wetland landscapes (blue) $v s$ small species with large specific leaf area (often annuals and aquatic plants), which are more common in wetland landscapes (both large river floodplains and pond basins; red). 


\section{Outlook}

The Pladias Database is the first comprehensive compilation of critically revised botanical data for the Czech Republic. It is internationally unique in that it integrates huge amounts of very detailed data on distributions, traits, and environmental associations of vascular plant taxa. The database has facilitated systematic mapping of plant distributions in the country (Kaplan et al. 2015, 2016a, b, 2017a, b, 2018a, b, 2019b, 2020) and numerous studies analysing biological and ecological plant traits performed within the Pladias project. Although the Pladias project was finished on 31 December 2018, the database infrastructure is further maintained and improved by the three institutions involved in its development. New data continue to be added and critically revised by experts, including external collaborators. The Pladias project also stimulated the development of the Database of Lichens and Bryophytes - DaLiBor, which has already integrated almost 600,000 occurrence records from the Czech Republic. DaLiBor uses the Pladias database infrastructure but is further developed separately to fulfil the specific requirements of bryologists and lichenologists. Nevertheless, shared database structure and software routines allow future integration and joint analyses.

Integration of various data on plant distributions, traits, plant environmental associations and vegetation types in a single platform provides unique opportunities for testing ecological hypotheses that could not be tested earlier and addressing entirely new research questions. The database also has enormous potential for applications, especially in biodiversity conservation. Last but not least, the data are also available for international collaboration.

\section{Acknowledgements}

The Pladias Database integrates data meticulously collected over more than two centuries by hundreds of field botanists. In particular, we thank our colleagues who contributed to species distribution mapping, including Lenka Bálková, Martina Bartošová, Jiří Bělohoubek, Jan Blahovec, Karel Boublík, Jiří Brabec, Leo Bureš, Petr Bureš, Roman Businský, Kryštof Chytrý, Luděk Čech, Alžběta Čejková, Martin Četner, Martin Dančák, Jan Doležal, Michal Ducháček, Martin Duchoslav, Martin Dýma, Václav Dvořák, Libor Ekrt, Ester Ekrtová, Karel Fajmon, Petr Filippov, Jaroslava Fojtíková, Irena Formanová, Hana Galušková, Michal Gerža, Michal Hájek, Miloš Hájek, Vladimír Hans, Martin Hanzl, Rudolf Hlaváček, David Hlisnikovský, David Horák, Ondřej Hornych, Věra Hromádková, Michal Hroneš, Zdenka Hroudová, Petr Hubatka, Jana Janáková, Vladimír Jehlík, 
Boleslav Jelínek, Jaroslav Jirásek, Jan W. Jongepier, Vít Joza, Petra Juřáková, Jiří Juřička, Nikol Kantorová, Jan Kirschner, Ondřej Knápek, Lucie Kobrlová, Jiří Kocián, Petr Kocián, Josef Komárek, Jan Košnar, Milan Kotilínek, Daniel Koutecký, Petr Koutecký, František Krahulec, Karel Kubát, Josef Kučera, Pavel Kúr, Martin Lepší, Petr Lepší, Pavel Lustyk, Jiří Maliček, Milan Marek, Vladimír Melichar, Lenka Moravcová, Jana Möllerová, Patrik Mráz, Zuzana Mruzíková, Pavel Novák, Klára Nunvářová Kabátová, Čestmír Ondráček, Radim Paulič, Tomáš Peterka, Lenka Pivoňková, Jan Prančl, Romana Prausová, David Půbal, Olga Rotreklová, Zdenka Rozbrojová, Radomír Řepka, Věra Samková, Milan Skalický, Hana Skálová, Ivan Suchara, Tomáš Svačina, Lenka Šafářová, Ota Šída, Lenka Šoltysová, Martin Šrámek, Michal Štefánek, Radek Štencl, Jitka Štěpánková, Martin Št’astný, Kateřina Šumberová, Přemysl Tájek, Vojtěch Taraška, Tomáš Tichý, Bohumil Trávníček, Linda Trunečková, Radim J. Vašut, Michal Vávra, Jiř́i Velebil, Michaela Vítková, Alena Vydrová, Jaroslav Zámečník and Jiř́ Zázvorka. Contributions to species-trait datasets and valuable technical support were provided by Alexandra Březinová, Josef Brůna, Karel Chobot, Kryštof Chytrý, Jan Divíšek, Anna Findurová, Hana Galušková, Ondřej Hájek, Vladimír Hans, Ludmila Harčariková, Lucie Horová, Katrin Karimová, Anna Kladivová, Ondřej Knápek, Ilona Knollová, Adam Knotek, Eva Koutecká, Petra Lovecká, Ludmila Mikovcová, Klára Nunvářová Kabátová, Dominika Prajzlerová, Lucie Rejchrtová, Jiř́i Rozehnal, Klára Řehounková, Zuzana Sixtová, Lucie Šmejdová, Jan Štěpánek, Václav Šulc, Kristýna Vazačová, Pavel Veselý, Kamila Vítovcová, Jiř́ Zázvorka, Václav Zouhar and many others. Tomáš Kebert participated in programming the new version of the Pladias website launched in September 2020. We thank Jens Kattge for helpful comments on a previous version of the manuscript and on the Pladias website. The Pladias Database of Czech Flora and Vegetation was developed by the Centre of Excellence Pladias, funded by the Czech Science Foundation in 2014-2018 (Centre of Excellence Pladias, project no. 14-36079G). Further funding after the year 2018 came from the institutional funding of Masaryk University (MC, JD, DH, MŘ, PD, VG, ZL, PŠm, PŠt, LT, IA, FMF, HP, JT and MV), Institute of Botany of the Czech Academy of Sciences (project no. RVO 67985939; JD, ZK, JW, JP, JS, JCh, WYGm TH, ZJ, LM, PPe and PPy) and the University of South Bohemia (JL, PB, MK, KP, MŠ and TT). Development of the affiliated DaLiBor database was supported by the Technology Agency of the Czech Republic (project no. TH02030644).

\section{Author contributions}

MC, PPy and JL coordinated the Pladias project at the three partner institutions. JW coordinated programming and database software management, ZK and JD coordinated taxonomic backbone and distribution mapping, with contributions from JW. MC coordinated the preparation of the trait data, vegetation data and public portal. PN and MR programmed the database software and the website. DH designed the first version of the website and collected the image database. MŘ technically managed the preparation of the trait data and the public portal. IA, AB, PB, JC, MC, PD, VG, WYG, TH, DH, ZJ, MK, IK, JK, JL, ZL, LM, JP, SP, KP, HP, PPy, MŘ, JS, PŠm, PŠt, MŠ, JT, TT, LT and DZ prepared different parts of the data on plant characteristics. LT developed the identification key for vegetation types. JK provided original drawings of belowground plant organs. JD and PŠt prepared the electronic version of the Flora of the Czech Republic. JD and PPe prepared bibliographies. MV prepared the maps used in this paper. JT, FMF and IA performed the PCA analysis. 


\section{References}

Bartušková A., Malíková L. \& Klimešová J. (2017) Checklist of root-sprouters in the Czech flora: mapping the gaps in our knowledge. - Folia Geobotanica 52: 337-343.

Bennett M. D. (1987) Variation in genomic form in plants and its ecological implications. - New Phytologist 106 (Suppl.): 177-200.

Benson D. R. (2016) Frankia \& actinorhizal plants. http://web.uconn.edu/mcbstaff/benson/Frankia/FrankiaHome.htm (accessed on 28 Apr 2016).

Berg C., Welk E. \& Jäger E. J. (2017) Revising Ellenberg's indicator values for continentality based on global vascular plant species distribution. - Applied Vegetation Science 20: 482-493.

Bjorkman A. D., Myers-Smith I. H., Elmendorf S. C., Normand S., Thomas H. J. D., Alatalo J. M., Alexander H., Anadon-Rosell A., Angers-Blondin S., Bai Y., Baruah G., Beest M. te, Berner L., Björk R. G., Blok D., Bruelheide H., Buchwal A., Buras A., Carbognani M., Christie K., Collier L. S., Cooper E. J., Cornelissen J. H. C., Dickinson K. J. M., Dullinger S., Elberling B., Eskelinen A., Forbes B. C., Frei E. R., IturrateGarcia M., Good M. K., Grau O., Green P., Greve M., Grogan P., Haider S., Hájek T., Hallinger M., Happonen K., Harper K. A., Heijmans M. M. P. D., Henry G. H. R., Hermanutz L., Hewitt R. E., Hollister R. D., Hudson J., Hülber K., Iversen C. M., Jaroszynska F., Jiménez-Alfaro B., Johnstone J., Jorgensen R. H., Kaarlejärvi E., Klady R., Klimešová J., Korsten A., Kuleza S., Kulonen A., Lamarque L. J., Lantz T., Lavalle A., Lembrechts J. J., Lévesque E., Little C. J., Luoto M., Macek P., Mack M. C., Mathakutha R., Michelsen A., Milbau A., Molau U., Morgan J. W., Mörsdorf M. A., Nabe-Nielsen J., Nielsen S. S., Ninot J. M., Oberbauer S. F., Olofsson J., Onipchenko V. G., Petraglia A., Pickering C., Prevéy J. S., Rixen C., Rumpf S. B., Schaepman-Strub G., Semenchuk P., Shetti R., Soudzilovskaia N. A., Spasojevic M. J., Speed J. D. M., Street L. E., Suding K., Tape K. D., Tomaselli M., Trant A., Treier U. A., Tremblay J.-P., Tremblay M., Venn S., Virkkala A.-M., Vowles T., Weijers S., Wilmking M., Wipf S. \& Zamin T. (2018) Tundra Trait Team: A database of plant traits spanning the tundra biome. - Global Ecology and Biogeography 27: 1402-1411.

Bond G. (1983) Taxonomy and distribution of non-legume nitrogen-fixing systems. - In: Gordon J. C. \& Wheeler C. T. (eds), Biological nitrogen fixation in forests: foundations and applications, p. 55-87, Martinus Nijhoff/Dr W. Junk Publ., The Hague.

Botta-Dukát Z. (2012) Co-occurrence-based measure of species' habitat specialization: robust, unbiased estimation in saturated communities. - Journal of Vegetation Science 23: 201-207.

Bruelheide H., Dengler J., Purschke O., Lenoir J., Jiménez-Alfaro B., Hennekens S. M., Botta-Dukát Z., Chytrý M., Field R., Jansen F., Kattge J., Pillar V. D., Schrodt F., Mahecha M. D., Peet R. K., Sandel B., Bodegom P. van, Altman J., Alvarez-Dávila E., Arfin Khan M. A. S., Attorre F., Aubin I., Baraloto C., Barroso J. G., Bauters M., Bergmeier E., Biurrun I., Bjorkman A. D., Blonder B., Čarni A., Cayuela L., Černý T., Cornelissen J. H. C., Craven D., Dainese M., Derroire G., De Sanctis M., Díaz S., Doležal J., Farfan-Rios W., Feldpausch T. R., Fenton N. J., Garnier E., Guerin G. R., Gutiérrez A. G., Haider S., Hattab T., Henry G., Hérault B., Higuchi P., Hölzel N., Homeier J., Jentsch A., Jürgens N., Kącki Z., Karger D. N., Kessler M., Kleyer M., Knollová I., Korolyuk A. Y., Kühn I., Laughlin D. C., Lens F., Loos 
J., Louault F., Lyubenova M. I., Malhi Y., Marcenò C., Mencuccini M., Müller J. V., Munzinger J., MyersSmith I. H., Neill D. A., Niinemets Ü., Orwin K. H., Ozinga W. A., Penuelas J., Pérez-Haase A., Petř́ik P., Phillips O. L., Pärtel M., Reich P. B., Römermann C., Rodrigues A. V., Sabatini F. M., Sardans J., Schmidt M., Seidler G., Silva Espejo J. E., Silveira M., Smyth A., Sporbert M., Svenning J.-C., Tang Z., Thomas R., Tsiripidis I., Vassilev K., Violle C., Virtanen R., Weiher E., Welk E., Wesche K., Winter M., Wirth C. \& Jandt U. (2018) Global trait-environment relationships of plant communities. - Nature Ecology \& Evolution 2: 1906-1917.

Bruelheide H., Dengler J., Jiménez- Alfaro B., Purschke O., Hennekens S. M., Chytrý M., Pillar V. D., Jansen F., Kattge J., Sandel B., Aubin I., Biurrun I., Field R., Haider S., Jandt U., Lenoir J., Peet R. K., Peyre G., Sabatini F. M., Schmidt M., Schrodt F., Winter M., Aćić S., Agrillo E., Alvarez M., Ambarlı D., Angelini P., Apostolova I., Arfin Khan M. A. S., Arnst E., Attorre F., Baraloto C., Beckmann M., Berg C., Bergeron Y., Bergmeier E., Bjorkman A. D., Bondareva V., Borchardt P., Botta-Dukát Z., Boyle B., Breen A., Brisse H., Byun C., Cabido M. R., Casella L., Cayuela L., Černý T., Chepinoga V., Csiky J., Curran M., Ćušterevska R., Dajić Stevanović Z., De Bie E., Ruffray P. D., Sanctis M. D., Dimopoulos P., Dressler S., Ejrnæs R., El- Sheikh M. A. E.-R. M., Enquist B., Ewald J., Fagúndez J., Finckh M., Font X., Forey E., Fotiadis G., García- Mijangos I., Gasper A. L. de, Golub V., Gutierrez A. G., Hatim M. Z., He T., Higuchi P., Holubová D., Hölzel N., Homeier J., Indreica A., Işık Gürsoy D., Jansen S., Janssen J., Jedrzejek B., Jiroušek M., Jürgens N., Kącki Z., Kavgacı A., Kearsley E., Kessler M., Knollová I., Kolomiychuk V., Korolyuk A., Kozhevnikova M., Kozub Ł., Krstonošić D., Kühl H., Kühn I., Kuzemko A., Küzmič F., Landucci F., Lee M. T., Levesley A., Li C.-F., Liu H., Lopez-Gonzalez G., Lysenko T., Macanović A., Mahdavi P., Manning P., Marcenò C., Martynenko V., Mencuccini M., Minden V., Moeslund J. E., Moretti M., Müller J. V., Munzinger J., Niinemets Ü., Nobis M., Noroozi J., Nowak A., Onyshchenko V., Overbeck G. E., Ozinga W. A., Pauchard A., Pedashenko H., Peñuelas J., Pérez-Haase A., Peterka T., Petřík P., Phillips O. L., Prokhorov V., Rašomavičius V., Revermann R., Rodwell J., Ruprecht E., Rūsiņa S., Samimi C., Schaminée J. H. J., Schmiedel U., Šibík J., Šilc U., Škvorc Ž., Smyth A., Sop T., Sopotlieva D., Sparrow B., Stančić Z., Svenning J.-C., Swacha G., Tang Z., Tsiripidis I., Turtureanu P. D., Uğurlu E., Uogintas D., Valachovič M., Vanselow K. A., Vashenyak Y., Vassilev K., Vélez-Martin E., Venanzoni R., Vibrans A. C., Violle C., Virtanen R., Wehrden H. von, Wagner V., Walker D. A., Wana D., Weiher E., Wesche K., Whitfeld T., Willner W., Wiser S., Wohlgemuth T., Yamalov S., Zizka G. \& Zverev A. (2019) sPlot - a new tool for global vegetation analyses. - Journal of Vegetation Science 30: 161-186.

Bureš P., Zedek F. \& Marková M. (2013) Holocentric chromosomes. - In: Leitch I. J., Greilhuber J., Wendel J. \& Wendel J. (eds), Plant genome diversity. Vol. 2. Physical structure, behaviour and evolution of plant genomes, p. 187-208, Springer, Wien.

Castroviejo, S., Laínz M., López González G., Montserrat P., Muñoz Garmendia F., Paiva J. \& Villar L. (eds) (1986) Flora Iberica. Plantas vasculares de la Península Ibérica e Islas Baleares. - Real Jardín Botánico, Madrid.

Chytrý M. (ed.) (2007-2013) Vegetace České republiky 1-4 [Vegetation of the Czech Republic 1-4]. Academia, Praha. 
Chytrý M. (2017) Physical geography of the Czech Republic. - In: Chytrý M., Danihelka J., Kaplan Z. \& Pyšek P. (eds), Flora and vegetation of the Czech Republic, p. 1-23, Springer International Publishing, Cham.

Chytrý M. \& Rafajová M. (2003) Czech National Phytosociological Database: basic statistics of the available vegetation-plot data. - Preslia 75: 1-15.

Chytrý M. \& Tichý L. (2003) Diagnostic, constant and dominant species of vegetation classes and alliances of the Czech Republik: a statistical revision. - Folia Facultatis Scientiarum Naturalium Universitatis Masarykianae Brunensis, Biologia, 108: 1-231.

Chytrý M., Pyšek P., Tichý L., Knollová I. \& Danihelka J. (2005) Invasions by alien plants in the Czech Republic: a quantitative assessment across habitats. - Preslia 77: 339-354.

Chytrý M., Wild J., Pyšek P., Tichý L., Danihelka J. \& Knollová I. (2009) Maps of the level of invasion of the Czech Republic by alien plants. - Preslia 81: 187-207.

Chytrý M., Hennekens S. M., Jiménez-Alfaro B., Knollová I., Dengler J., Jansen F., Landucci F., Schaminée J. H. J., Aćić S., Agrillo E., Ambarlı D., Angelini P., Apostolova I., Attorre F., Berg C., Bergmeier E., Biurrun I., Botta-Dukát Z., Brisse H., Campos J. A., Carlón L., Čarni A., Casella L., Csiky J., Ćušterevska R., Dajić Stevanović Z., Danihelka J., De Bie E., Ruffray P. de, De Sanctis M., Dickoré W. B., Dimopoulos P., Dubyna D., Dziuba T., Ejrnaes R., Ermakov N., Ewald J., Fanelli G., Fernández-González F., FitzPatrick Ú., Font X., García-Mijangos I., Gavilán R. G., Golub V., Guarino R., Haveman R., Indreica A., Işık Gürsoy D., Jandt U., Janssen J. A. M., Jiroušek M., Kącki Z., Kavgacı A., Kleikamp M., Kolomiychuk V., Krstivojević Ćuk M., Krstonošić D., Kuzemko A., Lenoir J., Lysenko T., Marcenò C., Martynenko V., Michalcová D., Moeslund J. E., Onyshchenko V., Pedashenko H., Pérez-Haase A., Peterka T., Prokhorov V., Rašomavičius V., Rodríguez-Rojo M. P., Rodwell J. S., Rogova T., Ruprecht E., Rūsiņa S., Seidler G., Šibík J., Šilc U., Škvorc Ž., Sopotlieva D., Stančić Z., Svenning J.-C., Swacha G., Tsiripidis I., Turtureanu P. D., Uğurlu E., Uogintas D., Valachovič M., Vashenyak Y., Vassilev K., Venanzoni R., Virtanen R., Weekes L., Willner W., Wohlgemuth T. \& Yamalov S. (2016) European Vegetation Archive (EVA): an integrated database of European vegetation plots. - Applied Vegetation Science 19: 173-180.

Chytrý M., Tichý L., Dřevojan P., Sádlo J. \& Zelený D. (2018) Ellenberg-type indicator values for the Czech flora. - Preslia 90: 83-103.

Danihelka J., Chrtek J. Jr. \& Kaplan Z. (2012) Checklist of vascular plants of the Czech Republic. - Preslia 84: 647-811.

Danihelka J., Chytrý M., Kučera J. \& Palice Z. (2017) History of botanical research in the Czech Republic. In: Chytrý M., Danihelka J., Kaplan Z. \& Pyšek P. (eds), Flora and vegetation of the Czech Republic, p. 25-87, Springer International Publishing, Cham.

Dayrell R. L., Arruda A. J., Pierce S., Negreiros D., Meyer P. B., Lambers H. \& Silveira F. A. (2018) Ontogenetic shifts in plant ecological strategies. - Functional Ecology 32: 2730-2741.

Dengler J., Jansen F., Glöckler F., Peet R. K., De Cáceres M., Chytrý M., Ewald J., Oldeland J., LopezGonzalez G., Finckh M., Mucina L., Rodwell J. S., Schaminée J. H. J. \& Spencer N. (2011) The Global Index of Vegetation-Plot Databases (GIVD): a new resource for vegetation science. - Journal of Vegetation Science 22: 582-597. 
Díaz S., Kattge J., Cornelissen J. H. C., Wright I. J., Lavorel S., Dray S., Reu B., Kleyer M., Wirth C., Prentice I. C., Garnier E., Bönisch G., Westoby M., Poorter H., Reich P. B., Moles A. T., Dickie J., Gillison A. N., Zanne A. E., Chave J., Joseph Wright S., Sheremet'ev S. N., Jactel H., Baraloto C., Cerabolini B., Pierce S., Shipley B., Kirkup D., Casanoves F., Joswig J. S., Günther A., Falczuk V., Rüger N., Mahecha M. D. \& Gorné L. D. (2016) The global spectrum of plant form and function. - Nature 529: 167-171.

Dierschke H. (1995) Phänologische and symphänologische Artengruppen von Blütenpflanzen in Mitteleuropa. - Tuexenia 15: 523-560.

Durka W. (2002) Blüten- und Reproduktionsbiologie. - In: Klotz S., Kühn I. \& Durka W. (eds), BIOLFLOR Eine Datenbank mit biologisch-ökologischen Merkmalen zur Flora von Deutschland, Schriftenreihe für Vegetationskunde 38: 133-175.

Edwards J. L., Lane M. A. \& Nielsen E. S. (2000) Interoperability of biodiversity databases: biodiversity Information on every desktop. - Science 289: 2312-2314.

Ellenberg H. (1979) Zeigerwerte der Gefäßpflanzen Mitteleuropas. 2. Aufl. - Scripta Geobotanica 9: 1-122.

Ellenberg H., Weber H. E., Düll R., Wirth V., Werner W. \& Paulißen D. (1991) Zeigerwerte von Pflanzen in Mitteleuropa. - Scripta Geobotanica 18: 1-248.

Enquist B. J., Condit R., Peet R. K., Schildhauer M. \& Thiers B. M. (2016) Cyberinfrastructure for an integrated botanical information network to investigate the ecological impacts of global climate change on plant biodiversity. - PeerJ Preprints 4: e2615v2.

Findurová A. (2018) Variabilita listových znaků SLA a LDMC vybraných druhů rostlin České republiky [Variability of leaf traits SLA and LDMC in selected species of the Czech flora]. - Master thesis, Masaryk University, Brno.

Fitter A. H. \& Peat H. J. (1994) The Ecological Flora Database. - Journal of Ecology 82: 415-425.

Flora of North America Editorial Committee (eds) (1993) Flora of North America North of Mexico. - Oxford University Press, New York.

Fridley J. D., Vandermast D. B., Kuppinger D. M., Manthey M. \& Peet R. K. (2007) Co-occurrence based assessment of habitat generalists and specialists: a new approach for the measurement of niche width. Journal of Ecology 95: 707-722.

Garnier E., Stahl U., Laporte M.-A., Kattge J., Mougenot I., Kühn I., Laporte B., Amiaud B., Ahrestani F.S., Bönisch G., Bunker D.E., Cornelissen J.H.C., Díaz S., Enquist B.J., Gachet S., Jaureguiberry P., Kleyer M., Lavorel S., Maicher L., Pérez-Harguindeguy N., Poorter H., Schildhauer M., Shipley B., Violle C., Weiher E., Wirth C., Wright I.J. \& Klotz S. (2017) Towards a thesaurus of plant characteristics: an ecological contribution. - Journal of Ecology 105: 298-309.

Greilhuber J. \& Leitch I. J. (2013) Genome size and the phenotype. - In: Leitch I. J., Greilhuber J., Doležel J. \& Wendel J. (eds), Plant genome diversity. Vol. 2. Physical structure, behaviour and evolution of plant genomes, p. 323-344, Springer, Wien.

Greilhuber J., Doležel J., Lysák M. A. \& Bennett M. D. (2005) The origin, evolution and proposed stabilization of the terms 'genome size' and 'C-value' to describe nuclear DNA content. - Annals of Botany 95: 255-260.

Grime J. P. (1974) Vegetation classification by reference to strategies. - Nature 250: 26-31.

Grime J. P. (1979) Plant strategies and vegetation processes. - Wiley, Chichester. 
Grime J. P., Hodgson J. G. \& Hunt R. (eds) (2007) Comparative plant ecology: A functional approach to common British species. 2nd edition. - Castlepoint Press, Colvend, Dalbeattie.

Groff P. A. \& Kaplan D. R. (1988) The relation of root systems to shoot systems in vascular plants. - Botanical Review 54: 387-422.

Grulich V. (eds) (2017) Červený seznam cévnatých rostlin ČR [The Red List of vascular plants of the Czech Republic]. - Př́roda 35: 75-132.

Guo W.- Y., van Kleunen M, Pierce S., Dawson W., Essl F., Kreft H., Maurel N., Pergl P., Seebens H., Weigelt P. \& Pyšek P. (2019) Domestic gardens play a dominant role in selecting alien species with adaptive strategies that facilitate naturalization. - Global Ecology and Biogeography 28: 628-639.

Heinken T., Diekmann M., Liira J., Orczewska A., Brunet J., Chytrý M., Chabrerie O., de Frenne P., Decoq G., Dřevojan P., Dzwonko Z., Ewald J., Feilberg J., Graae B. J., Grytnes J. A., Hermy M., Kriebitzsch W.-U., Laivins M., Lindmo S., Marage D., Marozas V., Meirland A., Niemeyer T., Paal J., Pyšek P., Roosaluste E., Sádlo J., Schaminée J., Schmidt M., Tyler T., Verheyen K. \& Wulf M. (2019) European forest plant species list. - Fighshare. https://doi.org/10.6084/m9.figshare.8095217.v1.

Hejný S., Slavík B., Chrtek J., Tomšovic P. \& Kovanda M. (eds) (1988) Květena České socialistické republiky [Flora of the Czech Socialist Republic]. Vol. 1. - Academia, Praha.

Hennekens S. M. \& Schaminée J. H. J. (2001) TURBOVEG, a comprehensive data base management system for vegetation data. - Journal of Vegetation Science 12: 589-591.

Herben T., Chytrý M. \& Klimešová J. (2016) A quest for species-level indicator values for disturbance. Journal of Vegetation Science 27: 628-636.

Hulme P. E., Bacher S., Kenis M., Klotz S., Kühn I., Minchin D., Nentwig W., Olenin S., Panov V., Pergl J., Pyšek P., Roques A., Sol D., Solarz W. \& Vilà M. (2008) Grasping at the routes of biological invasions: a framework for integrating pathways into policy. - Journal of Applied Ecology 45: 403-414.

IUCN (2012) Guidelines for application of IUCN Red List criteria at regional and national levels. Version 4.0. - IUCN, Gland.

IUCN (2014) Guidelines for using the IUCN Red List categories and criteria. Version 11. - IUCN, Gland.

Jäger E. J. (1968) Die pflanzengeographische Ozeanitätsgliederung der Holarktis und die Ozeanitätsbindung der Pflanzenareale. - Feddes Repertorium 79: 157-335.

Jäger E. J. \& Werner K. (eds) (2000) Rothmaler, Exkursionsflora von Deutschland. Band 3. Gefäßpflanzen: Atlasband. Ed. 10. - Spectrum Akademischer Verlag, Heidelberg \& Berlin.

Jin Y. \& Qian H. (2019) V.PhyloMaker: an R package that can generate very large phylogenies for vascular plants. - Ecography 42: 1353-1359

Johansson V. A., Cousins S. A. O. \& Eriksson O. (2011) Remnant populations and plant functional traits in abandoned semi-natural grasslands. - Folia Geobotanica 46: 165-179.

Kaplan Z. (2012) Flora and phytogeography of the Czech Republic. - Preslia 84: 505-573.

Kaplan Z., Danihelka J., Chrtek Jr. J., Kirschner J., Kubát K., Štěpánek J. \& Štech M. (eds) (2019a) Klíč ke květeně České republiky [Key to the Flora of the Czech Republic]. Ed. 2. - Academia, Praha.

Kaplan Z., Danihelka J., Chrtek Jr. J., Prančl J., Ducháček M., Ekrt L., Kirschner, Jan, Brabec, Jiří, Zázvorka, Jiří, Bohumil T., Dřevojan P., Šumberová K., Kocián P., Wild J., \& Petřík P. (2018b) Distributions of vascular plants in the Czech Republic. Part 7. - Preslia 90: 425-531. 
Kaplan Z., Danihelka J., Chrtek J. Jr., Zázvorka J., Koutecký P., Ekrt L., Řepka R., Štěpánková J., Jelínek B., Grulich V., Prančl J. \& Wild J. (2019b) Distributions of vascular plants in the Czech Republic. Part 8. Preslia 91: 257-368.

Kaplan Z., Danihelka J., Ekrt L., Štech M., Řepka R., Chrtek J. Jr., Grulich V., Rotreklová O., Dřevojan P., Šumberová K. \& Wild J. (2020) Distributions of vascular plants in the Czech Republic. Part 9. - Preslia 92: 255-340.

Kaplan Z., Danihelka J., Koutecký P., Šumberová K., Ekrt L., Grulich V., Řepka R., Hroudová Z., Štěpánková J., Dvořák V., Dančák M., Dřevojan P., \& Wild J. (2017a) Distributions of vascular plants in the Czech Republic. Part 4. - Preslia 89: 115-201.

Kaplan Z., Danihelka J., Lepší M., Lepší P., Ekrt L., Chrtek Jr. J., Kocián P., Prančl J., Kobrlová L., Hroneš M., \& Šulc V. (2016b) Distributions of vascular plants in the Czech Republic. Part 3. - Preslia 88: 459544.

Kaplan Z., Danihelka J., Štěpánková J., Bureš P., Zázvorka J., Hroudová Z., Ducháček M., Grulich V., Řepka R., Dančák M., Prančl J., Šumberová K., Wild J., \& Trávníček B. (2015) Distributions of vascular plants in the Czech Republic. Part 1. - Preslia 87: 417-500.

Kaplan Z., Danihelka J., Štěpánková J., Ekrt L., Chrtek Jr. J., Zázvorka J., Grulich V., Řepka R., Prančl J., Ducháček M., Kúr P., Šumberová K., \& Brůna J. (2016a) Distributions of vascular plants in the Czech Republic. Part 2. - Preslia 88: 229-322.

Kaplan Z., Danihelka J., Šumberová K., Chrtek J., Rotreklová O., Ekrt L., Štěpánková J., Taraška V., Trávníček B., Prančl J., Ducháček M., Hroneš M., Kobrlová L., Horák D., \& Wild J. (2017b) Distributions of vascular plants in the Czech Republic. Part 5. - Preslia 89: 333-439.

Kaplan Z., Koutecký P., Danihelka J., Šumberová K., Ducháček M., Štěpánková J., Ekrt L., Grulich V., Řepka R., Kubát K., Mráz P., Wild J., \& Brůna J. (2018a) Distributions of vascular plants in the Czech Republic. Part 6. - Preslia 90: 235-246.

Kattge J., Bönisch G., Díaz S., Lavorel S., Prentice I. C., Leadley P., Tautenhahn S., Werner G. D. A. et al. (2020) TRY plant trait database - enhanced coverage and open access. - Global Change Biology 26: 119188.

Király G., Virók V. \& Molnár V. (eds) (2011) Új Magyar füvészkönyv. Magyarország hajtásos növényei: ábrák [New Hungarian Herbal. The vascular plants of Hungary: Figures]. - Aggteleki Nemzeti Park Igazgatóság, Jósvafö.

Kleyer M., Bekker R. M., Knevel I. C., Bakker J. P., Thompson K., Sonnenschein M., Poschlod P., van Groenendael J. M., Klimeš L., Klimešová J., Klotz S., Rusch G. M., Hermy M., Adriaens D., Boedeltje G., Bossuyt B., Dannemann A., Endels P., Götzenberger L., Hodgson J. G., Jackel A. K., Kühn I., Kunzmann D., Ozinga W. A., Romermann C., Stadler M., Schlegelmilch J., Steendam H. J., Tackenberg O., Wilmann B., Cornelissen J. H. C., Eriksson O., Garnier E. \& Peco B. (2008) The LEDA Traitbase: a database of lifehistory traits of the Northwest European flora. - Journal of Ecology 96: 1266-1274.

Klimešová J. (2007) Root-sprouting in myco-heterotrophic plants: prepackaged symbioses or overcoming meristem limitation? - New Phytologist 173: 8-10.

Klimešová J. (2018) Temperate herbs: an architectural analysis. - Academia, Praha. 
Klimešová J. \& de Bello F. (2009) CLO-PLA: the database of clonal and bud bank traits of Central European flora. - Journal of Vegetation Science 20: 511-516.

Klimešová J. \& Klimeš L. (2006) CLO-PLA3: a database of clonal growth architecture of Central-European plants. - http://clopla.butbn.cas.cz.

Klimešová J. \& Klimeš L. (2007) Bud banks and their role in vegetative regeneration - a literature review and proposal for simple classification and assessment. - Perspectives in Plant Ecology, Evolution and Systematics 8: 115-129.

Klimešová J., Nobis M. P. \& Herben T. (2016) Links between shoot and plant longevity and plant economics spectrum: Environmental and demographic implications. - Perspectives in Plant Ecology, Evolution and Systematics 22: 55-62.

Klimešová J., Danihelka J., Chrtek J., de Bello F. \& Herben T. (2017) CLO-PLA: a database of clonal and bud-bank traits of the Central European flora. - Ecology 98: 1179.

Klotz S. \& Kühn I. (2002a) Blattmerkmale. - In: Klotz S., Kühn I. \& Durka W. (eds), BIOLFLOR - Eine Datenbank mit biologisch-ökologischen Merkmalen zur Flora von Deutschland, Schriftenreihe für Vegetationskunde 38: 119-126.

Klotz S. \& Kühn I. (2002b) Indikatoren des anthropogenen Einflusses auf die Vegetation. - In: Klotz S., Kühn I. \& Durka W. (eds), BIOLFLOR - Eine Datenbank mit biologisch-ökologischen Merkmalen zur Flora von Deutschland, Schriftenreihe für Vegetationskunde 38: 241-246.

Klotz S., Kühn I. \& Durka W. (eds) (2002) BIOLFLOR - Eine Datenbank mit biologisch-ökologischen Merkmalen zur Flora von Deutschland, Schriftenreihe für Vegetationskunde 38: 1-334.

Konečná M., Moos M., Zahradníčková H., Šimek P. \& Lepš J. (2018) Tasty rewards for ants: differences in elaiosome and seed metabolite profiles are consistent across species and reflect taxonomic relatedness. Oecologia 188: 753-764.

Krumbiegel A. (2002) Morphologie der vegetativen Organe (außer Blätter). - In: Klotz S., Kühn I. \& Durka W. (eds), BIOLFLOR - Eine Datenbank mit biologisch-ökologischen Merkmalen zur Flora von Deutschland, Schriftenreihe für Vegetationskunde 38: 93-118.

Kubát K., Hrouda L., Chrtek J. Jr., Kaplan Z., Kirschner J. \& Štěpánek J. (eds) (2002) Klíč ke květeně České republiky [Key to the Flora of the Czech Republic]. - Academia, Praha.

Kühn I. \& Klotz S. (2002) Angaben zu den Arealen. - In: Klotz S., Kühn I. \& Durka W. (eds), BIOLFLOR Eine Datenbank mit biologisch-ökologischen Merkmalen zur Flora von Deutschland, Schriftenreihe für Vegetationskunde 38: 227-239.

Laliberté E. \& Legendre P. (2010) A distance-based framework for measuring functional diversity from multiple traits. - Ecology 91: 299-305.

Leitch I. J. \& Bennett M. D. (2004) Genome downsizing in polyploid plants. - Biological Journal of the Linnean Society 82: 651-663.

Leitch I. J. \& Greilhuber J. (2013) Genome size diversity and evolution in land plants. - In: Leitch I. J., Greilhuber J., Doležel J. \& Wendel J. (eds), Plant genome diversity. Vol. 2. Physical structure, behaviour and evolution of plant genomes, p. 307-322, Springer, Wien. 
Lengyel S., Gove A. D., Latimer A. M., Majer J. D., Dunn R. R. (2010) Convergent evolution of seed dispersal by ants, and phylogeny and biogeography in flowering plants: A global survey. - Perspectives in Plant Ecology, Evolution and Systematics 12: 43-55.

Levin D. A. (2002) The role of chromosomal change in plant evolution. - Oxford University Press, Oxford.

MacQueen J. (1967) Some methods for classification and analysis of multivariate observations. - In:

Proceedings of the Fifth Berkeley Symposium on Mathematical Statistics and Probability, Volume 1: Statistics, p. 281-297, University of California Press, Berkeley.

Merckx V. S. F. T. (2012) Mycoheterotrophy: The biology of plants living on fungi. - Springer, Berlin.

Marcussen T., Heier L., Brysting A. K., Oxelman B. \& Jakobsen K. S. (2015) From gene trees to a dated allopolyploid network: Insights from the angiosperm genus Viola (Violaceae). - Systematic Biology 64: 84-101.

McGill B.J., Enquist B.J., Weiher E. \& Westoby M. (2006) Rebuilding community ecology from functional traits. - Trends in Ecology \& Evolution 21: 178-185.

Meusel H. \& Jäger E. (1992) Vergleichende Chorologie der zentraleuropäischen Flora. Band III. - Gustav Fischer, Jena.

Meusel H., Jäger E. \& Weinert E. (1965) Vergleichende Chorologie der zentraleuropäischen Flora. Band I. Gustav Fischer, Jena.

Meusel H., Jäger E., Rauschert S. \& Weinert E. (1978) Vergleichende Chorologie der zentraleuropäischen Flora. Band II. - Gustav Fischer, Jena.

Neuhäuslová Z., Blažková D., Grulich V., Husová M., Chytrý M., Jeník J., Jirásek J., Kolbek J., Kropáč Z., Ložek V., Moravec J., Prach K., Rybníček K., Rybníčková E. \& Sádlo J. (1998) Mapa potenciální přirozené vegetace České republiky. Textová část. - Academia, Praha.

Niklfeld H. (1971) Bericht über die Kartierung der Flora Mitteleuropas. - Taxon 20: 545-571.

Nordenskiöld H. (1951) Cytotaxonomical studies in the genus Luzula. - Hereditas 37: 325-355.

Oksanen J., Blanchet F. G., Friendly M., Kindt R., Legendre P., McGlinn D., Minchin P. R., O'Hara R. B., Simpson G. L., Solymos P., Stevens M. H. H., Szoecs E. \& Wagner H. (2019) vegan: community ecology package. R package version 2.5-6. https://CRAN.R-project.org/package=vegan

Ottaviani G., Martínková J., Herben T., Pausas J. G. \& Klimešová J. (2017) On plant modularity traits: functions and challenges. - Trends in Plant Science 22: 648-651.

Pawlowski K. \& Sprent J. I. (2007) Comparison between actinorhizal and legume symbioses. - In: Pawlowski K. \& Newton W. E. (eds), Nitrogen-fixing actinorhizal symbioses, p. 261-288, Springer, Dordrecht.

Pérez-Harguindeguy, N., Díaz, S., Gamier, E., Lavorel, S., Poorter, H., Jaureguiberry, P., Bret-Harte, M.S., Cornwell, W.K., Craine, J.M., Gurvich, D.E., Urcelay, C., Veneklaas E. J., Reich P. B., Poorter L., Wright I. J., Ray P., Enrico L., Pausas J. G., de Vos A. C., Buchmann N., Funes G., Quétier F., Hodgson J. G., Thompson K., Morgan H. D., ter Steege H., van der Heijden M. G. A., Sack L., Blonder B., Poschlod P., Vaieretti M. V., Conti G., Staver A. C., Aquino S. \& Cornelissen J. H. C. (2013) New handbook for standardised measurement of plant functional traits worldwide. - Australian Journal of Botany 61: 167234.

Pierce S., Negreiros D., Cerabolini B. E. L., Kattge J., Díaz S., Kleyer M., Shipley B., Wright S. J., Soudzilovskaia N. A., Onipchenko V. G., van Bodegom P. M., Frenette-Dussault C., Weiher E., Pinho B. 
X., Cornelissen J. H. C., Grime J. P., Thompson K., Hunt R., Wilson P. J., Buffa G., Nyakunga O. C., Reich P. B., Caccianiga M., Mangili F., Ceriani R. M., Luzzaro A., Brusa G., Siefert A., Barbosa N. P. U., Chapin F. S., Cornwell W. K., Fang J., Fernandes G. W., Garnier E., Le Stradic S., Peñuelas J., Melo F. P. L., Slaviero A., Tabarelli M. \& Tampucci D. (2017) A global method for calculating plant CSR ecological strategies applied across biomes world-wide. - Functional Ecology 31: 444-457.

Prach K., Řehounková K., Lencová K., Jírová A., Konvalinková P., Mudrák O., Študent V., Vaněček Z., Tichý L., Petř́ik P., Šmilauer P. \& Pyšek P. (2014) Vegetation succession in restoration of disturbed sites in Central Europe: the direction of succession and species richness across 19 seres. - Applied Vegetation Science 17: 193-200.

Prach K., Tichý L., Vítovcová K. \& Řehounková K. (2017) Participation of the Czech flora in succession at disturbed sites: quantifying species' colonization ability. - Preslia 89: 87-100.

Pyšek P., Sádlo J. \& Mandák B. (2002) Catalogue of alien plants of the Czech Republic. - Preslia 74: 97-186.

Pyšek P., Jarošík V., Pergl J., Randall R., Chytrý M., Kühn I., Tichý L., Danihelka J., Chrtek J. Jr. \& Sádlo J. (2009) The global invasion success of Central European plants is related to distribution characteristics in their native range and species traits. - Diversity and Distributions 15: 891-903.

Pyšek P., Danihelka J., Sádlo J., Chrtek J. Jr., Chytrý M., Jarošík V., Kaplan Z., Krahulec F., Moravcová L., Pergl J., Štajerová K. \& Tichý L. (2012) Catalogue of alien plants of the Czech Republic (2nd edition): checklist update, taxonomic diversity and invasion patterns. - Preslia 84: 155-255.

Pyšek P., Manceur A. M., Alba C., McGregor K. F., Pergl J., Štajerová K., Chytrý M., Danihelka J., Kartesz J., Klimešová J., Lučanová M., Moravcová L., Nishino M., Sádlo J., Suda J., Tichý L. \& Kühn I. (2015) Naturalization of central European plants in North America: species traits, habitats, propagule pressure, residence time. - Ecology 96: 762-774.

Pyšek P., Pergl J., Essl F., Lenzner B., Dawson W., Kreft H., Weigelt P., Winter M., Kartesz J., Nishino M., Antonova L. A., Barcelona J. F., Cabezas F. J., Cárdenas D., Cárdenas-Toro J., Castaño N., Chacón E., Chatelain C., Dullinger S., Ebel A. L., Figueiredo E., Fuentes N., Genovesi P., Groom Q. J., Henderson L., Inderjit, Kupriyanov A., Masciadri S., Maurel N., Meerman J., Morozova O., Moser D., Nickrent D., Nowak P. M., Pagad S., Patzelt A., Pelser P. B., Seebens H., Shu W., Thomas J., Velayos M., Weber E., Wieringa J. J., Baptiste M. P. \& van Kleunen M. (2017) Naturalized alien flora of the world: species diversity, taxonomic and phylogenetic patterns, geographic distribution and global hotspots of plant invasion. - Preslia 89: 203-274

Rauh W. (1937) Die Bildung von Hypocotyl- und Wurzelsprossen und ihre Bedeutung für die Wuchsformen der Pflanzen. - Acta Nova Leopoldina 4/24: 395-555.

Raunkiaer C. (1934) The life forms of plants and statistical plant geography. - Clarendon Press, Oxford.

Raven P. H. (1975) The bases of angiosperm phylogeny: cytology. - Annals of the Missouri Botanical Garden 62: 724-764.

Rice A., Glick L., Abadi S., Einhorn M., Kopelman N. M., Salman-Minkov A., Mayzel J., Chay O. \& Mayrose I. (2015) The chromosome counts database (CCDB): a community resource of plant chromosome numbers. - New Phytologist 206: 19-26. 
Richardson D. M., Pyšek P. \& Carlton J. T. (2011) A compendium of essential concepts and terminology in biological invasions. - In: Richardson D. M. (ed.), Fifty years of invasion ecology: the legacy of Charles Elton, p. 409-420, Blackwell Publishing, Oxford.

Richardson D. M., Pyšek P., Rejmánek M., Barbour M. G., Panetta F. D. \& West C. J. (2000) Naturalization and invasion of alien plants: concepts and definitions. - Diversity and Distributions 6: 93-107.

Sádlo J., Chytrý M. \& Pyšek P. (2007) Regional species pools of vascular plants in habitats of the Czech Republic. - Preslia 79: 303-321.

Sádlo J., Chytrý M., Pergl J. \& Pyšek P. (2018) Plant dispersal strategies: a new classification based on the multiple dispersal modes of individual species. - Preslia 90: 1-22.

Schmidt M., Kriebitzsch W.-U. \& Ewald J. (eds) (2011) Waldartenlisten der Farn- und Blütenpflanzen, Moose und Flechten Deutschlands. - BfN-Skripten 299: 1-111.

Serebryakov I. G. (1952) Morfologiya vegetativnykh organov vysshikh rastenii [Morphology of vegetative organs of higher plants]. - Sovetskaya nauka, Moskva.

Sernander R. (1906) Entwurf einer Monographie der europäischen Myrmekochoren. - Kungliga Svenska Vetenskapsakademiens Handlingar 41: 1-410.

Servigne P. (2008) Etude expérimentale et comparative de la myrmécochorie: le cas des fourmis dispersatrices Lasius niger et Myrmica rubra. - Ph.D. thesis, Université libre de Bruxelles, Bruxelles.

Skalický V. (1988) Regionálně fytogeografické členění [Regional phytogeographical division]. - In: Hejný S., Slavík B., Chrtek J., Tomšovic P. \& Kovanda M. (eds), Květena České socialistické republiky [Flora of the Czech Socialist Republic] 1: 103-121, Academia, Praha.

Slavíková Z. (1988) Terminologický slovník [Terminological dictionary]. - In: Hejný S., Slavík B., Chrtek J., Tomšovic P. \& Kovanda M. (eds), Květena České socialistické republiky [Flora of the Czech Socialist Republic] 1: 130-153, Academia, Praha.

Šmarda P. \& Bureš P. (2012) The variation of base composition in plant genomes. - In: Wendel J., Greilhuber J., Doležel J. \& Leitch I. J. (eds), Plant genome diversity. Vol. 1. Plant genomes, their residents, and their evolutionary dynamics, p. 209-235, Springer, Heidelberg.

Šmarda P., Bureš P., Šmerda J. \& Horová L. (2012) Measurements of genomic GC content in plant genomes with flow cytometry: a test for reliability. - New Phytologist 193: 513-521.

Šmarda P., Bureš P., Horová L., Leitch I. J., Mucina L., Pacini E., Tichý L., Grulich V. \& Rotreklová O. (2014) Ecological and evolutionary significance of genomic GC content diversity in monocots. Proceedings of the National Academy of Sciences of the USA 111: E4096-E4102.

Šmarda P., Knápek O., Březinová A., Horová L., Grulich V., Danihelka J., Veselý P., Šmerda J., Rotreklová O. \& Bureš P. (2019) Genome sizes and genomic guanine+cytosine (GC) contents of the Czech vascular flora with new estimates for 1700 species. - Preslia 91: 117-142.

Smith A. R., Pryer K. M., Schuettpelz E., Korall P., Schneider H. \& Wolf P. G. (2006) A classification for extant ferns. - Taxon 55: 705-731.

Sprent J. I. (2008) Evolution and diversity of legume symbiosis. - In: Dilworth M. J., James E. K., Sprent J. I.

\& Newton W. E. (eds), Nitrogen-fixing leguminous symbioses, p. 1-21, Springer, Dordrecht.

Stebbins G. L. (1950) Variation and evolution in plants. - Columbia University Press, New York. 
Študent V. (2012) Společné funkční vlastnosti myrmekochorních druhů rostlin České republiky a sezónní a denní dynamika odnosu diaspor všivce lesního (Pedicularis sylvatica) mravenci [Traits of myrmecochorous plants of the Czech Republic and a seasonal and daily seed's removal dynamics of lousewort (Pedicularis sylvatica) by ants]. - Master thesis, University of South Bohemia, České Budějovice.

Sukopp H. (1972) Wandel von Flora und Vegetation in Mitteleuropa unter dem Einfluß des Menschen. Berichte über Landwirtschaft 50: 112-139.

Tate J. A., Soltis D. E. \& Soltis P. S. (2005) Polyploidy in plants. - In: Gregory R. T. (ed.), The evolution of the genome, p. 371-426, Elsevier, Amsterdam.

Tavşanoğlu Ç. \& Pausas J. G. (2018) A functional trait database for Mediterranean Basin plants. - Scientific Data 5: 180135 .

Těšitel J. (2016) Functional biology of parasitic plants: a review. - Plant Ecology and Evolution 149: 5-20.

Tichý L. \& Chytrý M. (2006) Statistical determination of diagnostic species for site groups of unequal size. Journal of Vegetation Science 17: 809-818.

Tichý L. \& Chytrý M. (2019) Probabilistic key for identifying vegetation types in the field: A new method and Android application. - Journal of Vegetation Science 30: 1035-1038.

Trefflich A., Klotz S. \& Kühn I. (2002) Blühphänologie. - In: Klotz S., Kühn I. \& Durka W. (eds), BIOLFLOR - Eine Datenbank mit biologisch-ökologischen Merkmalen zur Flora von Deutschland, Schriftenreihe für Vegetationskunde 38: 127-131.

van Kleunen M., Pyšek P., Dawson W., Essl F., Kreft H., Pergl J., Weigelt P., Stein A., Dullinger S., König C., Lenzner B., Maurel N., Moser D., Seebens H., Kartesz J., Nishino M., Aleksanyan A., Ansong M., Antonova L. A., Barcelona J. F., Breckle S. W., Brundu G., Cabezas F. J., Cárdenas D., Cárdenas-Toro J., Castaño N., Chacón E., Chatelain C., Conn B., de Sá Dechoum M., Dufour-Dror J.-M., Ebel A-L., Figueiredo E., Fragman-Sapir O., Fuentes N., Groom Q. J., Henderson L., Inderjit, Jogan N. Krestov P., Kupriyanov A., Masciadri S., Meerman J., Morozova O., Nickrent D., Nowak A., Patzelt A., Pelser P. B., Shu W.-S., Thomas J., Uludag A., Velayos M., Verkhosina A., Villaseñor J. L., Weber E., Wieringa J., Yazlık A., Zeddam A., Zykova E. \& Winter M. (2019) The Global Naturalized Alien Flora (GloNAF) database. - Ecology 100: e02542

Veselý P., Bureš P., Šmarda P. \& Pavlíček T. (2012) Genome size and DNA base composition of geophytes: the mirror of phenology and ecology? - Annals of Botany 109: 65-75.

Violle C., Navas M.-L., Vile D., Kazakou E., Fortunel C., Hummel I., Garnier E. (2007) Let the concept of trait be functional! - Oikos 116: 882-892.

Wang H., Harrison S. P., Prentice I. C., Yang Y., Bai F, Togashi H. F., Wang M., Zhou S. \& Ni J. (2018) The China Plant Trait Database: toward a comprehensive regional compilation of functional traits for land plants. - Ecology 99: 500.

Weigelt P., König C. \& Kreft H. (2019) GIFT - A Global Inventory of Floras and Traits for macroecology and biogeography. - Journal of Biogeography 47: 16-43.

Westoby M. (1998) A leaf-height-seed (LHS) plant ecology strategy scheme. - Plant and Soil 199: 213-227.

Whittaker R. H. (1960) Vegetation of the Siskiyou Mountains, Oregon and California. - Ecological Monographs 30: 279-338. 
Wild J., Kaplan Z., Danihelka J., Petř́k P., Chytrý M., Novotný P., Rohn M., Šulc V., Brůna J., Chobot K., Ekrt L., Holubová D., Knollová I., Kocián P., Štech M., Štěpánek J. \& Zouhar V. (2019) Plant distribution data for the Czech Republic integrated in the Pladias database. - Preslia 91: 1-24.

Wu Z., Raven P. H. \& Huang D. (eds) (1994) Flora of China. - Science Press, Beijing \& Missouri Botanical Garden, St. Louis.

Zelený D. \& Chytrý M. (2019) Ecological Specialization Indices for species of the Czech flora. - Preslia 91: 93-116. 
Table 1. - Overview of 120 publicly available plant characteristics contained in the Pladias Database. The variable type can be categorical $(\mathrm{C})$ or numeric $(\mathrm{N})$. The table reports data for species, although the database also contains data for other taxa such as subspecies, varieties, aggregates, sections and hybrids. At least some data are available for 3878 species, which is the complete Czech flora including casual aliens and recently extinct species. The table reports the numbers and percentages of species for which information on each characteristic is available and for a subset of 2246 species which are usually considered in the analyses of the national flora (excluding species that are only cultivated in the country, casual neophytes and specious genera and groups with a large proportion of apomictic species: Alchemilla, Hieracium, Pilosella, Ranunculus auricomus agg., Rubus, Sorbus and Taraxacum). The traits used for PCA analysis are marked by an asterisk in the last column.

\begin{tabular}{|c|c|c|c|c|c|c|c|}
\hline Plant characteristic & Data type & $\begin{array}{c}\text { All } \\
\text { species } \\
(\mathrm{n}=3878)\end{array}$ & $\begin{array}{c}\% \\
\text { of all } \\
3878\end{array}$ & $\begin{array}{c}\text { Without } \\
\text { cultivated, } \\
\text { casual aliens } \\
\text { and } \\
\text { apomicts (n } \\
=2246)\end{array}$ & $\begin{array}{c}\% \\
\text { of } \\
224 \\
6\end{array}$ & $\begin{array}{c}\text { Rem } \\
\text { ark }\end{array}$ & PCA \\
\hline \multicolumn{8}{|l|}{ Habitus and growth type } \\
\hline Height & interval_avg & 3101 & 80 & 2083 & 93 & & $*$ \\
\hline Growth form & enum_nominal & 3106 & 80 & 2086 & 93 & & $*$ \\
\hline Life form & enum_nominal & 3042 & 78 & 2069 & 92 & & $*$ \\
\hline Life strategy & enum_nominal & 1692 & 44 & 1295 & 58 & & \\
\hline Life strategy (C-score) & percentage & 1692 & 44 & 1295 & 58 & & \\
\hline Life strategy (S-score) & percentage & 1692 & 44 & 1295 & 58 & & \\
\hline Life strategy (R-score) & percentage & 1692 & 44 & 1295 & 58 & & \\
\hline \multicolumn{8}{|l|}{ Leaf } \\
\hline Leaf presence and metamorphosis & enum_nominal & 3797 & 98 & 2210 & 98 & & \\
\hline Leaf arrangement (phyllotaxis) & enum_nominal & 3733 & 96 & 2165 & 96 & & $*$ \\
\hline Leaf shape & enum_nominal & 3780 & 97 & 2199 & 98 & & $*$ \\
\hline Stipules & boolean & 3800 & 98 & 2210 & 98 & & \\
\hline Petiole & enum_nominal & 3723 & 96 & 2164 & 96 & & \\
\hline Leaf life span & enum_nominal & 2065 & 53 & 1621 & 72 & & $*$ \\
\hline Leaf deciduousness in woody plants & enum_nominal & 467 & 12 & 223 & 10 & 1 & \\
\hline Leaf anatomy & enum_nominal & 2048 & 53 & 1586 & 71 & & $*$ \\
\hline Functional leaf type in woody plants & enum_nominal & 471 & 12 & 225 & 10 & 1 & \\
\hline Flower & & & & & & 2 & \\
\hline Flowering period & month & 3040 & 78 & 2067 & 92 & & $*$ \\
\hline Flowering phase & enum_nominal & 1308 & 34 & 1102 & 49 & & \\
\hline Flower colour & enum_nominal & 3714 & 96 & 2146 & 96 & & \\
\hline Flower symmetry & enum_nominal & 3023 & 78 & 1701 & 76 & 3 & \\
\hline Perianth & enum_nominal & 3675 & 95 & 2138 & 95 & & \\
\hline Fusion of the perianth & enum_nominal & 3434 & 89 & 1961 & 87 & 3 & \\
\hline $\begin{array}{l}\text { Shape of the sympetalous corolla or } \\
\text { syntepalous perigon }\end{array}$ & enum_nominal & 1409 & 36 & 744 & 33 & 4 & \\
\hline Calyx fusion & enum_nominal & 2480 & 64 & 1313 & 58 & 5 & \\
\hline Inflorescence type & enum_nominal & 3711 & 96 & 2146 & 96 & & \\
\hline Dicliny & enum_nominal & 2245 & 58 & 1703 & 76 & & $*$ \\
\hline Generative reproduction type & enum_nominal & 2297 & 59 & 1628 & 72 & & $*$ \\
\hline Pollination syndrome & enum_nominal & 2196 & 57 & 1676 & 75 & & $*$ \\
\hline Pollinator spectrum & enum_nominal & 293 & 8 & 237 & 11 & & \\
\hline \multicolumn{8}{|l|}{ Fruit, seed and dispersal } \\
\hline Fruit type & enum_nominal & 3674 & 95 & 2136 & 95 & & $*$ \\
\hline Fruit colour & enum_nominal & 1949 & 50 & 1500 & 67 & & \\
\hline Reproduction type & enum_nominal & 2282 & 59 & 1730 & 77 & & $*$ \\
\hline Dispersal unit (diaspore) & enum_nominal & 2782 & 72 & 1997 & 89 & & $*$ \\
\hline Dispersal strategy & enum_nominal & 2840 & 73 & 2026 & 90 & & $*$ \\
\hline
\end{tabular}




\begin{tabular}{|c|c|c|c|c|c|c|}
\hline Myrmecochory & enum_nominal & 3741 & 96 & 2164 & 96 & \\
\hline \multicolumn{7}{|l|}{ Belowground organs and clonality } \\
\hline Shoot metamorphosis & enum_nominal & 1384 & 36 & 1073 & 48 & 6 \\
\hline Root metamorphosis & enum_nominal & 422 & 11 & 360 & 16 & 6 \\
\hline Storage organ & enum_nominal & 1433 & 37 & 1282 & 57 & 6 \\
\hline Type of clonal growth organ & enum_nominal & 1020 & 26 & 823 & 37 & 7,8 \\
\hline $\begin{array}{l}\text { Freely dispersible organs of clonal } \\
\text { growth }\end{array}$ & boolean & 1025 & 26 & 828 & 37 & 7,8 \\
\hline Shoot life span (cyclicity) & enum_nominal & 1890 & 49 & 1491 & 66 & 7 \\
\hline $\begin{array}{l}\text { Branching type of stem-derived } \\
\text { organs of clonal growth }\end{array}$ & enum_nominal & 1258 & 32 & 1014 & 45 & 7,8 \\
\hline Primary root & boolean & 1986 & 51 & 1579 & 70 & 7 \\
\hline $\begin{array}{l}\text { Persistence of the clonal growth } \\
\text { organ }\end{array}$ & interval_avg & 998 & 26 & 807 & 36 & 7,8 \\
\hline Number of clonal offspring & interval_avg & 1001 & 26 & 812 & 36 & 7,8 \\
\hline $\begin{array}{l}\text { Lateral spreading distance by clonal } \\
\text { growth }\end{array}$ & interval_avg & 999 & 26 & 807 & 36 & 7,8 \\
\hline Clonal index & integer & 984 & 25 & 797 & 35 & 7,8 \\
\hline Position of root buds & enum_nominal & 345 & 9 & 267 & 12 & \\
\hline $\begin{array}{l}\text { Role of root buds in the life-history of } \\
\text { a plant }\end{array}$ & enum_nominal & 345 & 9 & 267 & 12 & \\
\hline $\begin{array}{l}\text { Number of buds per shoot at the soil } \\
\text { surface (root buds excluded) }\end{array}$ & interval_avg & 2112 & 54 & 1666 & 74 & \\
\hline $\begin{array}{l}\text { Number of buds per shoot at a depth } \\
\text { of } 0-10 \mathrm{~cm} \text { (root buds excluded) }\end{array}$ & interval_avg & 2115 & 55 & 1668 & 74 & \\
\hline $\begin{array}{l}\text { Number of buds per shoot at a depth } \\
\text { greater than } 10 \mathrm{~cm} \text { (root buds } \\
\text { excluded) }\end{array}$ & interval_avg & 2113 & 54 & 1666 & 74 & \\
\hline $\begin{array}{l}\text { Size of the belowground bud bank } \\
\text { (root buds excluded) }\end{array}$ & interval_avg & 2129 & 55 & 1673 & 74 & \\
\hline $\begin{array}{l}\text { Depth of the belowground bud bank } \\
\text { (root buds excluded) }\end{array}$ & interval_avg & 1995 & 51 & 1584 & 71 & \\
\hline $\begin{array}{l}\text { Number of buds per shoot at the soil } \\
\text { surface (root buds included) }\end{array}$ & interval_avg & 2112 & 54 & 1666 & 74 & \\
\hline $\begin{array}{l}\text { Number of buds per shoot at a depth } \\
\text { of } 0-10 \mathrm{~cm} \text { (root buds included) }\end{array}$ & interval_avg & 2115 & 55 & 1668 & 74 & \\
\hline $\begin{array}{l}\text { Number of buds per shoot at a depth } \\
\text { greater than } 10 \mathrm{~cm} \text { (root buds } \\
\text { included) }\end{array}$ & interval_avg & 2113 & 54 & 1666 & 74 & \\
\hline $\begin{array}{l}\text { Size of the belowground bud bank } \\
\text { (root buds included) }\end{array}$ & interval_avg & 2129 & 55 & 1673 & 74 & \\
\hline $\begin{array}{l}\text { Depth of the belowground bud bank } \\
\text { (root buds included) } \\
\text { Trophic mode }\end{array}$ & interval_avg & 2031 & 52 & 1608 & 72 & \\
\hline Parasitism and mycoheterotrophy & interval_avg & 3848 & 99 & 2225 & 99 & \\
\hline Carnivory & boolean & 3867 & 100 & 2242 & 100 & \\
\hline Symbiotic nitrogen fixation & interval_avg & 3798 & 98 & 2210 & 98 & \\
\hline \multicolumn{7}{|l|}{ Karyology } \\
\hline Chromosome number (2n) & integer & 1763 & 45 & 1458 & 65 & \\
\hline Ploidy level (x) & integer & 1771 & 46 & 1457 & 65 & \\
\hline 2C genome size & interval_avg & 1775 & 46 & 1461 & 65 & \\
\hline 1Cx monoploid genome size & interval_avg & 1771 & 46 & 1457 & 65 & \\
\hline Genomic GC content & percentage & 1722 & 44 & 1423 & 63 & \\
\hline \multicolumn{7}{|l|}{ Taxon origin } \\
\hline Origin in the Czech Republic & enum_ordinal & 3817 & 98 & 2209 & 98 & \\
\hline Invasion status & enum_ordinal & 3540 & 91 & 2160 & 96 & \\
\hline Geographic origin & enum_nominal & 1279 & 33 & 618 & 28 & 9 \\
\hline Year of the first record in the wild & year & 704 & 18 & 269 & 12 & 10 \\
\hline Introduction pathway & enum_nominal & 1258 & 32 & 603 & 27 & 9 \\
\hline \multicolumn{7}{|l|}{ Ecological indicator values } \\
\hline Light indicator value & enum_ordinal & 2273 & 59 & 1845 & 82 & \\
\hline Temperature indicator value & enum_ordinal & 2273 & 59 & 1845 & 82 & \\
\hline Moisture indicator value & enum_ordinal & 2273 & 59 & 1845 & 82 & \\
\hline Reaction indicator value & enum_ordinal & 2271 & 59 & 1843 & 82 & \\
\hline
\end{tabular}




\begin{tabular}{|c|c|c|c|c|c|}
\hline Nutrient indicator value & enum_ordinal & 2271 & 59 & 1843 & 82 \\
\hline Salinity indicator value & enum_ordinal & 2271 & 59 & 1843 & 82 \\
\hline $\begin{array}{l}\text { Whole-community disturbance } \\
\text { frequency indicator value }\end{array}$ & interval_avg & 1159 & 30 & 992 & 44 \\
\hline $\begin{array}{l}\text { Herb-layer disturbance frequency } \\
\text { indicator value }\end{array}$ & interval_avg & 1159 & 30 & 992 & 44 \\
\hline $\begin{array}{l}\text { Whole-community disturbance } \\
\text { severity indicator value }\end{array}$ & interval_avg & 1159 & 30 & 992 & 44 \\
\hline $\begin{array}{l}\text { Herb-layer disturbance severity } \\
\text { indicator value }\end{array}$ & interval_avg & 1159 & 30 & 992 & 44 \\
\hline $\begin{array}{l}\text { Whole-community structure-based } \\
\text { disturbance indicator value }\end{array}$ & interval_avg & 1159 & 30 & 992 & 44 \\
\hline $\begin{array}{l}\text { Herb-layer structure-based } \\
\text { disturbance indicator value } \\
\text { Habitat and sociology }\end{array}$ & interval_avg & 1159 & 30 & 992 & 44 \\
\hline Occurrence in habitats & $\begin{array}{l}\text { a set of } 88 \\
\text { variables of } \\
\text { enum_ordinal_sin } \\
\text { gle type }\end{array}$ & 2236 & 58 & 1796 & 80 \\
\hline $\begin{array}{l}\text { Affinity to the forest environment in } \\
\text { Thermophyticum }\end{array}$ & enum_nominal & 3542 & 91 & 2062 & 92 \\
\hline $\begin{array}{l}\text { Affinity to the forest environment in } \\
\text { Mesophyticum and Oreophyticum }\end{array}$ & enum_nominal & 3658 & 94 & 2132 & 95 \\
\hline Diagnostic taxon of classes & enum_syntaxons & 450 & 12 & 391 & 17 \\
\hline Diagnostic taxon of alliances & enum_syntaxons & 925 & 24 & 798 & 36 \\
\hline Diagnostic taxon of associations & enum_syntaxons & 1258 & 32 & 1083 & 48 \\
\hline Constant taxon of classes & enum_syntaxons & 183 & 5 & 150 & 7 \\
\hline Constant taxon of alliances & enum_syntaxons & 497 & 13 & 430 & 19 \\
\hline Constant taxon of associations & enum_syntaxons & 992 & 26 & 854 & 38 \\
\hline Dominant taxon of associations & enum_syntaxons & 582 & 15 & 497 & 22 \\
\hline $\begin{array}{l}\text { Ecological specialization index for all } \\
\text { vegetation types }\end{array}$ & real & 1493 & 38 & 1268 & 56 \\
\hline $\begin{array}{l}\text { Ecological specialization index for } \\
\text { non-forest vegetation }\end{array}$ & real & 1427 & 37 & 1216 & 54 \\
\hline $\begin{array}{l}\text { Ecological specialization index for } \\
\text { forest vegetation }\end{array}$ & real & 809 & 21 & 691 & 31 \\
\hline Index of colonization success (ICS) & real & 938 & 24 & 920 & 41 \\
\hline Index of colonization potential (ICP) & real & 938 & 24 & 920 & 41 \\
\hline Optimum successional age & real & 938 & 24 & 920 & 41 \\
\hline \multicolumn{6}{|l|}{ Distribution and frequency } \\
\hline Floristic zone & enum_nominal & 2148 & 55 & 1677 & 75 \\
\hline Floristic region & enum_nominal & 2196 & 57 & 1684 & 75 \\
\hline Continentality degree & integer & 1289 & 33 & 1057 & 47 \\
\hline $\begin{array}{l}\text { Distribution range extension along } \\
\text { the continentality gradient }\end{array}$ & integer & 1940 & 50 & 1606 & 72 \\
\hline Elevational belt in the Czech Republic & enum_ordinal & 2317 & 60 & 1814 & 81 \\
\hline $\begin{array}{l}\text { Occurrence frequency in the basic } \\
\text { grid mapping cells }\end{array}$ & $\begin{array}{l}\text { occurrence_frequ } \\
\text { ency }\end{array}$ & 3878 & 100 & 2246 & 100 \\
\hline $\begin{array}{l}\text { Occurrence frequency in quadrants } \\
\text { of the basic grid mapping cells }\end{array}$ & $\begin{array}{l}\text { occurrence_frequ } \\
\text { ency }\end{array}$ & 3878 & 100 & 2246 & 100 \\
\hline $\begin{array}{l}\text { Occurrence frequency in vegetation } \\
\text { plots }\end{array}$ & percentage & 1820 & 47 & 1500 & 67 \\
\hline $\begin{array}{l}\text { Occurrence frequency in vegetation } \\
\text { plots with a cover above } 5 \%\end{array}$ & percentage & 1820 & 47 & 1500 & 67 \\
\hline $\begin{array}{l}\text { Occurrence frequency in vegetation } \\
\text { plots with a cover above } 25 \%\end{array}$ & percentage & 1820 & 47 & 1500 & 67 \\
\hline $\begin{array}{l}\text { Occurrence frequency in vegetation } \\
\text { plots with a cover above } 50 \%\end{array}$ & percentage & 1820 & 47 & 1500 & 67 \\
\hline $\begin{array}{l}\text { Mean percentage cover in vegetation } \\
\text { plots }\end{array}$ & percentage & 1820 & 47 & 1500 & 67 \\
\hline $\begin{array}{l}\text { Maximum percentage cover in } \\
\text { vegetation plots }\end{array}$ & percentage & 1838 & 47 & 1517 & 68 \\
\hline $\begin{array}{l}\text { Number of narrow habitats in which } \\
\text { the taxon occurs }\end{array}$ & integer & 2234 & 58 & 1794 & 80 \\
\hline $\begin{array}{l}\text { Number of narrow habitats in which } \\
\text { the taxon has its optimum }\end{array}$ & integer & 2234 & 58 & 1794 & 80 \\
\hline
\end{tabular}




\begin{tabular}{|c|c|c|c|c|c|}
\hline $\begin{array}{l}\text { Number of broad habitats in which } \\
\text { the taxon occurs }\end{array}$ & integer & 2234 & 58 & 1794 & 80 \\
\hline $\begin{array}{l}\text { Number of broad habitats in which } \\
\text { the taxon has its optimum } \\
\text { Threats and protection }\end{array}$ & integer & 2234 & 58 & 1794 & 80 \\
\hline Red List 2017 (national categories) & $\begin{array}{l}\text { enum_ordinal_sin } \\
\text { gle }\end{array}$ & 3878 & 100 & 2246 & 100 \\
\hline Red List 2017 (IUCN categories) & $\begin{array}{l}\text { enum_ordinal_sin } \\
\text { gle }\end{array}$ & 3878 & 100 & 2246 & 100 \\
\hline Legal protection & $\begin{array}{l}\text { enum_ordinal_sin } \\
\text { gle }\end{array}$ & 3878 & 100 & 2246 & 100 \\
\hline
\end{tabular}

\section{Remarks}

1 Only for woody plants

2 Only for flowering plants

3 Only for plants with the developed perianth

4 Only for plants with sympetalous corolla or syntepalous perigon

5 Only for plants with heterochlamydeous flowers with calyx present

6 Only for plants with some kind of shoot metamorphosis, root metamorphosis or storage organ, respectively for the corresponding traits 7 Only for herbs

8 Only for clonal herbs

9 Only for alien plants

10 Only for neophytes

11 Only for the taxa listed in the Vegetation of the Czech Republic (if Vegetation lists aggregates, no value is assigned to the species within these aggregates) 


\section{Electronic appendix 1. Czech description of plant traits included in the Pladias Database.}

Elektronická př́loha 1. Český popis vlastností rostlin zahrnutých do databáze Pladias.

\section{Habitus a typ růstu}

\section{Výška}

Výšky rostlin se vztahují k území České republiky. Uvádějí se v metrech a vztahují se k plně vyvinutým rostlinám v generativním stavu rostoucím ve volné př́ŕrodě. Pro každý taxon jsou uvedeny dvě hodnoty: minimum (běžná dolní hranice) a maximum (běžná horní hranice). Údaje jsou převzaty z Klíče ke květeně České republiky (Kaplan et al. 2019a).

Zdroj dat a citace: Kaplan et al. (2019a).

\section{Růstová forma}

Růstová forma popisuje potenciální délku života rostliny a jejích částí (ramet), její reproduktivní strategii a trvalost nadzemních částí (Klimešová et al. 2016, Ottaviani et al. 2017). Růstové formy zde dělíme do devíti kategorií, které rovněž zohledňují bylinný nebo dřevnatý charakter stonku. Jednoleté byliny žijí obvykle jen jednu sezónu, během níž se pohlavně rozmnožují. Některé z nich mohou být klonální, ale klonalita u nich zpravidla nevede k fragmentaci. Vytrvalé byliny se dělí do tří kategorií: (1) monokarpické vytrvalé neklonální byliny, které se pohlavně rozmnožují jen jednou za život a nemají zdřevnatělé nadzemní části ani orgány klonálního růstu, (2) polykarpické vytrvalé neklonální byliny, které se pohlavně rozmnožují víc než jednou za život, ale nemají orgány klonálního růstu, a (3) klonální byliny, které mají orgány klonálního růstu, takže mohou během svého života fragmentovat a vytvářet samostatné jednotky (ramety) vegetativním rozmnožováním; celá rostlina se pohlavně rozmnožuje vícekrát za život, zatímco jednotlivé ramety se mohou rozmnožovat jedenkrát nebo vícekrát během svého života. Další kategorie zahrnují dřeviny, tj. rostliny s dřevnatějícími stonky, které mohou (ale nemusí) mít orgány klonálního růstu a 
být schopny fragmentace. Dřeviny se dělí na keřičky (rostliny vysoké zpravidla do $30 \mathrm{~cm}$, zahrnující i druhy, u nichž z dřevnaté báze vyrůstají přímé bylinné prýty, které na podzim odumírají s výjimkou nejspodnější části s obnovovacími pupeny), keře (vyšší dřeviny větvené na bázi), stromy (vy̌šsí dřeviny s vyvinutým kmenem a korunou), dřevnaté liány a parazitické epifyty, k nimž u nás patří jen Loranthus europaeus a Viscum album. Data byla zčásti převzata z agregované databáze CLO-PLA verze 3.4 (Klimešová et al. 2017), původní kategorie však byly doplněny rozlišením bylinných a dřevnatých druhů a kromě toho byly doplněny údaje pro taxony nezahrnuté v databázi CLO-PLA.

Kategorie

- jednoletá bylina

- monokarpická vytrvalá neklonální bylina

- polykarpická vytrvalá neklonální bylina

- klonální bylina
- keříček

- keř

- strom

- dřevnatá liána

- parazitický epifyt

Citace: Dřevojan P. (2020) Růstová forma. - www.pladias.cz.

\section{Životní forma}

Životní formy jsou klasifikovány podle Raunkiaerova systému (Raunkiaer 1934) na základě polohy obnovovacích pupenů, kterými rostliny přežívají nepříznivé období.

Makrofanerofyty jsou dřeviny s obnovovacími pupeny umístěnými nejméně 2 m nad zemí, obvykle stromy; nanofanerofyty jsou dřeviny s obnovovacími pupeny ve výšce 0,3-2 m nad zemí, obvykle keře; chamaefyty jsou byliny nebo nízké dřeviny s obnovovacími pupeny nad zemí do výše $30 \mathrm{~cm}$; hemikryptofyty jsou vytrvalé nebo dvouleté byliny s obnovovacími pupeny na nadzemních stoncích těsně při povrchu půdy; geofyty jsou vytrvalé byliny s obnovovacími pupeny pod povrchem půdy, obvykle s cibulemi, hlízami nebo oddenky; hydrofyty jsou rostliny s obnovovacími pupeny pod vodní hladinou, obvykle na dně; terofyty jsou jednoleté nebo ozimé byliny bez obnovovacích pupenů, které přežívají nepříznivá období pouze v semenech klíčících na podzim, v zimě nebo na jaře. Data byla převzata z Klíče ke květeně České republiky (Kaplan et al. 2019a). Některé taxony mohou mít víc než 
jednu životní formu, přičemž dominantní životní forma se v tom prrípadě uvádí na prvním místě.

Kategorie

- makrofanerofyt

- nanofanerofyt

- chamaefyt

- hemikryptofyt
- geofyt

- hydrofyt

- terofyt

Zdroj dat a citace: Kaplan et al. (2019a).

\section{Životní strategie}

Grime (1974, 1979) rozlišil tři základní ekologické strategie rostlin: (1) kompetitivní strategii $(C)$, výhodnou na stabilních stanovištích, kde je dostatek zdrojů, podmínky nejsou extrémní a narušování je omezené; (2) stres toleranční strategii (S), výhodnou na stanovištích s nedostatkem zdrojů, extrémními a velmi variabilními podmínkami, ale omezeným narušováním; a (3) ruderální strategii (R), výhodnou na stanovištích, kde je dostatek zdrojů, podmínky nejsou extrémní, ale často dochází k narušování.

Taxonům české flóry byly přiřazeny životní strategie metodou, kterou navrhl Pierce et al. (2017). Tato metoda používá data o třech klíčových funkčních vlastnostech listů, které odrážejí rozdíly v investování živin: listovou plochu (LA; je velká u konkurenčně silných taxonů), obsah sušiny v listech (LDMC; je velký u taxonů tolerujících stres) a specifickou listovou plochu (SLA; je velká u ruderálních taxonů). Z těchto dat se počítají skóre, která na procentické stupnici vyjadřují míru $\mathrm{C}, \mathrm{S}$ nebo R selekce. Tato míra se vyjadřuje $\mathrm{v}$ procentech a součet všech tří skóre pro každý jednotlivý taxon je 100 \%. Na základě získaných skóre se taxony řadí do základních strategií $\mathrm{C}, \mathrm{S}$ a R, přechodných strategií CS, CR, SR a CSR a přechodů mezi nimi, např. C/CS nebo SR/CSR (viz Grime 1979). Údaje o vlastnostech listů pro tyto výpočty, případně přímo vypočtené hodnoty byly převzaty $\mathrm{z}$ databáze LEDA (Kleyer et al. 2008) a dalších prací (Bjorkman et al. 2018, Dayrell et al. 2018, Findurová 2018, Tavşanoğlu \& Pausas 2018). Databáze Pladias obsahuje jednak tři hodnoty skóre pro strategie $\mathrm{C}, \mathrm{S}$ a R, jednak kategorizované životní strategie. 
Kategorie

- $\mathrm{C}$

- $\mathrm{C} / \mathrm{CR}$

- $\mathrm{C} / \mathrm{CS}$

- $\mathrm{C} / \mathrm{CSR}$

- $\mathrm{CR}$

- $\mathrm{CR} / \mathrm{CSR}$

- $\mathrm{CS}$
- $\mathrm{CS} / \mathrm{CSR}$

- CSR

- $\mathrm{R}$

- $\mathrm{R} / \mathrm{CR}$

- $\mathrm{R} / \mathrm{CSR}$

- $\mathrm{R} / \mathrm{SR}$

- $\mathrm{S}$
- $\mathrm{S} / \mathrm{CS}$

- $\mathrm{S} / \mathrm{CSR}$

- $\mathrm{S} / \mathrm{SR}$

- $\mathrm{SR}$

- $\mathrm{SR} / \mathrm{CSR}$

Citace: Guo W.-Y. \& Pierce S. (2019) Životní strategie. - www.pladias.cz.

\section{List}

\section{Př́tomnost a přeměna listu}

Údaje o přítomnosti listů na rostlině, přeměnách a redukcích listů byly převzaty z Květeny České republiky (díly 1-8; Hejný et al. 1988 et seq.) a Klíče ke květeně České republiky (Kaplan et al. 2019a).

\section{Kategorie}

- listy přítomny, nejsou přeměněné

- listy přeměněné na trny

- listy přměněné na úponky

- listy přeměněné na fylodia

- listy přeměněné na láčky
- listy redukované na objímavé lemy

- listy redukované na pochvy

- listy redukované na šupiny

- listy chybějí

Zdroj dat a citace: Hejný et al. (1988 et seq.), Kaplan et al. (2019a).

\section{Usporádání listi̊ na stonku (fylotaxe)}

Rozlišují se čtyřri kategorie postavení listů na stonku: střídavé, vstřícné, přeslenité a v přízemní růžici. Znak je hodnocen u dobře vyvinutých rostlin, nikoli u jedinců kompenzačně 
větvených po poškození sečí nebo okusem ani jedinců teratologicky změněných. Pokud může tento znak nabývat více než jednoho stavu u jednoho taxonu, jsou zaznamenány všechny (např. Hylotelephium jullianum a Salix purpurea). Hodnoceny jsou i př́pady, kdy je odlišné postavení listů a lupenitých listenů v květenství (např. Veronica persica a $V$. polita). Listy s vmezeřenými palisty u čeledi Rubiaceae jsou hodnoceny jako přeslenité. U Rhamnus cathartica jsou listy považovány za vstřícné, i když obvykle jsou na letorostu od sebe poněkud oddáleny.

Uspořádání listů na stonku bylo hodnoceno podle popisů v Květeně České republiky (díly 1-8; Hejný et al. 1988 et seq.) a v případech nejasností (především u nepůvodních taxonů) konfrontováno s dalšími prameny, zejména s popisy v kompendiích Flora of North America (Flora of North America Editorial Committee 1993 et seq.), Flora of China (Wu et al. 1994 et seq.) a Flora of Pakistan (www.tropicos.org/Project/Pakistan).

Kategorie

- strí́davé

- vstř́ícné
- přeslenité

- v př́zemní růžici

Citace: Grulich V., Holubová D., Štěpánková P. \& Řezníčková M. (2017) Uspořádání listů na stonku. - www.pladias.cz.

\section{Tvar listu}

Podle tvaru se rozlišují listy jednoduché a složené. Jednoduché listy se dále dělí podle členění čepele a souvisejícího uspořádání žilnatiny na celistvé (např. Fagus sylvatica), dlanitě členěné (např. Alchemilla), peřeně členěné (např. Achillea millefolium), vidličnaté (např. Batrachium, Ceratophyllum a Utricularia) a znožené (Helleborus). Uvedené zařazení do kategorií se vztahuje k dobře vyvinutým listům. I tak je členění listů často proměnlivé a na jedné rostlině existují přechody mezi listy celistvými a členěnými. Za listy členěné se považují listy se zářezy mezi úkrojky dosahujícími nejméně do 1/4 šiřky čepele. Mnohé taxony s variabilními listy jsou zařazeny do dvou a více kategorií.

Složené listy se dělí na dlanité a zpeřené. Rostliny, které mají menší listy trojčetné a větší zpeřené, se dvěma jařmy (např. Aegopodium podagraria a některé další druhy čeledi Apiaceae), jsou klasifikovány v obou kategoriích. Uváděný stupeň vícenásobného zpeření se 
vztahuje k dobře vyvinutým listům, a to zejména $\mathrm{k}$ jejich bazální části. Taxony s vícenásobně zpeřenými listy jsou klasifikovány ve více než jedné kategorii složeného listu, ale velmi malé listy, které mohou mít charakter listu jednoduchého členěného, nejsou vzaty $\mathrm{v}$ potaz.

Nezřídka existují i přechody mezi jednoduchými a složenými listy, zejména mezi peřenosečnými a zpeřenými. Listy s čárkovitými až nitkovitými úkrojky jsou hodnoceny jako jednoduché, a to i u listů vícenásobně členěných (např. lodyžní listy Batrachium fluitans, Cardamine pratensis a druhů rodu Seseli). Naopak širší úkrojky přisedající na vřeteno zřetelným zúžením nebo stopečkou jsou hodnoceny jako listy složené (napřr. lodyžní listy Cardamine dentata nebo přízemní listy Pimpinella saxifraga). Vícenásobně zpeřené listy se považují za složené v případě, že alespoň první stupeň členění odpovídá listu složenému.

Heterofylní (různolisté) rostliny jsou zařazeny do více kategorií, za heterofylii se však nepovažuje odlišná míra členění mladších listů. Pro rostliny s listy zakrnělými (paraziti, např. Cuscuta) nebo s fylokladii nahrazujícími (zakrnělé) listy (např. Asparagus) je použita kategorie listy redukované.

Zdrojem údajů jsou popisy v Květeně České republiky (díly 1-8; Hejný et al. 1988 et seq.). V nejasných případech (především u nepůvodních taxonů naší flóry) byly použity i další prameny, zejména Flora of North America (Flora of North America Editorial Committee 1993 et seq.), Flora of China (Wu et al. 1994 et seq.) a Flora of Pakistan (www.tropicos.org/Project/Pakistan).

Kategorie

- jednoduchý - celistvý

- jednoduchý - dlanitě členěný

- jednoduchý - peřeně členěný

- jednoduchý - vidličnatě členěný

- jednoduchý - znožený

- složený - trojčetný

- složený - dlanitě složený pětičetný

- složený - dlanitě složený sedmičetný
- složený - dlanitě složený mnohočetný

- složený - lichozpeřený

- složený - sudozpeřený

- složený - přetrhovaně zpeřený

- složený - dvakrát zpeřený

- složený - trrikrát zpeřený

- složený - čtyřikrát zpeřený

- redukovaný 
Citace: Grulich V., Holubová D., Štěpánková P. \& Řezníčková M. (2017) Základní tvar listu. - www.pladias.cz.

\section{Palisty}

Palisty, tedy párové listové úkrojky na bázi řapíku nebo přisedlé listové čepele, mohou být príitomny nebo chybět. Palisty prchavé, tj. záhy opadavé (zpravidla po vývinu listové čepele), jsou posuzovány jako př́tomné (např. Prunus). Za palisty se považují i palisty vmezeřené, které nejsou morfologicky odlišitelné od pravých listů, s nimiž tvoří čtyřčetné nebo vícečetné přesleny (např. Rubiaceae). Palisty přeměněné na žlázky (např. Lotus) nebo chlupovité útvary (např. Portulacaceae) se zde nepovažují za palisty.

Přítomnost palistů byla excerpována z popisů v Květeně České republiky (díly 1-8; Hejný et al. 1988 et seq.) a v nejasných případech (především u nepůvodních taxonů) byly popisy konfrontovány s dalšími prameny, zejména s popisy v kompendiích Flora of North America (Flora of North America Editorial Committee 1993 et seq.), Flora of China (Wu et al. 1994 et seq.) a Flora of Pakistan (www.tropicos.org/Project/Pakistan).

Kategorie

- př́tomny

- chybějí

Citace: Grulich V., Holubová D., Štěpánková P. \& Řezníčková M. (2017) Palisty. www.pladias.cz.

\section{̌̌apík}

Řapík může být př́itomen nebo chybět. U některých rostlin může být u některých listů přítomen a u jiných chybět. Jako zdroj dat byla použita Květena České republiky (díly 1-8; Hejný et al. 1988 et seq.), Klíč ke květeně České republiky (Kubát et al. 2002) a atlasy Új magyar füvészkönyv (Király et al. 2011) a Exkursionsflora von Deutschland (Jäger \& Werner 2000).

Kategorie 
- prítomen

- převážně prítomen

- prítomen i chybí
- převážně chybí

- chybí

Citace: Prokešová H. \& Grulich V. (2017) Řapík. - www.pladias.cz.

\section{Vytrvalost listi̊}

Vytrvalost listů je důležitá vlastnost pro konkurenceschopnost rostliny. Je ovlivněna jednak podnebím v areálu taxonu, jednak mikroklimatem a dostupností živin a světla na stanovištích taxonu. Údaje jsou převzaty z databáze BiolFlor (Klotz \& Kühn 2002a).

Kategorie

- přezimující - listy se vyvíjejí na podzim, přezimují zelené a odumírají na jaře nebo v létě

- jarní - listy zelené od časného jara do časného léta, potom obvykle odumírají

- letní - listy zelené v teplém období roku

- stálezelený - listy zelené po celý rok, často přežívají víc než jeden rok

Zdroj dat a citace: Klotz \& Kühn (2002a).

\section{Opadavost listů dřevin}

Listy různých druhů dřevin se fenologicky výrazně liší. Většina druhů středoevropských dřevin má listy opadavé na zimu, zatímco menší část má listy vždyzelené. Poloopadavé listy se vyskytují jen vzácně, většinou jen u pěstovaných druhů. Do kategorie listů poloopadavých na zimu řadíme jen listy aspoň částečně zelené přes zimu a opadávající na jaře, nikoliv tzv. marcescentní listy, které odumírají na podzim, ale přes zimu ještě vytrvávají v suchém stavu na matečné rostlině (např. u mladých jedinců rodu Quercus).

Údaje o opadavosti listů byly převzaty z Květeny České republiky (díly 1-8; Hejný et al. 1988 et seq.), Klíče ke květeně České republiky (Kaplan et al. 2019a), některých zahraničních flór a doplněny vlastním pozorováním. 
Kategorie

- vždyzelené

- opadavé na zimu
- poloopadavé na zimu

- poloopadavé v období sucha

Citace: Štěpánková P. \& Grulich V. (2020) Opadavost listů dřevin. - www.pladias.cz.

\section{Anatomie listı̊}

Anatomie listů je důležitá ekologická adaptace rostlin zajišt'ující co nejúčinnější fotosyntézu v různých podmínkách prostředí. Odráží především dostupnost vody na stanovišti (Klotz \& Kühn 2002a). Sukulentní a skleromorfní listy jsou adaptovány na suchá stanoviště. Oba tyto typy mají silnější pokožku a kutikulu. Zatímco sukulentní listy obsahují dužnaté pletivo pro uchovávání vody, skleromorfní listy mají mechanismy podporující transport vody v obdobích jejího dostatku. Mezomorfní listy jsou adaptovány na méně suchá stanoviště, hygromorfní listy na stinná prostředí, která jsou suchem postižena jen vzácně, helomorfní listy na nedostatek kyslíku na zamokřených půdách a hydromorfní listy na vodní prostředí. Nejčastějším typem listů v naší flóře jsou listy mezomorfní. Anatomie listů je převzata z databáze BiolFlor (Klotz \& Kühn 2002a), která obsahuje rozššřrenou a korigovanou verzi datové sady, kterou původně zveřejnil Ellenberg (1979).

Kategorie

- sukulentní

- skleromorfní

- mezomorfní
- hygromorfní

- helomorfní

- hydromorfní

Zdroj dat a citace: Klotz \& Kühn (2002a).

\section{Funkční typ listi̊ dřevin}

Fukční typy listů dřevin, často používané pro fyziognomickou klasifikaci lesní a keřové vegetace, jsou rozlišovány podle morfologie, anatomické stavby a vytrvalosti. Většina krytosemenných dřevin středoevropské flóry má široké opadavé nebo poloopadavé listy, které mají velkou specifickou listovou plochu, tj. jsou relativně velké vzhledem ke své 
tloušt'ce. Ostatní typy listů jsou až na vzácné výjimky (Larix) víceleté a zpravidla se označují jako vždyzelené. Jehlicovité a šupinovité listy se vyskytují zejména u jehličnanů a některých druhů čeledi Ericaceae. Sklerofylní listy jsou ploché, ale mají silně vyvinuté sklerenchymatické pletivo, což způsobuje jejich tuhost; zpravidla jde o malé kožovité listy s malou specifickou listovou plochou, které jsou přizpůsobeny suchému klimatu. Laurofylní listy jsou větší a tenčí než sklerofylní listy a mají menší podíl sklerenchymatického pletiva; zpravidla jsou tmavě zelené, hladké a lesklé. Tyto listy jsou adaptovány na celoročně vlhké klima s mírnou zimou. Několik málo druhů, které je obtížné zařadit do těchto kategorií, jsou hodnoceny jako „zvláštní typ”.

Údaje o typech listů byly převzaty z Květeny České republiky (díly 1-8; Hejný et al. 1988 et seq.), Klíče ke květeně České republiky (Kaplan et al. 2019a), některých zahraničních flór a doplněny vlastním pozorováním.

Kategorie

- jehlicovité

- šupinovité

- široké opadavé nebo poloopadavé
- sklerofylní

- laurofylní

- zvláštní typ

Citace: Štěpánková P. \& Grulich V. (2020) Funkční typ listů dřevin. - www.pladias.cz.

\section{Květ}

\section{Doba kvetení}

Doba kvetení je uvedena jako měsíce začátku a konce kvetení taxonu v České republice. Údaj je převzat z Klíče ke květeně České republiky (Kaplan et al. 2019a).

Zdroj dat a citace: Kaplan et al. (2019a).

\section{Fáze kvetení}


Doba kvetení rostlin se obvykle uvádí v měsících. Protože však začátek a konec kvetení závisí na počasí, přesná doba kvetení se rok od roku může měnit. $Z$ toho důvodu Dierschke (1995) rozdělil rostlinné taxony do symfenologických skupin, tj. do skupin taxonů, které kvetou současně. Údaje jsou převzaty z databáze BiolFlor (Trefflich et al. 2002).

Kategorie

- 1 Corylus-Leucojum vernum (předjaří)

- 2 Acer platanoides-Anemone nemorosa (začátek časného jara)

- 3 Prunus avium-Ranunculus auricomus (konec časného jara)

- 4 Fagus sylvatica-Galeobdolon (začátek plného jara)

- 5 Sorbus aucuparia-Galium odoratum (konec plného jara)

- 6 Cornus sanguinea-Melica uniflora (začátek časného léta)

- 7 Ligustrum vulgare-Stachys sylvatica (konec časného léta)

- 8 Clematis vitalba-Galium sylvaticum (plné léto)

- 9 Hedera helix-Solidago (časný podzim)

- 10 podzimní fáze

Zdroj dat a citace: Trefflich et al. (2002).

\section{Barva květu}

Barva květu je uvedena pro téměř všechny krytosemenné rostliny s výjimkou okřehků (Araceae p. p.) a některých kř́ženců, k nimž se přesné údaje o barvě květů nepodařilo zjistit.

Pokud má jeden druh více barev květu, jsou u planých druhů uvažovány všechny, a to bez ohledu na jejich frekvenci. Stejným způsobem jsou tedy hodnoceny jak druhy, které pravidelně vytvářejí populace rostlin s různou barvou květů (např. Corydalis cava a Iris pumila), tak druhy, kde se s barevnou odchylkou setkáváme spíše výjimečně (např. albinismus u Salvia pratensis nebo růžové květy u Ajuga reptans). Celá variabilita barvy květů ale není důsledně uvedena u rostlin pěstovaných, tudíž nemusí být zahrnuty všechny barevně odlišné kultivary (např. Gladiolus hortulanus a Callistephus chinensis). U rostlin s květy dvoubarevnými (např. Cypripedium calceolus) jsou uvedeny barvy obě, u rostlin s květy vícebarevnými (např. „strakatý“ pysk u Ophrys apifera) je uvedena barva převažující. 
Má-li květ zřetelnou korunu nebo okvětí, udávaná barva květů se řídí těmito částmi. Pokud jsou u takového květu kontrastně zbarveny listeny (např. Melampyrum nemorosum), jejich barva se nebere v potaz. Pokud koruna nebo okvětí není vyvinuto, barva květu vychází z kalicha (např. Daphne mezereum), listenů (např. Aristolochia clematitis), souboru listenů a listenců v květenství (Euphorbia) nebo listenů obalíčku (Bupleurum longifolium). U áronovitých rostlin s kontrastně zbarveným vlastním květenství a toulcem (např. Calla palustris) je uvedena barva obou částí. U některých skupin rostlin s velmi redukovanými květy se udává celková barva květenství (např. Betula, Salix, některé Cyperaceae a Typhaceae). U lipnicovitých (Poaceae) jsou klásky hodnoceny jako zelené, a to bez ohledu na př́ípadný fialový nádech; výjimkou jsou např. Melica ciliata agg. a Cortaderia, hodnocené jako bílé. Rovněž v dalších, vzácných případech je jako barva květů uvedena barva květenství (např. zelená u Ficus carica). U zástupců hvězdnicovitých byla zvlášt’ hodnocena barva paprsku a terče $v$ př́ipadě, že paprsek je vyvinut a kontrastně zbarven (napřr. Bellis perennis). U druhů s velmi drobnými úbory a málo zřetelnými květy byla hodnocena především barva zákrovu (např. Artemisia campestris a Xanthium). Barva zákrovu byla hodnocena i u „slaměnek“ (např. Helichrysum a Xeranthemum).

Informace o barvě květů byla získána $\mathrm{z}$ terénní znalosti, různých fotografií a popisů v Květeně České republiky (díly 1-8; Hejný et al. 1988 et seq.). U taxonů, které v Květeně České republiky nejsou uvedeny, jakož i ve sporných př́padech (převážně u nepůvodních druhů naší flóry), byly použity další prameny, zejména Flora of North America (Flora of North America Editorial Committee 1993), Flora of China (Wu et al. 1994) a Flora of Pakistan (http://www.tropicos.org/Project/Pakistan).

Kategorie

- bílá (včetně šedé nebo stř́ibřité a vzácných př́ípadů jedinců s bílými květy) - např. květy paprsku u Leucanthemum vulgare, albinotické rostliny Glechoma hederacea, „kočičky“ Salix caprea

- žlutobílá (včetně bíložluté a smetanové) - např. Scabiosa ochroleuca

- zelenobílá (včetně bílozelené a nazelenalé) - např. Orthilia secunda

- zelená - napřr. Poa pratensis (barva plev a pluch)

- Žlutozelená (včetně zelenožluté) - např. Acer pseudoplatanus, Rhamnus cathartica

- Žlutá - např. Taraxacum spp.

- oranžová - např. Pilosella aurantiaca 
- růžová (včetně bílorůžové, růžovobílé a tmavě růžové) - např. Malva alcea, Rosa canina

- růžovofialová - např. Allium schoenoprasum

- červená - např. Papaver rhoeas

- červenofialová (zahrnuje všechny odstíny nachové (purpurové), růžově a fialově červené) - např. Astragalus onobrychis, Cirsium palustre

- fialová (včetně tmavě fialové až černofialové) - napřr. Bartsia alpina, Salvia verticillata

- modrá - např. Centaurea cyanus

- modrofialová - např. Aconitum plicatum

- hnědá (včetně žlutohnědé, hnědožluté, béžové a hnědofialové) - např. Euonymus verrucosus, Neottia nidus-avis

- červenohnědá - např. Asarum europaeum, Scrophularia nodosa

- černá - např. Carex acuta (barva plev)

Citace: Štěpánková P. \& Grulich V. (2019) Barva květu. - www.pladias.cz.

\section{Symetrie květů}

Květy krytosemenných rostlin se dělí na zygomorfní (souměrné, s jednou rovinou souměrnosti) a aktinomorfní (pravidelné, se dvěma nebo více rovinami souměrnosti). Symetrie květů se neuvádí u taxonů, jimž květní obaly chybějí nebo jsou zakrnělé a přeměněné v šupinovité nebo štětinovité útvary. Byla však posuzována u taxonů, jejichž květní obaly jsou redukovány jen na petalizované kalichy (např. Aizoaceae a Daphne) nebo kde je v květu složitý soubor útvarů listového původu (listeny) spolu s vlastními květními obaly a př́ípadně i petalizovanými staminodii a tyčinkami (např. Canna). Spirální a spirocyklické květy, ve skutečnosti asymetrické, jsou přriřazeny ke květům aktinomorfním u čeledi Nymphaeaceae a většiny druhů čeledi Ranunculaceae, zatímco u některých druhů druhé z čeledí (např. Aconitum a Delphinium) jsou hodnoceny jako zygomorfní. Květy bisymetrické (Brassicaceae, Dicentra a Lamprocapnos) jsou vždy hodnoceny jako aktinomorfní. Zygomorfní i aktinomorfní květy jsou současně uváděny u taxonů s oběma typy symetrie (např. Succisa pratensis). 
Údaje o symetrii květů byly získány z popisů v Květeně České republiky (díly 1-8; Hejný et al. 1988 et seq.) a v př́ípadech nejasností (zejména u nepůvodních taxonů naší flóry) konfrontovány s dalšími prameny, zejména s popisy v kompendiích Flora of North America (Flora of North America Editorial Committee 1993 et seq.), Flora of China (Wu et al. 1994 et seq.) a Flora of Pakistan (www.tropicos.org/Project/Pakistan).

Kategorie

- zygomorfní (jedna rovina souměrnosti)

- aktinomorfní (dvě a více rovin souměrnosti)

Citace: Grulich V., Holubová D., Štěpánková P. \& Řezníčková M. (2017) Symetrie květů. www.pladias.cz.

\section{Květní obaly}

Květní obaly krytosemenných, tj. části květu, které nemají reprodukční funkci, mohou být rozděleny na kalich a korunu (heterochlamydní kěty), anebo mohou být kalich a koruna morfologicky nerozlišitelné a tvořit okvětí (homochlamydní květy). Květní obaly mohou být redukované nebo mohou chybět.

V čeledi Apiaceae je př́tomnost kališních zoubků hodnocena jako kalich redukovaný; pokud tyto zoubky nejsou zřetelné, je kalich hodnocen jak chybějící. U čeledi Asteraceae je kalich považován za redukovaný, jestliže je přeměněn v chmýr, šupiny nebo zřetelný lem na vrcholu nažky; pokud tyto struktury nejsou přítomny, je kalich považován za chybějící. V čeledi Cyperaceae je přítomnost okvětních štětinek hodnocena jako okvětí redukované. Květy u všech zástupců čeledi Poaceae jsou hodnoceny jako květy s okvětím redukovaným. U rodu Basella jsou květní obaly arbitrárně hodnoceny jako kalich, ačkoli je některé prameny klasifikují jako okvětí. Hodnocení „okvětí, někdy chybí“ nebo „okvětí redukované, někdy chybí“ znamená, že na rostlině mohou být současně přítomny květy s okvětím (případně redukovaným) i bez něj (např. Atriplex).

Údaje byly excerpovány z popisů v Květeně České republiky (díly 1-8; Hejný et al. 1988 et seq.) a v případech nejasností (především u nepůvodních taxonů naší flóry) konfrontovány s dalšími prameny, zejména s popisy v kompendiích Flora of North America (Flora of North 
America Editorial Committee 1993 et seq.), Flora of China (Wu et al. 1994 et seq.) a Flora of Pakistan (www.tropicos.org/Project/Pakistan).

Kategorie

- okvětí

- okvětí, někdy redukované

- okvětí, někdy redukované nebo chybí

- okvětí, někdy chybí

- okvětí, redukované nebo chybí

- kalich a koruna

- kalich a koruna, koruna redukovaná nebo chybí

- kalich a koruna, koruna někdy chybí

- kalich přítomen, koruna někdy redukovaná

- kalich př́tomen, koruna redukovaná

- kalich přítomen, koruna redukovaná nebo chybí

- kalich přítomen, koruna někdy chybí

- kalich přítomen, koruna chybí

- kalich redukovaný, koruna př́ítomna

- kalich někdy chybí, koruna prrítomna

- kalich chybí, koruna př́tomna

- kalich chybí, koruna někdy přítomna

- redukované

- redukované nebo chybí

- květ bezobalný

Citace: Grulich V., Prokešová H. \& Štěpánková P. (2017) Květní obaly. - www.pladias.cz.

\section{Srůst koruny/okvětí}

Tato vlastnost květů krytosemenných se týká bud' srůstu koruny, anebo v př́padě nerozlišených květních obalů srůstu okvětí (napřr. Amaryllidaceae, Liliaceae a Orchidaceae). Nejsou posuzovány rostliny, jimž květní obaly chybějí (např. Salix) nebo jejichž květní obaly jsou zakrnělé, nezřetelné, nepočitatelné nebo přeměněné v šupinovité 
nebo štětinovité útvary, které mohou být bud' volné (např̀. Cyperaceae), anebo částečně srostlé (např. většina Poaceae). Květní obaly těchto rostlin jsou označeny jako redukované. Rovněž květní obaly rodu Aristolochia jsou redukovány na nepatrné šupinovité útvary na dně srostlého trubkovitého útvaru listenového původu. Pokud se u taxonů s jednopohlavnými květy tyto květy srůstem koruny nebo okvětí liší (např. Cannabis), jsou zařazeny do obou hlavních kategorií. Do obou kategorií jsou rovněž zařazeny taxony, jejichž některé květy mají květní obaly a jiné nikoli (např. Atriplex).

Údaje byly získány z popisů v Květeně České republiky (díly 1-8; Hejný et al. 1988 et seq.) a v nejasných př́ípadech (zejména u nepůvodních taxonů naší flóry) srovnány s dalšími prameny, zejména s popisy v kompendiích Flora of North America (Flora of North America Editorial Committee 1993 et seq.), Flora of China (Wu et al. 1994 et seq.) a Flora of Pakistan (www.tropicos.org/Project/Pakistan).

Kategorie

- volné

- srostlé

- redukované

Citace: Grulich V., Holubová D., Štěpánková P. \& Řezníčková M. (2017) Srůst koruny/okvětí. - www.pladias.cz.

\section{Tvar srostlé koruny nebo srostlého okvětí}

Tato vlastnost květů krytosemenných není uváděna u taxonů, jimž květní obaly chybějí (např. Salix) nebo jsou zakrnělé nebo přeměněné v šupinovité nebo štětinovité útvary (např. u čeledí Cyperaceae a Poaceae). U zástupců čeledi Amaranthaceae a rodu Cannabis jsou sice květní obaly víceméně zřetelné a jsou hodnoceny z hlediska srůstu, u srostlého okvětí však není jeho tvar hodnocen. Pokud koruna nebo okvětí svým tvarem stojí mezi základními rozlišovanými kategoriemi, je taxon přiřazen k oběma. U srostlých korun (okvětí) existuje mnoho obtížně kategorizovatelných zvláštností. Proto byla použita kategorie koruny nebo okvětí zvláštního typu, a to zejména u rodů Canna, Cyclamen, Dicentra, Gladiolus, Impatiens a Iris. 
Základní informace byly získány z popisů v Květeně České republiky (díly 1-8; Hejný et al. 1988 et seq.) a v nejasných př́ípadech (zejména u nepůvodních taxonů naší flóry) konfrontovány s dalšími prameny, zejména s popisy v kompendiích Flora of North America (Flora of North America Editorial Committee 1993 et seq.), Flora of China (Wu et al. 1994 et seq.) a Flora of Pakistan (www.tropicos.org/Project/Pakistan).

Kategorie

- baňkovitá

- dvoupyská

- jazykovitá

- kolovitá
- nálevkovitá

- řepicovitá

- šklebivá

- tlamatá
- trubkovitá

- zvonkovitá

- nit’ovitá

- zvláštního typu

Citace: Grulich V., Holubová D., Štěpánková P. \& Řezníčková M. (2017) Tvar srostlé koruny nebo srostlého okvětí. - www.pladias.cz.

\section{Srůst kalicha}

Kalich květů krytosemenných rostlin může být bud’ srostlý do kališní trubky (srostlolupenný, synsepalní kalich), nebo tvořený volnými kališními lístky (volnolupenný, chorisepalní kalich). U některých rostlin (zejména v čeledi Asteraceae) se kalich mění ve věneček štětinek označovaný jako chmýr. Taxony, které mají jak srostlolupenný, tak volnolupenný kalich (např. Platanus), se zde klasifikují jako „srostlolupenný i volnolupenný““. Češule (hypanthium) vzniká při srůstu květního lůžka s dolní částí květních obalů a tyčinkami. Podle jiných názorů jde o výsledek interkalárního růstu květního lůžka, v jehož důsledku vzniká pohárkovitý útvar, který na horním okraji nese oba kruhy květních obalů a tyčinky. Někdy dokonce srůstá vnitřní strana hypanthia s vnějšími stěnami plodolistů, čímž vzniká spodní semeník. U většiny rodů čeledi Onagraceae hypanthium vytváří nad semeníkem delší nebo kratší květní trubku.

Údaje o srůstu kalicha byly sestaveny podle př́ruček Květena České republiky (díly 1-8; Hejný et al. 1988 et seq.), Klíč ke květeně České republiky (Kubát et al. 2002), jakož i atlasů Új magyar füvészkönyv (Király et al. 2011) a Exkursionsflora von Deutschland (Jäger \& Werner 2000). 
Kategorie

- volnolupenný

- $\quad$ srostlý na bázi

- srostlolupenný i volnolupenný
- srostlolupenný

- chmýr

- češule/hypanthium

Citace: Prokešová H. \& Grulich V. (2017) Srůst kalicha. - www.pladias.cz.

\section{Typ květenství}

Typy květenství vycházejí z morfologického systému použitého v Květeně České republiky (díly 1-8; Hejný et al. 1988 et seq.). Přesné určení typu květenství je však často nejednoznačné kvůli různým interpretacím téhož objektu. U druhů s jednopohlavnými květy mohou být květy různých pohlaví uspořádány v odlišných typech květenství. V některých případech není možné typ květenství rozlišit bez podrobnějších znalostí evoluční morfologie, napřr. okolík versus lichookolík u rodu Butomus. Vyskytují se také květenství složená, jejichž jednotlivé komponenty mohou mít výrazně odlišnou stavbu, zejména u čeledi Asteraceae, kde může být až trojité skládání (např. Echinops sphaerocephalus má často kružel hlávek úborů).

Údaje byly získány z popisů v Květeně České republiky (díly 1-8; Hejný et al. 1988 et seq.) a v případech nejasností (především u nepůvodních taxonů naší flóry) konfrontovány $\mathrm{s}$ dalšími prameny, zejména s popisy v kompendiích Flora of North America (Flora of North America Editorial Committee 1993 et seq.), Flora of China (Wu et al. 1994 et seq.) a Flora of Pakistan (http://www.tropicos.org/Project/Pakistan). U kritických skupin (např. Rubus) byla zejména u nedávno popsaných druhů tato charakteristika vyhledána v originálních pramenech.

Kategorie

- cyathium $\mathrm{v}$ lichookolíku

- hlávka

- hlávka (klas) samičí

- hlávka klásků
- hlávka lichopřeslenů

- hlávka samičí

- hlávka úborů

- hrozen

- hrozen hlávek
- hrozen chocholíků úborů

- hrozen klásků

- hrozen lichopřeslenů

- hrozen okolíků 
- hrozen samčí

- hrozen samičí

- hrozen svazečků

- hrozen úborů

- hrozen úborů samčí

- hrozen vijanů

- chocholičnatá lata

- chocholičnatá lata svazečků

- chocholičnatá lata svazečků úborů

- chocholičnatá lata úborů

- chocholík

- chocholík úborů

- jehněda

- jehněda samčí

- jehněda samičí

- klas

- klas klásků

- klas samčí

- klas samičí

- klásek

- kružel

- kružel hlávek úborů
- kružel klásků

- kružel samčí

- kružel úborů

- květy jednotlivé

- květy jednotlivé samčí

- květy jednotlivé samičí

- lata

- lata hlávek

- lata hlávek úborů

- lata chocholíků

- lata klásků

- lata klásků samčí

- lata lichoklasů

- lata samčí

- lata svazečků

- lata šroubelů

- lata úborů

- lata vidlanů

- lata vijanů

- lichoklas

- lichoklas hlávek

- lichoklas klásků

- lichoklas lichopřeslenů

- lichoklas samičí
- lichoklas úborů

- lichookolík

- lichookolík úborů

- lichopřeslen

- nepravý hrozen

- okolík

- okolík klasů klásků

- palice

- palice samičí

- složený okolík

- svazeček

- svazeček samčí

- svazeček samičí

- svazeček úborů samičí

- sykonium

- Šištice

- šroubel

- úbor

- úbory jednotlivé

- vějíř́ek

- vidlan

- vidlan samičí

- vidlan úborů

- vijan

Citace: Grulich V. \& Štěpánková P. (2019) Typ květenství. - www.pladias.cz.

\section{Diklinie}


Diklinie popisuje prostorové oddělení samčích a samičích generativních orgánů. Synecické (monoklinní) rostliny, zahrnující většinu taxonů středoevropské flóry, mají jen oboupohlavné (hermafroditní) květy. Rostliny s jednopohlavnými květy jsou jednodomé (monoecické, s květy různých pohlaví na témže jedinci), anebo dvoudomé (diecické, s květy různých pohlaví na různých jedincích). Rostliny gynomonoecické mají samičí a oboupohlavné květy na jednom jedinci, zatímco rostliny andromonoecické mají samčí a oboupohlavné květy na jednom jedinci. Rostliny gynodiecické mají samičí a oboupohlavné květy na různých jedincích, anebo někteří jedinci mají jen samičí květy a jiní jedinci samčí i samičí květy. Rostliny androdiecické mají samčí a oboupohlavné květy na různých jedincích, anebo někteří jedinci mají jen samčí květy a jiní jedinci samčí i samičí květy. Rostliny triecické mají jedince jen se samčími květy, jedince jen se samičími květy a jedince s oboupohlavnými (nebo samčími i samičími) květy. Rostliny trimonoecické mají na jedné rostlině samčí, samičí i oboupohlavné květy. Další rostliny mají samčí orgány sterilní. Údaje byly převzaty z databáze BiolFlor (Durka 2002).

Kategorie

- synecický

- jednodomý

- dvoudomý

- gynomonoecický

- andromonoecický
- gynodiecický

- androdiecický

- triecický

- trimonoecický

- samčí sterilní

Zdroj dat a citace: Durka (2002).

\section{Způsob generativního rozmnožování}

Způsob generativního rozmnožování je určován původem gamet, které se účastní vzniku potomstva. Na jedné straně může jít o obligátní alogamii (cizosprášení, kdy je k opylení potřeba pyl geneticky odlišného jedince), podmíněnou geneticky odmítnutím vlastního pylu (autoinkompatibilita), vzájemným časovým posunem tvorby vaječných buněk a pylu v rámci jednoho květu nebo jedné rostliny (dichogamie) nebo prostorovým oddělením samčích a samičích orgánů (v krajním případě dvoudomost). Na druhé straně může jít o obligátní autogamii, kdy dochází k opylení a oplození v rámci jednoho květu. Zřejmě nejčastější jsou 
smíšené strategie, kdy rostliny v různé míře využívají opylení jak cizím, tak i vlastním pylem. Míra samosprášení může být ovlivněna jak genetickými, tak ekologickými faktory, mimo jiné frekvencí, diverzitou a způsobem pohybu opylovačů. Zde se rozlišují tři kategorie: (1) fakultativní alogamie (cizosprášení převládá, samosprášení je ale možné, často jako ,pojistka“ při nedostatku cizího pylu), (2) fakultativni autogamie (převážně samosprášení, občas ale i cizosprášení) a (3) smišsená reprodukce, kde podíl cizosprášení a samosprášení kolísá v rámci jednoho druhu (časté jsou např. rozdíly mezi populacemi na gradientu určitého geograficky strukturovaného ekologického faktoru). Poslední hlavní kategorií je apomixe, tj. tvorba semen bez oplození vaječné buňky. Může být bud' obligátní (potomstvo je geneticky totožné s mateřskou rostlinou), nebo fakultativní (doprovázená zbytkovou sexualitou, zpravidla ale s malou četností). Nejasné případy spadají do kategorie apomixe. Hybridní rostliny jsou často sterilní (sterilita), ale mohou se někdy šířit vegetativně, a tak na lokalitě dlouhodobě přežívat a vytvářet porosty. V některých případech (např. Pilosella) jsou sterilní hybridy hodnoceny jako druhy a zařazeny do tohoto seznamu. Některé morfologicky dobře definované a široce přijímané druhy zahrnují populace $\mathrm{s}$ kontrastními způsoby reprodukce (zpravidla úzce spojenými s ploidní úrovní), např. některé populace jsou sexuální a alogamické, zatímco jiné jsou apomiktické. Údaje o způsobu generativního rozmnožování taxonů české flóry byly získány rešerší různých literárních zdrojů.

Kategorie

- alogamie

- alogamie autoinkompatibilita

- fakultativní alogamie

- autogamie

- fakultativní autogamie
- smíšená reprodukce

- apomixe

- obligátní apomixe

- fakultativní apomixe

- sterilita

Citace: Chrtek J. jun. (2018) Způsob rozmnožování. - www.pladias.cz.

\section{Způsob opylení}

Přenos pylu na bliznu je zprostředkován bud' abiotickými vektory (přenašeči), jako je vítr (anemofilie) nebo voda (hydrofilie), anebo biotickými vektory, jako je hmyz (entomofilie). 
Alternativním mechanismem je samoopylení (autogamie), které může mít různé speciální formy, jako je kleistogamie (samoopylení v neúplně vyvinutých, obligátně autogamních květech), pseudokleistogamie (samoopylení v květech, které se neotevřou kvůli nepříznivým podmínkám prostředí) nebo geitonogamie (samoopylení pylem ze sousedního květu stejné rostliny, kdy pyl není přenesen vektorem). Informace o způsobech opylení byla převzata $\mathrm{z}$ databáze BiolFlor (Durka 2002).

Kategorie

- anemofilie

- hydrofilie

- entomofilie

- autogamie
- kleistogamie

- pseudokleistogamie

- geitonogamie

Zdroj dat a citace: Durka (2002).

\section{Spektrum opylovačů}

Pro vybrané rostlinné taxony je uvedeno zastoupení jednotlivých funkčních skupin opylovačů. Rozlišujeme 13 funkčních skupin opylovačů a sběrnou kategorii pro neurčené opylovače. Vymezení těchto skupin odráží (1) podobnost chování zahrnutých taxonů z hlediska opylování, (2) náročnost determinace jednotlivých skupin pro polinační biology a (3) četnost výskytu mezi návštěvníky květů rostlin české flóry (např. můry a lišajové představují specifickou skupinu, ale kvůli malým zaznamenaným četnostem byli zahrnuti mezi ostatní motýly). Na webu databáze Pladias se z technických důvodů zobrazuje pouze výčet funkčních skupin, které se vyskytují u daného druhu rostliny. Funkční skupiny, které se podílejí méně než $10 \%$ na celkovém složení společenstva opylovačů, jsou uvedeny v závorce.

Údaje jsou založeny převážně (asi z 80 \%) na evropských studiích, které kvantitativně zaznamenávaly všechny funkční skupiny opylovačů navštěvujících cílové druhy rostlin. Zbývajících asi 20 \% údajů bylo získáno původním výzkumem. Spektra opylovačů byla vytvořena převážně pro běžné byliny nelesních biotopů, a to na základě pozorování přibližně 220 tisíc jedinců opylovačů zaznamenaných na jednotlivých rostlinách. Rostlinný taxon byl zahrnut do databáze, pokud pro něj bylo zaznamenáno aspoň 25 jedinců opylovačů. 
Spektrum opylovačů daného rostlinného taxonu bylo stanoveno ze součtu pozorovaných opylovačů ze všech studií, v nichž byl rostlinný taxon zachycen. Záznamy ze studií s četnostmi opylovačů udanými pouze procenticky musely být před sečtením převedeny na početnosti. To bylo provedeno na základě konzervativního předpokladu, že taxon opylovače s nejnižším procentickým podílem v rámci daného rostlinného taxonu a studie odpovídá početnosti jedna, čímž bylo možné dopočítat základ počtu opylovačů, na němž byla procenta založena. U studií, které před vyjádřením spektra opylovačů procentickým složením průměrovaly počty opylovačů z několika dílčích ploch, tento postup nebylo možné použít (průměrování skutečný počet získaný výše uvedenou metodou nadhodnocuje). Početnost opylovačů u druhů z takových studií byla odhadnuta jako polovina zpětně transformované předpovídané hodnoty z regresní rovnice: $\log ($ počet jedinců $) \sim 0,461 \times \log ($ počet taxonů $)+$ $0,815\left(\mathrm{~F}_{1,3774}=1073 ; \mathrm{p}<0,001 ; \operatorname{adj} . \mathrm{R}^{2}=0,221\right)$ získané $\mathrm{z}$ dat pro jednotlivé lokality a druhy u všech studií se zaznamenanými početnostmi opylovačů.

Kategorie

- včela medonosná - Apis mellifera

- čmeláci - rod Bombus incl. Psithyrus

- samotářské včely - druhy „včel“ (Apoidea: Anthophila) krmící potomstvo pylem mimo včelu medonosnou a čmeláky

- ostatní blanokřídlí - Hymenoptera s výjimkou čmeláků, samotářských včel a včely medonosné

- pestřenky - Syrphidae větší než $5 \mathrm{~mm}$

- mouchy s. 1. - krátkorozí dvoukřídlí z nadčeledí Muscoidea a Sphaeroceroidea (mouchy, květilky, mrvnatky a př́íbuzní) větší než $5 \mathrm{~mm}$

- masařky s. 1. - masařky a bzučivky (čeledi Sarcophagidae, Calliphoridae, Rhinophoridae) větší než $5 \mathrm{~mm}$

- ostatní dvoukřrídlí - Diptera nepatřící mezi mouchy, masařky ani pestřenky (nebo patřící do jmenovaných skupin, ale menší než $5 \mathrm{~mm}$ )

- motýli - Lepidoptera včetně můr a lišajů

- brouci - Coleoptera bez lesknáčků

- „lesknáčci“ - malí agregovaně se vyskytující florikolní brouci (čeledi Nitidulidae, Kateridae, Byturidae, Phalacridae)

- tř́sněnky - Thysanoptera 
- ostatní skupiny - pravidelní návštěvníci květů s předpokládaným podílem na opylování (mimo řády Diptera, Hymenoptera, Lepidoptera, Coleoptera a Thysanoptera)

- neurčení - opylovači bez bližšího určení v původní práci nebo určení tak, že je nebylo možné jednoznačně přiřadit k žádné z rozeznávaných skupin opylovačů

Citace: Janovský Z. (2020) Opylovači. - www.pladias.cz.

\section{Plod, semeno a šíření}

\section{Typ plodu}

Základní členění plodů je na suché a dužnaté. V rámci těchto kategorí jsou plody dále klasifikovány typologickou metodou podle schématu popsaného v prvním svazku Květeny České republiky (Slavíková 1988). Typ plodu tedy není odvozen od typu plodu u blízce př́ibuzných druhů nebo rodů, pokud plod z morfologického hlediska formálně naplňuje charakteristiku jiného typu plodu.

Jednosemenné nepukavé plody u druhů čeledi Brassicaceae jsou důsledně hodnoceny jako nažka (např. Crambe). Nepukavé vícesemenné plody v téže čeledi, které se rozlamují na jednosemenné díly, se označují jako struk (např. Bunias a Raphanus), a to i v prŕípadě, kdy se plod láme na dvě samostatné části, z nichž jedna je jednosemenná a nepukavá, zatímco druhá, morfologicky odlišná dvousemenná nebo vícesemenná část se otvírá (např̀. Rapistrum rugosum). Podobně jsou posuzovány i plody u většiny zástupců čeledi Fabaceae. Pukavé plody většiny taxonů jsou označeny jako lusk, zatímco nepukavé vícesemenné plody, které se lámou na jednosemenné díly, jsou označeny jako struk (např. Hippocrepis a Securigera). Nepukavé jednosemenné plody jsou hodnoceny jako nažka (např. Onobrychis a Trifolium). Termín lusk však zůstal zachován pro dvousemenné a vícesemenné, ale nepukavé plody, pro něž v české morfologické terminologii neexistuje vhodné označení (Sophora japonica, Vicia faba). Plody všech pryšců (Euphorbia) jsou hodnoceny jako tobolky, ačkoli v některých př́padech se zřejmě samotná semena neuvolňují. Do samostatné kategorie plodů zvláštního typu se řadí plody, které se podle použitých schémat obtížně 
klasifikují. Dužnaté nepravé plody rodů Basella, Ficus, Maclura, Morus, Nuphar a Nymphaea jsou sloučeny do zvláštní kategorie.

Informace o typu plodů byly získány především z popisů v Květeně České republiky (díly 1-8; Hejný et al. 1988 et seq.). U taxonů, které v Květeně České republiky nejsou uvedeny, jakož i ve sporných případech (převážně u nepůvodních taxonů naší flóry), byly konfrontovány další prameny, zejména kompendia Flora of North America (Flora of North America Editorial Committee 1993 et seq.), Flora of China (Wu et al. 1994 et seq.) a Flora of Pakistan (www.tropicos.org/Project/Pakistan), v př́padě čeledi Fabaceae také Flora iberica (Castroviejo et al. 1986 et seq.).

Kategorie

- $\quad$ suchý plod - diskovitý

- suchý plod - dvounažka

- $\quad$ suchý plod - dvounažka s karpoforem

- suchý plod - kř́ídlatá dvounažka

- suchý plod - lusk

- $\quad$ suchý plod - měchýřek

- suchý plod - nažka

- suchý plod - nažka v mošničce

- suchý plod - obilka

- suchý plod - oříšek

- suchý plod - poltivý

- suchý plod - souplodí měchýřků

- suchý plod - souplodí nažek
- $\quad$ suchý plod - struk

- suchý plod - šešule

- $\quad$ suchý plod - šešulka

- $\quad$ suchý plod - tobolka

- $\quad$ suchý plod - tvrdka

- suchý plod - zobanitý

- dužnatý plod - bobule

- dužnatý plod - malvice

- dužnatý plod - peckovice

- dužnatý plod - souplodí peckoviček

- dužnatý plod - šípek

- dužnatý plod - zvláštního typu

Citace: Grulich V., Holubová D., Štěpánková P. \& Řezníčková M. (2017) Typ plodu. www.pladias.cz.

\section{Barva plodu}


Barva plodu se stupnicí standardizovanou do desíti základních barev podle Květeny České republiky (díly 1-8; Hejný et al. 1988 et seq.) a Klíče ke květeně České republiky (Kubát et al. 2002). Pro každý taxon je uvedena pouze jedna základní barva zralého plodu.

Kategorie

- bílá

- zelená

- žlutá

- oranžová
- fialová

- červená

- modrá

- hnědá

Zdroj dat a citace: Hejný et al. (1988 et seq.), Kubát et al. (2002).

\section{Způsob rozmnožování}

Rozmnožování je tvorba potomků, kteří jsou fyzicky oddělení od mateřské rostliny. Rostliny se rozmnožují bud' semeny (nebo sporami), anebo vegetativně, přičemž kombinace obou typů rozmnožování u jednoho taxonu je běžná. Nepohlavní tvorba semen (apomixe) není považována za vegetativní rozmnožování. Údaje byly převzaty z databáze BiolFlor (Durka 2002).

Kategorie

- výhradně vegetativně

- převážně semeny/sporami

- převážně vegetativně

- výhradně semeny/sporami

- semeny/sporami a vegetativně

Zdroj dat a citace: Durka (2002).

\section{Jednotka šírení (diaspora)}

Diaspora, nazývaná také disperzule nebo propagule, je generativní nebo vegetativní část těla rostliny, která se šiří od mateřské rostliny a může dát vzniknout novému jedinci.

Generativní diaspory zahrnují spory, semena a plody nebo podobné jednotky šíření (napřr. souplodí v rodu Fragaria, plodenství v rodu Morus, šiška nahosemenných, semeno 
obklopené míškem v rodu Taxus nebo klásky a jejich různé fragmenty v čeledi Poaceae). U rostlin s pukavými plody nebo rozkládajícími se zralými dužnatými plody, které uvolňují semena, lze za diasporu považovat semeno i plod, zatímco u rostlin s nepukavými plody je diasporou pouze plod. Zvláštním typem generativních diaspor jsou velké nadzemní části rostlin s větvemi a velkým květenstvím u tzv. stepních běžců (napřr. Crambe tataria a Falcaria vulgaris).

Vegetativní diaspory jsou životaschopné a přenositelné části rostlin, které vznikají nad zemí nebo ve vodě a oddělují se od mateřské rostliny před zakořeněním a tvorbou výhonků. Za vegetativní diaspory nepovažujeme klonální orgány spojené s mateřskou rostlinou do té doby, než se dceřiná rostlina osamostatní (napřr. výběžky v rodu Fragaria), a různé typy podzemních orgánů nebo bazálních částí prýtů rostoucích v zemi (např. hlízy u Helianthus tuberosus a podzemní výběžky trav). Vegetativní diaspory zahrnují (1) turiony (např. v rodech Myriophyllum a Utricularia) a podobné přezimující struktury (např. oddělitelné pupeny v rodech Elodea a Groenlandia a zkrácené prýty některých rdestů na vrcholu oddenku nebo výběžku, např. u Potamogeton alpinus); (2) pacibulky a hlízky stonkového původu (např. u Allium oleraceum a Dentaria bulbifera) nebo kořenového původu (jen v rodu Ficaria); (3) rostlinky vzniklé pseudoviviparií, tj. vyrostlé vegetativně v květu nebo klásku (např. Poa alpina); (4) rostlinky vzniklé z pupenů na listech (napřr. Cardamine pratensis); (5) rostlinky vzniklé na koncích výběžků a oddělitelné před zakořeněním (např. Hydrocharis a Jovibarba); (6) nespecializované fragmenty prýtů (např. Sedum album a řada vodních rostlin), konce výhonků (např̀. Ceratophyllum demersum) nebo oddělitelné útvary vzniklé z úžlabních pupenů (např. Agrostis canina, Arabidopsis halleri a Rorippa amphibia); (7) rostliny množicí se pučením (jen Lemnaceae); a (8) gemy tvořené gametophyty (jen Trichomanes speciosum).

Údaje jsou převzaty z publikace Sádlo et al. (2018).

Kategorie

- semeno

- spora

- plod, plodenství nebo jeho část

- stepní běžec

- turion

- pacibulka nebo hlízka
- pseudoviviparie

- rostlinka vyrostlá z listu mateřské rostliny

- rostlinka vyrostlá z výběžku mateřské rostliny

- fragment stonku 
- pučení

- gemma na gametofytu

Zdroj dat a citace: Sádlo et al. (2018).

\section{Strategie šíření}

Rostliny se šíří různými způsoby, pomocí různých vektorů. Například anemochorie je šíření větrem, hydrochorie šíření vodou, endozoochorie v trávicím traktu zvíraat, epizoochorie přichycením na povrchu těla zvířat apod. Jednotlivé rostlinné taxony však využívají spíše kombinace různých způsobů šíření než jediný způsob. Kombinace způsobů šíření, které se opakovaně vyskytují u různých rostlinných taxonů, se nazývají strategie šíření. Sádlo et al. (2018) rozlišili devět strategií šíření nazvaných podle rodových jmen typických zástupců. Zařazení jednotlivých taxonů české flóry do strategií je převzato $\mathrm{z}$ tohoto zdroje.

Kategorie

- Allium - převážně autochorie, vzácněji anemochorie, endozoochorie a epizoochorie. Jde o nejběžnější strategii šíření zahrnující asi 56 \% taxonů české flóry. Přibližně polovina zahrnutých taxonů jsou z hlediska šíření generalisté bez jasného morfologického přizpůsobení k anemochorii nebo zoochorii. Velká část myrmekochorních nebo pravděpodobně myrmekochorních druhů je také zařazena do této kategorie.

- Bidens - převážně autochorie a epizoochorie, méně často endozoochorie. Tato strategie kombinuje dva základní způsoby šíření, z nichž autochorie je významnější, a to i přes prŕítomnost morfologických struktur naznačujících epizoochorii.

- Cornus - převážně autochorie a endozoochorie. Tato strategie je typická pro byliny, keře a nižší stromy s dužnatými plody, často z čeledi Rosaceae. Patří sem i vyšší stromy s velkými, těžkými a živinami bohatými semeny.

- Epilobium - převážně anemochorie a autochorie, méně často endozoochorie a epizoochorie. Rostliny s touto strategií šíření jsou typické pro mezická a suchá stanoviště.

- Lycopodium - převážně anemochorie, méně často autochorie, endozoochorie, epizoochorie a hydrochorie. Tato strategie šíření se spoléhá na lehké, velmi malé 
spory a semena, které jsou kromě větru šířeny i různými jinými vektory. Ve srovnání s jinými strategiemi zde má malý význam autochorie.

- Phragmites - převážně anemochorie a hydrochorie, méně často autochorie, endozoochorie a epizoochorie. Mokřadní rostliny s lehkými semeny nebo plody vybavenými létacím aparátem. Většina taxonů s touto strategií postrádá vegetativní diaspory. Typické růstové formy spojené s touto strategií šíření jsou dřeviny, vysoké klonální traviny a byliny.

- Sparganium - převážně autochorie a hydrochorie, méně často endozoochorie a epizoochorie. Tato strategie je mokřadní analogií strategie Wolffia, která je typická pro vodní rostliny. Patří sem převážně jednoděložné rostliny tvořící nažky s dobrou plovatelností a často s vegetativními diasporami.

- Wolffia - převážně hydrochorie, méně často endozoochorie a epizoochorie. Tato strategie šíření je typická pro vodní makrofyty šśřící se pomocí plodů, semen i spor. U většiny z nich však převládá vegetativní reprodukce, napřr. fragmentací stonků, tvorbou výběžků nebo v čeledi Lemnaceae pučením.

- Zea. Taxony s touto strategií se šíří generativními diasporami jen výjimečně nebo vůbec ne a netvoří nadzemní vegetativní diaspory.

Zdroj dat a citace: Sádlo et al. (2018).

\section{Myrmekochorie}

Myrmekochorní rostliny, tedy taxony šířené mravenci, mají semena nebo plody s elaiozomem, dužnatým přívěskem bohatým na živiny. U mnoha taxonů je však morfologická indikace myrmekochorie nejistá a prŕímé doklady jsou sporné. Pro spolehlivé rozhodnutí, zda je daný př́ivěsek semene elaiozom, by byl nutný odnosový experiment (nabídnutí semen s přívěskem a bez něj mravencům) nebo chemické analýzy (obsah živin v elaisomech se liší od semen a je poměrně stabilní i u nepř́ibuzných taxonů; Konečná et al. 2018). Proto je zde rozlišen větší počet kategorií než jednoduché binární dělení na myrmekochorní a nemyrmekochorní taxony:

- myrmekochorní - elaiozom (zřetelný dužnatý prŕivěsek semene či plodu) je přítomen 
- pravděpodobně myrmekochorní - dužnatá struktura připomínající elaiozom je prrítomna, poměr velikosti přívěsku a semene je však velmi malý, a potenciální výhoda přenosu semen by tedy pro mravence byla malá

- pravděpodobně nemyrmekochorní - na semeni nebo plodu je vyvinuta struktura nepodobná elaiozomu, např. nedužnatý přívěsek nebo lem

- nemyrmekochorní (a) - elaiozom není přítomen, přestože v literatuře je taxon uváděn jako myrmekochorní nebo taxony jemu blízce př́buzné jsou považovány za myrmekochorní

- nemyrmekochorní (b) - elaiozom není př́ítomen a taxon není v literatuře zmiňován jako myrmekochorní

Za nemyrmekochorní se považují ty rostlinné taxony, jejichž diaspory jsou přenášeny mravenci do mraveniště, aniž by měly elaiozom (např. slouží jako materiál na stavbu hnízda nebo obsahují chemické atraktanty lákající mravence bez odměny za odnos).

Údaje jsou založeny na literární rešerši a studiu vzorků semen taxonů, které jsou v literatuře uváděny jako myrmekochorní nebo jsou blízce příbuzné myrmekochorním taxonům. Seznam těchto taxonů s fotografiemi jejich semen je uložen na http://botanika.prf.jcu.cz/myrmekochorie/. Taxony byly vybrány z čeledí české flóry obsahujících aspoň jeden taxon považovaný v literatuře za myrmekochorní (Sernander 1906, Hejný et al. 1988 et seq., Fitter \& Peat 1994, Klotz et al. 2002, Grime et al. 2007, Kleyer et al. 2008, Lengyel et al. 2010, Servigne 2008, Študent 2012). Tyto taxony patří do těchto 37 čeledí: Amaryllidaceae, Apiaceae, Apocynaceae, Aristolochiaceae, Asparagaceae, Asteraceae, Boraginaceae, Campanulaceae, Caryophyllaceae, Celastraceae, Colchicaceae, Crassulaceae, Cyperaceae, Dipsacaceae, Euphorbiaceae, Fabaceae, Iridaceae, Juncaceae, Lamiaceae, Liliaceae, Linaceae, Montiaceae, Orobanchaceae, Oxalidaceae, Papaveraceae, Plantaginaceae, Poaceae, Polygalaceae, Polygonaceae, Portulacaceae, Primulaceae, Ranunculaceae, Rosaceae, Resedaceae, Santalaceae, Urticaceae a Violaceae. Taxony z jiných čeledí byly klasifikovány jako nemyrmekochorní (b).

Pro každou z pěti výše uvedených kategorií je použita subkategorie nv (= non vidimus, tj. neviděli jsme) u taxonů, pro které se nepodařilo najít žádný literární údaj, fotografii semene, ani získat vlastní sběr, ale dotyčná klasifikace je pravděpodobná na základě vlastností blízce př́ibuzných taxonů. Např́iklad nemáme údaje pro Centaurea bruguiereana, ale řadíme ji do subkategorie myrmekochorní nv, protože všechny taxony rodu Centaurea, pro které máme údaje, elaiozom mají. 
Kategorie

- myrmekochorní

- myrmekochorní nv

- pravděpodobně myrmekochorní

- pravděpodobně myrmekochorní nv

- pravděpodobně nemyrmekochorní
- pravděpodobně nemyrmekochorní nv

- nemyrmekochorní (a)

- nemyrmekochorní (a) nv

- nemyrmekochorní (b)

- nemyrmekochorní (b) nv

Citace: Konečná M., Štech M. \& Lepš J. (2018) Myrmekochorie. - www.pladias.cz.

\section{Podzemní orgány a klonalita}

\section{Stonková metamorfóza}

Stonkové metarmorfózy jsou přeměny stonku, při nichž se vyvíjejí různé struktury zajišstující speciální funkce, jako je vegetativní šíření a ukládání zásobních látek. Údaje o stonkových metamorfózách jsou převzaty z databáze BiolFlor (Krumbiegel 2002).

Kategorie

- výběžek - boční (výjimečně hlavní) prýt s dlouhými články a adventivními kořeny; jeho oddělením od mateřské rostliny vznikají samostatné ramety

- výběžek zakončený hlízou - podzemní výběžek s hlízovitým zduřením několika článků na distálním konci, které se vyvíjí na konci vegetačního období a slouží k ukládání živin; v dalším vegetačním období se z těchto hlíz vyvíjejí nadzemní prýty

- výběžek zakončený cibulí - podzemní výběžek zakončený cibulí na distálním konci; v dalším vegetačním období se z těchto cibulí vyvíjejí nadzemní prýty

- oddenek - podzemní nebo při povrchu půdy rostoucí prýt, většinou ztlustlý, žijící déle než jeden rok, nesoucí adventivní kořeny, pupeny a obvykle i redukované listovité struktury; oddenek má význam pro šíření i jako zásobní orgán 
- oddenek podobný výběžku - oddenek s delšími články, který má význam hlavně pro šíření

- pleiokorm - systém nahloučených vytrvalých prýtů na proximálním konci

vytrvávajícího hlavního kořene; nové prýty vznikají z pupenů v paždí bazálních listi̊ a spojení těchto prýtů s hlavním kořenem je trvalé

- pleiokorm podobný oddenku - pleiokorm, u kterého nové prýty nejprve vyrůstají z pupenů v paždí bazálních listů, později vzniklé prýty ale vyrůstají z adventivně kořenících oddenkovitých prýtů, které později ztrácejí spojení s hlavním kořenem

- stonková hlíza - ztlustlá, většinou podzemní část stonku přetrvávající méně než jeden rok, využívaná k ukládání zásobních látek

- cibule - silně zkrácená část stonku s nahloučenými šupinovitými listy nebo listovými bázemi, která slouží k ukládání zásobních látek i vegetativnímu rozmnožování

- pacibulka - silně zkrácená část nadzemního stonku se slabě vyvinutými nebo nevyvinutými orgány, která se po oddělení od mateřské rostliny vyvíjí v novou rostlinu

- pseudoviviparní klásek - klásek trav přeměněný na drobný prýt, který se po oddělení od matečné rostliny vyvíjí v novou rostlinu

- turion - silně zkrácený vegetativní prýt pupenovitého tvaru, který přezimuje s listy nebo částmi listů; po oddělení od mateřské rostliny se vyvíjí v novou rostlinu

- kolec - trn stonkového původu vznikající většinou v místě bočního prýtu

- úponka - nit’ovitá, větvená nebo nevětvená část stonku, kterou se rostlina přidržuje opory

- stonková sukulence - tvorba většího množství pletiva sloužícího jako zásobárna vody projevující se dužnatým ztlustnutím stonku

- asimilující stonek - stonek sloužící k asimilaci místo listů nebo doplňkově k nim

Zdroj dat a citace: Krumbiegel (2002).

\section{Kořenová metamorfóza}

Kořenové metamorfózy jsou přeměny stonku, při nichž se vyvíjejí různé struktury zajišt’ující speciální funkce, jako je vegetativní šiřrení a ukládání zásobních látek. Údaje o stonkových metamorfózách jsou převzaty z databáze BiolFlor (Krumbiegel 2002). 
Kategorie

- hlavní zásobní kořen - ztlustlý hlavní (primární) kořen včetně hypokotylu a epikotylu, který slouží jako zásobní orgán

- sekundární zásobní kořen - částečně ztlustlý adventivní nebo boční kořen, který slouží jako zásobní orgán; na rozdíl od kořenové hlízy ztratil primární funkce kořene, jako je uchycení rostliny v půdě a př́ijem vody a minerálů

- kořenová hlíza - ztlustlý, nevětvený adventivní kořen rostoucí z obnovovacího pupenu; primárně slouží jako zásobní orgán, zatímco na př́ímu vody a minerálů se podílí vzácně

- kořenový výběžek - adventivně zakořenělý prýt rostoucí z hlavního nebo bočního kořene; při růstu v půdě je bud’ bezlistý nebo má redukované listové fragmenty

- kořenový náběh - horní část bočního kořene stromu; jeho ztlustlá horní část tvoří opěrné pilíře, které zesilují bázi kmene a zvyšují jeho stabilitu

- prř́čepivý kořen - krátký vzdušný kořen připevněný k substrátu, kmenu nebo zdi, aniž by pronikal dovnitř

- bez kořene

Zdroj dat a citace: Krumbiegel (2002).

\section{Zásobní orgán}

Existence orgánů sloužících jako zásobárna živin nebo vody je u rostlin často propojená se schopností vegetativního rozmnožování a šíření. Údaje o zásobních orgánech byly převzaty z databáze BiolFlor (Krumbiegel 2002).

\section{Kategorie}

- výběžek - boční (výjimečně hlavní) prýt s dlouhými články a adventivními kořeny; jeho oddělením od mateřské rostliny vznikají samostatné ramety

- výběžek zakončený hlízou - podzemní výběžek s hlízovitým zduřením několika článků na distálním konci, které se vyvíjí na konci vegetačního období a slouží k ukládání živin; v dalším vegetačním období se z těchto hlíz vyvíjejí nadzemní prýty 
- výběžek zakončený cibulí - podzemní výběžek zakončený cibulí na distálním konci; v dalším vegetačním období se z těchto cibulí vyvíjejí nadzemní prýty

- oddenek - podzemní nebo při povrchu půdy rostoucí prýt, většinou ztlustlý, žijící déle než jeden rok, nesoucí adventivní kořeny, pupeny a obvykle i redukované listovité struktury; oddenek má význam pro šíření i jako zásobní orgán

- oddenek podobný výběžku - oddenek s delšími články, který má význam hlavně pro šíření

- pleiokorm - systém nahloučených vytrvalých prýtů na proximálním konci vytrvávajícího hlavního kořene; nové prýty vznikají z pupenů v paždí bazálních listů a spojení těchto prýtů s hlavním kořenem je trvalé

- pleiokorm podobný oddenku - pleiokorm, u kterého nové prýty nejprve vyrůstají z pupenů v paždí bazálních listů, později vzniklé prýty ale vyrůstají z adventivně kořenících oddenkovitých prýtů, které následně ztrácejí spojení s hlavním kořenem

- stonková hlíza - ztlustlá, většinou podzemní část stonku přetrvávající méně než jeden rok, využívaná k ukládání zásobních látek

- cibule - silně zkrácená část stonku s nahloučenými šupinovitými listy nebo listovými bázemi, která slouží k ukládání zásobních látek i vegetativnímu rozmnožování

- pacibulka - silně zkrácená část nadzemního stonku se slabě vyvinutými nebo nevyvinutými orgány, která se po oddělení od mateřské rostliny vyvíjí v novou rostlinu

- turion - silně zkrácený vegetativní prýt pupenovitého tvaru, který přezimuje s listy nebo částmi listů; po oddělení od mateřské rostliny se vyvíjí v novou rostlinu

- sukulence - přítomnost speciálního pletiva sloužícího jako zásobárna vody

- hlavní zásobní kořen - ztlustlý hlavní kořen včetně hypokotylu a epikotylu, který funguje jako zásobní orgán

- sekundární zásobní kořen - částečně ztlustlý adventivní nebo boční kořen, který funguje jako zásobní orgán; na rozdíl od kořenové hlízy ztratil primární funkce kořene, jako je př́ijem vody a minerálů a uchycení rostliny v půdě

- kořenová hlíza - ztlustlý, nevětvený adventivní kořen rostoucí z obnovovacího pupenu; primárně slouží jako zásobní orgán a na příjmu vody a minerálů se podílí vzácně 
- trs - svazek víceméně vzhůru rostoucích prýtů, které jsou hustě nahloučené v důsledku mnohonásobného a víceméně pravidelného větvení bazálních částí prýtů, které adventivně zakořeňují

- hypokotylová hlíza - ztlustlý hypokotyl se zásobní funkcí

Zdroj dat a citace: Krumbiegel (2002).

\section{Typ orgánu klonálního růstu}

Typ orgánu klonálního růstu se uvádí jen pro klonální byliny. Klonalita je zde definována jako potenciál pro tvorbu nezávislých klonálních potomků. Morfologickým předpokladem pro klonální růst je tvorba adventivních kořenů na stoncích nebo adventivních prýtů $\mathrm{z}$ pupenů na kořenech, čímž mohou vznikat fyzicky nezávislí jedinci (Groff \& Kaplan 1988).

Orgány klonálního růstu jsou morfologické kategorie, jejichž definice je založena na několika znacích:

- orgán nesoucí banku pupenů, které dávají vznik daném orgánu klonálního růstu (stonek nebo kořen)

- poloha, kde je orgán uložen vzhledem k povrchu půdy (nadzemní, podzemní, napřed nadzemní a později podzemní, voda)

- orgán, v němž jsou uloženy zásobní látky (stonek, list, kořen)

Pro každý taxon je uveden jen jeden typ orgánu klonálního růstu, přestože některé taxony mají několik nezávislých typů takových orgánů. Uveden je ten typ, který lze považovat za nejvýznamnější pro životní cyklus taxonu, tj. který tvoří nejvíc potomků nebo umožňuje jedinci rozšíriit své potomky na největší vzdálenost. Některé z těchto typů jsou vegetativní diaspory, zatímco jiné jsou důležité pro lokální rozrůstání, ale ne pro šiřrení na větší vzdálenosti. Kategorie jsou rozděleny na nadzemní a podzemní orgány a řazeny podle jejich klesající frekvence v české flóře.

Kategorie

Nadzemní orgány

- nadzemní kořenící stonek - horizontální nadzemní prýt kořenící v půdě a zajišstující spojení dceřinných rostlin s mateřskou, případně tvořený plazivým hlavním prýtem 
- turion - oddělitelný přezimující pupen vodních rostlin tvořený hustě nahloučenými listy se zásobními látkami

- fragment stonku - úlomek stonku schopný zakořenit

- pučící rostlina - extrémně redukované tělo vodních rostlin tvořené malým listem (např. Lemna)

Podzemní orgány

- epigeogenní oddenek - vytrvalý klonální orgán stonkového původu rostoucí vodorovně při půdním povrchu; jeho distální část je kryta půdou, opadem nebo stařinou, případně je zatažena do země kontrakcí kořenů; uzliny nesou zelené listy, články jsou obvykle krátké

- hypogeogenní oddenek - vytrvalý klonální orgán stonkového původu rostoucí zpravidla horizontálně v druhově specifické hloubce pod zemí; po určité době mění směr růstu na vertikální a vytváří nadzemní výhonky; horizontální část má dlouhé články a nese listeny a kořeny (obvykle jen na uzlinách)

- podzemní stonková hlíza - podzemní, obvykle krátkověký zásobní a regenerativní orgán stonkového původu

- cibule - zásobní orgán tvořený zásobními listy a zkrácenou bází stonku

- kořen s adventivními pupeny - hlavní kořen včetně hypokotylu nebo adventivní kořen tvořící adventivní pupeny spontánně nebo po poškození

- kořenová hlíza - podzemní zásobní orgán kořenového původu vyrůstající ze stonku nesoucího pupeny

- nadzemní kořenící stonek zakončený hlízou - výběžek s podzemním, obvykle krátkověkým zásobním a regenerativním orgánem vyvíjejícím se na jeho distálním konci

Zdroj dat a citace: Klimešová \& Klimeš (2006).

\section{Volně šiřitelné klonální potomstvo}

Tato vlastnost je definována pro klonální byliny. Klonalita bylin může být zprostředkována klonálními potomky, kteří jsou volně šiřitelní, což znamená, že brzy po svém vzniku ztrácejí spojení s mateřskou rostlinou a mohou se šírit pomocí větru nebo vody. Jde o různé nadzemní odlomitelné pupeny, které mohou dát vznik novým samostatným rostlinám, např. 
rostlinky vzniklé v květenství, pacibulky suchozemských rostlin, turiony nebo fragmenty stonku vodních rostlin. Přítomnost volně šiřitelných klonálních potomků je uvedena na základě informací pro jednotlivé taxony v databázi CLO-PLA 3.4 (Klimešová \& Klimeš 2006, Klimešová et al. 2017).

Kategorie

- prí́tomno

- chybí

Zdroj dat a citace: Klimešová \& Klimeš (2006), Klimešová et al. (2017).

\section{Délka života prýtu (cyklicita)}

Tato vlastnost, definovaná pro byliny, vyjadřuje počet roků od začátku formování nadzemní části prýtu po jeho kvetení a plození (Serebryakov 1952). Protože podle morfologických znaků (např. př́ítomnost zbytků listů z předcházejícího roku) lze bezpečně rozeznat jen prýty s cyklicitou více než jeden rok (dicyklické a polycyklické prýty) od prýtů s cyklicitou jeden rok (monocyklické prýty), používáme pouze tyto dvě kategorie. U sympodiálně větvených rostlin se vlastnost týká všech prýtů rostliny, protože všechny jsou potenciálně schopné vykvést, ale u monopodiálně se větvících rostlin se cyklicita týká jen květonosných prýtů (vysvětlení rozdílu mezi monopodiálním a sympodiálním větvením viz „Typ větvení orgánů klonálního růstu stonkového původu“). Monocyklické prýty jsou zpravidla bez listové růžice a všechny prýty v populaci mohou kvést. Oproti tomu dicyklické a polycyklické prýty obvykle mají př́zemní listovou růžici a populace prýtů obsahuje nekvetoucí listové růžice i kvetoucí prýty. Př́ítomnost květonosných prýtů a současně nekvetoucích listových růžic je však také typická pro monopodiálně se větvící rostliny.

Údaje vznikly agregací různých pozorování pro jednotlivé taxony z databáze CLO-PLA 3.4 (Klimešová \& Klimeš 2006) tak, že byla vybrána častější hodnota (Klimešová et al. 2017).

Kategorie

- prýt převážně monocyklický

- prýt převážně dicyklický nebo polycyklický 
Zdroj dat a citace: Klimešová \& Klimeš (2006), Klimešová et al. (2017).

\section{Typ větvení orgánů klonálního růstu stonkového původu}

Typ větvení stonků je definován pro klonální byliny. Tato vlastnost určuje, zda má rostlina dva typy prýtů, které se liší kvetením, nebo má jeden typ prýtu. Jsou-li všechny prýty potenciálně schopné kvetení, jde o sympodiální větvení, kdy se prýty obdobné stavby $\mathrm{v}$ ontogenezi vzájemně nahrazují. Má-li rostlina dva typy prýti̊, z nichž jeden nikdy nekvete a druhý kvete a současně vyrůstá z paždí listů nekvetoucího prýtu, potom jde o monopodiální větvení. U výtrusných rostlin se vyskytuje dichotomické větvení, které je funkčně podobné monopodiálnímu větvení. Údaje vznikly agregací různých pozorování pro jednotlivé taxony z databáze CLO-PLA 3.4 (Klimešová \& Klimeš 2006) tak, že byla vybrána častější hodnota (Klimešová et al. 2017).

Kategorie

- monopodiální

- sympodiální

- dichotomické

Zdroj dat a citace: Klimešová \& Klimeš (2006), Klimešová et al. (2017).

\section{Hlavní kořen}

Přítomnost hlavního (primárního) kořene je zaznamenána pro byliny. Hlavní kořen může být bud' zachován po celý život rostliny, anebo v průběhu ontogeneze nahrazen adventivními kořeny. Je-li hlavní kořen jediným kořenem po celý život rostliny, rostlina není schopná tvořit kořeny na stoncích (adventivní kořeny) a je neklonální (pokud současně nedovede tvořit ani adventivní pupeny na kořenech; Groff \& Kaplan 1988). Naopak v případě, že má rostlina hlavní kořen jen $\mathrm{v}$ raných stadiích ontogeneze a ten je později nahrazen adventivními kořeny vyrůstajícími z podzemních částí stonků, má předpoklady růst klonálně. U některých rostlin, které zachovávají hlavní kořen po celý život, může u starých jedinců docházet ke štěpení kořene a rozpadu rostliny na několik samostatných částí. 
Některé taxony produkují adventivní kořeny jen za určitých podmínek, jako je vlhká půda, poranění hlavního kořene nebo velké stáří rostliny.

Údaje o prŕitomnosti hlavního kořene vznikly agregací různých pozorování pro jednotlivé taxony z databáze CLO-PLA 3.4 (Klimešová \& Klimeš 2006) tak, že byla vybrána častější hodnota (Klimešová et al. 2017).

Kategorie

- př́ítomen

- chybí

Zdroj dat a citace: Klimešová \& Klimeš (2006), Klimešová et al. (2017).

\section{Vytrvalost orgánu klonálního růstu}

Vytrvalost orgánu klonálního růstu, definovaná pro klonální byliny, udává, kolik roků trvá spojení mezi rodičovským prýtem a jeho klonálním potomkem. Protože podle morfologických znaků lze pro většinu taxonů s jistotou určit stáří orgánů přežívajících jeden, dva, nebo více než dva roky, je údaj založen na nich. Vytrvalost byla odhadnuta $\mathrm{v}$ kategoriích $(<1,1-2,>2$; Klimešová \& Klimeš 2006) a dále se pracovalo se středními hodnotami $(0,5,1,5,4)$. Výsledná hodnota je průměr středních hodnot uváděných pro jeden taxon a daný typ orgánu klonálního růstu v databázi CLO-PLA 3.4 (Klimešová et al. 2017).

Zdroj dat a citace: Klimešová \& Klimeš (2006), Klimešová et al. (2017).

\section{Počet klonálních potomků}

Tato vlastnost je definována pro klonální byliny. Počet dceřiných prýtů vytvořených na jeden mateřský prýt klonální byliny za rok je odhadnut v kategoriích $(<1,1,1-10,>10$; Klimešová \& Klimeš 2006), které jsou reprezentovány středními hodnotami intervalů (0,5, $1,5,15)$. Výsledná hodnota je průměr všech těchto hodnot uváděných pro jeden taxon a daný typ orgánu klonálního růstu v databázi CLO-PLA 3.4 (Klimešová et al. 2017).

Zdroj dat a citace: Klimešová \& Klimeš (2006), Klimešová et al. (2017). 


\section{Vzdálenost klonálního šíření}

Vzdálenost klonálního šíření je definována pro klonální byliny jako vzdálenost mezi mateřským a dceřiným prýtem. Volně šiřitelné vegetativní diaspory přitom nejsou vzaty $\mathrm{v}$ úvahu. Vzdálenosti byly odhadnuty v kategoriích $(<0,01,0,01-0,25,>0,25 \mathrm{~m}$ za rok; Klimešová \& Klimeš 2006), které jsou reprezentovány středními hodnotami intervalů $(0,005,0,13,0,5)$. Výsledná hodnota je průměr středních hodnot uváděných pro jeden taxon a daný typ orgánu klonálního růstu v databázi CLO-PLA 3.4 (Klimešová et al. 2017).

Zdroj dat a citace: Klimešová \& Klimeš (2006), Klimešová et al. (2017).

\section{Klonální index}

Klonální index (Johansson et al. 2011), zde uváděný pro klonální byliny, je míra schopnosti klonálního růstu taxonu. Je definován jako součet pořadí čtyř kategorií „počtu dceřných prýtư“ (kódovaných jako 1, 2, 3,4) a tř́i kategorií „vzdálenosti klonálního šíření“ (kódovaných jako 1, 2, 3), přičemž přítomnost volně šiřitelných vegetativních diaspor je doplněna jako čtvrtá kategorie (4). Hodnoty indexu se pohybují v rozsahu od 2 do 8 , přičemž vyšší hodnoty vyjadřují lepší schopnost klonálního růstu.

Prezentovaná data jsou založena na kategoriích vlastností „,počet dceřiných prýtư“a „Vzdálenost klonálního šíření“ vytvořených agregací jednotlivých záznamů v databázi CLOPLA 3.4 (Klimešová \& Klimeš 2006, Klimešová et al. 2017).

Zdroj dat a citace: Klimešová \& Klimeš (2006), Klimešová et al. (2017).

\section{Umístění pupenů na kořenech}

Na rozdíl od pupenů na stoncích, které se vždy nacházejí v paždí listového orgánu, adventivní pupeny na kořenech nebo hypokotylu jsou rozmístěny na těchto orgánech nepravidelně. Vyskytují se jen na některých typech kořenů nebo se objevují až po poranění rostliny, př́ípadně jen po poranění kořene. Adventivní pupeny mohou být umístěny na hypokotylu, hlavním kořeni nebo na adventivních kořenech. Hypokotyl je uveden, když se 
pupeny nemohou vyskytovat na žádném typu kořenů; hlavní kořen je uveden, pokud se pupeny mohou vyskytovat na hypokotylu a hlavním kořeni; adventivní kořeny jsou uvedeny, když se pupeny vyskytují na všech třech typech orgánů. Údaje jsou převzaty z práce Bartušková et al. (2017).

Kategorie

- hypokotyl

- hlavní kořen

- boční a adventivní kořeny

Zdroj dat a citace: Bartušková et al. (2017).

\section{Role pupenů na kořenech $v$ životním cyklu rostliny}

Adventivní pupeny na kořenech nebo hypokotylu se vyskytují asi u $10 \%$ druhů české flóry a u jednotlivých druhů mají různý význam. U některých taxonů se adventivní pupeny na kořenech nebo hypokotylu zakládají po poranění rostliny a umožňují její regeneraci, mají tedy regenerativní roli. U dalších taxonů se tvoří pupeny nezávisle na poranění, a přispívají tak ke zvětšení počtu prýtů a tím potenciálně i k semenné produkci, prrípadně ke klonálnímu šíření rostliny. Vyskytují se jen v některých populacích nebo u některých jedinců populace a nejsou nezbytné pro dokončení životního cyklu rostliny. Mají tedy obohacující (aditivní) roli. Malý počet taxonů je na adventivních kořenech a z nich vyrůstajících odnožích závislý, protože jen s jejich pomocí může rostlina vykvést nebo přezimovat. U těchto taxonů se pupeny na kořenech vyskytují u všech jedinců a ve všech populacích a role pupenů na kořenech je v životě rostliny nezbytná (Rauh 1937, Klimešová 2007). Údaje jsou převzaty z práce Bartušková et al. (2017).

Kategorie

- regenerativní

- aditivní

- nezbytné

Zdroj dat a citace: Bartušková et al. (2017). 


\section{Banka pupenů}

Jako banka pupenů jsou označovány všechny spící pupeny na rostlině, z nichž mohou vyrůst nové prýty, a to jak pupeny na stonku, tak pupeny na kořenech (Klimešová \& Klimeš 2007). Nejdůležitější část pupenů je v našich podmínkách uložena při povrchu nebo pod povrchem půdy, tedy mimo dosah narušení nebo sezónního mrazu nebo sucha (Raunkiaer 1934). Zde uvedené údaje se proto týkají jen přízemní a podzemní banky pupenů.

Počet pupenů na orgánech uložených v různé hloubce půdy byl odhadnut podle morfologických znaků (Klimešová \& Klimeš 2007). Odhad vychází z předpokladu, že v úžlabí každého listu (nebo listenu) je jeden pupen. Počty pro rostlinné jedince byly odhadnuty v kategoriích $(0,0-10,>10$ pupenů na prýt; Klimešová \& Klimeš 2006) a dále byly použity středy těchto kategorií $(0,5,15)$. Výsledná hodnota pro taxon je průměr těchto hodnot uváděných pro daný taxon a danou hloubku banky pupenů v databázi CLO-PLA 3.4 (Klimešová et al. 2017). Velikost podzemní banky pupenů byla stanovena jako součet počti̊ pupenů na prýt na povrchu půdy a v půdě. Hloubka podzemní banky pupenů byla stanovena jako průměrná hloubka pupenů. Kromě pupenů na stoncích má asi $10 \%$ taxonů české flóry schopnost tvořit př́ídatné (adventivní) pupeny na kořenech nebo hypokotylu. Protože adventivní pupeny obvykle nelze přesně spočítat, pro kategorie se zahrnutými adventivními pupeny na kořenech nebo hypokotylu bylo arbitrárně přidáno pro každou hloubku 15 pupenů (pro zjednodušení používáme jen označení „,pupeny na kořenech“ místo „,adventivní pupeny na kořenech a hypokotylu“; Klimešová et al. 2017). Všechny charakteristiky se uvádějí jednak pouze pro pupeny stonkového původu (s vyloučením pupenů na kořenech), jednak pro všechny pupeny (včetně pupenů na kořenech):

- Počet pupenů na prýt na povrchu půdy (bez pupenů na kořenech)

- Počet pupenů na prýt v hloubce 0-10 cm (bez pupenů na kořenech)

- Počet pupenů na prýt v hloubce více než $10 \mathrm{~cm}$ (bez pupenů na kořenech)

- Velikost podzemní banky pupenů (bez pupenů na kořenech)

- Hloubka podzemní banky pupenů (bez pupenů na kořenech)

- Počet pupenů na prýt na povrchu půdy (včetně pupenů na kořenech)

- Počet pupenů na prýt v hloubce $0-10 \mathrm{~cm}$ (včetně pupenů na kořenech)

- Počet pupenů na prýt v hloubce více než $10 \mathrm{~cm}$ (včetně pupenů na kořenech)

- Velikost podzemní banky pupenů (včetně pupenů na kořenech) 
- Hloubka podzemní banky pupenů (včetně pupenů na kořenech)

Zdroj dat a citace: Klimešová \& Klimeš (2006), Klimešová et al. (2017).

\section{Způsob výživy}

\section{Parazitismus a mykoheterotrofie}

Rostlinný parazitismus je založen na dvou mechanismech. První skupina parazitických rostlin parazituje př́mo na jiné rostlině. K čerpání zdrojů z cévních svazků hostitele používají tito paraziti specializovaný orgán, haustorium, proto se označují jako haustorioví paraziti. Rostliny druhé skupiny parazitují na houbách, s nimiž navazují mykorhizní interakci a čerpají od nich organický uhlík; tyto rostliny se nazývají mykoheterotrofové.

Zástupci obou skupin vykazují různou míru závislosti na hostiteli. V rámci haustoriových parazitů se tradičně rozlišují zelení poloparaziti (tj. částeční paraziti s vlastní fotosyntézou, kteří ovšem mohou získávat i část organického uhlíku od hostitele) a nezelení holoparaziti (úplní paraziti bez schopnosti fotosyntetizovat). Z funkčního hlediska je dále významné, zda se napojují na kořen, anebo stonek hostitele. Hranice mezi částečným a úplným parazitismem není vždy ostrá. V české flóře však lze odlišit stonkové hemi- a holoparazity, které je obtížné odlišit v celosvětové flóře (Těšitel 2016). Proto zde používáme tradiční klasifikaci a jako holoparazity hodnotíme ty rostliny, které jsou v dospělosti převážně nezelené, i když některé mohou mít reziduální fotosyntézu (např. Cuscuta).

Ve skupině mykoheterotrofů existuje kontinuum od iniciálních mykoheterotrofů přes částečné mykoheterotrofy až po úplné mykoheterotrofy. U iniciálních mykoheterotrofů je mykoheterotrofní pouze gametofyt nebo klíčící rostlina, jejíž přežití je závislé na přítomnosti houby, ale dospělci jsou plně autotrofní, ač stále závislí na mykorhizní symbióze jakožto zdroji vody a minerálních živin. U částečných mykoheterotrofủ fotosyntetizující dospělci od hub přijímají kromě vody a minerálních živin v různé míře i organický uhlík. Úplní mykoheterotrofové ztratili chlorofyl a mohou být s jistotou zařazeni mezi úplné parazity. U některých částečných mykoheterotrofů (napřr. rod Cephalanthera), můžeme najít chlorotické jedince, kteří postrádají chlorofyl a jsou zcela závislí na houbovém hostiteli. 
Klasifikace haustoriových parazitů byla převzata z práce Těšitel (2016) a upravena zahrnutím stonkových polo- a holoparazitů. Mykoheterotrofní rostliny byly identifikovány podle práce Merckx (2012).

Kategorie

- autotrofní

- kořenový poloparazit

- stonkový poloparazit

- kořenový holoparazit
- stonkový holoparazit

- částečně nebo iniciálně mykoheterotrofní

- plně mykoheterotrofní

Citace: Těšitel J., Těšitelová T., Blažek P. \& Lepš J. (2016) Parazitismus a mykoheterotrofie. - www.pladias.cz.

\section{Masožravost}

Masožravé rostliny přitahují, chytají a zabíjejí svoji kořist, tj. živočichy (hlavně hmyz, nebo malé korýše) a prvoky, a následně získávají živiny z jejich mrtvých těl.

Kategorie

- masožravá rostlina

- rostlina není masožravá

Zdroj dat a citace: Hejný et al. (1988 et seq.).

\section{Symbiotická fixace dusíku}

Rostliny se dělí na ty, které nemají symbiotické bakterie fixující vzdušný dusík, a ty, které je mají. Druhou skupinu dále dělíme na rostliny, jejichž symbiotické bakterie patří do skupiny rhizobií (např. rody Allorhizobium, Bradyrhizobium, Mesorhizobium, Rhizobium a Sinorhizobium), a rostlin tvořící symbiózu s bakteriemi rodu Frankia (Bond 1983, Pawlowski \& Sprent 2007, Sprent 2008, Benson 2016).

Kategorie 
- symbióza s rhizobii

- symbióza s Frankia

- bez symbiontů fixujících dusík

Citace: Blažek P. \& Lepš J. (2016) Symbiotická fixace dusíku. - www.pladias.cz.

\section{Karyologie}

\section{Počet chromozomů (2n)}

Údaj se vztahuje k somatickému počtu chromozomů v zygotickém stadiu, tj. bez prrípadné endopolyploidie somatických pletiv. Pokud je pro daný taxon známo několik různých počtů chromozomů, je primárně uveden počet zjištěný na území České republiky, počet na našem území nejčastější, nebo počet, který lze u nás jako nejpravděpodobnější očekávat na základě údajů z okolních zemí. Ostatní méně časté počty chromozomů, které jsou z našeho území dokumentovány nebo by se u našich rostlin mohly vyskytovat na základě údajů z okolních zemí, jsou uvedeny v závorce. Přehled nezohledňuje jednotlivé anomální počty aneuploidních, euploidních, haploidních nebo autopolyploidních rostlin, které mohou vzácně vznikat v přírodních nebo experimentálních populacích, ani počty chromozomů uváděné ve velmi starých pracích nebo z geograficky vzdálených území, kde není jistá taxonomická identita s našimi rostlinami. Údaje byly převzaty převážně z Květeny České republiky (Hejný et al. 1988 et seq.) a Chromosome Count Database (Rice et al. 2015; http://ccdb.tau.ac.il/). V př́padě, že je pro taxon znám jen údaj o ploidním stupni z měření pomocí průtokové cytometrie, je uveden chromozomový počet typický pro daný ploidní stupeň u blízce př́buzných taxonů.

Citace: Šmarda P. (2018) Počet chromozomů (2n). - www.pladias.cz.

\section{Stupeň ploidie (x)}

Stupeň ploidie je somatický počet sad chromozomů v zygotickém stadiu, tj. bez př́padné endopolyploidie somatických pletiv. Stupeň ploidie určuje minimální počet kopií většiny 
genů, ovlivňuje minimální velikost buněk a další morfologické i ekologické vlastnosti (Stebbins 1950, Levin 2002, Tate et al. 2005, Dar \& Rehman 2017). Údaj vychází ze znaků „počet chromozomů“ a „2C velikost genomu“, v menším počtu případů také z excerpce dostupných cytometrických prací se vztahem k české flóře. Primárně se a udává ploidní stupeň, který je pro daný taxon uváděn z našeho území, je na našem území nejčastější nebo se zde alespoň jako nejčastější dá očekávat na základě údajů z okolních zemí. Další méně časté stupně ploidie (cytotypy), které jsou z našeho území dokumentovány nebo by se u našich rostlin mohly vyskytovat na základě údajů z okolních zemí, jsou uvedeny v závorce. Přehled nezohledňuje údaje z pozorování jednotlivých haploidních nebo autopolyploidních rostlin, které mohou vzácně vznikat $\mathrm{v}$ prrírodních nebo experimentálních populacích, ani údaje založené na počtech chromozomů uváděných pro daný taxon ve velmi starých pracích nebo z geograficky vzdálených území, kde taxonomická identita s našimi rostlinami není jistá.

Velikost jedné sady chromozomů (x, „základní chromozomové číslo“) pro výpočet stupně ploidie je zde odvozena od nejnižšího počtu chromozomů známého v daném rodě nebo skupině blízce příbuzných rodů (např. Raven 1975), přičemž takový minimální počet je většinou považován za diploidní (tj. obsahující dvě sady chromozomů). Za polyploidní je taxon považován vždy, když je jeho počet chromozomů a velikost genomu shodně víceméně násobně větší než u diploidních taxonů prríbuzných rodů, přestože diploidní stupeň ploidie nemusí být $\mathrm{v}$ daném rodě znám u žádného taxonu. Tato absence diploidů může být dána (1) malou karyologickou probádaností daného rodu, (2) vymřením diploidních zástupců rodu nebo (3) vznikem celého rodu v důsledku nedávné polyploidizace, přičemž v genomu dosud ještě nedošlo k výraznější zpětné „,diploidizaci“. Použití velikosti genomu umožňuje odvodit ploidní stupeň i pro většinu taxonů s holocentrickými chromozomy (Cyperaceae, Juncaceae, Drosera, Cuscuta sect. Cuscuta a C. sect. Gramica), kde vzhledem k jejich možné fragmentaci a fúzi (agmatoploidii a symploidii) počet chromozomů a ploidní stupeň ne vždy pozitivně korelují (Bureš et al. 2013). V rodě Luzula, vykazujícím časté fúze chromozomů, byly při odvození stupně ploidie vzaty v potaz i velikostní tř́ídy chromozomů (Nordeskiöld 1951). Odhad stupně ploidie v rodě Viola je založen na výsledcích specializované studie (Marcussen et al. 2015).

Citace: Šmarda P. (2018) Stupeň ploidie (x). - www.pladias.cz. 


\section{C velikost genomu}

$2 \mathrm{C}$ velikost genomu je somatický obsah jaderné DNA zygotické buňky udávaný v megapárech (milionech párů) bází (Mbp). Ten se může lišit mezi taxony jak v důsledku polyploidie, tak v důsledku variability v obsahu nekódující DNA (Leitch \& Greilhuber 2013). Velikost genomu ovlivňuje minimální velikost buněk, délku trvání buněčného cyklu a buněčného dělení, jakož i nároky na živiny, a do značné míry tak může předurčovat životní strategie rostlin (Bennett 1987, Veselý et al. 2012, Greilhuber \& Leitch 2013). Uváděné hodnoty byly v naprosté většině případů naměřeny u rostlin sbíraných na území České republiky (Šmarda et al. 2019). Vždy se vztahují k dominantnímu počtu chromozomů a dominantnímu stupni ploidie daného taxonu.

Zdroj dat a citace: Šmarda et al. (2019).

\section{Cx monoploidní velikost genomu}

1Cx monoploidní velikost genomu je množství DNA obsažené v jedné sadě chromozomů udávané v megapárech (milionech párů) bází (Mbp). Údaje jsou převzaty z práce Šmarda et al. (2019), kde byly pro jednotlivé taxony vypočteny jako podíl 2C velikosti genomu a stupně ploidie (Greilhuber et al. 2005). Rozdíly v $1 \mathrm{Cx}$ hodnotách mezi taxony proto téměř nesouvisejí s ploidií (tj. jsou hlavně důsledkem amplifikace nekódující DNA), i když u polyploidů bývají $1 \mathrm{Cx}$ hodnoty zpravidla o něco menší v důsledku tendence $\mathrm{k}$ eliminaci duplikované, redundantní DNA (Leitch \& Bennett 2004). Protože 1Cx hodnoty bývají u př́buzných taxonů podobné, lze je použít $\mathrm{k}$ hrubému odhadu $2 \mathrm{C}$ velikosti genomu $\mathrm{u}$ př́ibuzných taxonů, kde je znám dosud jen stupeň ploidie, nebo naopak k odhadu stupně ploidie pro př́buzné taxony, kde je zatím známa jen velikost genomu.

Zdroj dat a citace: Šmarda et al. (2019).

\section{Genomický obsah GC bází}

Genomický obsah GC bází je procentické zastoupení bází guaninu a cytosinu v jaderné DNA. To do značné míry určuje termální stabilitu DNA a možná i její skladnost v jádře, 
energetické nároky na její syntézu nebo citlivost buněk k vysychání (Šmarda \& Bureš 2012, Šmarda et al. 2014). Uváděné hodnoty byly v naprosté většině naměřeny u rostlin sbíraných na území České republiky (Šmarda et al. 2019). Vždy se vztahují k převládajícímu počtu chromozomů a nejčastějšímu stupni ploidie daného taxonu. Odlišnosti do $1 \%$ u blízce prŕibuzných taxonů nebo do $2 \%$ u nepř́ibuzných taxonů se vzhledem $\mathrm{k}$ možné chybě metody považují za nevýznamné (Šmarda et al. 2012).

Zdroj dat a citace: Šmarda et al. (2019).

\section{Původ taxonu}

\section{Puvodnost v České republice}

Taxony se dělí do skupin podle toho, zda jsou na území České republiky původní, anebo nepůvodní. Původní taxon vznikl na území České republiky v průběhu evoluce nebo se sem dostal bez přispění člověka z území, kde vznikl. Nepůvodní taxon se na území České republiky dostal v důsledku činnosti člověka z území, ve kterém je původní, anebo přirozenou cestou z území, ve kterém je nepůvodní. Nepůvodní taxony se dělí podle doby zavlečení na naše území na archeofyty a neofyty. Archeofyty jsou nepůvodní taxony zavlečené v období mezi počátkem neolitického zemědělství a rokem 1500 , tj. dobou po objevu Ameriky charakterizovanou rozvojem zámořského obchodu. Neofyty jsou nepůvodní taxony zavlečené po roce 1500 (podrobné definice viz Richardson et al. 2000, Pyšek et al. 2008). Zvlášt’ jsou uvedeny nepůvodní taxony, které se na území České republiky častěji pěstují, ale zatím nezplaňují. Údaje o původnosti a době zavlečení pocházejí z Katalogu nepůvodní flóry České republiky (Pyšek et al. 2012; tam jsou uvedeny i odkazy na originální zdroje informací o původu taxonů) a jsou doplněny o novější poznatky.

Kategorie

- původní

- archeofyt
- neofyt

- jen pěstovaný

Zdroj dat a citace: Pyšek et al. (2012). 


\section{Invazní status}

Invazní status je rozdělení nepůvodních taxonů do tří skupin v závislosti na stupni jejich zapojení do místní flóry. Taxony přechodně zavlečené jsou taxony, jejichž přeživání v území závisí na opakovaném přísunu diaspor v důsledku lidské činnosti; pokud se rozmnožují mimo kulturu, tak pouze přechodně. Taxony zdomácnělé (naturalizované) se v území pravidelně rozmnožují po dlouhou dobu a nezávisle na činnosti člověka. Taxony invazní jsou zdomácnělé taxony, které se v území rychle šírí na značné vzdálenosti od mateřské populace a zpravidla na rozsáhlém území (Richardson et al. 2000, 2011). Tato klasifikace není použita pro původní taxony, které jsou označeny zvlášt'. Klasifikace byla převzata z Katalogu nepůvodní flóry České republiky (Pyšek et al. 2012), kde jsou také uvedeny odkazy na zdroje originálních informací.

Kategorie

- přechodně zavlečený

- invazní

- zdomácnělý

- původní

Zdroj dat a citace: Pyšek et al. (2012).

\section{Geografický původ}

Údaj o geografickém původu je uveden jen pro nepůvodní taxony. Pokud původní areál taxonu zahrnuje více než jednu oblast, je taxon zařazen do více než jedné kategorie. Evropský původ se vztahuje k částem Evropy jiným, než je území České republiky a Středomoří. Středomoří zahrnuje části jižní Evropy, severní Afriky a západní Asie od Turecka a Izraele po Afganistán, které se vyznačují charakteristickým středomořským podnebím a tomu odpovídající vždyzelené vegetaci. Naopak údaje o původu z Afriky, Asie a Evropy se nevztahují ke středomořské části těchto světadílů. Hybridní původ označuje taxony vzniklé kř̌ižením; ty jsou považovány za nepůvodní, pokud je nepůvodní alespoň jeden z rodičů. Anekofyt je taxon, pro který není známa oblast jeho původního rozšsiřrení. Data byla převzata z Katalogu nepůvodní flóry České republiky (Pyšek et al. 2012), kde jsou také uvedeny odkazy na zdroje originálních informací. 
Kategorie

- Evropa

- Středomoří

- Severní Amerika

- Střední Amerika
- Jižní Amerika

- Asie

- Afrika

- Austrálie
- hybridní původ

- anekofyt

Zdroj dat a citace: Pyšek et al. (2012).

\section{Rok zplanění}

Údaje o prvním záznamu o zplanění na území České republiky jsou udávány pro neofyty. Jsou převzaty z katalogu nepůvodních rostlin České republiky (Pyšek et al. 2012). U mnoha taxonů však tento údaj není $\mathrm{k}$ dispozici.

Zdroj dat a citace: Pyšek et al. (2012).

\section{Způsob zavlečení}

Údaj o způsobu zavlečení je uváděn jen pro nepůvodní taxony. Zavlečení nepůvodních taxonů rostlin může být úmyslné, nebo neúmyslné (Hulme et al. 2008). Úmyslné zavlečení zahrnuje jak přímou výsadbu do př́rody (např. za účelem krajinářských úprav), tak pěstování v kulturách (např̀. produkční lesní porosty, okrasné rostliny a plodiny), odkud taxon postupně unikl do př́rody. Neúmyslně zavlečené taxony se do území dostaly např. jako př́íměs osiva a zemědělských komodit nebo jako „,̌erní pasažéři” rozličných dopravních prostředků. Některé taxony mohou být zavlékány oběma způsoby. Data byla převzata z druhého vydání Katalogu nepůvodní flóry České republiky (Pyšek et al. 2012), kde jsou také uvedeny odkazy na zdroje originálních informací.

Kategorie

- náhodné zavlečení

- úmyslné zavlečení 
Zdroj dat a citace: Pyšek et al. (2012).

\section{Ekologické indikační hodnoty}

\section{Ellenbergovské indikační hodnoty}

Ellenberg et al. (1991) definovali pomocí ordinálních stupnic indikační hodnoty pro hlavní faktory prostředí, které ovlivňují výskyt rostlinných taxonů. Chytrý et al. (2018) tyto hodnoty upravili a rozšśřili pro českou flóru. Databáze obsahuje tyto indikační hodnoty:

- Indikační hodnota pro světlo

- Indikační hodnota pro teplotu

- Indikační hodnota pro vlhkost

- Indikační hodnota pro reakci

- Indikační hodnota pro živiny

- Indikační hodnota pro salinitu

Stupnice indikačních hodnot mají rozsah od 1 do 9 s výjimkou vlhkosti (1-12) a salinity (09). Hodnoty se znakem „X“ označují generalisty, tedy taxony s širokou ekologickou amplitudou ve vztahu k danému faktoru. Pro světlo hodnota 1 označuje rostliny silně stinných míst a hodnota 9 rostliny plně osvětlených míst (indikační hodnoty pro stromy se vztahují k mladým jedincům rostoucím v bylinném nebo keřovém patře). Pro teplotu hodnota 1 charakterizuje indikátory výrazného chladu vyskytující se v alpínském a niválním stupni hor, zatímco hodnota 9 označuje indikátory výrazného tepla vyskytují se jen na nejteplejších lokalitách v jižní části střední Evropy. Pro vlhkost hodnota 1 označuje indikátory silného sucha, zatímco hodnota 12 je přiřazena stále nebo téměř stále ponořeným vodním rostlinám. Indikační hodnota pro reakci indikuje $\mathrm{pH}$ půdy nebo vody, zejména v kyselých prostředích, zatímco v neutrálních nebo alkalických podmínkách vyjadřuje spís koncentraci vápníku. Hodnota 1 se vztahuje $\mathrm{k}$ indikátorům silné acidity, které se nikdy nevyskytuji v mírně kyselých nebo alkalických podmínkách, zatímco hodnota 9 je přiřazena indikátorům bazí a vápníku, které vždy rostou v podmínkách bohatých vápníkem. Čísla jsou hodnoty ordinální stupnice, které nemají př́mý vztah k absolutním hodnotám pH. Indikační hodnota pro živiny vyjadřuje dostupnost dusíku nebo fosforu a do značné míry koreluje s primární produktivitou stanoviště. Hodnota 1 označuje taxony vyskytující se na živinami 
nejchudších místech a hodnota 9 taxony rostoucí převážně na nadměrně živinami bohatých místech. Pro salinitu hodnota 0 označuje glykofyty, tj. rostliny netolerantní k lehce rozpustným solím, zatímco hodnota 9 se vztahuje euhalinním až hypersalinním taxonům, které rostou na půdách s hodně velkým, v suchých obdobích extrémně velkým obsahem solí, zejména síranů, chloridů a uhličitanů sodíku, draslíku, vápníku a hořčíku.

Zdroj dat a citace: Chytrý et al. (2018).

\section{Indikační hodnoty pro disturbanci}

Indikační hodnoty pro disturbanci (Herben et al. 2016) vyjadřují vztah běžných taxonů jednak k frekvenci, jednak k intenzitě disturbance. Nerozlišují se jednotlivé typy disturbance, hodnoty však pokrývají široké spektrum typů disturbance, jako je těžba dřeva, seč, pastva, sešlap, použití herbicidů, požáry, polomy, půdní eroze, orba, hrabání živočichy, působení vody (vlny nebo proud) a záplavy. Rozlišují se tři typy indikačních hodnot pro disturbanci:

- Indikační hodnoty pro frekvenci disturbance jsou vyjádřeny jako převrácená hodnota doby mezi dvěma disturbancemi na logaritmické stupnici (v rocích, dekadické logaritmy). Např́klad hodnota -2 znamená sto let mezi dvěma disturbancemi, hodnota -1 znamená deset let, zatímco hodnota 0 znamená disturbanci přicházející v průměru jednou za rok. Jednotkový rozdíl odpovídá desetinásobnému zvýšení frekvence disturbancí.

- Indikační hodnoty pro intenzitu disturbance jsou vyjádřeny na arbitrární stupnici od 0 (nejmírnější) po 1 (nejintenzivnější). Vycházejí z odhadu podílu odstraněné biomasy a plošného podílu narušeného půdního povrchu při jedné disturbanci. Indikační hodnoty pro frekvenci a intenzitu sice spolu částečně korelují, ale přesto mohou sloužit k vyjádření těchto dvou složek disturbanční niky taxonů odděleně.

- Indikační hodnoty pro disturbanci stanovené jako strukturní index vyjadřují disturbanční režim pomocí strukturních parametrů společenstev. Strukturní index je normalizován na rozpětí $0-1$, kdy vyšší hodnoty znamenají větší míru disturbance.

Každý z těchto tř̌́ typů indikačních hodnot je vytvořen zvlášt' pro disturbance postihující celý porost a pro menší disturbance, které v lesích postihují bylinné, ale nikoliv stromové patro. Pro taxony otevřených stanovišt' mají oba indexy stejné hodnoty. 
Databáze obsahuje tyto indikační hodnoty pro disturbanci:

- Indikační hodnota pro frekvenci disturbance celého porostu

- Indikační hodnota pro frekvenci disturbance bylinného patra

- Indikační hodnota pro intenzitu disturbance celého porostu

- Indikační hodnota pro intenzitu disturbance bylinného patra

- Indikační hodnota pro disturbanci celého porostu (strukturní index)

- Indikační hodnota pro disturbanci bylinného patra (strukturní index)

Indikační hodnoty pro disturbanci byly vypočteny ze stratifikovaného souboru 30.115 fytocenologických snímků z České národní fytocenologické databáze (Chytrý \& Rafajová 2003 ) pro taxony, které se vyskytovaly aspoň ve 20 snímcích. Celý soubor snímků byl klasifikován expertním systémem do 39 vegetačních tříd podle Vegetace České republiky (Chytrý 2007-2013). Těmto třídám byly přiřazeny hodnoty průměrné frekvence a intenzity disturbance na základě terénní zkušenosti. Indikační hodnoty pro disturbanci pak byly vypočteny jako průměrná frekvence nebo intenzita disturbance jednotlivých vegetačních tř́íd vážená frekvencí výskytu taxonu ve snímcích vegetace těchto tříd. Strukturní indexy byly vypočteny na základě variability výšky rostlin a variability součtu pokryvností všech taxonů zaznamenaných ve snímcích s výskytem př́íslušného taxonu.

Zdroj dat a citace: Herben et al. (2016).

\section{Stanoviště a sociologie}

\section{Výskyt v biotopech}

Výskyt taxonu v biotopech České republiky byl hodnocen pomocí údajů z České národní fytocenologické databáze (Chytrý \& Rafajová 2003), jejich expertní revize a doplňků na základě literatury a terénní zkušenosti, zejména pro vzácné a taxonomicky obtížné taxony. Použitá klasifikace rozlišuje 88 základních biotopů sdružených do 13 širších biotopů, které vymezují Sádlo et al. (2007: Appendix 1):

- 1 Vegetace skal, sutí a zdí

- 1A Vápnité skály

- 1B Bazické skály a droliny 
$\circ \quad 1 \mathrm{C} Z \mathrm{di}$

- 1D Pohyblivé vápnité sutě

- 2 Vegetace alpínských a subalpínských trávníků

- 2A Alpínské trávníky na silikátech

- 2B Subalpínská vysokobylinná vegetace

- 3 Vodní vegetace

- 3A Makrofytní vegetace eutrofních a mezotrofních stojatých vod

- 3B Makrofytní vegetace vodních toků

- 3C Makrofytní vegetace oligotrofních jezírek a tůní

- 4 Mokřadní a pobřežní bylinná vegetace

- 4A Rákosiny eutrofních stojatých vod

- 4B Slanomilné rákosiny a ostřicové porosty

- 4C Eutrofní vegetace bahnitých substrátů

- 4D Říční rákosiny

○ 4E Pobřežní vegetace toků

- 4F Mezotrofní vegetace bahnitých substrátů

- 4G Vegetace vysokých ostřic

○ 4H Vegetace nízkých jednoletých vlhkomilných bylin

- 4I Vegetace nitrofilních jednoletých vlhkomilných bylin

- 4J Štěrkové říční náplavy

- 4K Devětsilové lemy horských potoků

- 4L Nitrofilní bylinné lemy nížinných řek

- 5 Vegetace prameništ' a rašeliništ'

- 5A Pěnovcová prameniště

- 5B Nížinná až horská prameniště bez tvorby pěnovců

- 5C Subalpínská prameniště

○ 5D Vápnitá slatiniště

- 5E Kyselá mechová slatiniště a rašelinné louky

- 5F Přechodová rašeliniště

- 5G Vrchoviště

- 5H Vlhké rašelinné půdy a vrchovištní šlenky

- 6 Louky a mezofilní pastviny

- 6A Mezofilní ovsíkové louky 
○ 6B Horské mezické louky

- 6C Pastviny a parkové trávníky

○ 6D Aluviální louky nížinných řek

- 6E Vlhké pcháčové louky

- 6F Stř́davě vlhké bezkolencové louky

- 6G Vegetace vlhkých narušovaných půd

- 7 Acidofilní trávníky

- 7A Subalpínské a horské acidofilní trávníky

- 7B Submontánní smilkové trávníky

- 8 Suché trávníky

- 8A Hercynské suché trávníky skalních výchozů

- 8B Submediteránní suché trávníky skalních výchozů

- 8C Úzkolisté subkontinentální stepi

- $8 \mathrm{D}$ Širokolisté suché trávníky

- 8E Acidofilní suché trávníky

- $\quad 8 \mathrm{~F}$ Teplomilná vegetace lesních lemů

- 9 Trávníky písčin a vegetace skalních výchozů

- 9B Otevřené trávníky kyselých písčin

- 9C Kostřavové trávníky kyselých písčin

- 9D Panonské stepní trávníky na písku

- 9E Acidofilní vegetace jarních efemér a sukulentů

- 9F Bazifilní vegetace jarních efemér a sukulentů

- 10 Vegetace slanisk

- 10G Kontinentální vegetace jednoletých halofilních trav

- $10 \mathrm{H}$ Vnitrozemská vegetace sukulentních halofytů

- 10I Vnitrozemské slané louky

- 10J Slané stepi

- 11 Vřesoviště a křoviny

- 11A Suchá nížinná až subalpínská vřesoviště

- 11D Kosodřevina

- $11 \mathrm{H}$ Subalpínské listnaté křoviny

- 11I Mokřadní vrbiny

- 11J Vrbové křoviny hlinitých a písčitých náplavů 
- 11L Vysoké mezofilní a xerofilní křoviny

- $11 N$ Nízké xerofilní křoviny

- 11R Křoviny a pionýrské lesíky lesních pasek

- 12 Lesy

- 12A Mokřadní olšiny

- 12B Lužní lesy

- 12C Dubohabřiny

- 12D Sut'ové lesy

- 12E Květnaté bučiny

- 12F Vápnomilné bučiny

- $\quad 12 \mathrm{G}$ Acidofilní bučiny

- $12 \mathrm{H}$ Perialpidské bazifilní teplomilné doubravy

- 12I Subkontinentální teplomilné doubravy

- 12J Acidofilní teplomilné doubravy

- 12K Acidofilní doubravy

- 12L Boreokontinentální bory

- $12 \mathrm{O}$ Perialpidské bory

- 12P Rašelinné bory

- 12Q Rašelinné březiny

- 12R Acidofilní smrčiny

- 12S Vysokobylinné smrčiny

- 12T Akátiny

- 12U Lesní kultury nepůvodních listnatých dřevin

- $12 \mathrm{~V}$ Smrkové kultury

- $12 \mathrm{~W}$ Borové a modřínové kultury

- 13 Antropogenní vegetace

- 13A Jednoletá ruderální vegetace

- 13B Jednoletá vegetace polních plevelů

- 13C Jednoletá vegetace sešlapávaných stanovišt'

- 13D Vytrvalá teplomilná ruderální vegetace

- 13E Vytrvalá nitrofilní bylinná vegetace mezických stanovišt'

- 13F Bylinná vegetace lesních pasek a ostružiníkové křoviny 
Charakter výskytu taxonu v každém biotopu je hodnocen expertním odhadem pomocí čtyřstupňové stupnice:

- 1 - výskyt - taxon se v biotopu vyskytuje, ale nemá zde ekologické optimum a často je zde vzácný

- 2 - optimum - biotop nebo jeho část je ekologickým optimem taxonu

- 3 - dominanta - taxon má v biotopu ekologické optimum a dosahuje zde často pokryvnosti vyšší než $25 \% \mathrm{v}$ plochách o velikosti $\geq 10 \mathrm{~m}^{2}$ v bylinné vegetaci nebo o velikosti $\geq 100 \mathrm{~m}^{2} \mathrm{v}$ lesní a křovinné vegetaci

- 4 - konstantní dominanta - taxon je dominantou podle definice v předchozím bodě a současně určuje fyziognomii biotopu (např. vřes obecný na vřesovišti) a vyskytuje se alespoň na $40 \%$ lokalit biotopu

Zdroj dat a citace: Sádlo et al. (2007).

\section{Vazba na lesní prostředí}

Vazba taxonů na lesní prostředí je hodnocena s použitím kategorií německého národního seznamu lesních taxonů (Schmidt et al. 2011). Každý taxon je hodnocen samostatně pro oblast termofytika a oblast sloučeného mezofytika a oreofytika (Skalický 1988). Kompilace byla zpracována na základě seznamu taxonů v českých biotopech (Sádlo et al. 2007), vlastní terénní zkušenosti a literatury. Výsledný národní seznam byl zahrnut do Evropského seznamu lesních rostlinných druhů (Heinken et al. 2019).

\section{Kategorie}

- 0 - taxon se v českých lesích spontánně nevyskytuje

- 1.1 - taxon se vyskytuje hlavně v zapojeném lese

- $\quad 1.2$ - taxon se vyskytuje hlavně v lesních lemech a na lesních světlinách včetně lesních cest, míst vývratů, požářišt’ a pasek

- 2.1 - taxon se vyskytuje v lese i v nelesní vegetaci

- 2.2 - taxon se vyskytuje zčásti v lese, ale převážně v nelesní vegetaci

Citace: Dřevojan P., Chytrý M., Sádlo J. \& Pyšek P. (2016) Vazba na lesní prostředí. www.pladias.cz. 


\section{Diagnostický taxon}

Údaj, zda je daný taxon hodnocen jako diagnostický pro určité fytocenologické třídy, svazy nebo asociace ve Vegetaci České republiky (Chytrý 2007-2013). Diagnostické taxony se vyznačují koncentrací svého výskytu v porostech dané vegetační jednotky, ale jsou vzácné nebo chybějí v jiných vegetačních jednotkách. Byly stanoveny výpočtem míry fidelity (věrnosti) taxonu ke skupině fytocenologických snímků reprezentujících danou vegetační jednotku v geograficky a ekologicky stratifikovaném výběru snímků všech vegetačních typů z České národní fytocenologické databáze (Chytrý \& Rafajová 2003). Jako míra fidelity byl použit phi koeficient asociace, přičemž velikosti skupin snímků byly virtuálně standardizovány na $1 \%$ celkové velikosti datového souboru (Tichý \& Chytrý 2006). Taxony s hodnotou koeficientu phi vyšší než 0,25 , jejichž koncentrace v dané vegetační jednotce byla signifikantní podle Fisherova exaktního testu $(\mathrm{P}<0,001)$, se považují za diagnostické. Počty fytocenologických snímků použitých pro výpočty jsou uvedeny v jednotlivých dílech Vegetace České republiky.

Zdroj dat a citace: Chytrý (2007-2013).

\section{Konstantní taxon}

Údaj, zda je daný taxon hodnocen jako konstantní pro určité fytocenologické třídy, svazy nebo asociace ve Vegetaci České republiky (Chytrý 2007-2013). Konstantní taxony se vyznačují častým výskytem v porostech dané vegetační jednotky, na rozdíl od diagnostických taxonů se však mohou hojně vyskytovat i v jiných vegetačních jednotkách. Byly stanoveny výpočtem procentické frekvence výskytu (konstance) taxonu ve skupině fytocenologických snímků reprezentujících danou vegetační jednotku v geograficky a ekologicky stratifikovaném výběru snímků všech vegetačních typů z České národní fytocenologické databáze (Chytrý \& Rafajová 2003). Taxony s frekvencí v dané vegetační jednotce větší než 40 \% jsou zde považovány za konstantní. Počty fytocenologických snímků použitých pro výpočty jsou uvedeny v jednotlivých dílech Vegetace České republiky. 
Zdroj dat a citace: Chytrý (2007-2013).

\section{Dominantní taxon}

Údaj, zda je daný taxon hodnocen jako dominantní pro určité asociace ve Vegetaci České republiky (Chytrý 2007-2013). Dominantní taxony jsou zde definovány jako taxony, které se vyskytují s pokryvností větší než $25 \%$ ve více než $5 \%$ fytocenologických snímků zařazených do dané asociace. Nemusí to být jen taxony, které mají největší pokryvnost v konkrétním porostu. Tyto taxony byly stanoveny podle fytocenologických snímků reprezentujících danou asociaci v geograficky a ekologicky stratifikovaném výběru snímků všech vegetačních typů z České národní fytocenologické databáze (Chytrý \& Rafajová 2003). Počty fytocenologických snímků použitých pro výpočty jsou uvedeny v jednotlivých dílech Vegetace České republiky.

Zdroj dat a citace: Chytrý (2007-2013).

\section{Indexy ekologické specializace}

Stupeň ekologické specializace jednotlivých taxonů je odhadnut z jejich společného výskytu s jinými taxony. Předpokládá se, že čím větší je počet taxonů, s nimiž se cílový taxon vyskytuje na různých místech, tím větši je rozsah stanovištních podmínek vyhovujících tomuto taxonu (Fridley et al. 2007). Taxon rostoucí opakovaně na různých místech s víceméně stejnými doprovodnými taxony je spíše specialistou na určitý typ stanoviště, zatímco taxon rostoucí na různých místech s různými doprovodnými taxony je spíše generalistou. Index ekologické specializace taxonu (ESI) je tak nepř́imo úměrný beta diverzitě (heterogenitě druhového složení) souboru lokalit, na nichž se daný taxon vyskytuje.

Indexy ekologické specializace byly vypočteny na základě souboru fytocenologických snímků z České národní fytocenologické databáze (Chytrý \& Rafajová 2003). Byly použity tři soubory snímků vytvořené výběrem z geograficky stratifikovaného podsouboru této databáze: (1) soubor obsahující všechny vegetační typy (30.115 snímků, 1935 taxonů), (2) soubor obsahující pouze nelesní vegetaci (24.712 snímků, 1875 taxonů) a (3) soubor obsahující pouze lesní vegetaci (5403 snímků, 1264 taxonů). Whittakerova multiplikativní 
míra beta diverzity (Whittaker 1960) byla vypočtena rarefakcí pro náhodný výběr 10 fytocenologických snímků, které obsahovaly cílový taxon $\left(\beta_{10}\right)$. Před vlastní rarefakcí byly z výběru odstraněny snímky výrazně odlišné od ostatních, jak doporučuje Botta-Dukát (2012). Vzhledem k tomu, že se hodnota beta diverzity s předpokládanou mírou specializace snižuje, je hodnota indexu vypočítána jako ESI $=10-\beta_{10}$ a dosahuje hodnot v teoretickém rozsahu 0-9, přičemž velké hodnoty indikují specialisty a malé hodnoty generalisty.

Ke každému indexu je zároveň udávána tzv. váha taxonů, reprezentující počet snímků $\mathrm{s}$ výskytem taxonu v daném souboru. Váhu taxonů lze použít jako kritérium spolehlivosti indexu specializace pro daný taxon, protože s rostoucí frekvencí taxonu ve snímkovém souboru vzrůstá spolehlivost vypočtené hodnoty indexu. Minimální počet výskytů taxonu pro výpočet indexu byl stanoven na 10 . Teoretickým maximem je počet snímků v daném souboru.

Databáze obsahuje tyto indexy a odpovídající váhy taxonů (v závorce s rozsahem hodnot):

- Index ekologické specializace ve všech vegetačních typech $(2,69-7,95)$

- Index ekologické specializace v nelesní vegetaci $(2,63-7,49)$

- Index ekologické specializace v lesní vegetaci $(2,61-7,95)$

- Váhy taxonů pro index ekologické specializace ve všech vegetačních typech (105020; teoretické maximum 30.115)

- Váhy taxonů pro index ekologické specializace v nelesní vegetaci (10-4542; teoretické maximum 24.712)

- Váhy taxonů pro index ekologické specializace v lesní vegetaci (10-2032; teoretické maximum 5403)

Zdroj dat a citace: Zelený \& Chytrý (2019).

\section{Kolonizační schopnost}

Indexy vyjadřující kolonizační schopnost taxonů české flóry vytvořili Prach et al. (2017). Hodnoty indexů pro jednotlivé taxony vypočítali z databáze 21 sukcesních sérií (primární i sekundární sukcese) začínajících na holém substrátu. Tato databáze (Databáze sukcesních sérií, DaSS; Prach et al. 2014) obsahuje 1013 taxonů cévnatých rostlin zaznamenaných ve 
2817 fytocenologických snímcích z území České republiky pořízených v rozmanitých biotopech a různě starých sukcesních stadiích od 1 do 150 let. Rozlišují se tyto indexy:

- Index kolonizační úspěšnosti v sukcesních stadiích (ICS) vyjadřuje frekvenci taxonu v databázi sukcesních sérií. Tento index byl vypočítán pomocí vzorce:

$$
\mathrm{ICS}^{*}=\log ((\mathrm{SF}+\mathrm{EGSSF}) / 2)+1
$$

kde SF je celková frekvence taxonu v Databázi sukcesních sérií a EGSSF je frekvence taxonu v geograficky stratifikovaném výběru z této databáze. Hodnoty ICS* byly následně převedeny do rozsahu od 1 (absence) do 9 (vysoká frekvence taxonu v sukcesních stadiích).

- Index kolonizačního potenciálu (ICP) zohledňuje, že výskyt taxonů v sukcesních stadiích je ovlivněn vedle jejich biologických vlastností i jejich hojností v krajině. Frekvence výskytu v sukcesních stadiích byla proto korigována frekvencí příslušných taxonů v geograficky stratifikovaném podsouboru České národní fytocenologické databáze (ČNFD; soubor 30.115 snímků a 1935 taxonů; Chytrý \& Rafajová 2003). Index je vypočítán jako:

$$
\mathrm{ICP}=0.5+\operatorname{arctg}(\mathrm{relEGSSF} / \mathrm{relCNPD}) / 10
$$

kde relEGSSF je geograficky stratifikovaná frekvence taxonu v Databázi sukcesních sérií a relCNPD je geograficky stratifikovaná frekvence taxonu v České národní fytocenologické databázi. Index je stanoven v rozsahu 1 (nízká) až 9 (vysoká kolonizační schopnost). Hodnoty pod 5 tedy odpovídají relativně převažujícímu výskytu v České národní fytocenologické databázi, hodnoty nad 5 naopak relativně převažujícímu výskytu v Databázi sukcesních sérií.

- Optimum sukcesního stář́ je medián doby v letech od okamžiku disturbance, kdy se taxon v průběhu sukcese vyskytuje. Optimum bylo stanoveno v rozsahu 1-50 roků. Pro taxony, jejichž optimum bylo vyšší než 50 roků od poslední disturbance a nebylo možno je přesněji dopočítat pro malý počet sukcesních stadií, je hodnota nastavena na 75 roků.

Zdroj dat a citace: Prach et al. (2017).

\section{Rozšíření a hojnost}




\section{Floristická zóna}

Floristické zóny Země, kde se taxon vyskytuje podle fytogeografických atlasů (Meusel et al. 1965, 1978, Meusel \& Jäger 1992). Údaje jsou převzaty z databáze BiolFlor (Kühn \& Klotz 2002).

Kategorie

- arktická - zóna tundry severně od arktické hranice lesa

- boreální - zóna severních jehličnatých lesů (tajgy)

- severní temperátní - severní zóna opadavých listnatých lesů

- jižní temperátní - jižní zóna opadavých listnatých lesů

- submeridionální - zóna suchých opadavých lesů a stepí

- meridionální - zóna vždyzelených širokolistých a jehličnatých lesů, stepí a pouští

- subtropická - zóna savan a suchých lesů se zimním obdobím sucha

- tropická - vlhká zóna vždyzelených širokolistých lesů

- australská nebo antarktická - floristické zóny jižní polokoule odpovídající temperátní až arktické zóně severní polokoule

Zdroj dat a citace: Kühn \& Klotz (2002).

\section{Floristická oblast}

Floristická oblast je udávána jako kontinent nebo jeho část, kde se taxon vyskytuje podle map celkového areálu (Meusel et al. 1965, 1978, Meusel \& Jäger 1992). Použité kategorie nejsou vzájemně diskrétní a některé oblasti mohou být součástí jiných oblastí (např. Západní Sibiř - Sibiř - Asie). Z př̌ekrývajících se kategorií je pro daný taxon vybrána ta, která nejlépe popisuje jeho areál nebo část areálu. Údaje jsou převzaty z databáze BiolFlor (Kühn \& Klotz 2002).

Kategorie

- Evropa

- Evropa-Západní Asie
- Západní Evropa

- Východní Evropa

- Alpy
- Karpaty

- Kavkaz

- Asie 
- Západní Asie

- Malá Asie

- Blízký Východ

- Střední Asie

- Centrální Asie

- Sibiř

- Západní Sibiř
- Východní Asie

- Afrika

- Východní Afrika

- Amerika

- Severní Amerika

- Východní

Amerika
- Západní Amerika

- Grónsko

- Austrálie, Nový Zéland

- cirkumpolární

Zdroj dat a citace: Kühn \& Klotz (2002).

\section{Míra kontinentality}

Míra kontinentality je odvozena z polohy areálu taxonu na gradientu od oceánické západní Evropy do kontinentální střední Asie. Koncepce a údaje jsou převzaty z práce Berg et al. (2017), ve které autoři revidovali předchozí systém indikačních hodnot pro kontinentalitu (Ellenberg et al. 1991). Větší hodnoty na ordinální stupnici od 1 do 9 znamenají rozšíření taxonu v kontinentálnějších oblastech. Taxony rozšířené ve více než čtyřech regionech přiřazených do různých tř́d kontinentality podle práce Jäger (1968) se považují za indiferentní s výjimkou těch, jejichž dolní hranice kontinentality se nachází v regionech přiřazených ke třídě kontinentality 2 nebo vyšší.

Zdroj dat a citace: Berg et al. (2017).

\section{Rozsah areálu podle gradientu kontinentality}

Rozsah areálu taxonu podle gradientu kontinentality od oceánické západní Evropy do kontinentální střední Asie vyjádřený pomocí tříd kontinentality, které pro holarktickou květennou oblast definoval Jäger (1968). Hodnota vyjadřuje počet sousedních regionů přiřazených do různých tříd kontinentality, do nichž zasahuje areál taxonu.

Zdroj dat a citace: Berg et al. (2017). 
Nejnižší a nejvyšší výškový vegetační stupeň, v němž se taxon běžně vyskytuje v České republice. U některých taxonů jsou navíc uvedeny jako extrémy i výškové stupně, v nichž se taxon vyskytuje vzácně mimo své hlavní výškové rozpětí. Podhůří odpovídá sloučenému suprakolinnímu a submontánnímu stupni a hory odpovídají sloučenému montánnímu a supramontánnímu stupni v podrobnější klasifikaci výškových stupňů vymezené v Květeně České republiky (Skalický 1988). Údaje jsou převzaty z Klíče ke květeně České republiky (Kaplan et al. 2019a).

Kategorie

- nížiny

- pahorkatiny

- podhưrí
- hory

- subalpínský stupeň

Zdroj dat a citace: Kaplan et al. (2019a).

\section{Frekvence výskytu v základních polích a kvadrantech sít’ového mapování}

Počet základních polí a počet kvadrantů sítového mapování středoevropské flóry na území České republiky, v nichž byl taxon zaznamenán, se generují dynamicky z aktuálních záznamů v modulu s daty o rozšíření taxonů databáze Pladias. Základní pole mají rozměr 10 minut ve směru západ-východ a 6 minut ve směru jih-sever, což na 50. rovnoběžce odpovídá přibližně $12,0 \times 11,1 \mathrm{~km}, \mathrm{tj} .133,2 \mathrm{~km}^{2}$. Území České republiky pokrývá celkem 679 těchto základních polí (včetně neúplných pohraničních polí). Kvadranty odpovídají základním polím sítového mapování rozděleným na čtvrtiny a mají rozměr 5 minut ve směru západ-východ a 3 minuty ve směru jih-sever, což na 50. rovnoběžce odpovídá přibližně $6,0 \times 5,55 \mathrm{~km}, \mathrm{tj} .33,3 \mathrm{~km}^{2}$. Údaje označené při revizi jako chybné nebo nejisté se nezapočítávají.

Citace: Pladias. Databáze české flóry a vegetace. - www.pladias.cz.

\section{Hojnost ve fytocenologických snímcích z České republiky}


Míry hojnosti ve fytocenologických snímcích vyjadřují, jak často se taxon vyskytuje v konkrétních porostech a jaké v nich dosahuje pokryvnosti. Všechny tyto míry byly stanoveny ze souboru fytocenologických snímků všech vegetačních typů, který byl v březnu 2013 exportován z České národní fytocenologické databáze (Chytrý \& Rafajová 2003). Tyto snímky byly klasifikovány do fytocenologických asociací expertním systémem vyvinutým v projektu Vegetace České republiky (Chytrý 2007-2013). Snímky nezařazené do žádné asociace byly odstraněny a ze souboru snímků každé asociace byl vybrán reprezentativní podsoubor na základě geografické stratifikace, která omezila nevyvážený počet snímků z různých území. $Z$ výsledného souboru obsahujícího 30.115 fytocenologických snímků zařazených do 494 asociací byly spočítány tyto míry hojnosti:

- Frekvence výskytu ve fytocenologických snímcích - procentická frekvence výskytu taxonu vypočtená ze všech snímků

- Frekvence výskytu ve fytocenologických snímcích s pokryvností nad $5 \%$ procentická frekvence výskytu s pokryvností nad 5 \% vypočtená ze všech výskytů taxonu (snímky s absencí taxonu nebyly vzaty v úvahu)

- Frekvence výskytu ve fytocenologických snímcích s pokryvností nad 25 \% procentická frekvence výskytu s pokryvností nad $5 \%$ vypočtená ze všech výskytů taxonu (snímky s absencí taxonu nebyly vzaty v úvahu)

- Frekvence výskytu ve fytocenologických snímcích s pokryvností nad 50 \% procentická frekvence výskytu s pokryvností nad 5 \% vypočtená ze všech výskytů taxonu (snímky s absencí taxonu nebyly vzaty v úvahu)

- Průměrná procentická pokryvnost ve fytocenologických snímcích (snímky s absencí taxonu nebyly do výpočtu zahrnuty)

- Maximální procentická pokryvnost ve fytocenologických snímcích

Citace: Chytrý M. (2016) Hojnost ve fytocenologických snímcích. - www.pladias.cz.

\section{Počet biotopů s výskytem taxonu v České republice}

Počet biotopů, v nichž se taxon vyskytuje podle údajů z České národní fytocenologické databáze (Chytrý \& Rafajová 2003) a jejich expertní revize provedené zejména pro vzácné a taxonomicky obtížné taxony. Tento údaj je mírou ekologické amplitudy taxonu. Použitá 
klasifikace rozlišuje 88 základních biotopů sdružených do 13 širších biotopů, které definují

Sádlo et al. (2007: Appendix 1, viz také Výskyt v biotopech). Jsou vymezeny čtyři míry:

- Počet úzce vymezených biotopů s výskytem taxonu - počet biotopů z celkového počtu 88 , v nichž se taxon vyskytuje; taxon v těchto biotopech nemusí, ale může mít ekologické optimum

- Počet úzce vymezených biotopů, v nichž má taxon optimum - počet biotopů z celkového počtu 88 , v nichž se taxon vyskytuje a současně zde má ekologické optimum (může být i dominantou nebo konstantní dominantou)

- Počet široce vymezených biotopů s výskytem taxonu - počet sdružených biotopů z celkového počtu 13, v nichž se taxon vyskytuje; taxon v těchto biotopech nemusí, ale může mít ekologické optimum

- Počet široce vymezených biotopů, v nichž má taxon optimum - počet sdružených biotopů z celkového počtu 13, v nichž se taxon vyskytuje a současně zde má ekologické optimum (může být i dominantou nebo konstantní dominantou)

Zdroj dat a citace: Sádlo et al. (2007).

\section{Ohrožení a ochrana}

\section{Červený seznam 2017 (národní kategorie ohrožení)}

Národní kategorie ohrožení podle Červeného seznamu cévnatých rostlin České republiky z roku 2017 (Grulich 2017). Tyto kategorie, zavedené v předchozích vydáních Červeného seznamu, jsou podobné kategoriím používaným pro červené seznamy IUCN, přesně jim však neodpovídají. Hlavní kategorie „A“ zahrnuje taxony vyhynulé nebo nezvěstné, zatímco hlavní kategorie „C“ zahrnuje taxony ohrožené včetně vzácnějších taxonů vyžadujících pozornost a nejasných př́ípadů.

Kategorie

- A1 - vyhynulý taxon

- A2 - nezvěstný taxon

- A3 - vyhynulý nebo nezvěstný taxon (nejasný případ) 
- $\mathrm{C} 1 \mathrm{~b}$ - kriticky ohrožený taxon, vzácný a ustupující

- $\mathrm{C} 1 \mathrm{r}$ - kriticky ohrožený taxon, vzácný

- $\mathrm{C} 1 \mathrm{t}$ - kriticky ohrožený taxon, ustupující

- $\mathrm{C} 2 \mathrm{~b}$ - silně ohrožený taxon, vzácný a ustupující

- $\mathrm{C} 2 \mathrm{r}$ - silně ohrožený taxon, vzácný

- $\mathrm{C} 2 \mathrm{t}$ - silně ohrožený taxon, ustupující

- $\mathrm{C} 3$ - ohrožený taxon

- C4a - vzácnější taxon vyžadující pozornost

- $\mathrm{C} 4 \mathrm{~b}$ - vzácnější taxon, nejasný př́pad

- taxon není zařazen do Červeného seznamu

Zdroj dat a citace: Grulich (2017).

\section{Červený seznam 2017 (kategorie ohrožení IUCN)}

Mezinárodní kategorie ohrožení podle IUCN stanovené v Červeném seznamu cévnatých rostlin České republiky z roku 2017 (Grulich 2017). Taxony byly do těchto kategorií zařazeny s ohledem na mezinárodně uznávaná pravidla (IUCN 2012, 2014) a poněkud se liší od národních kategorií tradičně používaných v České republice. Do národního červeného seznamu jsou zařazeny jen taxony s určitou mírou skutečného nebo možného ohrožení, zatímco u nezařazených taxonů se předpokládá, že jsou bez ohrožení. Proto byly taxony nezařazené do červeného seznamu v databázi označeny jako LC(NA) - málo dotčený (není zařazen do Červeného seznamu).

Kategorie

- EX - vyhynulý nebo vyhubený

- $\mathrm{RE}$ - regionálně vyhynulý nebo vyhubený

- $\quad \mathrm{CR}$ - kriticky ohrožený

- EN - ohrožený

- VU - zranitelný

- NT - téměř ohrožený
- LC - málo dotčený

- $\mathrm{LC}(\mathrm{NA})$ - málo dotčený (není zařazen do Červeného seznamu)

- $\quad \mathrm{DD}$ - taxon, o němž jsou nedostatečné údaje

- NA - nevhodný pro hodnocení

- $\mathrm{NE}$ - nevyhodnocený 
Zdroj dat a citace: Grulich (2017).

\section{Zákonná ochrana}

Zákonná ochrana se v České republice vztahuje na zvláště chráněné druhy, což jsou vzácné, ohrožené a vědecky nebo kulturně významné taxony zahrnuté v př́iloze II vyhlášky č.

395/1992 Sb. Zahrnují 487 taxonů cévnatých rostlin rozdělených na kriticky ohrožené, silně ohrožené a ohrožené.

Kategorie

- kriticky ohrožený taxon

- ohrožený taxon

- silně ohrožený taxon

- taxon není zákonem chráněný

Zdroj dat a citace: Vyhláška Ministerstva životního prostředí č. 395/1992 Sb. 